University of Louisville

ThinkIR: The University of Louisville's Institutional Repository

Electronic Theses and Dissertations

$12-2009$

\title{
Friedrich Schiller's play : a theory of human nature in the context of the eighteenth-century study of life.
}

Susan M. Bentley

University of Louisville

Follow this and additional works at: https://ir.library.louisville.edu/etd

\section{Recommended Citation}

Bentley, Susan M., "Friedrich Schiller's play : a theory of human nature in the context of the eighteenthcentury study of life." (2009). Electronic Theses and Dissertations. Paper 101.

https://doi.org/10.18297/etd/101

This Doctoral Dissertation is brought to you for free and open access by ThinkIR: The University of Louisville's Institutional Repository. It has been accepted for inclusion in Electronic Theses and Dissertations by an authorized administrator of ThinkIR: The University of Louisville's Institutional Repository. This title appears here courtesy of the author, who has retained all other copyrights. For more information, please contact thinkir@louisville.edu. 
FRIEDRICH SCHILLER'S PLAY:

A THEORY OF HUMAN NATURE

IN THE CONTEXT OF

THE EIGHTEENTH-CENTURY STUDY OF LIFE

By

Susan M. Bentley

B.A., University of Colorado, 1969

M.A., University of Denver, 1997

M.D., University of Louisville, 1980

\begin{abstract}
A Dissertation
Submitted to the Faculty of the

Graduate School of the University of Louisville in Partial Fulfillment of the Requirements

for the Degree of
\end{abstract}

Doctor of Philosophy

Department of Humanities

University of Louisville

Louisville, Kentucky

December 2009 
Copyright 2009 by Susan M. Bentley

All rights reserved 
FRIEDRICH SCHILLER'S PLAY:

A THEORY OF HUMAN NATURE

IN THE CONTEXT OF

THE EIGHTEENTH-CENTURY STUDY OF LIFE

By

Susan M. Bentley

B.A., University of Colorado, 1969

M.A., University of Denver, 1997

M.D., University of Louisville, 1980

A Dissertation Approved on

December 3, 2009

by the following Dissertation Committee:

Dissertation Director

Dissertation Director 


\section{DEDICATION}

This dissertation is dedicated to my husband

Kim R. Jonason, Ph.D.

and

to my father

Richard W. Molthop 


\section{ACKNOWLEDGEMENTS}

I would like to thank my Dissertation Committee for all the time, effort and encouragement they provided. I am particularly grateful to the Director of Humanities Doctoral Program and Co-Chairperson of my Committee, Dr. Annette Allen, for her untiring support of me (and everyone else) and to my Co-Chairman, Dr. Mark E. Blum, for his helpful enthusiasm and his enjoyment of scholarship. I am much in Dr. Alan C. Leidner's debt for introducing me to Friedrich Schiller and German intellectual history, and for the example he provides in pursuing his intellectual interests. I am grateful as well to Dr. Osborne P. Wiggins, Jr. for making the many difficult things in philosophy more straightforward and to Dr. Lee A. Dugatkin for guiding my study of evolutionary biology. Thanks also to Melissa Horrar, Department Head of Circulation and Interlibrary Loan at Ekstrom Library.

I can't thank my husband, Kim Jonason Ph.D., enough for all the help he has given over the years and the honest pleasure he takes in my work. Thanks too to the rest of the family, children and grandchild, Jesse, Carmen and Alton Mather, J. Pike Mather and Melissa Noyes, and to the Love family - especially Sarah, who helped me by reading and also by allowing me to help her with her work. I am also very grateful for the long-time support, friendship and recent proof-reading of Lois U. Davis. I have worked in the memory of my stepson Kristofor R. Jonason, my mentor Lawrence A. Davis, M.D. and my father Richard W. Molthop who managed a disability with intelligence and humor. 


\section{ABSTRACT \\ FRIEDRICH SCHILLER'S PLAY: \\ A THEORY OF HUMAN NATURE \\ IN THE CONTEXT OF \\ THE EIGHTEENTH-CENTURY STUDY OF LIFE}

Susan M. Bentley

December 15, 2009

Friedrich Schiller's psychological theory of play, his hypothesis about human nature, is embedded in the Aesthetic Letters. Its trans-historical value owes much to the committed interest in life in the late Enlightenment, and the theory itself is an example of that period's enthusiastic study of living organisms. It is within this context - of eighteenth-century natural history, natural philosophy and medicine - that the theory can be profitably evaluated. That it is also an example of the connection of the humanities of the time and the emerging life sciences suggests its usefulness as a paradigm today: as a general theory of human nature, it might serve as a bio-cultural ground for the humanities.

In this dissertation, Schiller's theory's situation in several contemporary contexts is explored and its relevance to the contemporary humanities and biological sciences, asserted. Chapter II presents Schiller's theory of play. In hypothesizing a theory of species-specific drives, Schiller approached human nature as a unity. In us, the actions of two drives, the sense-drive and the form-drive, create a play-drive which, in relation to 
beauty, promotes full personal development. Chapter III reviews the activities of mideighteenth-century researchers whose attention was turned to the anomalies that defined life. From their work, Schiller drew ideas about nature and the human species. Chapter IV celebrates the identification of a program of life study, vitalism. Schiller's mix of mechanical and organic metaphors, his drives and his history of play are based on its science. Chapter V presents the period's vitalistic epistemology. In it, comparison, analogy and hypothesizing augment observation, experimentation and analysis. As a vitalist, Schiller combined Kant's epistemology with Goethe's scientific intuition. Chapter VI reviews Schiller's German aesthetic heritage. Special focus is given to his text as an example of art, as an organic product, and to Schiller's own life, as an example of the whole man in the process of development. The Epilogue notes current play research in biology and the humanities and suggests that Schiller's play is an evolutionary mechanism, a structural and behavioral adaptation and, as such, a firm ground upon which to steady the humanities against aspects of its own relativism. 
TABLE OF CONTENTS

PAGE

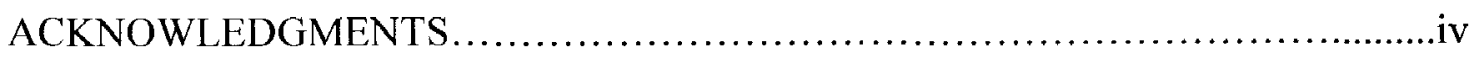

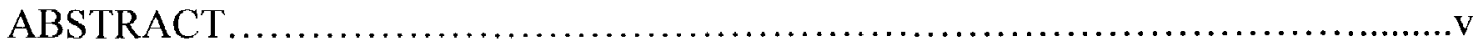

CHAPTER

I. INTRODUCTION: AT PLAY WITH SCHILLER .............................1

II. SCHILLER'S THEORY OF PLAY ......................................

III. THE STUDY OF LIFE IN THE EIGHTEENTH CENTURY..................57

IV. SCHILLER AND LATE EIGHTEENTH-CENTURY VITALISM................107

V. A MODEST YET DARING EPISTEMOLOGY ...........................................171

VI. AESTHETICS AND ANTHROPOLOGY: THE WHOLE MAN...............217

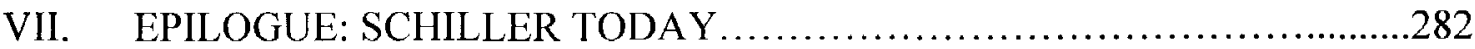

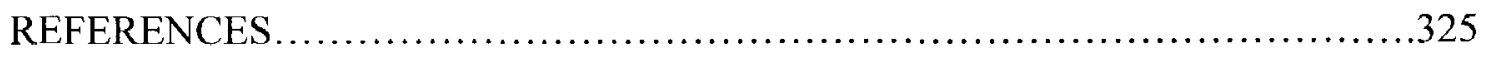

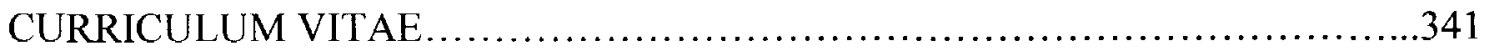




\section{CHAPTER I}

\section{INTRODUCTION: AT PLAY WITH SCHILLER}

Friedrich Schiller's psychological theory of play - his hypothesis about human nature - is embedded in On the Aesthetic Education of Man in a Series of Letters. It is a red thread laid down by his exploration of the labyrinthine structure of our humanity, a guide that can best be uncovered through careful excavation with the trowels, picks and brushes of late eighteenth-century natural history and natural philosophy, the time's science of life and science of man.' His theory's form, its content and its trans-historical value owe much to the committed interest in life at the end of the Enlightenment; the theory itself can be understood as an example of that period's enthusiastic and contentious study of living organisms. That it is also an example of the connection of the humanities of the time and its sciences, the complex reciprocal relationship between particular research, philosophy and the arts - among anatomists, physiologists, physicians, philosophers, historians and artists - suggests its usefulness as a paradigm today. As a general theory of human nature, it might serve as a bio-cultural ground for the humanities.

${ }^{1}$ Citation to the Über die Ästhetische Erziehung des Menschen in einer Reihe von Briefen by Johann Christoph Friedrich Schiller (1759-1805), the Aesthetic Letters, will be made by letter (Roman numeral, I-XXVII) and paragraph (Arabic numeral), then footnote if appropriate (by number if more than 1). For example, XV.9 or XIII.4 fn 2. Citation to the Introduction, Commentary or Appendices will be to the translators: W\&W. 
Understanding Schiller's theory of play requires a changed perception of its contexts: given the Aesthetic Letters as the immediate context, the theory benefits from new attention paid to a broader frame, a coherent life-science research tradition of the late Enlightenment. Late eighteenth-century and early nineteenth-century life science was generally a neglected area of scholarship: before the last quarter century only the admittedly monumental activities of eighteenth-century classifiers, codifiers and popularizers were acknowledged by science historians. ${ }^{2}$ The identification of a program of life study that was neither animism, mechanism nor materialism, i.e., one that was essentially (but variably) vitalistic, grew out of insights possible only with the maturation of biological science (specifically evolutionary biology and genetics) and the development of a philosophy of biology that incorporated the content of the time-related biological disciplines. To many late twentieth-century science historians, it was evident that the scientific study of life was undertaken - avidly, carefully and creatively - during the late eighteenth century and early nineteenth century but that it had been hidden by the

${ }^{2}$ Neither a diachronic, "vertical," progressive science narrative that emphasized the great men, great discoveries and great revolutions, nor a synchronic, "horizontal" historiography that elaborated connections between science and other endeavors focused on the study of life in the eighteenth century: only in 1977 after Kuhn proposed his nonprogressive discontinuous model of normal science and paradigm change did Richard Toellner argue "that the emergence of vitalism [was] a good example of a Kuhnian 'change of paradigm,' and [that] Haller's discovery of irritability [was] responsible for that change throughout Europe." (Roger in Rousseau 276 fn 58. Toellner). Jacques Roger agreed that the shift to vitalism occurred but not with the timing of the shift. Likewise, Kuhn himself later considered Lavoisier's chemistry a paradigm shift (K. on Lavoisier Structure 53-56). Cantor noted the Bachelardian perspective that "natural philosophy [exclusive of Newtonian mechanics] was a publicly-enacted pre-science containing elements of drama, paradox and wonder": such a view precluded taking the embryonically organizing study of life seriously (48). A contrary view was expressed by Ernst Cassirer: "d'Alembert called the eighteenth century the philosophical century but with equal justification and pride this era often labeled itself the century of natural science" (45 my emphasis). 
celebrated parameters of physical science and by its definition of methods. The study of Schiller's theory of play in the Aesthetic Letters benefits from their contributions to this paradigm change.

In addition to placing the theory of play within the study of life forms, contextualizing Schiller's theory within the eighteenth century's science of man, within the stirrings of psychology and anthropology that were part and parcel of both Enlightenment medicine and the German aesthetic tradition, is key to understanding his hypothesis as synthesizing the various concerns of the late Enlightenment. The polarities of mind and body, sense and thought, perceptions and ideas, autonomy and necessity, imagination and reason are all crafted into his general theory of human nature. It is important to understand as well the cosmopolitan nature of the late Enlightenment and the intimate place of science within the humanities. Even as physics, chemistry, and medicine were separating, psychology and anthropology were incompletely differentiated from philosophy, and biology was yet to have a name. In this environment, and specifically the Weimar community, the study of all life organisms combined with philosophy and aesthetics (the "science of the senses") to form a rudimentary science of human nature. It is within these parameters that Schiller's new definition of play as a drive and a state is to be discovered and appreciated.

The above contexts of the theory of play to be explored then - the Aesthetic Letters itself, the study of life and the study of man in the late Enlightenment - are objective and subjective: they are environments but they are dynamic - past identities created by and being created by perceiving subjects. They are reality-based but must also be intuited and appreciated: they require the application of sense and experience, of ideas and 
imagination. I hope to show that they function as a part of play and that our grasp of them is an aspect of an aesthetic education.

\section{The Text as Context}

Schiller's On the Aesthetic Education of Man in a Series of Letters is the carrying document for his theory of play, his theory of human nature. It is important to see the Aesthetic Letters not only as an aesthetic work - artistic and philosophical - but as a natural philosophical document as well. The effort to research and develop evidence of natural philosophy's importance to Schiller's Aesthetic Letters and the psychological theory of play within it, however, in no way argues to diminish the other numerous sources - artistic, personal, professional and philosophical - that have long been identified as contributory to his achievement. It is rather an attempt to draw attention to a liminal area of scholarship, to break out of the usual spaces marked by our disciplines and to make a contribution to strengthening the relationship of science and the humanities. ${ }^{3}$ Contextualizing his theory is also an effort to elucidate what Schiller may have meant when he called himself a Zwitterart, perhaps not an artist-philosopher as we understand the dichotomy today, but as an artist-and-scientist-philosopher, a humanist negotiating the current of natural philosophy. ${ }^{4}$

${ }^{3}$ Wilkinson and Willoughby (W\&W), remarking on aspects of their work as translators, noted that "some aspects of Schiller's thesis ... have been generally misunderstood, or totally ignored .... [T] here has been a marked tendency to play down his concern for science and politics in this particular work, if not elsewhere, and - though to a lesser extent perhaps - his concern for reason and morality too" (lxii).

${ }^{4}$ In a letter to Goethe dated 31.viii.1794 (Trans. W\&W xxix; Briefe on line). Comparing himself to Goethe he wrote: "My understanding works more in a symbolising method, and thus I hover, as a hybrid [Zwitterart], between ideas and perceptions [Anschauung], between law and feeling, between a technical mind and genius ... in my earlier years ... 
What is the history of Schiller's most problematic work? What is the cultural understanding of it?

The twenty-seven letters that make up the Aesthetic Letters were published in 1795 in three issues of the Horen. ${ }^{5}$ Their inspiration was Schiller's correspondence with his patron Friedrich Christian, Duke of Schleswig-Holstein-Augustenburg, and the published series was produced in agreement with him. ${ }^{6}$ These original letters, the Augustenburger Briefe of 1793, were destroyed in a fire and only partially replaced by Schiller at the Duke's request. Two of the published sections, Letters I-IX and XXIII-XXVII, are based on the replacements; their vastly different contents provide a broad natural division within the finished work itself. The first group contains an apology for undertaking an aesthetic subject when Europe's attention was riveted by violent political change: here Schiller connected aesthetics and politics, giving an urgent, practical explanation for his interest in beauty. In the last section, Schiller superseded historical arguments about the effect of the arts on morality and against the capacity of beauty to accomplish civilizing ends with a new developmental argument about the appearance of artistic agency in humans. He traced the production of two varieties of actual beauty in the world and the possibility of individual development toward the goals of human life (through the beauties that we have). His summation is a meditation on the attributes of the aesthetic

an awkward appearance both in the field of speculation as well as in that of poetry ..." (Trans. Schmitz 12).

${ }^{5}$ The stated aims of the Horen were the following: to "inquire of history concerning the past and of philosophy concerning the future, and be actively engaged in unobtrusive cultivation of those better insights, clearer principles, nobler morals, on which any improvement of our social condition must ultimately depend" (W\&W xv).

${ }^{6}$ There are many presentations of the Letters in their historical context; I am following Beiser (121ff). 
state in individuals and the Aesthetic State in the world. Between the two sections based on the original private letters, Schiller added an analysis of beauty, a section that was not anywhere part of the original: this new part (X-XXII) includes the hypothesis about play and an argument for the appreciation of beauty as crucial to human wholeness. ${ }^{7}$

The final work suffered from vicissitudes of influence and intention ("an almost astonishing vacillation and uncertainty"): was it to be a reaction to the violent events of the French Revolution (Beiser 122)? Would it be an analysis of beauty? A treatise on education? A critique of contemporary culture? A prescription for what ails the Enlightenment? Itself a work of art? Yes. ${ }^{8}$

In his Schiller as Philosopher, Frederick Beiser argued that the Aesthetic Letters is both a unified philosophical work of merit and a political document setting out the strengths and weaknesses of republicanism. Beiser tasked himself with placing the Aesthetic Letters in its historical context and with "understand[ing] it as a response to some of the cultural, political and aesthetic issues of the age" (120), finally finding its aim to be "precisely" this: "to rescue the causes of enlightenment and republicanism in

${ }^{7}$ This section about play was written and edited at the beginning of Schiller's intense friendship and collaboration with Goethe; the marks of Goethe's scientific interests and his epistemology are apparent and will be detailed in Chapter V.

${ }^{8}$ Schiller's theory of play is presented in no other work. Because, in The Aesthetic Letters, it is a small mechanism for his philosophical and political purposes and only the skeleton of that organic art object, and further, because my work involves a novel perception and focuses on a part, through the application of eighteenth-century natural history and natural philosophy like a magnifying glass, I have relied upon other approaches to the whole text. L. A. Willoughby and Elizabeth Wilkinson's translation of the text (with their reflections on etymology) and Frederick Beiser's understanding of Schiller's philosophical project have been indispensible. In addition, I am indebted to the examination, presentation and ideas of Elias, Martinson, Reed "Delights," Savile, Schaper and Sharpe among others. 
the face of . . conservative criticism." ${ }^{\prime 9}$ But the Aesthetic Letters is a deeply political work on several levels, and this final aim is actually a harmonizing of conflictual purposes: it is at once a positive response to the promise of the French Revolution, to the possibility of political freedom and a just and interactive society - and it is a work reflecting passionate disappointment in the revolution's failure through lack of action with respect to basic needs (like safety and sustenance) and its horrible violence, especially exemplified in the execution of Louis XVI. As such, the violence of the revolution and the failure of the French constitution represented defeats of the Enlightenment's optimistic appraisal of the agency of reason to effect a safe environment for humankind and to further enlightenment itself. Schiller's optimism in writing implied that a battle had been lost, but that the war must be won.

According to Elizabeth Wilkinson and L. A. Willoughby, the latest and most authoritative of the English translators, what readers find in the text is

an impassioned analysis of the cultural predicament of modern man: the evils of specialization, whether of knowledge or skill, or of one function of the psyche at the expense of the others; the dissociation of what once was united - sensibility and thought, feeling and morality, body and mind; the cleavage between different branches of learning, between sciences and the arts, between the development of the individual and the welfare of the community, between those who are too exhausted by the struggle for existence to think for themselves and those who are too indolent to make creative use of their leisure; the reduction of man to a mere $\operatorname{cog}$ in the wheel of an over-developed society; the de-humanization of the citizen in a State where he is valued for the function he performs rather than the being that he is ... (W\&W xii).

${ }^{9}$ These criticisms included the intuition that Reason could not be sufficiently incentivized and that Reason was not and could not be practical, i.e. be applied to local and particular circumstances. 
In this work, Schiller analyzed in order to repair, described in order to unify. He sought a harmonious balance, a unity of opposites and conflicted elements, of being and becoming, of thinking and doing, of subjective and objective, of experiencing and organizing, of feeling and valuing. He wrote as a synthesizer of the Enlightenment and Counter-Enlightenment, seeking a correction at a moment when he hoped cohesion was still possible. He was not in search of a meta-concept as had been attempted before in rational systems so much as an engaging and transforming experience for the whole person, an actual reflection of our own structure and the unity of nature. He sought a combination of self-with-experience that each of us as members of the species is specially equipped for, a subject-object relation that marshals our being - perceptions, our feelings and our thoughts - into harmony and balance. He believed that beauty as a regulatory ideal expressed the possibility that humans could have such experiences. Encounters with beauty, according to Schiller, would play out in the particular, as integrating occurrences in a life of continuous development. From this perspective, the Aesthetic Letters is a catalogue of the ills of modern man, a diagnostic survey and a prescription in advance of treatment. It is also a part of that treatment that is aesthetic education.

Accompanying the argument for treatment is a further analysis, one of beauty. The whole is a treatise on aesthetic education and an analytic of the beautiful. Considering Schiller's consistent attention to unity and his drive to discover a third born of the combination of two poles, Frederick Beiser suggested that "the best way to account for both halves of the work, and so to explain its underlying unity is to describe it as an apology for beauty, a defense of the aesthetic dimension in life" (123). Schiller's intent 
was to establish that we must develop ourselves through Beauty to be fully human, that each of us humanizes himself and his neighbors by striving to enact his potential, by seeking human wholeness.

For Beiser, the Aesthetic Letters as an apology for beauty is also a critique of the progress of the Enlightenment in general, an exploration of his century's failure to dare to know, to have the courage to feel and the energy to explore the limitations and the possibilities of human nature. He presented Schiller as a philosopher for whom reason alone is a fragment of our nature. In order for man to be wise, to participate in his own experience passively and actively, Schiller believed that our capacities must be integrated: thought and feeling must function together. Beiser's Schiller re-evaluated his century's readiness for political change and, while upholding reason (our moral nature), re-introduced human physicality (our species-specific senses and feelings) as absolutely essential to enlightenment itself. The continuous work of developing an aesthetic state in each person's separate self is a life-long prescription, a remediation for living with the chronic condition of falling-out-of-balance. For Schiller, it is beauty that develops mankind, making each whole, and it is the society of whole humans that makes a just political state possible. The developmental connection between aesthetics and politics justifies the attention he gave beauty at a time of crisis. Schiller's philosophic goal then was to maintain autonomous agency for mankind, for when he marked out humans as the playful species, he posited that our "sensuo-rational" nature is, in effect, free and pluripotential.

The text is not just a philosophical work or a rhetorical argument; it is also a consciously crafted art object. The Aesthetic Letters in its English translation of by L. A. 
Willoughby and Elizabeth Wilkinson displays the organic complexity, the form applied to content, that allows for creativity not just in its agent artist, but in the reader (and the translator (Wilkinson "Reflections"). Because Wilkinson and Willoughby's work with the text was one of translation and clarification -both of Schiller's intent and their own choices - they approached the Aesthetic Letters as an environment of developing word use and an organized whole, both rhetorically and artistically. Their exhaustive introduction, commentary and glossary, taken together, present an exegesis based on a perception of the text's organic unity, and their intent was to be persuasive in their presentation of Schiller as consciously crafting a representation [a Schein] that makes of his analysis an autonomous whole. Their etymological approach underscored the significance of development to the work and suggested the influence of contemporary organic theories. They posited that Schiller, through navigation of his dynamic use of language, created a complex organization productive of transformational elements analogous to that of a life form (lxviii-lxxiii, Appendix III). In essence, Wilkinson and Willoughby prepared an English text wherein it could be found that Schiller's art imitates the eighteenth-century understanding of life. The Schiller of the Aesthetic Letters was a practical idealist, pressing for progress through our potentiality but acknowledging limits derived from the imperative of self-preservation, the innate teleology of our ratio-sensual nature.

Politics, etymology, philosophy, and art do not exhaust this text: using the discoveries of the analyzers and the philologists, readers can engage the work of art as if it were an organism, an end in itself. They can follow Schiller's understanding of human nature, as one transformable by play, as drive-dependent and yet in need of a unifying 
goal, one in need of both experience and ideal. In terms of its association with the study of life, the text is a rich and dependable site: it incorporates fragments of discoveries, contemporary research and popularizations, and it is energized by the controversies of the contemporary study of life. It is replete with life metaphors functioning in precarious balance with mechanical tropes. And the work itself functions like a living organism with complex organization and special capacities for interacting with its environment (readers) to create transformations. In short, the Aesthetic Letters both explains and models the enormously complex organization of a living form and is itself a labyrinth that represents the mind/body problem of the late eighteenth century, complete with path toward its solution. And when carefully extracted from the text, Schiller's theory of human nature itself is expressed in terms of drives and an archetype, the language of eighteenth-century natural philosophy.

\section{The Organic Body as Context: A Vital, Late Enlightenment Life-Science Tradition}

One necessary approach to human nature is through the body, the body like other bodies, the organism existing in time and space. Life in all its known forms presented a tremendous challenge to naturalists of Schiller's century. ${ }^{10}$ Their efforts to organize and catalogue relentlessly accumulating knowledge had them grappling with burgeoning nature: extensive exploration of the globe provoked discovery of a sublime nature of extreme habitats, a chaotic nature teaming with life forms. Naturalists were presented

\footnotetext{
10 "One particularly arbitrary form of classification is the division of intellectual work into centuries .... Many eighteenth-century scholars have approached this bizarrierie with appropriate flexibility: while they may shorten their period by ending it in 1789 , they can also colonize others by referring to the "long eighteenth century (1660-1830)"' (Still 364). I follow the latter tendency which includes, of course, Weimar classicism imbedded securely within the period, as a synthesis of the Enlightenment and its correction.
} 
with a superabundance of specimens; intensive observation by microscope provided previously unimagined complexity - environments within environments, where fleas had their own demonstrable fleas. " Observers with a new appreciation of the fact, the historical nature of life, atomized time with their documentations: they watched sleepless, chronicling the life cycles, reproductive events and behaviors of their favored life forms. The efforts to manage this knowledge and to cater to the immense interest in it fueled the great knowledge enterprises: the dictionaries, the classification systems, the encyclopedias and the natural histories. After mid-century within this environment fed by intense interest in life, a vitalist research program developed, one that spanned the broad middle ground between the dualisms (whether mechanical or animistic) and materialism. For Schiller and many of his contemporaries it constituted a "mentality."12

11 "Fleas, so naturalists say, /Have smaller fleas that on them prey. /These have smaller still to bite "em, /And so proceed ad infinitum" (Jonathan Swift, "Poetry: A Rhapsody" 633).

${ }^{12}$ Several science historians have written comprehensive narratives characterizing life studies of the eighteenth through the early nineteenth centuries; they identify variously a research program ("teleomechanism") research tradition ("Enlightenment vitalism"), or a mentality ("vital materialism"), all vitalistic life studies by different names and slightly altered time frames. Whether it be the Enlightenment vitalist language (term coined by Reill), research program, tradition or mentality (Roger) or the teleo-mechanist research program (posited by Timothy Lenoir), the discovery came out of historiography of the late twentieth century fostered in the expansion of the philosophy of biology by evolutionary theory. References: Ernst Mayr's The Growth of Biological Thought: Diversity, Evolution, and Inheritance and his "The Idea of Teleology." (Mayr's tome, The Growth of Biological Thought, appeared in 1982; his essays and lectures on questions in the philosophy of science quoted in this dissertation in 1961, 1974 and 1985. He wrote more than 600 journal articles, 200 after his retirement in 1975, and edited or authored 20 books (NYT obituary, 2/5/2005)). G. S. Rousseau and Roy Porter's The Ferment of Knowledge: Studies in the Historiography of Eighteenth-Century Science. An overview and creative synthesis of many researchers' work is found in Jacques Roger's Les sciences de la vie dans la pensée francaise au XVIII siècle (1963) (The Life Sciences in Eighteenth-Century French Thought), Peter Hanns Reill's Vitalizing Nature in the Enlightenment and in Timothy Lenoir's The Strategy of Life: Teleology and 
How is this mentality characterized?

Natural philosophers then both accepted and challenged the mechanistic (Newtonian) worldview. They accepted, challenged and modified as well the place of mathematics in the science of life, and they redefined the meaning of certainty by way of probability. They sought truth by falling away from a priori reasoning through induction to hypothetico-deductive theorizing. In understanding life, they began with Newtonian principles: these explained inanimate matter but could not in their view adequately explain some aspects of the living organism. For those in late Enlightenment studying living nature, there was something more to life, to living matter, than could be described and demonstrated by these known principles. ${ }^{13}$ Their theories hypothesized forces within living matter, and the researchers named these forces by function or effect (e.g. Bildungstrieb, Blumenbach's developmental drive), without expecting to be able to Mechanics in Nineteenth-Century German Biology. Robert Richards connected late Enlightenment life science to Darwin in his The Romantic Conception of Life: Science and Philosophy in the Age of Goethe. I have followed Reill's and Roger's narratives and language more closely but am also indebted to the others and to a number of historians whose research interests have been individuals and/or the relationship between individuals. The detailed description of the eighteenth-century tradition and Schiller's use of it as well as the reciprocal relations of the two time-separated traditions (life studies in the eighteenth century and the late twentieth century, play in the eighteenth century and play studies in the late twentieth century) combine with the importance of science to the current humanities project to undergird later chapters.

${ }^{13}$ An earlier Schiller, the medical student author of "On the difference between Inflammatory and Putrid Fevers" (Latin, 1780) commented, "I was certainly lost in various labyrinths of error before I was persuaded that the natural order is not as we have arranged it in our textbooks. 'There are more things in Heaven and Earth/ Than are dreamt of in our [sic.] philosophy"' (Dewhurst 206, [sic.] is Schiller's). Such a point-ofview, created a big tent that Steven Shapin summarized as follows: "Against an older view that the 'new science' (and especially the 'Newtonianism') of early and mideighteenth century was the underpinning of 'the Enlightenment,' we now have a developing perspective which points out the existence of a number of species of natural knowledge, and a number of opposed 'Enlightenments"' (Rousseau 111-112). 
explain from empirical research how they worked. This place-holding way of formatting theory allowed the characterization of living nature and living organisms in spite of gaps in knowledge.

Their understanding and characterization of life followed from scientific engagement with several compelling issues. Natural philosophers struggled with the exceptional nature of life. What made life life? Organizational complexity? Force(s) within matter? Intrinsic ends and teleological processes? How could its capacities be documented and described? In their search for answers, researchers experimented with particular plants and animals, making minute and often controversial observations; these observations then led to comparison, analogy and hypotheses about specialized life functions, particularly reproduction and development. What is generation? Is it preformation and encapsulation? Is it organization of unformed material? What is the male contribution? The female? What is the cause of monstrosities? They worked with a deeper history and a growing sense of dynamism. Puzzling over identity and change, they sought a way to nail down and acknowledge the historical fact. How can life's relation with time be scientifically expressed? What are the parameters of change in living organisms? How is development to be explained? How is change to be documented? And more particularly, do species transmute? Do human beings constitute a single genus and species? How are differences in races to be explained? What is our species' relationship with other species?

Life was approached and described by these eighteenth-century natural philosophers and historians as organized in a complex and multi-leveled way; they conceived of this organization as somehow both cause and effect of forces within matter itself. These 
forces-in-matter give rise to life's special functions, functions that (circularly) characterized life. For them, the harmoniously balanced tension of forces within each organism was analogous to the harmonious balance without - in local environment and of nature itself. Research, controversy and speculation then created a tradition that characterized life in the following general ways:

1) Life is based on complex organization within a boundary system.

From the naturalists' point-of-view, life exhibited complex organization, not just a multiplication of components, but a development of systems that was reciprocally coordinated and multi-causally involved. A life form was an individual, its own means and its own end, complete in itself due to the harmonious relation of its inseparable parts. Because of the boundary conditions, the whole was transformative; as end, it impacted the separate elements or parts.

2) Forces-in-matter promote special life functions.

Living matter was seen as distinguished by in-dwelling forces that promoted through reciprocal relations the functions specific to life - self-creation, nutrition, sensitivity, irritability, generation and development. These forces (also referred to as principles or qualities) were inseparable from matter. It was clear to many eighteenth century researchers that living organisms were the sites of events that could not be explained mechanistically, and that the forces within them seemed responsible for processes that appeared directed, planned or designed. That organisms often appeared to behave like agents, to seem purposeful or goal-directed [zweckmäßig], was the ground of the difference between life and lifelessness. Such seminal observations or descriptions like the above could not be followed up empirically at the time; in fact, many researchers then 
believed that proofs of in-dwelling forces and the manner of their function would always be beyond human capacity. In sum, the organism appeared to natural philosophers of the time to be a privileged "middle ground" where something transformative happened; in this process, scientists hypothesized and philosophers speculated that polar forces contributed without being destroyed. The observations of life often countered or complicated the linkage that reason made between development and progress. Consequently, living organisms might only be understood through that regulatory conceptualization "as if": because of indwelling forces, life forms appeared as if agented, goal-directed or designed.

3) Life exists in a harmonious balance, in a tension of maintained polarities. All of living nature was seen as related and structurally invested in balanced or harmonious economies in space. Each organ, each organism's own economy, each individual was likewise part of an environment, that is, of an infinite number of reciprocal and interdependent relations (oeconomia naturae). ${ }^{14}$ Thus, balance and harmony were at the heart of the period's appreciation of the workings of nature in general, of capital-N nature (meta-nature personification). ${ }^{15}$ In such a system, means and ends were reciprocal, with time and oppositional elements providing dynamism.

${ }^{14}$ Oeconomia naturae was Linnaeus' concept of a natural economy, part of Adam Smith's calculations and a remote starting point for Charles Darwin's ideas. (Roger in Rousseau 269).

15 "Nature miniscule merged with Nature majuscule in the figure of personification or prosopopeia, so ubiquitous in Enlightenment poetry and prose .... [P]utting the face to abstraction ... inspired neoclassical critics and electrified Enlightenment readers: how else to render a universal norm vivid and sensually intelligible, as sensationalist psychology demanded?" (Daston 123). Not to mention that it, according to Robert Richards, put Darwin on the road to discovering evolution by natural selection (Romantic). 
4) Life is intimately identified with time and therefore history.

Time was the context of life and was the ground of life's characteristic dynamism: the harmonious balance presented above was a dynamic one, constantly adjusting in time. Implicit in this description is that life was change; life was its own history and as such it existed as distinctly individual, never to be repeated entities. This understanding - in reciprocal relationship with a budding historical consciousness - transformed the epistemological status of historical facts: with regard to nature, the existence of an individual both contemporaneously and historically was real. The individual existed over time, not only sustaining itself, self-creating and developing; it degenerated, became ill and died as well.

Living nature - of which mankind is a part - was the continuous creation of time, ever-deepening time, and the interested and educated were increasingly aware of the constant change and the dynamic equilibrium in all environments, whether inside the body, within the ducal forests, or in civil society. A caveat: although the action of time on life forms was appreciated in terms of development and environmental variation, belief in transformation or transmutation of species was not broad-based in the late eighteenth century. Schiller does not appear to have been influenced by such a theory nor did he include ideas about any essential change in species (as Maupertuis, Diderot, Erasmus Darwin, or even Buffon conceived of it) as a possibility in his theory of play. ${ }^{16}$

What is the epistemology of this tradition? How was living nature studied by these vitalists of the late Enlightenment? This research program enlarged the usual empirical

\footnotetext{
${ }^{16}$ During the seventeenth and eighteenth centuries, the word "evolution" referred to a method of generation, preformation. It did not gain its current meaning until the nineteenth century.
} 
methods of observation and experiment with comparison and analogy and with the determination of probabilities. The end of such exploration was the (historical) fact; truth was statistical, a probability that approached certitude. In short, theirs was a modest epistemology. In terms of human comprehension, careful combined attention might bring about an intuitive grasp [Anschauung] of the general from the particular, a way of knowing living phenomena and the whole of nature. By studying life forms, the researcher could have the experience [Erfahrung] of "seeing" the archetype [Urtyp, Urbild, Gestalt, Haupttypus, Hauptform], the original natural (and shared) form of a group of organisms. Goethe, for example, was over long periods of his life intimately involved in this kind of morphological exploration, and his theories about an original plant form and about vertebrate commonalities stem from this understanding of relationship. Influenced by Goethe, Schiller, I believe, based his idea of an archetypal human nature on a similar intuition. ${ }^{17}$

Enlightenment vitalists typically presented their findings and defined a direction of discovery through hypotheses that included terms representing unknowns. This blackboxing of special qualities of life (which were the incompletely understood properties) allowed observation, experimentation and comparison to continue and empirical data to be gathered. With unknowns segregated into regulatory space, even speculation could proceed. As Georges-Louis Leclerc, Comte de Buffon (1707-1788) said, "Let us gather facts in order to get ourselves thinking" (in Roger Life 440).

\footnotetext{
${ }^{17}$ Schiller-Goethe "fortunate encounter" over just this issue will be discussed in Chapter $\mathrm{V}$.
} 


\section{Organic Body, Organic Mind: A New Working Context}

What is man? At the end of the eighteenth century, human nature was just such an area of speculation. Though much of what the Enlightened wanted to know about themselves could only be subjectively accessed and, therefore, was situated with the unknowns, the human mind was often studied as if it were an organism, more specifically, as if it were a function of an organ. In the context of vitalist science, this view was a part of Schiller's perspective. Such a study was infused with lively curiosity and contention about the methods, discoveries and theories relating to human nature - all before the life sciences themselves were distinct from the humanities and before psychology and anthropology as the sciences of human nature had their identities. Anthropology advanced within natural history through the study of cultures and the discovery of the ruins of ancient civilizations; psychology within philosophy and philosophical physiology proceeded by experiment, through dissection and study of the nervous system, by applying statistics to behavioral phenomena and by observing and examining the self and the behavior of others. By the end of the century, German psychological novels proliferated (e.g., Goethe's Die Leiden des jungen Werthers Sorrows of Young Werther) and Moritz' Anton Reiser) and the first German psychological journal had been published. The discoveries and theories about the human mind also generated a new discipline: they were the ground of aesthetics, the new "science of the senses."

At the time, German aestheticians found the experience of beauty, in art or in nature, to be a pleasure. This experience had a natural theological ground in the discovery of divine agency. From early in the tradition, then, in addition to producing a valuable 
physical response, art had a positive impact on man's moral aspect: pleasure was the perception of perfection in nature or in art, which in turn mirrors the perfection of God. Humans, in perceiving God's perfection, attained perfection and thus fulfilled their function in creation. Based on the value of beauty as perfection, Alexander Baumgarten began a rehabilitation of sense by examining its reason, the lower faculties' unique contribution to man's knowledge. This science identified Leibniz's confused ideas [petites perceptions, dunkle Vorstellungen] as profoundly important to understanding wholes, their relations and connections (including organisms and other objects - the knowledge about which was diminished or destroyed by analysis).

As a new generation expressed itself in the popular literature of the Sturm und Drang movement in the 1760 's and 1770 's, the valorization of feeling washed through Germany like a cultural wave. This correction of rationalism established the capacity to experience powerful, integrating feeling [Empfindsamkeit], including pleasure, as a good in itself. Herder carried data and theories from the life sciences forward in the period's enthusiasm while at the same time attempting to protect the gains of Enlightenment reason.

Developments in aesthetic theory (through the philosophizing of Mendelssohn, Kant and others) delineated the capacity of art, specifically, to provide pleasure by provoking play among the faculties of the mind or among ideas within the mind's sphere of attention. Part of the legacy of Shaftesbury and the Scottish school to the Germans, the recognition of the fundamental importance of disinterestedness of response as a distinguishing feature of art, served to distinguish aesthetics' independence as well. ${ }^{18}$ This turn away from practical, didactic or sentimental effect toward reception and contemplation by an

${ }^{18}$ These philosopher's views were available to Schiller through his tutor Abel, through Mendelssohn, Garve (as translator) and Kant. 
autonomous subject underscored the values of the whole Enlightenment: freedom from tutelage could be claimed for this kind of civilized development [Bildung]. Through Kant as well, beauty became more subjective, bound to the configuration of the mind, and as disinterested beauty, not related to any concept. In particular, beauty was not dependent on a concept of utility, any outside purpose. In a word, it was like an organism. ${ }^{19}$ Art was an integrated whole, appearing to be at once its own means and end, as if organized to some interior plan or purpose. This assumption of internal teleology, of "purposeful purposelessness," constituted a function of reason, a regulatory judgment with respect to beauty.

The "science of the senses" was not simply confined to the fine arts but extended to the art of living. The whole man came down to earth in the late eighteenth century particularly through the cultural dissemination of German aesthetics. A discipline fostering the rehabilitation of sense, both as a species of reason and as man's undervalued physicality, the aesthetic tradition presented man as a whole with all his connections and relations. It presented his products, science and art, as autonomous privileged areas of human endeavor. Schiller wrote: "Art, like science, is absolved from all positive constraint and from all conventions introduced by man; both rejoice in absolute immunity from human arbitrariness" in their search for truth (IX.3). The ideal relation of these endeavors with the community was the following: privileged exemption from dependent relations with power and independence from the distortion of influence and prejudice. Their creators as well, though they may be children of their cultures, must not be their

${ }^{19}$ Goldthwait on Kant's subjectivism: While "beauty seems phenomenally to belong to the object, the feeling of beauty is simply the sign of the harmonious working of certain faculties of the mind when they are attending to a particular object" (Kant Observations 21). 
creatures [Zöglinge, Günstlinge] (IX.4). The scientist, on the one hand, must "approach [Nature] with his sense-organs untroubled, innocent and wide open .... [without] the tendency to prejudge [or the] premature hankering after harmony." He must come to phenomena with both a sense-faculty amenable to form and a reasoning faculty open to content (XIII.4 fn*2). The artist, whose commission it was to ensure that "Truth lives on in the illusion of Art, and [that] from this copy, or after-image ... the original will once again be restored," must strive "to produce the Ideal out of the union of what is possible with what is necessary" $(\mathrm{IX} .4,5)$. He was to "surround [his contemporaries] with great and noble forms of genius, and encompass them about with symbols of perfection, until Semblance conquer Reality, and Art triumph over Nature" (IX.7).

In his life and work, Schiller exemplified both artist and scientist-philosopher. In the Aesthetic Letters specifically, he wrote not only a treatise about aesthetics (including a theory of human nature) but an aesthetic treatise, and he offered an aesthetic space to his readers where they might function as complete human beings - observing human nature contemplatively, as an organic whole, with all its relations and connections. Then, with him, they would be moved to analyze its separate elements, then encouraged to synthesize again. In the work, he questioned his experience openly, considered the contemporary situation critically and fashioned his creative response - so that readers, acting autonomously, might do the same.

Schiller described the experience of beauty as a developmental force for human beings, and he modeled aesthetic education as a way of life, a journey for the whole man. For this purpose, he found autonomy and beauty to be necessary for mature involvement in civic life. Just as the concept of matter had been enriched in the vitalist tradition to 
include something more so that it might approach the reality of life, so the concept of man as a rational being (actually, by that time, of limited reason) needed to be enriched by full recognition of sensibility. The whole man and his whole life in the community was Schiller's subject. The work of art and the way of living aesthetically was Schiller's object. Beauty was the relation. In this way Schiller represented that play is about engagement.

For Schiller, in summary, aesthetics was the study of the uniquely human, our capacity for Beauty. And German aesthetics was his birthright. His inheritance, aspects of which were expressed and elaborated in his theory of play and were connected to the study of life, included: 1) a respect for pleasure - in relation to motivation, happiness and the Ideals of human life, Truth, Beauty and Morality (and consequently a demand for a positive relation between Art and Morality); 2) a respect for the body and its primacy, for sense and its knowledge; 3) an interest in taste, its individual yet communal ground; 4) a movement from didacticism and eudaemonism to disinterestedness in art through an exploration of goal-direction in nature and agency in man, 5) an identification of the reciprocal relations between art and nature, art and organism, and 6) an enlargement of aesthetics from a study of a faculty of mind to an education of the whole man - and from art to the art of living. ${ }^{20}$ These issues are amply reflected in the Aesthetic Letters, and they are played out in Schiller's life and the lives of his contemporaries.

\footnotetext{
${ }^{20}$ It is also necessary to consider the sublime, an eighteenth century obsession, the fruitful relation of play and the sublime, the ongoing struggle to bring that which is beyond the bounds of pleasurable and enframed attention into human life.
} 


\section{Organic Environment: The Cosmopolitan Culture}

The humanities and the sciences in the late eighteenth century were involved in intimate, responsive interactions. Humanists (academic scientists and amateurs as well) had privileged access to the "facts;" they had the use of the discoveries and epistemology of the natural philosophy of life, and they both welcomed and incorporated, rejected and revised, analyzed and synthesized new creations - theory, metaphor and art - from the raw material research into nature provided. The familiar disciplines were not separate; in fact, even the cleavage among the human, social and life sciences [Naturwissenschaften and Geisteswissenschaften] had yet to occur. According to Peter Hanns Reill, "Enlightenment thinkers never conceived of separating the humanities from the study of nature. For them, nature served as the basic model informing all human activities, the grand analogue upon which existence was grounded. ${ }^{21}$ In The Sciences of Enlightened Europe, Lorraine Daston summarized the close-knit feel of the educated community: "[m]uch of Enlightenment intellectual life, including that of the sciences, resembled a great echo chamber, in which not a word was whispered but that multiple voices took it up, repeating and reshaping the sound" (Daston in Clark 498). The study of living nature then was part of the humanities - the results readily accessible and the theories controversial. And the methods and discoveries of science were still valorized by the majority of humanists. Empirical science was distinguished; a new modest epistemology

\footnotetext{
${ }^{21}$ Vitalizing 2. Reill continued: "Chemists trained as doctors, doctors who taught moral philosophy, moral philosophers who pondered the secrets of generation, polymaths who wrote poetry and studied comparative anatomy, amateur and professional natural historians bent upon collecting as many new specimens as possible, mathematicians who wrote about chemistry and chemists who wrote about mathematics, theologians, civil servants, diplomats, and educated lay persons - all were fascinated by the need to establish a new vocabulary to account for living nature" (11).
} 
of the emerging sciences of life and man grounded their knowledge base. Observation, serial observation, comparison and experimentation were the accepted methods of this philosophy and the probabilities that repeated observation provided addressed their needs for practical certainty.

Schiller saw and lamented the increasing fragmentation of the individual and of society but from a context of an achievable synthesis. He had struggled with himself, worked to integrate his capacities and inclinations, and he saw his social circle as a community that provided the support for aesthetic living. Schiller's intellectual milieu at Weimar received science as the leading edge of the humanities project, a situation that continued to the end of the eighteenth century. There, an intense web of visits, correspondence and reading kept the small community current with regard to life science controversies. Goethe, Herder, Fichte, Reinhold, Kant, Forster, Blumenbach were all in the mix. There, Schiller, educated as a physician, became Goethe's colleague and confidant. $^{22}$ They met in 1794 at the home of August Batsch (the botanist) at a meeting of the Natural Historical Society of Jena and began a 10-year period of intense collaboration after one evening's earnest discussion and amicable disagreement about epistemology and natural archetypes. ${ }^{23}$ Goethe, in addition to his literary efforts, studied

${ }^{22}$ Roger: "The study of living beings was traditionally reserved for medical doctors. Medical studies had for a long time been the only regular scientific training available. Anatomy, physiology and botany were regularly taught in medical schools, and a professorship in medicine was the only way to make a living out of those studies. It was therefore accepted that a professor of medicine should be primarily interested in anatomy or botany, provided that it was human anatomy and botany considered essentially for its medical uses. This state of affairs lasted and even developed during the eighteenth century, especially in countries such as Germany ..." (in Rousseau 258-9).

${ }^{23}$ Schiller had experienced, perhaps been saved by, a previous community: his friends in Leipzig, Körner and his circle. He and Körner continued their intimate correspondence, 
and wrote scientifically; his interests included morphology, geology, mineralogy and optics. The Humboldts lived nearby; they, grounded in natural philosophy, at that time were studying anatomy. Goethe often accompanied them to dissections, and he communicated his enthusiasms to Schiller. Schiller, for his part, despite his disclaimer, was widely read, known particularly to rely during the composition of the Aesthetic Letters on the synthesizing naturalists, Herder, Rousseau and Kant. ${ }^{24}$

This functioning community of humanists [Gesellschaft $]$ was for Schiller objective humanity, the outward, the empirical, pledge of man's capacity for harmony and balance and an indication of his unifiable internal organization. For us today, the close connection between the humanities and its life sciences could represent an example of the organization of knowledge, one that grounds the humanities not just in culture but in the world of nature and civilization.

\section{Organic Environment: Reciprocal Relations over Time}

What is man, and what has he to do with play? The exploration of humanness as a part of nature and the scientific approach to the phenomenon of play - each of these has a history, and these histories are interdependent, co-ordinate and subordinate to other

one that included the seminal Kallias letters. Schiller to Körner, 7.v.1785: "I feel that we have attained the goal which I had but dreamt of. The brotherhood of minds is the surest key to knowledge. Alone we are powerless. If the bold flight of our imagination carry us into the most distant spheres of truth, we should suddenly start at our own loneliness" (I:23).

${ }^{24}$ Schiller's disclaimer: "My ideas, derived from constant communication with myself rather than from any rich experience of the world or from reading ..." (I.2). A prodigious number of his sources were documented by Wilkinson and Willoughby in their Introduction and Commentary. The natural philosophy and history involvements of the three just mentioned were explored by Denby, Hulliung, Larson (Interpreting), Nisbett (Herder and "Herder"), Roger, Sloan ("Kant" and "Performing"), and Zammito among others. 
endeavors. The study of life in the late eighteenth century and the designation of play as the ground of humanity (as a profoundly important behavior) were revolutionary endeavors. But the occurrence of change (of a paradigm shift) and its recognition are two separate operations. The first is a change in real time; it is a shift in science on the ground arising from an accumulation of transgressive content (things that just don't fit the accepted frame) and a change in retrospection. The second is the awareness of change in the history of science. Then, new interests, new discoveries or new techniques reflect backward allowing for a deeper and more empathic questioning of time past or a fuller appreciation of the roots of current knowledge. Vitalistic life studies in the eighteenth century constituted a paradigm shift by Kuhnian standards, but one that could not be appreciated until biology had incorporated genetics and evolution into its body of knowledge. ${ }^{25}$ It was neither genetics nor evolution itself that compelled Enlightenment scholars, but rather they were impelled by their own epistemological black-boxing of these unknowns, the recognition that their current understanding of matter could not explain life's functions or complexity. Their modest epistemology (knowing what they could not know), their understanding of the importance of the individual, their acceptance of probability in a dynamically altering environment, and their acknowledgement of the need for natural classification were retrospectively valorized by late twentieth-century philosophy of biology.

${ }^{25}$ The change previously was encoded as a reaction against the past, propelling humanity from mechanistic dualism to Naturphilosophie and nineteenth-century biology; this view left the natural philosophy Schiller and Goethe together flourished in, like a town without a railroad station, an underserved moment in that history of science. Cantor commented in his review of The Ferment of Knowledge that "[w]hatever ferment of knowledge there was in the eighteenth century ... [there is] another very real ferment, productive of much heat and considerable light, among scholars of the eighteenth century" (62). 
Schiller's theory of play gave full weight to the aesthetic: he made feeling an equal partner with reason, allowing leisure and purposeful purposelessness to be the prerequisites of personal and societal development. The historic and scientific significance of his ideas could not be fully appreciated before the re-characterization of natural philosophy and natural history of the late eighteenth century. His place in the history of the study of play cannot even now be properly identified - his contribution must be carefully teased from its literary context and placed with contemporary research on play. Then Schiller's theory, seen as a scientific model, can be updated into the program of the biological and social sciences. And as a general theory of human nature, formatted by today's evolution-based life science, the theory of play can then be productively integrated into today's humanities as well. To rephrase the possibility, the reciprocal relations between the study of life and the study of man in each time period can inform each other. Just as we learn about the character of eighteenth-century unknowns and apply the knowledge that has become available to us since the late Enlightenment, we are alerted to the size, shape and possible content of our own black boxes. As such, Schiller's theory of human nature might prove a valuable counterbalance to two contemporary trends: the rootless, self-referential, post-modern cast of the humanities and, in popular science, the modular theories of evolutionary psychology. The theory's appearance [Schein] was a contribution to the science and study of man in the eighteenth century and it is our legacy today.

The late eighteenth century presents another paradigm: the humanities functioned then as the study and the celebration of the sum of human endeavors. Through a continuous revision of facts and reworking of empirical surfaces provided by its scientific 
programs, through the correction of interpretive assumptions arising from previous science, humanists directed attention toward both universally held meaning and value and toward the practical implementation of those values in politics. Life science was the forward edge of the endeavor until it had extended as far as technology would allow, not only because such curiosity about nature drives humans generally but because it is practically necessary to well-being. Organic syntheses of human activities, the reciprocal, co-operative relations of knowledge, were basic to Schiller's sense of practical human possibility. ${ }^{26}$

Many stances in the argument about human nature dating from the Enlightenment are still part of common sense about what it means to be a human being in the world. What is man? And what is mind? Schiller began and ended with mind/body relations: what kind of existence does the mind have - is it an idea, an experience or an entity? What is its relation to the body? Like him, we also work from the polarities of nature/nurture: are there innate ideas, or are we solely the products of our senses? Do we unfold, are we pieced together by our experience or are we productions of yet another mother, culture (as Schiller would say, our second creatress, Beauty)? Of nature/civilization; are we corrupt or corrupted? Of heredity/environment - is there a common ground of humanity? These questions, and the barely conscious life-stances referable to them, play out moment by moment in civic and personal behavior. All are addressed by Schiller who was intimately concerned with behavior, with our capacity to learn and improve. His theory, rather than attempting "to break down the wall between

${ }^{26}$ The argument can be made that the maturation of chemistry, the "fact" of the cell, the theory of evolution by natural selection, the discovery of radiation and the science of genetics did the heavy lifting in opening up the late Enlightenment unknowns about life forces and functions, about regulatory ideas and teleological processes. 
matter and mind and explain human nature by the physical workings of the body," bends along the walls of separation (Thomson 1). He traces the labyrinth of our nature, the bounds of which surround and juxtapose polarities. There, in an internal field where abstractions materialize, where complex space is emptied and filled with new or different appearance, he found our specific ground. Play felt organic to him, and Schiller described it both as a place of being and a place of becoming. 


\section{CHAPTER II}

\section{SCHILLER'S THEORY OF PLAY}

But how can we speak of mere play, when we know that it is precisely play and play alone, which of all man's states and conditions is the one which makes him whole and unfolds both sides of his nature at once? What you, according to your idea of the matter, call limitation, I, according to mine - which I have justified by proof - call expansion. (XV.7).

What is Schiller's theory of human nature? Schiller believed that the capacity to play with beauty is specifically human, and that playing with beauty develops each individual into a human being. Although he set his explanation in a literary essay, he proposed his theory using the language of the natural philosophy and the natural history of his time. His theory suggests a basic type for humanity, an archetype that is both observed and intuited. It describes a system of life forces or drives, organized in a complex way to promote the possibility of a dynamically balanced, internal environment. The interaction between drives that stimulates the reciprocal relations among the capacities of the mind also fosters a dynamic equilibrium between the individual and his environment.

Schiller's theory redefines play: he posited playing as genus- and species-defining, that is, as a peculiarly human capacity and behavior. We are, he wrote, human because we play, and only humans play. The word "play" he made specific, like many words

\footnotetext{
1 "Also there was the pleasant rhetorical shock produced by saying that play, not reason, duty, or religion, was the highest fulfillment of humanity" (Engell 236).
} 
used when bent to science. He meant to attach it to a particular set of parameters; for him play is a drive state that signifies the human species, and that drive state has a particular goal, the sensate ideal (beauty), and a particular resolution, the aesthetic state.

Schiller's theory of human nature is crafted out of the raw materials of his time's vitalistic science (familiar to us from the previous chapter): his forces in the mind, drives, were forces in living matter. According to him, humans share a sensate drive with animals, but only humans have a sufficiently independent rational drive to counter, in a fruitful and reciprocal relation, their physicality (their perceptions and feelings). Only humans have this opposition of drives, as a balanced antinomy. The drives' polar tension and interaction create a composite drive. It, through its goal-direction, can in turn promote development of the individual toward a harmonious balance of free and gracious living. In short, the play-drive he intuited as the ground of our uniqueness is produced by two polar drives acting reciprocally in a dynamic equilibrium. Our drive for content (for matter, for stuff or reality) called the material-drive or the sense-drive [Stofftrieb], and its opposite (one that develops later in time), the drive to form and manage that content, called the form-drive or rational drive [Formtrieb], interact. Consciously and unconsciously, we crave experience and we are equally intent on framing that experience. That dynamic interaction creates the play-drive [Spieltrieb] and a mental arena of thought and feeling, a middle-ground for contemplation called the aesthetic state. ${ }^{2}$ The play-drive is in turn developed and matured through experiences with beauty. Such experiences

\footnotetext{
2 "The sensuous drive awakens with our experience of life (with the coming of our individuality); the rational drive, with our experience of law (with the beginning of our personality); and only at this point when both have come into existence": essentially, only with the possibility of the play drive, are we human (XIX.12).
} 
change the drive's object of satisfaction so that an individual's way of living shows his approach to the ideal.

\section{But, Why Call It Play?}

"Violation or distortion of a previously unproblematic scientific language is the touchstone for revolutionary change" (Kuhn "What" 21).

By choosing to use the word "play," Schiller must have intended the richness of its dynamic history to be subsumed into its new particularity. He used a familiar word with a surfeit of associations and connotations, a concept with a curious aesthetic feeling of its own. And its additional complexity? Play is an amorphous combination of subjective experience and objective conditions. Play's subjective components are many: unconscious playfulness (in-the-flow), a player's own awareness of pleasure and desire, his recognition and acceptance of play's forms, and the player's and spectators' empathic identification of playfulness in others. All these combine with a variable repertoire of observable (empirically describable or objective) behaviors that occur in other contexts as well. Human personal experience floods the concept "play" with memories and anticipation; historical cultural convention has already defined play as a class of behavior. Play is tricky territory for Schiller and everyone else who investigates it.

Schiller's new use is problematic: it both calls upon and transgresses this old word's etymology. It is a function of his redefinition of play that, through his theory, we will come to see play as the common structure of human activity, as a whole where once we saw parts. Before the Aesthetic Letters, we knew what mere play was; we were familiar with our pleasures, with the activities of animals, of children, gamblers, of various faculties or states of mind. Through reading his text, however, we are to gain a new 
understanding of play as a specific mental operation and a general category. We will appreciate it as a potentiator of our own freedom. By reframing our perception of play through redefinition and by providing a semblance of play to encourage autonomous human development (in the form of the Aesthetic Letters), Schiller offered us, his readers, a transformational experience of human nature.

One of the most difficult challenges in the study of play is defining "play" itself both in Schiller's time and in our own. The concept "play" covered a broad field of meaning in the eighteenth century. It was an activity of living things in general and of social animals, a type of human activity or way of human doing, and an internal capacity of mind specific to humans and dependent on self-consciousness: all these were in use before Schiller presented his own ideas in the Aesthetic Letters. Das Deutsche Wörterbuch von Jacob und Wilhelm Grimm presents a long and productive use of the word - documented in prose and poetry beginning in the eighth century with Otfrid of Weißenburg. There was a huge explosion of its use in literature during and beyond the period of Weimar Classicism - represented by Kant, Goethe, Lessing, Hamann and, superabundantly, by Schiller. "Spiel" [play] itself conventionally refers to non-goaldirected, pleasure driven activities of children, older humans and animals, including with one-sided play, exemplified by an ironic Luther: "The cat's play is death for the mouse" [der katzen spiel ist der mäuse tod]. ${ }^{4}$ By the time Schiller wrote, although physical play

\footnotetext{
${ }^{3}$ On line resource: http://germazope.uni-trier.de/Projects/DWB.

${ }^{4}$ This last brings up the ambiguity, the deep structure of "purposeful purposelessness" and practice - an issue that has dogged evolutionary explanations of play, particularly with reference to animals.
} 
and games of all sorts were still denoted, "Spiel" was very much associated with mental

and verbal activity, the interaction between faculties of the mind, from joking to

contemplating, from judging to fantasizing. With the help of Leibniz's petites

perceptions [dunklen Vorstellungen, unclear, obscure representations], Germans, like

English-speakers, played much within the theatre of their minds. "Spiel" carried the

meaning of an act, a theatrical piece, the execution (of an artwork), role-playing, and it

${ }^{5}$ Regarding the use of the word play in English: "The Indo-European root behind the Old English 'plegian' - a root also found in Celtic, Germanic, Slavic and possibly Latin - is dlegh-: meaning, 'to engage oneself.' [At a root level then] play is about engagement" (my emphasis). The English word "play" includes activity and mode (a way or manner of doing something). As activity, it includes performance (of an action or role) or use of a musical instrument, participation in a contest, a gambling activity or recreation. As a mode, "play" is used in English often to indicate a frivolous, jesting, irregular, free, childlike, graceful, light or trifling manner of doing something or moving freely in a bounded space (e.g. gears). It is often combined in a phrase to connote some pretense, manipulation, or illicit sexual activity: "play along" (pretend to co-operate), "play around" (philander), "play down" (minimize), "play off" (set one person against another), "play on" (manipulate someone's feelings), "play out" (use up, exhaust, drive to an end), or "play up" (emphasize). As an idiom, it appears in constructions about conduct in life ("to play fair," "to play fast and loose," "to play the game," "to play cards close to the vest," "to play with fire," "to play into the hands of" or "to play with a full deck"). It also appears in constructions about freedom, scope and room ("to give full play"), inclusion ("to be in or out of play"), co-operation ("to play ball"), manipulation, covert motives or pretense ("to pitch," "to play it in Peoria," "to play for time," "to play possum," "to play dumb" and "to play up to someone"), devaluation ("to play with feelings"), simulation or mimesis ("to play a role or part") of course, sex ("to play around," "to play the field," "to play with oneself," and "foreplay"), or in referencing or receiving internal mental operations and language ("the play of the imagination" or "to play with words, ideas, to write a play"). The etymology of the word "game," so much a part of our concept of play, is as follows: "perhaps derived from obsolete 'gamel,' to play games, from Middle English 'gamen, ' 'gamenen,' to play, from Old English 'gamenian,' from 'gamen,' fun," to which the world "gamble" (to risk or hazard, to bet) is closely related. Game includes wild animals (on the hoof or as food) as well as human activities and modes of being. A game is a competition, contest or sport played with rules within the boundaries of set time and space, with a defined goal. As a mode it indicates accommodation to the way things are run ("playing" the game, the system), willingness ("I'm game"), duplicity or mockery ("She's gamey." "They made a game of him.") and structured criminality (a "game," a "racket") (Play resources). 
had hefty infusions of chance, as in gambling and card-playing. ${ }^{6}$ Risk as one of its common connotations extended its meaning to physical tolerance and slackness. Idiomatic constructions of "Spiel" allowed for dissimulation, trivialization, criminality, and manipulation, but also for freedom and separation from consequences. "Spiel". might, for example, stand opposed to "work" [Arbeit], but such an antithesis could easily break down: "Spiel," although it forms an antimony with work along the lines of pleasure and utility, aligns with it through emphasis on the energy at its command. The scientific definition of work as energy expended later provided the paradoxical (and anachronistic) convergence. ${ }^{7}$

In eighteenth-century German culture, "play" then had at least three valences: First, the concept encompassed the superfluous activity of animals, the non-goal-directed behavior of children and the trivial pastimes of adults. Second, it described natural and mental processes that involved relation, reciprocity and dynamic interconnection. "Play" denoted the interactivity of the faculties of the human mind and particularly the activity of its imagination and ideas. The internal capacity to create representations, both knowledge-apprehending concepts and whole-picture intuitions that relate and create, is referenced in this use of play. Third, the word "play" included the imitation or representation [Schein] of ideas and objects - included are all the art forms and particularly the literary ones, poetry, fiction, satire, and drama. It was as well the descriptor of Rococo style. In summary, "play" came to Schiller as an admixture of

\footnotetext{
${ }^{6}$ Schiller wrote and worried about this connection.

${ }^{7}$ Schiller never played with this antithesis. A scientific definition of work came through Gauss, Joule and Kelvin who developed the relation of work to heat in the mid-1800's.
} 
outward and visible, empirical and subjective, rational and self-observational fields. It not only described organismic interaction but also was itself described as a mimic of organisms and complex phenomena. In the late eighteenth century, playful phenomena were not only being avidly studied and but that investigation led to a new understanding of reciprocal relations in the individual, the environment and history. ${ }^{8}$

Was Schiller's use of the word "play," burdened as it was with so many associations and manifestations, playful? Well, yes. It has the feel of wildness, and it was and still is a feat to manage the word, to control the damage of its unintended consequences. Schiller, however, counted on the joy and energy it engendered, the unexpected fertility and life of the concept, and all of the facets of experience it commanded. Schiller's goal of ensuring human freedom required a play that opened up our potential as human beings. By describing our nature as a coupling of drives to form another drive, one that orients to beauty, he sought to protect and further our capability to choose. That natural ability to pause, to incorporate into our repertoire moments of contemplation, defines our genus and species.

\footnotetext{
${ }^{8}$ Weather and cloud formation constitute examples of the complex phenomena studied in the late 1700 's, information about which was taken immediately up into the arts. Luke Howard's work on clouds coupled Linnaean classification with a capacity to manage indeterminacy and dynamic phenomena due to organic paradigms. Goethe wrote a series of poems in tribute to Howard after reading his "Essay on the Modification of Clouds" (1803) and was instrumental in introducing Howard's cloud classification in Germany, a system he extended and refined. He prevailed upon Howard to write an essay which he then translated into German, "Wolkengestalt nach Howard" (1822). In addition, Goethe set up a local weather observation network. John Constable, who wrote that painting should be considered a science, documented in his art the interest in weather - one of the many complex physical phenomena that can only be framed probabilistically. His series of cloud studies (1820's) perpetuated Howard's influence by way of Alexander Cozen.
} 
By calling the drive and state that distinguishes the human being by the name of "play," Schiller combined two archetypal intuitions and made two distinct classifying maneuvers based on those apperceptions. He posited the human mind as unitary (a natural whole) in the individual and in the species (even if its potential is incompletely expressed in each particular person). Schiller defined humanity as a historic entity, a reproducing kindred, separate from any other species (and yet in analogous relation with other playing entities). The choice of the word was the result of years of living and research, the research of a physician and a dramatist. It was as if Schiller gathered together all the playing he had observed, all the complex interactions in nature and all the objective behavior among animals and in humans. In humans, he observed all historic and current behaviors that were not directly related to the survival drives for food, sex and shelter. He collected histories of his own mental activity and the subjective accounts of others. He read and he compared. He chose the word because its uses, spin-offs and connotations only underscored the enormous and successful versatility of its simple skeleton. He intuited the deep structure of the concept, "play" and found that it includes all our doing and being. Generally play is pleasurable and expectant attention (a modulated drive-state attention to things), promoted and intensified by enjoyable framing and reframing (conscious and unconscious drive-state application of forms to attention). Whether we play, work, read, imagine, think, even when we perceive, we play: all are the flesh on the bones of enjoyable and framed attending. He recognized that behavioral morphology of humans - our pleasure in attention and its conscious and unconscious flexible structuring. Of all the playing, only one kind of play was associated with human development, however; our play can and should include interaction with beauty, the 
sensate ideal. This tethering of play makes it species-specific: only then can we be whole, only then can we develop our human potentiality. Again, he synthesized: he simplified and clarified a mental category and applied it to the world of experience. Play became, by his use of it, a natural classificatory device - a way of both distinguishing our species from other species and also uniting all our varieties into one genus and species.

The experience of beauty is fundamental to Schiller's human play, and it has both objective and subjective components. As object, the beautiful draws and fixes our attention. As a subjective experience it (combined with the play-drive) is a distinctly human purpose/perception/goal, one that has an organic form, a reciprocal manner of developing each individual along the lines of his potential humanity. It engenders a state of harmonious balance, a contemplative position that opens the individual up to internal possibility and external chance. We can play, but to be fully human, we must play with beauty.

\section{The Theory of Play in the Aesthetic Letters}

What then are the specific references to play as a drive and a state, as archetypal for human beings? The following excerpts from the Aesthetic Letters highlight Schiller's argument, and they take added meaning from the eighteenth-century understandings about forces in living matter and from a changed epistemological stance, a new way of knowing the general from the study of the particular (by intuiting similarities through observation, comparison and analogy to derive an archetype, Urbild, or Haupttyp). Schiller's choices also reflected contemporary philosophical controversies about natural and artificial classification, the emerging biological meaning of the categories like genus 
and species and the current understanding(s) of generation (reproduction, continuation of organic forms). ${ }^{9}$

Every individual human being, one may say, carries within him, potentially and prescriptively, an ideal man, [Anlage und Bestimmung] the archetype of a human being, and it is his life's task to be, through all his changing manifestations, in harmony with the unchanging unity of this ideal (IV.2),

In this passage, Schiller's archetypal man has one aspect that functions like a sort of genotype available to all members of a species, and a destiny, an aesthetico-rational goal toward which a person functioning at his best might approximate. By using Anlage (embryological rudiment or predisposition) and Bestimmung (destiny, vocation) together, Schiller synthesized, perhaps conflated, concepts like Urtyp, Haupttyp or moule intérieur [internal mold] - these closer to eidos, a concept from Aristotelian natural history - and the Platonic ideal form. He conceptualized the basic type of human nature as his friend Goethe might experience (apperceive) the common bone structure of vertebrates. He followed Buffon, Kant and Goethe in claiming commonly held biological predispositions for the species, and he depended on Buffon's single-species hypothesis of human origins as argued by Kant. According to Schiller, as a genus (and species), humans have a basic design: the play drive structure gives humans the capacity to be flexible, primed for possibility. ${ }^{10}$ The template is given in nature and carried by each individual; the fulfillment is the destiny of each person to accomplish. ${ }^{11}$

\footnotetext{
${ }^{9}$ These will be detailed in the next chapter.

${ }^{10}$ Homo is the genus, of which for the single-species theorists, sapiens was the single species; the races were "varieties."
} 
Schiller continued:

But can Man really be destined to miss himself for the sake of any purpose whatsoever? Should Nature, for the sake of her own purposes, be able to rob us of a completeness which Reason, for the sake of hers, enjoins upon us? It must, therefore, be wrong if the cultivation of individual powers involves the sacrifice of wholeness. Or rather, however much the law of Nature tends in that direction, it must be open to us to restore by means of a higher Art the totality of our nature which the arts themselves have destroyed (VI.15).

Many eighteenth-century ideas about variation within species (the rise of races and varieties) held that each member of a species included within itself the whole range of species-possible traits [Keim und Anlagen] and that degeneration caused by environment, resources or climate modified or eliminated some possible expressions. From theories of the continued existence of unexpressed traits (e.g. Kant's modified preformationism, his Keim und Anlagen), Schiller hypothesized that while civilization as an environment caused fragmentation (degeneration), culture could also restore potential expression by means of development [Bildung] through aesthetic experience. In fact, he stated that human nature itself is based on maximizing flexibility, that humans have one special way of developing latent capacities, and that way is human play.

$[T]$ o mince matters no longer, man only plays when he is in the fullest sense of the word a human being, and he is only fully a human being when he plays. This proposition, which at the moment may sound like a paradox, will take on both weight and depth of meaning once we have got as far as applying it to the two-fold earnestness of duty and destiny. It will, I promise you, prove capable of bearing the whole edifice of the art of the beautiful, and of the still more difficult art of living (XV.9).

\footnotetext{
${ }^{11}$ Buffon (1776) on human potential: "For what we already know should allow us to judge of what we will be able to know; the human mind has no frontiers, it extends proportionately as the universe displays itself; man, then, can and must attempt all, and he needs only time in order to know all" (Roger Life 458).
} 
Play, a drive and a state, is described much as an organism would be described characterized by wholeness seeking wholeness through reciprocity. This balance and harmony of polar components essentially creates a state of contemplation of variable duration that gives individual's access to the genus' potential. ${ }^{12}$

[The aesthetic mode of the psyche] which contains within it the whole of human nature must necessarily contain within it in potentia every individual manifestation of it too .... because it takes under its protection no single one of man's faculties to the exclusion of the others, it favours each and all of them without distinction; and it favours no single one more than another for the simple reason that it is the ground of possibility of them all .... the aesthetic alone is a whole in itself, since it comprises within itself all the conditions of both its origin and its continuance (XXII.1).

His theory turns of course on his definition of playing as a drive state. For him, playing is our broad way of doing and being, just as for him aesthetics is a way of life. He defined human beings as those who, driven (by the pleasure of it) to be attentive and to organize the objects of that attention, are the flexible ones in nature. ${ }^{13}$ Play for Schiller

12 "Contemplation (or reflection) is the first liberal relation which man establishes with the universe around him" (XXV.2). "Admittedly the rapidity with which certain types pass from sensation to thought or decision scarcely - if indeed at all - allows them to become aware of the aesthetic mode through which they must in that time necessarily pass" (XXI.5fn).

13 "The faculty of attention and its distinctive pleasures were objects of considerable theorizing in the late seventeenth and eighteenth centuries .... According to contemporary physiology, attention diverted nervous fluid from all other fibers of the brain so that no other external impression could register upon the soul in that rapt state. The saturated fibers held the soul in contented captivity, mingling intellectual concentration with sensory and emotional transports ... . Bonnet posited that attention was proportional to the pleasure excited by the object. But the experiences narrated by the naturalists suggested that the equation could be reversed: attention also created pleasure ..." (Daston 117-8). There was considerable pathologizing of attention during this period; it was considered injurious to the health of the obsessive natural historian and the virtuoso. Schiller's archetypal play, on the other hand, with its contemplative state, is a type of attention protective of function and development. 
then is a drive, a force in us, and a state (capacity, faculty). It is actually a combination of polar drives, reciprocally organized to create a transformational third. He hypothesized that play is a reciprocal, complex amalgam of two forces or instincts, the one craving reality and content [Stofftrieb], the other, a compulsion to form or to organize experience [Formtrieb]. These two energies bring forth a third drive, the play drive [Spieltrieb]. This new drive is itself in a reciprocal organization with an ideal that energizes and motivates, that is, with beauty.

Here are the elements of Schiller's drive argument:

[T]wo fundamental laws of man's sensuo-rational nature. The first insists upon absolute reality: he is to turn everything which is mere form into world, and make all his potentialities fully manifest. The second insists upon absolute formality: he is to destroy everything in himself which is mere world, and bring harmony into all his changes. In other words, he is to externalize all that is within him, and give form to all that is outside him (XI.9).

In man's nature, which is nothing if not physical, mind always of the body, Schiller, like his contemporaries, observed and experienced two polar impulses, sense and reason. Prevailing Enlightenment theory (i.e., Kant) demanded that reason must subordinate sense, that morality hold against desire, and that duty be enjoined without much respect for inclination. But Schiller was dynamic synthesizer: he saw the need to save the Enlightenment project by incorporating counter-Enlightenment corrections. He depended on insights from his psychosomatically based medical training, from mid-century skepticism and developed Lockean sensationalism as well as the German "science of sense" tradition. He demanded that sense have its place. Sense must be to be considered with reason, Schiller held, for feeling provides the energy, the motivation that reason needs for its purposes. 
Towards the accomplishment of this twofold task - of giving reality to the necessity within, and subjecting to the law of necessity the reality without - we are impelled by two opposing forces [Kräfte] which, since they drive us to the realization of their object, may aptly be termed drives. The first of these, which I will call the sensuous drive, proceeds from the physical existence of man, or his sensuous nature .... And since form is never made manifest except in some material, nor the Absolute except through the medium of limitation, it is indeed to this sensuous drive that the whole of man's phenomenal existence is ultimately tied (XII.1,3).

The above statement is a late Enlightenment correction of the primacy of reason.

The basis of humanness as a nature shared with animals, with other sentient beings, must be recognized in order to provide the energy necessary for the moral life, and Schiller introduced it as a drive component antecedent in time. It was a drive without which the other drive component, reason, could not be expressed. It is only within the strictures of phenomenal existence - material being-and-becoming in history - that man may have experience of the absolute or ideal. Schiller's deliberate equal treatment of the drives lifted the lower faculties that were the subject of German aesthetics. Then,

The second of the two drives, which we may call the formal drive, proceeds from the absolute existence of man, or from his rational nature, and is intent on giving him the freedom to bring harmony into the diversity of his manifestations, and to affirm his Person among all his changes of Condition (XII.4).

Reason-the-faculty becomes reason-the-force, but it is an internal force, needing the sense drive for external action. It functions to hone, organize and structure the contents of attention at several levels - one of them being the experience of the self (Person) as stable in time.

At first sight nothing could seem more diametrically opposed than the tendencies of these two drives, the one pressing for change, the other for changelessness. And yet it is these two drives which, between them, exhaust our concept of humanity, and make a third fundamental drive 
which might possibly reconcile the two a completely unthinkable concept. How, then, are we to restore the unity of human nature. . . [?] (XIII.1).

Schiller's understanding of the interaction of drives includes the important unity of the parts; that unity is a transformation wherein a complex organization brings about new capacities while preserving the original polarities.

Both [drives] . . . are . . a at once subordinated to each other and coordinated with each other, that is to say, they stand in reciprocal relation to each other: without form no matter, and without matter no form . . . . Assigning each of them its own sphere, we are by that very fact excluding the other from it, and setting bounds to each, bounds which can only be transgressed at the risk of detriment to both (XIII.2fn).

In his description of drives, Schiller relies on organic organization: complex reciprocal relations within boundaries that promote the creation of a transformative third space. The new state or space is a new environment that makes new functions possible. For him, drives are the motive forces. These mental drives (he abstracts) function like life-forces in animals (for example, the drive to sustain life or to reproduce): they have specific objects. Their satisfactions function like goals or ends.

We have now been led to the notion of a reciprocal action between two drives, reciprocal action of such a kind that the activity of the one both gives rise to, and sets limits to, the activity of the other, and in which each in itself achieves its highest manifestation [höchsten Verkündigung] precisely by reason of the other being active (XIV.1).

The sense-drive demands that there shall be change and that time shall have a content; the form-drive demands that time shall be annulled and that there shall be no change. That drive, therefore, in which both the others work in concert, . . . the play-drive ... would be directed towards annulling time within time, reconciling becoming with absolute being and change with identity (XIV.3) .... The object of the sense-drive, expressed in a general concept, we call life, in the widest sense of this term: a concept designating all material being and all that is immediately present to the senses. The object of the form-drive, expressed in a general concept, we call form, both in the figurative and in the literal sense of this word: a concept which includes all the formal qualities of things and all 
the relations of these to our thinking faculties .... The object of the playdrive, represented in a general scheme, may therefore be called living form: a concept serving to designate all the aesthetic qualities of phenomena and, in a word, what in the widest sense of the term we call beauty (XV.2).

Since the satisfaction or goal of the archetypal human drive, the play drive, is beauty, beauty "would have to be shown to be a necessary condition of Human Being [Menschheit]" (X.7).

In summary Schiller (in what might be considered ironically religious language figural of both the creation and the Incarnation [the Annunciation: höchsten Verkündigung]) had both drive "parents" participate equally in the generation of the play drive, a reproductive event that references the theories of Maupertuis and Buffon, and the sensibility of Herder:

Reason, on transcendental grounds, makes the following demand: Let there be a bond of union between the form-drive and the material drive; that is to say, let there be a play-drive, since only the union of reality with form, contingency with necessity, passivity with freedom, makes the concept of human nature complete ... . Let humanity exist, [thereby] it has by the very pronouncement also promulgated the law: Let there be beauty (XV.4).

\section{Sense First}

[T]hought needs a body, and form can only be realized in some material.

(XXIII.4)

In the Aesthetic Letters, Schiller posited that the human mind is an embodied mind. Schiller's human mind has no existence outside the body. It has necessary and reciprocal connections with the rest of the body, and its sensuo-rational nature has its locus in the nervous system. It impacts and is impacted by the functions of other organs and 
systems. ${ }^{14}$ Our human nature is embodied, organic; as such, the mind is complexly and reciprocally organized. Its sustenance is to maintain harmony and balance through the action of polarities within it. It has the capacity to create third entities, transformational structures, forces or qualities. Further, it works to be in harmonious balance, through reciprocal drive relations, with its immediate environment, the body, and its greater environment, the world. ${ }^{15}$ As the seat of the self, of the experience of continuity of person amid the changes not only of his own individual attributes and capacities but of things in the world, the organic mind is both means and end of its own action in time, rather than the means to some other non-autonomous end (XIII).

The mind, like the organ and the organism, has the capacity for development, for Bildung, especially through play. Schiller, as a vitalist, had a deep interest in change over time, development and history. In the Aesthetic Letters, partly as a critique of Rousseau and Herder, he traced the developmental path of play in both the species and the

${ }^{14}$ Because studying the mind is an occupation that cannot be based mainly on empirical methods, Schiller subjected human nature to analysis using the empirically derived descriptions of organisms and then used the features of organism to communicate his intuition (based on years of studying himself and others) about its historical development, its function and its fundamental or archetypal identity. The epistemological possibilities of this vitalistic position are explored in Chapter V.

${ }^{15}$ This Linnaean idea (1760) of natural economy was an eighteenth-century truism: as the view of Nature became more dynamic, balancing and harmonizing were seen to include tension over time. Already accepted and acknowledged as part of such a system was the violence, disadvantage to or demise of individuals or individual parts. As Schiller remarked of balance: "The scales of the balance stand level when they are empty; but they also stand level when they contain equal weights" (XX.3). Any organic whole is always becoming - always dynamically stressed as it is harmoniously balanced. Schiller's view of harmony in human nature is that it is dependent on access to that middle ground: "Nature is not meant to rule him exclusively, nor Reason rule him conditionally. Both these systems of rule are meant to co-exist, in perfect independence of each other, and yet in perfect concord" (XXIV.8). 
individual. According to him, we do not as individuals and we did not as a species begin playing at our fullest potential. At first living as animals do, we played socially only in the absence of fear and want, out of exuberance. The sense drive came first, followed by a rudimentary reason, a budding rational drive.

The sensuous drive ... comes into operation earlier than the rational, because sensation precedes consciousness, and it is this priority of the sensuous drive that provides the clue to the whole history of human freedom (XX.2).

These interacting polar drives created a higher integration and a third, the early play drive. Then Schiller proposed that, human beings, through developing awareness of self and the beginnings of empathy, began to take pleasure in gratuitous adornment. "Man adorns himself. Disinterested and undirected pleasure is now numbered among the necessities of existence, and what is in fact unnecessary soon becomes the best part of his delight" (XXVII.5). This early form of play, the interest and delight in appearance, found pleasure in 'something added' to bare utility. ${ }^{16}$ Attention was then broadened from basic needs, from the necessary satisfaction of hunger, safety or sex, to a mediated curiosity; sustained attention then extended to interest and delight in appearance [Schein]. Appreciation of beauty in reality, of Schein, the reciprocal relation of the object itself with the perceiving and forming subject, is the additional element necessary to keep us from getting trapped. We can be constrained either by what gets our attention or by

\footnotetext{
16 "Whenever, then, we find traces of a disinterested and unconditional appreciation of pure semblance, we may infer that a revolution of this order has taken place in his nature, and that he has started to become truly human. Traces of this kind are, however, actually to be found even in his first crude attempts at embellishing his existence ... as soon as ever he starts preferring form to substance, and jeopardizing reality for the sake of semblance ... a breach has been effected in the cycle of his animal behavior, and he finds himself set upon a path to which there is no end" (XXVII.1).
} 
being possessed by our own creating. This appreciation of Schein is intimately and mysteriously connected and reciprocally involved with those two early capacities related to gratuitous adornment, self-consciousness (self-awareness, self-representation [Selbstbewußtsein]) and empathy, (i.e., a person who wants to please must attend to what gives pleasure to others) (XXVII.5). An organic relation, dynamic and reciprocal, with an ideal motivates and energizes when it is approached through such experience. For Schiller, that ideal is beauty. The ideal beauty functioned to enlarge the aesthetic space as a sort of mental arena.

Our first representation, self-representation, according to Schiller, arose prior to our willing and is responsible for the original manifestation of personality:

Only of him who is conscious of himself can we demand Reason, that is, absolute consistency and universality of consciousness; prior to that he is not a human being at all, and no act of humanity can be expected of him (XIX.11).

At first humans experienced reason as external because it was inhibitory. Then, as we developed further through self-representation, representation and contemplation, we came to identify reason as the law-giver within. Man, he wrote, was once "a creature of sense . .. an animal first devoid of reason .... [Then he became] an animal endowed with reason. What he is meant to be, however, is neither of these; he is meant to be a human being" (XXIV.8 my emphasis). We became human as a species because of complex aesthetic integration - and this integration is recapitulated in each individual and in each separate act of creative perception. First we are dominated by sense (which has its rudimentary reason); then by the slow process of aesthetic transformation we move from practicing virtues, comprehending truths, noticing a beautiful object and enjoying 
happy hours - toward morality, truth, beauty and happiness (XVI). It is through the aesthetic that we become truly reasonable, and it is "only through Beauty that man makes his way to Freedom" (II.5). For Schiller, then, we are human because of beauty - and our humanity is reinstantiated in each individual and in each encounter with the aesthetic.

\section{Archeology: The Labyrinth as the Structure of Play}

In the above, Schiller appears to be working from a model of human nature. He begins with our animal nature: first sense - and to it he adds rudimentary reason. This common reason (for self-preservation) is necessarily present in animals. In us, it develops to create the primitive aesthetic spaces of self-awareness, of empathy (the capacity to experience another's humanity and subsequently his individual understanding of himself) and of response to representation, our general capacity to create and appreciate signs, symbols and art. Human capacity for representation is most highly developed in the elaboration of two senses, the eye and the ear. Expression in sound (language and music) and sight (materials including the written word) of our mental contents is the hallmark of our humanity. The three human capacities - self, other and object representation [Schein] - reciprocally develop each other, by modification and transformation, in association with beauty toward the full expression of potential humanity. Beauty as an ideal has important attributes in comparison to other ideals: it is sufficiently pleasurable (connected to sense) without needing a concept, and it does not have implicit in it a physical or moral demand (we are not impelled by physical need to pursue it nor enjoined to it by duty).

Throughout the literature of the eighteenth century, the image and analogy of the labyrinth is used to describe aspects of the Enlightenment project - the collection and 
organization of human knowledge, the psyche itself and the situation of the human being in the natural and civilized world. ${ }^{17}$ It is the application of labyrinth as representation of the human mind that I hope will give an analogical boost, a graspable - at once artistic and didactic - appearance [Schein] to Schiller's theory of play and the conception of human nature described above. Imagine an excavation in progress of an ancient structure, a geometric form sunken in the landscape. As the dirt and fill of time are removed, debris carted away, some corridors can be traced. The walls of various weathered heights can be imagined to stand, but passages leading to lower levels remain covered, and the towers of course are down, their rubble obscuring the past. Schiller would reconstruct these towers. Were there ever domes or a roof? Was the whole always

17 "Let us . . . / Expatiate free o'er all this scene of Man; / A mighty maze! but not without a plan ...." (Pope, An Essay on Man, Epistle I: 4-6, 272). In their introduction, Wilkinson and Willoughby wrote that Schiller's aesthetic construction itself was a "labyrinth ... devised for leading [the reader] to the centre and out again, not only in the most convincing and persuasive way, but in a way that has been determined by the conclusions meanwhile reached by the author" (lvii). Schiller to Körner, 7.v.1785: "It is said of Newton, that the fall of an apple revealed to him the whole system of gravitation. Through how many thousand labyrinths must an ordinary mind have worked its way before it would have made the discovery which the daring genius of Newton attained by one mighty spring!" (24). La Mettrie: "Physicians have explored and thrown light on the labyrinth of man; they alone have revealed the springs hidden under the covering which keep so many marvels from our gaze. They alone, calmly contemplating our soul, have caught it a thousand times unawares, in its misery and its grandeur, without either despising it in one state or admiring it in the other" (La Mettrie Trans. Thomson 4). Reed found the "labyrinth image singularly apt to express [a] dutiful perspective [of "larger than human coherence, a divine plane for whose purposes our plans sometimes have to be thwarted']. It simultaneously connotes order and confusion - the order of an objective structure designed by divine Daedalus, and the confusion of man's subjective experience within it" ("Paths" 83). The labyrinth's dual aspects of order and incomprehensibility seem adequate to express the unknowns the psychologists of the late Enlightenment were facing. Like Schiller, they sought the theoretical "thread of truth" to work themselves out of the puzzle of human nature. While the labyrinth was a metaphor for them of the confusing order of nature (that seemed designed), it was also a fixture in the gardens of the eighteenth century $(92,93)$. 
open to the sky? The structure runs like a maze - and not on a single level: high and low gates, a second level, towers ....We would follow Schiller's red thread. ${ }^{18}$ The labyrinth is the self, known and unknown; the corridors are the drives of sense and reason, and the towers are each aspect of representation: self-awareness, empathy and art. These elevations, we know from our own experience, communicate with one another extensively to form a canopy of play, from which one can perceive and experience various aspects of the self, others (their labyrinths) and the world. And Reason? It is a hot-air balloon tethered by many cords, floating directly above. Some prospects will always be hidden - some turns in the maze always, even from each person's own heights, will remain unconsciously sensed but unknown.

\section{What Play Is and What Play Is Not}

Schiller's mapping of the labyrinth of human nature and his path of argument in the Aesthetic Letters provide a representation of play as an action of the embodied mind. Play stands as an archetypal intuition and a defining capacity of the species: it is a forcein-matter tending toward dynamic harmony and balance. It is also an example of organismic complexity according to the standards of eighteenth-century natural philosophy, a product of polar entities functioning reciprocally to create a third force and

\footnotetext{
18 "And if we succeed in solving this problem satisfactorily, we shall at the same time have found the thread which will guide us through the whole labyrinth of aesthetics." This problem for Schiller refers to the contradictory experiences and conceptualizations: "There must be a state midway between matter and form, passivity and activity, and that it is to this middle state that beauty transports us ... [on the other hand, it seemed that] Beauty links the two opposite conditions of feeling and thinking; yet between these two there is absolutely no middle term. The former truth we know from Experience; the latter is given to us directly by Reason" (XVIII.3).
} 
promoting other transformations such as self-awareness, empathy and appreciation of representation. And it is a trait demonstrating a developmental history.

Schiller also clarified, step-by-step, what human play is not. For him, although playing is a part of all nature, "even inanimate nature exhibits a . . luxuriance of forces, coupled with a laxity of determination which ... might be called play" (XXVII.3), this is not the play that he believed defined humanity. And though compelling, the "sheer plenitude of vitality," the "physical superabundance of living nature" is not Schiller's play either. The tree that "puts forth innumerable buds which perish without ever unfolding, and sends out far more roots, branches, and leaves in search of nourishment than are ever used for the sustaining of itself or its species" is not playing as Schiller defined it nor are the "insects swarm[ing] in the sunbeam" playing Schiller's archetypal play. ${ }^{19}$ Although birds and mammals are active under the stimulus of "sheer plenitude of vitality" rather than some lack, while these play, theirs is the play of a physical "compulsion of superfluity" and not the kind of play that is the focus of Schiller's attention in the Aesthetic Letters.

Human beings, particularly children, play as animals do. Again, humans play mentally under the compulsion of energy: even "imagination [which] has its free movement and its material play, an activity in which ... it simply delights in its own absolute and unfettered power," is at base physical and natural (XXVII.4). Though

\footnotetext{
19 "To know which is to nature's greatest credit - precise economy or superfluous profusion - it would be necessary to understand her designs .... We have, however, before our eyes many examples of the same profusion [i.e. the overabundance of spermatic animalcules in male seminal fluid] in the reproduction of trees and plants. How many millions of acorns fall from an oak to dry up or rot, as compared to the very small number that germinate and become trees!" (Maupertuis 16).
} 
Schiller sees that Nature makes the transition through this kind of physical play to aesthetic play, even imaginative play (a capacity confined to our species) is not the ground of humanity. Physical play is driven by life's craving for content or material, but is formatted by outside forces - by available resources, by time and energy, by the safety of the environment, by the social situation. Much play even in us is formatted externally.

We humans pour ourselves into projects, tasks, professions, interests, or games, contexts formed and limited by attention, reason and emotion. We seek through attention "a superfluity in material things, an aesthetic surplus, in order to satisfy the formal impulse too, and extend enjoyment beyond the satisfaction of every need" (XXVII.2). While form enters and attention is fixed, activity is driven. We are not living differently. While we might be tempted to call this paradigmatic human behavior, for Schiller it is not. Though we crave content and organize it, though the sense drive and the form drive are both active and in that sense are playing, we are not playing Schiller's play. We are rather the creatures of our creations or of someone else's: for, by "confining our activity to a particular sphere, we have given ourselves a master within, who not infrequently ends by suppressing the rest of our potentialities" (VI.6). By allowing the community to take our measure according to function, skill or office, we become isolates and are estranged from ourselves and each other. ${ }^{20}$ Even though the basic two drives are in play and interacting, the outcome is earnestness and limitation; men become martyrs to a capacity or a function. (Schiller's example is Kant.) Thus, Schiller warned that

\footnotetext{
${ }^{20}$ Society, according to Schiller, colludes with man by insisting on "special skills being developed with a degree of intensity which is only commensurate with its readiness to absolve the individual citizen from developing himself in extensity" (VI.8).
} 
particularly in his enlightened age, men live as fragments or reflections of culture. Some remain savages, men living within the necessity of nature, or evolve into barbarians, those who eschew nature and reside in artificial niches of culture. ${ }^{21}$ And these, though one would not realize it from their ubiquity in experience, are not playing archetypically.

The play of living nature and of animals, the play of children and primitives, and the play of savages or barbarians are but suggestions of Schiller's play. These types of play involve the original sense and form drives, but the drives not equally matched. Further the drives, when transmuted into the play-drive, are not modulated or collected by a sensate ideal. It is this collection and reciprocal modulation that allows for contemplation, free choice and free action. Schiller saw human nature as the archetypical provision of agency - free and autonomous thinking and doing - and he believed that it was secured through capacity to play in a way that involves an organic relationship with an ideal. According to Schiller, our human potential is potential: it is flexibility, but it is a dedicated flexibility. The play drive with its created aesthetic space is every individual's practical promise of possibility, but this potential broadens and deepens only if our drive's goal is an ideal that reciprocally motivates and energizes as it is dynamically conceived. And playing balances and harmonizes our humanity only if that drive functions as a means and an end. In order to make our development and our

${ }^{21}$ Again, while all specialized activity fulfills part of Schiller's definition of play, it could not lead to development of autonomous individuals: through it, "[c]ivilization, far from setting us free, in fact creates some new need with every new power it develops in us" (V.5). Schiller saw the behaviors around him lurching between savagery and barbarianism, "wavering between perversity and brutality, between unnaturalness and mere nature, between superstition and moral unbelief, ... only through an equilibrium of evils...still sometimes kept within bounds" (V.5). For him, this trend was part of what in modernity fragments individuals for the sake of the whole: through it, some are sacrificed for the material progress of the species (VI.11). 
freedom possible, its goal must be ideal beauty, a dynamic combination of feeling and reason, of perception and creation. It is extremely important to Schiller that, as ideal, beauty can never be attained. Never to be realized, it is accomplished in the process of approach: it is "the Direction [that] is at once the Destination, and the Way [that] is completed from the moment it is trodden" (IX.6). "With beauty man shall only play, and it is with beauty only that he shall play (XV. 8). Schiller's archetypal human play drive depends on our capacity to be in a relation with a sensate ideal, that is, in a continuous dynamic relation with beauty. Through this relation, man in time is "ennobled to the stature of man as Idea" (IV.3). ${ }^{22}$

${ }^{22}$ ["dass der Mensch in der Zeit zum Menschen in der Idee sich veredelt."] 56 


\section{CHAPTER III}

\section{THE STUDY OF LIFE IN THE EIGHTEENTH CENTURY}

Scientific progress often consists not so much in a progress within science as it does in taking something that formerly was not science and making it part of science itself (Bondi qtd. in Rossi xiv).

Schiller's theory of play, a species-specific theory of drives, is embedded in his Aesthetic Letters like a vine in a tree trunk. Both the theory and its carrying document are grounded in a vitalistic approach to nature, a tradition which gained its maturity in Germany at the end of the eighteenth century. Schiller was quite familiar with the natural history, natural philosophy, and medicine of the period, and he used life-science - its basic tenets, historical examples, epistemological values, language and metaphor - to recruit both feeling and reason to his argument for the development of autonomous human functioning through play. He called up data from its particular knowledge about nature, concepts from its speculative theories, perspectives from its epistemology, events from its history, energy from its controversies and even organizational templates from its literature.

What was this rich tradition? Schiller lived at the confluence of three great streams of knowledge about nature, at a cultural delta: these wetlands teemed with facts and theories. His inheritance included the data and collections of natural history, the 
experience and considerations of two medical traditions, and the theories and systems of natural philosophy. ${ }^{1}$

\section{Natural Philosophy and Natural History in the Eighteenth Century}

The character of the age must therefore ... on the one hand, emancipate itself from the blind forces of Nature; on the other, return to her simplicity, truth, and fullness - a task for more than one century (VII.3).

Who collected and catalogued Nature's fullness and described her simplicity, discovered her blind forces, understood her truth? And how did Schiller synthesize these contributions in order to make his case for man's playful nature? From natural history, the eighteenth-century scholars of life gained facts, data collected both from a vastly

${ }^{1}$ The contents of these categories, natural philosophy and natural history, are not necessarily self-evident, as the division of knowledge in the century was different than it is today. As d'Alembert wrote in the Discours préliminaire (Preliminary Discourse to the Encyclopedia of Diderot, reflecting on the abundance of information and the difficulties of organizing it, "[ $[$ ] he general system of the sciences and arts is a sort of labyrinth, a tortuous road which intellect enters without quite knowing what direction to take" (46). The Encyclopédie (which Richard Schwab described as envisioned "to contain nothing less than the basic facts and basic principles of all knowledge" and "a sort of war machine of the thought and opinion of the Enlightenment" (d'Alembert xxv)) ascribed natural history to the mental faculty of memory, and natural philosophy to the mental faculty of reason. "Natural philosophy was still part of philosophy ["classical and humanistic traditions had placed natural philosophy in the category of letters, or literature"] and still struggled with philosophical questions such as those concerning the existence of the soul, the activity and passivity of matter, the freedom of the will, and the existence of God" (Hankins 8, 11). Thomas Hankins defined the categories of science further: "'physics,' at the beginning of the Enlightenment, was 'the science that teaches us the reasons and causes of all the effects that Nature produces,' and this included both living and non-living phenomena. Medicine and physiology, as well as the study of heat and magnetism, were part of physics ... [and] much of what we would now call physics was called 'mixed mathematics' in the eighteenth century. Mixed mathematics included astronomy, optics, statics, hydraulics, gnomonics (concerned with sundials), geography, horology (concerned with clocks), navigation, surveying, and fortification." Concerning the study of life, chemistry was the province of physicians (iatrochemistry): chemistry elided with the study of minerals, and therefore natural history, "the science that described and classified all forms of nature .... .Our modern sciences of zoology, botany, geology and meteorology were all subsumed (at least in part) under natural history" (11). 
enlarged known world and from a lengthened perception of time. From the divided medical traditions, came the iatromechanical art of comparative anatomy (with the accompanying philosophy of physiology replete with mechanical metaphors). From the iatrochemical tradition came a rapidly advancing and expanding interest in all of botany, rather than medicinal herbs alone. Natural philosophy supplied a dualist mechanistic philosophy which was further developed by Newton's and Leibniz' theories of force. ${ }^{2}$

${ }^{2}$ Why are the terms "study of life," "natural history" and "natural philosophy" used in this text instead of the word "biology"? Foucault's caveat is widely known, that there was no biology before 1750: his comment reflects the absence of a discipline, not necessarily the absence of a distinction between living and dead nature, active and passive matter, matter and organized matter and the great interest in the latter members of each pair. The science of biology and "biology" as a word are mainly nineteenth century productions. Hankins wrote: "The creation of biology as a separate discipline came only after a strong reaction against the mechanical philosophy had separated the study of living things from inanimate nature and had explained 'life' by principles that did not apply to the inanimate world" (117). According to Joseph Caron (who provided a historiography of biology by examining the histories of biology where attempts were made to identify the discipline's beginnings), the word first occurred in the literature in 1802(Treviranus and Lamarck), but the content of biological science and its institutionalization took the rest of the century. During that time, general physiology, cell theory and embryology predominated, Comte posited a trinity of physiology, anatomy and ecology (interactions between the organism and the environment) as its content, and morphology diminished (234). Evolution was not specifically mentioned in texts about biology until the mid-1870's and not in elementary texts until the 1890's (250). Two trends insured the discipline's survival: biology emerged as a "publicist science" in Victorian England, a powerful organizer of institutional possibilities. Even without specific specific disciplinary content, it functioned in an introductory capacity for all the life sciences. "Biology" thereby became a generic term for the life sciences, and with that successful designation, continued into the twentieth century (254-55). According to Richards, Linnaeus (1736) used the term "biology" in Latin form to refer to botanists who researched the life cycle of plants - and it was carried forward in German botanical literature as a designator of the work of all such botanists. In 1797 a usage broadened its meaning to include the study of life force, and right at the turn of the century the meaning broadened yet again (by Karl Friedrich Burdach) to include "the study of human beings from a morphological, physiological and psychological perspective." In Biologie, oder Philosophie der lebenden Natur (1802-22), Treviranus wrote "the objects of our research will be the different forms and manifestations of life, the conditions and laws under which these phenomena occur, and the causes through which they have been effected. 
Schiller's management of the individual in all his particularity and of human nature in its unity had its foundation in the content and controversies of natural history; his use of force in the play drive theory grew out of the mechanical philosophy and its elaborations by Newton and Leibniz.

\section{Fullness and Simplicity, Multiplicity and Unity: Data and Its Classification}

Several factors during the early eighteenth century opened the study of living nature, then based in the mechanical philosophy, to new theoretical perspectives. ${ }^{3}$ From the seventeenth century, "a flood of new information swept over the life sciences. Overseas exploration brought knowledge of a host of new plants and animals; the microscope revealed new realms of life [including old life - the identification of fossils, 'marinemountainous objects' as petrified life forms or their casts - and] intensified anatomical research uncovered new information about what had been considered well-known" (Westfall 82). ${ }^{4}$ A growing recognition of a class of facts about things - the historical or

The science that concerns itself with these objects we will indicate by the name biology [Biologie] or the doctrine of life [Lebenslehre]" (Richards, Romantic $4 \mathrm{fn} 8$ ).

3 "The mechanical philosophy required that the changes observed in the natural world be explained only in terms of motion and rearrangements of the parts of matter. But beyond these basic assumptions, the mechanical philosophers were divided. Was matter moved by external powers, an internal power, or by no power at all?" Westfall identified Descartes with the last position, Newton (with caveats) and Malebranche with the first and Leibniz with the middle description. Leibniz' position, that "force was internal to matter" and his influence in Germany and France was the vitalizing impetus of late Enlightenment life studies (13-14). In this dualistic philosophy, even with Leibniz, a force outside nature was the source of motion or the origination of motion, of complex creation even if, finally, forces became internal to matter: they originated with God.

${ }^{4}$ Briefly, fossil finds (fascinating for centuries) were often referred to as "sports of nature," jests made to show the limits of human reason or the creative power of God in Nature. For painter Agostino Scilla (1629-1700) however, they were "marinemountainous objects" and he countered the natural-theological speculation about them 
genetic account of the manner in which present nature came to be in time -was

augmented by extensive geological studies and by the intensive re-examination of the old inhabitants of curiosity cabinets, the fossils. Nature was rediscovered as spatially vast and it had a complex history as well. This explosion of knowledge about nature instantaneously moved from raw data to a deeply stirring, "startling influx of new ideas" (Hazard 9), to accounts too numerous to read: that is, it became the "early modern information overload" (Rosenberg). While this superabundance delighted some, who could never exhaust their own interest, investigations and accumulations, it also fueled a crisis of form; the eighteenth century was continuously involved in controversies of classification, the difficulties of definition, ordering and valuation. ${ }^{5}$ How were accounts

with a hypothesis wielded like Occam's razor: he sought the simplest, empirical explanation - that such objects were organic remnants or impressions of the forms of real animals deposited under layers of sediment in ancient bodies of water. In La vana speculazione disingannata dal senso (1670) (Vain Speculation Undeceived by Sense), he wrote: "What I do know is that the corals, the shells, the sharks' teeth, the dogfish teeth, the echinoids, etc., are real corals, real shells, real teeth; shells and bones that have indeed been petrified" (in Rossi 22). Prior to the work of Fabio Colonna (circa 1616), Scilla and his contemporaries (John Ray, Robert Hooke and Nicolas Steno), there was no consensus that those artifacts we call fossils were the remains of organic life. In fact, Glossopetrae (tongue-stones) were common in Malta and throughout Europe and were believed to have sympathetic properties, symbolic value or miraculous capacity: Steno (an anatomist who had dissected a shark's head) and Scilla each identified glossopetrae as petrified sharks' teeth; their work and near simultaneous but independent conclusions would over time undermine earlier explanations and attributions, both secular and religious. Others had thought them natural growths from rocks analogous to crystal formation or through some "plastick virtue [Kircher's spiritus plasticus] inherent in the earth" (Hooke). The above naturalists claimed an identity: glossopetrae do not just look like sharks' teeth, they are sharks' teeth (Summary from Rudwick 49-60 and Rossi 3-24).

${ }^{5}$ Buffon complained that this perseveration led to "immense volumes on natural history . .. which could be reduced to one tenth their present size if all those things which are useless or foreign to the subject were removed. This prolixity (which, I confess, is overwhelming), [accounts for a man who] sits in his library and reads one after the other the Ancients, the Moderns, the philosophers, the theologians, the jurists, the historians, the explorers and the poets ... copies down all the remarks, arranges them alphabetically, 
to be verified? What was to be considered a fact? There were wonders and monsters; there were breathless travel narratives and painstaking descriptions with measurements and drawings, and there were experiments and flights of imagination. But there were too few anomalies, because an anomaly is an unusual occurrence that does not fit into an accepted structure of knowledge, into a recognized pattern of nature, and even the systems were in flux.

There was so much spectacle in early eighteenth-century nature that doubt and method were the only ways of taming the material and developing a truly natural system for understanding nature. What is the relation of one fact with another? How is all this information to be arranged? How should this knowledge be structured? By mid-century Linnaeus' method was established internationally (and not without continuing opposition), but by then more than two dozen other taxonomies had already been proposed. ${ }^{6}$ The attention to detail and the effort to make some sense of the incredible

and, after having filled several portfolios ... he begins to work on a particular subject, wishing to let nothing that he has gathered go unused. Thus when writing a natural history of cocks or oxen, he tells you everything that has ever been said about cocks or oxen, everything the Ancients have thought about them, everything that has been imagined about their qualities, their character, their courage; all the things they have been used for; all the old wife's tales about them; all the miracles attributed to them in various religions; all the superstitious stories they have occasioned; all the comparisons poets have drawn from them; all the attributes which certain people have ascribed to them; all the representations of them found in hieroglyphics or on coats-of arms - in a word, all the stories and all the fables which have ever been noticed about cocks or oxen" (!Lyon 1589).

${ }^{6}$ Botany was a huge enterprise, a new science taken beyond the iatrochemical specialty of medicinal remedies made from herbs: by the end of the seventeenth century, John Ray included 18,000 species of plants in his General History of Plants (Westfall 83). For reference: today, there are approximately 100,000 known tree species, and that number is $25 \%$ of the total number of plant species. For the early eighteenth-century natural historian, the study of plants provided a fresh field; zoology, according to Westfall, had already been worked by Aristotle. According to Mayr, in the 1750's, Linnaeus knew 
number of observations, methods of discovery and description, and the explanations spinning from them, encouraged the development of a more inclusive perspective.

Attention turned from the multiplicity of life forms to the phenomena that characterized life. What is life?

The academic medical professionals continued dissecting and experimenting, but with the changed focus of distinguishing living tissue. The coupling of close anatomical dissection with explanation grounded in the iatromechanical philosophy of physiology connected the largesse of observation with great gains in description through repeated demonstrations and experiments. This philosophy proliferated mechanical metaphors and elaborate analogies: for example, in these theories the heart was described as a pump, "a

about 6,000 species of plants, 4,000 species of animals; he estimated that about 10,000 species in each group would be identified. In 1778 Zimmerman made more realistic estimates of 150,000 plant species and 7 million animal species: for reference, Linnaeus knew of 236 species of Swedish algae, lichens, and fungi; 13,000 are known today (Growth 172). To draw attention to the profusion of organic nature, Buffon did a number of calculations meant to amaze, and one of his hypotheticals related to chickens: "if we were to hatch every egg produced by hens for the space of 30 years there would be a sufficient number of fowls to cover the whole surface of the earth (Lyon 179).

${ }^{7}$ There was a great hope that the microscope would bring about a qualitative change in the understanding of nature. Its use created and multiplied the knowledge of small organisms in the late seventeenth century: what it did for the small, it also did for fossils, allowing very close examination of ambiguous objects for the purposes of discrimination or entertainment. In many ways, however, the microscope simply confirmed the impenetrability of function: what was observed by natural historians was more of the "outsides" of beings, unimaginably small complex things rather than their workings. So, with this new technology came great disappointment. Unlike the telescope which, directly responsible at the hands of Galileo for discoveries of orbits of moons that should not have existed and the very real pocks on our perfect moon, effectively challenged the Ptolemaic universe and supported Copernican theory, discoveries by microscope generated more information and imaginative reporting but no refutation: in spite of all the detail and the delighted amazement at the complexity (not chaos) revealed at a whole new level of seeing, microscopy provided mainly a cascade of phenomena to be organized but no way into history and no empirically-based explanations of function. 
system reminiscent of the waterworks which ran the elaborate fountains admired by seventeenth-century monarchs" (Harvey), a bellows and a tea kettle, and the body, a clock with "counterweights and wheels" (Descartes), a "hydraulic machine contrived with the most exquisite art in which there are numberless tubes" (Dr. Richard Mead), and a mechanism filled with microscopic pipes and channels. In his survey of eighteenthcentury science, Richard Westfall reviewed this analogical simplification and found it symptomatic of a deficiency in the understanding of matter itself: "Beside the subtlety of biological processes, the ... mechanical philosophy [in its "urge to prune all that smacked of the occult from the body of natural philosophy" (120)] was crudity itself. Above all, it lacked a sophisticated chemistry which has turned out to be a prerequisite for the rapprochement [between] the physical and biological sciences" (examples 82-104, quote 104). Roger wrote in his contribution to The Ferment of Knowledge, "The great weakness of the mechanical model though was that, in fact, it was almost entirely imaginary" (Rousseau 271). The mechanical analogies, inadequate and unsatisfying, were coupled with explanations in the service of existing beliefs so tortuous that they became the templates for the period's satire. ${ }^{8}$ Fontanelle's challenge serves as an example: "Do you say that beasts are machines just as watches are? Put a male dogmachine and a female dog-machine side by side, and eventually a third little machine will be the result, whereas two watches will lie side by side all their lives without ever producing a third watch" (qtd. in Roe, Matter 1). Taken too far the explanation of living

\footnotetext{
${ }^{8}$ Regarding earlier satirical use of the mechanical philosophy, see Voltaire, $\underline{\text { Candide, }}$, (Leibniz' harmonious balance), Swift, Gulliver's Travels (the value of microscopy) and Sterne, Tristram Shandy (preformationism, studies of generation). The religious tradition satirized is the physico-theological one.
} 
things by mechanism (i.e. mechanism's own early simplicity and popularity) proved selfdefeating but, as the concept of matter became fuller and more nuanced by the end of the eighteenth century, materialists adopted the internal logic of that philosophy: all explanations must be from nature and all life functions based on physicochemical reactions. The vitalists accepted mechanism as ground, and as a group, they held that a broader set of "unknowns" - whether yet-to-be discovered physico-chemical forces or never-to be known entities - was possible.

\section{Matter and Forces: Mechanical Philosophy, Newton and Leibniz}

Natural philosophy itself was augmented - many felt completed - by Newton's late seventeenth and early eighteenth-century contributions. According to the judgment of the eighteenth century, "what Galileo had called for became reality in Newton": in his laws "the victory of human knowledge [had been] decided and an elemental power of knowledge had been discovered which seemed equal to the elemental power of nature. In this sense the whole eighteenth century understood and esteemed Newton's achievement" (Cassirer 43-44). In crafting Newton's eulogy, Pope wrote for the age:

Nature and Nature's laws lay hid in night, God said: 'Let Newton be,' and all was light (272).

Newton's postulate, that forces act between particles and that forces act at a distance, coupled with his mathematical expression of it, "constituted a major break with the prevailing mechanical philosophy of nature." With his second law of motion, he added an ontological category to the mechanical universe: "Newton ... considered forces between particles, not as a denial of the mechanical philosophy, but as the conception needed to perfect it. By adding a third category, force, to matter and motion, he sought to reconcile mathematical mechanics to the mechanical philosophy" (Westfall 142-3). 
The idea of force, for Newton, was an abstract construct of relationship measurable in mathematical terms, but as an idea it was so powerful and so native to our conception of things that it - like an anointed offspring - developed an unimagined life of its own. In 1686, in an objection to Descartes which "fluttered the philosophic dovecots," Leibniz made a distinction between living and dead force. And in an effort to argue for conservation of living force [vis viva], "he ... coined the word 'dynamics' to describe a mechanics built on his concept of force." According to Phillip Sloan, the Leibnizian conception of matter, based on a centre of force rather than on material extension or mass, gave reality a dynamic character which was applied to nature as a whole. It also restored the Aristotelian concept of an immanent teleological agency in nature itself. Leibnizian nature was not an inert system acting by contact action. Instead it followed out an internal, telos-laden career, governed by in-dwelling law, directed to rational ends. God's intervention was unnecessary in this system precisely because it carried out by its own power its divine mandate. In this respect, Leibnizian nature was at least practically autonomous, and able to fulfil and even create by its own internal dynamism without divine intervention. For eighteenth-century thinkers able to draw upon these developments, the ideal of a science of Nature distinct from rational mechanics or experimental physics, presented new possibilities ("Natural" 302-303). ${ }^{10}$

\footnotetext{
${ }^{9}$ In the full quote, Westfall was ambiguous in his attribution of "dynamic" but multiple sources credit Leibniz with the term. "Leibniz's concept of force, however, was a different concept from the one that modern physics, following Newton, employs. 'Force' as Leibniz used it can be most readily translated into our term, 'kinetic energy."" (137). In another context Westfall queried: "What is force? In the context of the prevailing mechanical philosophy, it could mean only one thing: 'Force is the pressure or crowding of one body upon another.' Descartes, who tended to think of the moving particle as a causal agent, had spoken of the 'force of a body's motion.' On the other hand, Newton was thinking in terms of an abstract quantity which could measure the change in the motion of a moving body. Impact was the sole origin of force which he was then prepared to admit, so that 'force' as he used it did not differ ontologically from Descartes' 'force of a moving body' .... There can be no serious doubt that Newton considered the forces between particles as ontological realities, and not just appearances. In so far as he was prepared to discuss their cause at all, he referred them directly to the agency of God" (145).

${ }^{10}$ The concept of Bildung as physiological development as well as cultural development is reflected in Leibniz' system of monadology: "The monads are the subjects from which
} 
Implicit in Leibniz' stance is the immanence of time and space. For him, they are phenomenal and did not exist absolutely, but were realized through things: "time does not exist apart from objects, but is grounded in their successional existence ... [and] space exists only in the relationship of bodies, and not as a container in which they are located" (ibid). ${ }^{11}$ Leibniz' dynamic organic philosophy with its distinction of living force became an underground current for change: it emerged in mid-century through Maupertuis and Buffon in France and naturally in German aesthetics. It had an enormous impact on the study of life in the late eighteenth century.

The buoys of sea-change bounced and hurled then with the turn of the century. Not only was there change in the concept of matter by the addition of force but there was also a movement from multiplicity to unity, from the collection of particular living things and the data about them to the understanding of the concept of life. From Paul Hazard's perspective, the progressive focusing of interest toward establishing the object itself - not

all events originate, and the principle of their activity, of their progressive development, is not the mechanical connection of causes and effects, but a teleological relationship. Every monad is a true entelechy; each strives to develop and improve its being, to rise from one stage of its development to another which is more complete ... the dynamic processes ... go on within substantial entities, within teleological forces" (Cassirer 83).

${ }^{11}$ Schiller used Leibniz's dynamics: “And so we would ... have the condition of all contingent being or becoming, that is to say, Time. 'Time is the condition of all becoming' is an identical proposition, for it does nothing but assert that 'succession is the condition of things succeeding one upon another"' (XI.4). Again, in another context, be began, "Since everything that exists in time exists as a succession ..." (XII.3), but there he sought a middle ground between Newtonian absolutes and Leibnizian phenomenology in this way: "Before we determine a point in space, space does not exist for us; but without absolute space we should never be able to determine a point at all. It is the same with time. Before we become aware of the moment, time does not exist for us; but without infinite time we should never have any awareness of the moment. We do then, admittedly, only reach the whole through the part, the limitless only through limitation; but it is no less true that we only reach the part through the whole, and limitation only through the limitless" (XIX.5). 
man, not all natural entities, but the phenomenon of life, and the development of curiosity particular to that phenomenon, promoted yet another change. Intense curiosity coupled with changing methods and technology led to the understanding that life differed from other matter, but how it differed, was the subject of hypotheses throughout the century. The empirical, experimental and inductive base of these operations underscored that such efforts (however amateur some participants might be) were scientific, in that those endeavors benefitted from accumulated information and effort. ${ }^{12}$

As a consequence of the new general focus on describing living matter as a class, exchange of information increased among disparate groups - amateurs and professionals, academics and clinicians, artists and philosophers. They grappled with a common problem, the definition of life, and their mutual interest functioned as a meta-category, an area of inclusion. Anatomists, physiologists and clinicians steeped in iatromechanism, the descriptive natural historians (the botanists, the entomologists, the microscopists, the travelers) and philosophers (natural and general) had a place of meeting in their common interest in life - and in the explosion of information about it in the popular and scientific press. The whole community incorporated scientific information and the theories that organized it.

Two trends helped restructure the cultural space and prepare for what many believe were paradigm-changing mid-century developments. Nature, studied as a mirror of divine attributes, became an interest in its own right. With this change of emphasis, the

${ }^{12}$ This distinction between science and arts, developed out of the querelle at the beginning of the eighteenth century. Roger: "If the historian, then, feels uneasy with the definitions of science offered by the scientist and the philosopher, what definition will he furnish himself? The simplest and broadest possible one is: every activity that aims at knowledge of nature" (Life xxi). 
huge investment of time and energy in writing and reading natural theology diminished. With the focus on nature then, man, once apart, became more and more a part of nature itself. As a consequence of these changes, man's capacity for knowledge about nature, once perceived as complete (Descartes), was reexamined. The limits of man's own capacity to know (Locke) and the contours of that capacity came into question (from d'Alembert to Kant). Newton himself evinced an experimental and empirical modesty: in the Opticks (1704) he wrote, "[T]he functioning animal may manifest phenomena for which the physiologist could currently find no explanation in physical terms. In this situation one is better advised to exercise 'Newtonian' restraint by observing, collecting, and cataloging the phenomena than to formulate 'Cartesian' hypotheses" (Brown 189).

Newton's 'restraint' was just one of his epistemological contributions to the science of the eighteenth century and the emerging study of living nature. He constituted the scientific method as we know it today, using analysis - a method of resolving mathematical problems by reducing then to equations - as part of a procedure that included both analysis and synthesis. He started with the complex phenomena of observation, analyzed them into simple components by experiment and then recombined the experimental results by synthesis into an explanatory theory.

Throughout the seventeenth century, analysis and synthesis were regarded as two separate methods: analysis, or 'resolution,' was a method of discovery, whereas synthesis, or 'composition,' was a method of proof. With Newton, however, they became one method and were applied not merely to the course of thought but also to the actual doing of experiments. Analysis, for Newton, consisted in 'making experiments and observations and in drawing general Conclusions from them by Induction.' Analysis and synthesis meant the resolution and composition of nature to understand how it operated (Hankins 20-1). ${ }^{13}$

${ }^{13}$ Working with his ambivalence about epistemological necessities and constraints, Schiller used the metaphors of both chemical analysis and anatomical dissection with 
On what grounds does the general follow from the particular? Starting with the particular, the individual fact, as the known quantity, and then moving from simple observation and experiment - that is, going beyond Baconian induction - by analogy and comparison to a general concept or theory was an epistemological leap ... and it was Willem Jakob 'sGravesande (1688-1742) who marked out the trajectory. According to him, the axiom of the uniformity of nature, by dint of which the epistemological weight of empirical observations becomes cumulative, is not a "strictly logical, but a pragmatic axiom; its validity does not lie in the necessity of thought, but in that of action. For all action, all practical relationships with things, would be impossible, if we could not assume that the lessons of former experience will be valid in the future." Therefore, scientific prediction is "a valid and indispensable conclusion by analogy .... whose denial would imply the negation of all man's empirical existence and all his social life" (Cassirer 61). ${ }^{14}$ As Haller wrote, considering the experiments he had performed

reference to analysis (See Chapter V). Lavoisier, for example, used this method to "resolve the atmosphere into its constituents and then bring them back together again to create an 'air' indistinguishable from atmospheric air" (ibid.). Schiller (who may have thought of Lavoisier due to his execution in 1794 just prior to his writing the Aesthetic Letters) used the separated ideas of analysis and synthesis to show why Beauty as both an aspect of things and a psychological application of human nature to objects, was not easy to apprehend. Speaking of two opposing groups of aestheticians, he wrote: "The first are afraid that by a too rigorous dissection [Zergliederung, analysis] they will rob beauty of some measure of her freedom; the latter are afraid that by too audacious a synthesis they will destroy the precision of their concept." Schiller seeks the "freedom that is not just lawlessness but rather harmony of laws, not arbitrariness but supreme inner necessity" that is, the transformational process of dynamic interaction between these two. (XVIII.4). In the Aesthetic Letters he offered proof by deduction and analysis but he wanted his synthesis lived out through Bildung, a personal progressive experiment with Beauty.

${ }^{14}$ Schiller's posit, "Not because we think, will, or feel, do we exist; and not because we exist, do we think, will, or feel. We are because we are; we feel, think and will, because outside of ourselves something other than ourselves exists too" (XI.3), referenced by 
sufficient to support a specific opinion: "nature is too constant, and I have seen her act too often to be deceived on this point" (697). In this new epistemology, the accumulation of experience develops to a point where probability approaches a certainty. According to Buffon,

Physical truths ... are in no way arbitrary, and in no way depend on us. Instead of being founded on suppositions which we have made, they depend only on facts. A sequence of similar facts or, if you prefer, a frequent repetition and an uninterrupted succession of the same occurrences constitute the essence of this sort of truth. What is called physical truth is thus only a probability, but a probability so great that it is equivalent to a certitude (Lyon 174).

In summary, physics separated first from the humanities, becoming a new paradigm and the subsequent normal science tradition, mechanism. It was fulfilled in Newtonian laws and experimental philosophy. All of nature seemed its preserve: all matter was passive, uniform and characterized by extension, fully described by known physicochemical laws, and it made up the world of our sensations. A force above or outside nature put all things in motion. This view, however, did not always fit - and could not be made to fit - the behavior exhibited by life forms. The disparity was twofold: the science's own valorization of empirical basis of fact, that "[a]11 knowledge required empirical grounding, [that the] only argument worthy of the name was argument from fact" (Roger Life 150), was a lesson learned from the successful study of nature. Reasons therefore were more and more sought within the boundaries of nature itself. By definition, no argument from fact could prove the existence of a force outside nature; none could justify an explanation of motion as an action on matter by something other

some as derivative of Fichte, as a grounding in plain empirical existence, has a nice Dutch common sense about it. 
than matter. More, due to the abundance of discovery and the efforts to develop a vantage point, anomalies began to accumulate around the phenomenon of life, specifically when life was considered within the joint axes of space and time. Those qualities of life - like the establishment of complex structure and apparent goal-directed change in the individual over time - seemed beyond the explanatory capacity of mechanical science.

The failure of the mechanical paradigm to account for life-in-time was part of that process that led to the reframing of problems. How is a particular characteristic function to be explained? Reproduction? Development? Activity? Much was retained to help in the work: the facts and their value, the value of the empirical method - these were lessons learned from the study of nature. The mechanical model remained as well to explain known functions, to be applied more often to the parts rather than the whole of organisms. Also, the view of nature's dynamic constancy that allowed for generalization and theory-building was carried forward; it would become the current that ran through to the modern evolutionary synthesis. D'Alembert (1751) described the change through a discussion of new method:

All the properties we observe in these bodies have relationships among themselves that are more or less accessible to us. The knowledge or the discovery of these relationships is almost always the only object we are permitted to attain, and consequently the only one we ought to propose for ourselves. Thus it is not at all by vague and arbitrary hypotheses that we can hope to know nature; it is by thoughtful study of phenomena, by comparisons we make among them, by the art of reducing, as much as that may be possible, a large number of phenomena to a single one that can be regarded as their principle. Indeed, the more one reduces the number of principles of a science, the more one gives them scope, and since the object of a science is necessarily fixed, the principles applied to that object will be so much the more fertile as they are fewer in number. This reduction which, moreover, makes them easier to understand, constitutes 
the true "systemic spirit." One must be very careful not to mistake this for the "spirit of system," with which it does not always agree (22-23).

A natural, intense interest in life, a biophilia that seems basic to human orientation in the world, built through the century; men who would be systematizers found themselves focused on the individual in all its multiplicity - and then they generalized from individuals' complexity. ${ }^{15}$ Upon consideration, it is probably not possible to be intuitively satisfied with the description of living things as machines or automatons. Indeed, as Robert Young wrote, "the concept of matter bequeathed . . by the seventeenth century [was] simply too impoverished - too stripped of the qualities of lived experience - for it to be credible that that matter can produce life and mind" (708). The dualism of mechanistic philosophy put agency outside of matter and removed the questions of origin from science; it cast unfathomable beginnings outside of history and set man safely apart. However satisfying and useful this solution proved to be in rationalizing conventional religious beliefs, it was no match for man's intuitive interest in life. Life's complexity, each organism's seeming goal-direction and agency, and the ease with which human understanding was refracted in nature's mirror drove the study of life. Dualism proved no match the human intuition of kinship with all life forms. It proved no match for our driving curiosity, nor did it stand up against Schiller's subjective sense of wholeness, the

${ }^{15}$ Re: biophilia. Schiller wrote in "Über naive und sentimentalische Dichtung" (1795-6) ("On Naïve and Sentimental Poetry"): "There are moments in our lives when we dedicate a kind of love and tender respect to nature in plants, minerals, animals, and landscapes, as well as to human nature in children ... not because it gratifies our senses, nor yet because it satisfies our understanding or taste . . rather simply because it is nature . . . Every person of a finer cast who is not totally lacking in feeling experiences this when he wanders in the open air, when he stays in the country, or lingers before the monuments of ancient times; in short, whenever he is surprised in the midst of artificial circumstances and situations by the sight of simple nature. It is this interest, not infrequently elevated to a need. ... (Nisbet German 180). 
connectedness of the self, both feelings and thought - and how such harmony could be furthered and ensured.

\section{Mid-century Ferment: Complex Relations with Haller, Maupertuis, Buffon, and Trembley}

The first truth which issues from this serious examination of nature is a truth which perhaps humbles man. This truth is that he ought to classify himself with the animals, to whom he bears resemblance by everything he has that is material (Buffon in Lyon 150). ${ }^{16}$

For the Enlightenment philosophers themselves, mid-century was the watershed.

According to d'Alembert (1759),

If one examines carefully the mid-point of the century in which we live, the events which excite us or at any rate occupy our minds, our customs, our achievements and even our diversions, it is difficult not to see that in some respects a very remarkable change in our ideas is taking place, a change whose rapidity seems to promise an even greater transformation to come .... Natural science from day to day accumulates new riches. . . . The true system of the world has been recognized, developed, and perfected ... . natural philosophy has been revolutionized; and nearly all other fields of knowledge have assumed new forms .... Nevertheless the discovery and application of a new method of philosophizing, the kind of enthusiasm which accompanies discoveries, a certain exaltation of ideas which the spectacle of the universe produces in us; all these causes have brought about a lively fermentation of minds. Spreading throughout nature in all directions, this fermentation has swept with a sort of violence everything before it which stood in its way, like a river which has burst its dams (Cassirer 3-4, 46-7).

Then, the skeptical critique of Hume, Buffon, de Maupertuis, and the French

Encyclopédistes, coupled with a great many paradigm-disrupting intellectual discoveries, created a fluid intellectual environment where life became the focus - life and its unique properties. Publications of research and theory, based on empirical study particularly,

${ }^{16}$ This idea is not new (Aristotle). Linnaeus too agreed; however, in at least one edition, he put man in the order Anthropomorpha along with, as Buffon reported, "the ape, the sloths, and scaly lizards. One must indeed have a mania for classification in order to put together beings as different as man and the sloths, or the ape and scaly lizards" (Lyon 165). 
presented facts that could not, even ingeniously, be fitted into the settled way of experiencing the world. The discoveries and theories associated with these publications worked their way into culture. They stimulated natural history and natural philosophy to more observation, experiment and hypothesis - and they also stimulated philosophy, theology and the arts to reaction and incorporation. ${ }^{17}$

For the development of the vitalistic life science tradition of the eighteenth century as well - of the vitalism in all its variety - "the turning point was obviously the middle of the century" when, according to Jacques Roger, the approaches of Maupertuis and Buffon and the experimental research of Haller and Trembley "raised ... difficulties," provoking open and lively controversy about the general nature of life and the capacity of the human mind to discover satisfactory answers (in Rousseau 274). The degree to which educated persons were caught up imaginatively and intellectually in these efforts can be traced in language as Trembley's polyps, Maupertuis' seductive discourse about active particles, Buffon's panoramic natural history, his ideas of reproduction and diachronic species, and Haller's discovered properties, irritability and sensibility, diffused through the

${ }^{17} \mathrm{Re}$ : the long century formulation. "The whole concept of a basic continuity stretching from the end of the seventeenth century to the end of the eighteenth has been called into doubt. Reinhart Koselleck. . . argue[d] that a major shift in interests and thought - an Erfahrungswandel [experiential-shift] - took place around the middle of the eighteenth century" (Reill "Science 432-3). Neubauer's insight into the three different phases of scientific theory formation has application here: mid-century was a perfect storm, a period during which such phases of scientific dissemination were intensely compacted. "[F]irst of all, the formulation of a theory on the basis of a technological apparatus, existing theories, empirical data, and a verbal, mathematical, and /or pictorial 'vocabulary of representation'; secondly, the conceptualization and rhetorical structuring of the material to maximize its persuasive power with respect to the specialized disciplinary community by foregrounding the observational and experimental dimensions and the 'reliability' of the results; and lastly, a reformulation of this highly specialized discourse in terms of concepts and ideas understandable to a broader lay public" (744). 
atmosphere of the Enlightenment community. Their theoretical stances were also avidly taken up as positions of argument in art, philosophy, history, politics and theology by, for example, Rousseau, Herder, Kant, Goethe and of course Schiller. ${ }^{18}$ These events, whether discoveries, theories or their publication, were seminal for the new vitalism of the late eighteenth-century Enlightenment. For Schiller, these mid-century developments were part of his medical and cultural education. His early responses to them were character-building and character-revealing - and his later use of them in writing, art. For example, Haller's work on the human nervous system, on irritability and sensibility, was referenced in Schiller's first dissertation (Dewhurst and Reeves), and the man himself made an appearance in the Philosophische Briefe (Aesthetical 390). Schiller used the theories of iatromechanical medicine and metaphors of the mechanical philosophy as signifiers of character in Die Räuber (The Robbers) and as indicators of basic function or diminution from organic function in the Aesthetic Letters. ${ }^{19}$ In the latter, Schiller used

${ }^{18}$ There is a great deal of scholarship establishing the natural historical and philosophical connections and contributions of Rousseau, Herder, Kant and Goethe; many scholars in particular have traced the importance of Maupertuis and Buffon (who themselves were friends in the 1740's) to Kant and Goethe. Both of these last were conduits of natural history and philosophy to Schiller. With regard to Kant, John Zammito established the importance of Maupertuis to Kant and to the exposition of epigenesis in the Critique of Judgment $\$ 81$, a direct connection to Schiller ("Kant's Early Views on Epigenesis: The Role of Maupertuis" in Smith 317-354). Phillip Sloan explored the intellectual connection between Buffon and Kant in "Buffon, German Biology and the Historical Interpretation of the Biological Sciences" (109-53).

${ }^{19}$ In Act 2, Franz disappointed by his father's heartiness and his expected recovery, considers how to bring about his death: "Doctors and philosophers have taught me how finely the motions of the mind are attuned to those of the machine that houses it. Convulsive attacks are accompanied by dissonant vibrations in the machine; passions disturb the vital force; the overburdened spirit weighs down its vehicle." Here Schiller had Franz resort to a staple of iatromechanical psychosomatic medicine, disturbing the "sweet peace and harmony of body and soul": Franz chooses terror as the weapon to kill his father -"no trace of a wound nor corrosive poison for an anatomist's knife to reveal." 
the epigenetic theory championed by Maupertuis and Buffon as well as Trembley's polyps. There too, he employed Buffon's assertion of the biological significance of the individual, his natural definition of species and his argument for the unity of the human race. And he recalled Haller's research for his drives, the forces-in-matter that constituted his theory of human nature. As history, mid-century research and theories were, moreover, part of the natural philosophical (vitalistic) milieu he shared with his contemporaries and assumed in his readers.

\section{Haller's Sensitivity and Irritability, Forces-In-Matter and Schiller's Drives}

In my modest opinion, no psychology is possible which is not in each step determinate physiology. Haller's physiological work raised to psychology, and enlivened with mind like Pygmalion's statue - then we can say something about thinking and sensation.... Sensation is only the aggregate of all obscure irritations, just as thought is the luminous aggregate of sensation. Physiology is the shrine of the soul. Haller's work is Pygmalion's statue warming under the hands of the lover of the human soul (Herder, trans. Forster "On the Cognition" 197, draft).

Through his study of life, Albrecht Haller became a reluctant foundational contributor to the mid-century ferment. Schiller knew Haller (1708-1777) from his time as a medical student - as something of an ideal - as a poet polymath whose interests ranged from anatomy, physiology (iatromechanical medicine) and botany (developing out of iatrochemical medicine) to theology and law. Haller composed original lyrics and literary translations of classical authors; he published texts in botany about the distribution of flora in the Swiss Alps, ones that included his own classification system, and he introduced the first volumes of Buffon's Histoire naturelle in the German

The theoretical base is compatible with both the animism of Stahl and the early vitalism of Haller - the mechanical body is animated by the soul (Robbers 56-8; Neubauer "Freedom"). 
translation, Allgemeine Historie der Natur nach allen besondern Theilen abgehandelt. In his introduction to that work, Haller made the argument "that hypotheses are questions addressed to nature" (Larson Interpreting 15). Haller, himself sensitive and irritable, still had time to be quarrelsome - with both antecedents and contemporaries - particularly with Buffon, Linnaeus, La Mettrie and Wolff.

Through his experiments on living tissues to establish sensibility and irritability as properties of matter, Haller accelerated the nascent vitalism, one he vigorously distinguished from the animism of Georg Stahl and Robert Whytt. ${ }^{20}$ As an iatromechanist mentored by Hermann Boerhaave, a cautious experimental physiologist, Haller was one who "turned from the description of the body's organs as levers, pulleys, pumps, and sieves to the investigation of those characteristics such as growth, nutrition, and regeneration that make living things different from machines" (Hankins 120). Working with a number of pupils and colleagues at the University of Göttingen, Haller actively and repeatedly experimented on a variety of animals and human beings using different methods of stimulation in an effort to isolate the phenomena of sensibility and irritability in living tissues. As Owsei Temkin wrote, these "phenomena ... were known long before Haller and the very terms had been coined by others. The significance of Haller's contribution lies in the method by which he approached the subject" (in Haller,

20 "Dr. WHYTT, and the followers of STHAL, alledge that it is owing to the soul, which being sensible of touch, contracts the fibres that are touch, and pulls them back to prevent their being injured. However simple this theory may be, and however commodious for disembarrassing us from several difficulties, yet it is not agreeable to the phaenomena which are observed" (Haller 691 spelling and capitalization of the original is maintained). Haller used his findings to refute his opponents by name, particularly concentrating on the opinions of the animists and materialists. 
"Introduction" 651). ${ }^{21}$ From his observations, he posited both sensitivity and irritability as properties of matter. He defined sensibility experimentally as a function of nerves, not their sheaths but their medullae; the fibers themselves carried information from enervated structures particularly the skin, heart and intestines (not the dura mater, the tendons, ligament or periosteum for example) to the brain. ${ }^{22}$ He showed by countless experiments that sensibility required attachment, connection between the periphery and the head of the animal, and that sensation was destroyed when the nerve was severed or tied off. $\mathrm{He}$ limited irritability (contractility) by experimental definition to muscles - finding that the heart ("the most irritable organ of all" (687)) and all muscles, the esophagus, stomach, intestines and uterus retained their capacity for response to stimulation even after death of the individual, removal from the body and division into pieces. ${ }^{23}$ By repetition with different agents and species, he established to his and others' satisfaction that 1) "The nerves ... are the source of all sensibility .... We have seen that the sensible parts of the

21 "But the theory, why some parts of the human body are endowed with these properties, while others are not, I shall not at all meddle with. For I am persuaded that the source of both lies concealed beyond the reach of the knife and microscope, beyond which I do not chuse to hazard many conjectures, as I have no desire of teaching what I am ignorant of myself" (658).

${ }^{22} \mathrm{Haller}$ : "the skin is sensible, and indeed more so than any other part of the body; for in whatever manner you irritate it, the animal makes a noise, struggles, and gives all the marks of pain that it is capable of. This great sensibility of the skin has determined me to take it as a fixed standard of that property .... But a wound to the nerve produces the most violent symptoms ..." $(660,664)$.

23 "I have seen the heart divided into several small pieces, each of which moved upon the table" (678). "But all the muscles are irritable. I do not know one that has not a natural palpitation after death; they all tremble, and are alternately contracted and relaxed .... with regard to the sternocostals, I have often seen with pleasure, that upon cutting away the sternum, they still preserved a sufficient force to bend the cartilages of the ribs" (683). 
body are the nerves themselves, and those to which they are distributed in the greatest abundance." The nerves and brain are necessary to sensibility and by "intercepting the communication between a part and its nerve, either by compression, tying, or cutting, [the sensible part] is thereby immediately deprived of sensation" (674). ${ }^{24}$ 2) Regarding irritability: Haller evidenced it to be a property of moist muscle tissue (690). He further maintained that his results were independent of and irrelevant to question of the existence of the soul: "For if Irritability subsists in parts separate from the body, and not subject to command of the soul, if it resides everywhere in the muscular fibres, and is independent of the nerves, which are the satellites of the soul, it is evident, that it has nothing in common with the soul, and it is absolutely different from it; in a word, that neither Irritability depends upon the soul, nor is the soul what we call Irritability in the body" (696).

In Friedrich Schiller: Medicine, Psychology, Literature, Kenneth Dewhurst and Nigel Reeves noted that one of the standard medical texts at Karl Eugen's Military Academy was Haller's First Lines of Physiology (1747) and, based on quotations from Haller's poetry included in Schiller's dissertation, acknowledged that Haller "inspired Schiller not only as a physiologist but as a poet" as well (43-44). They believe that Haller's "early and influential poem 'Die Alpen' [was] one of the first sources of Schiller's admiration for simple cultures and intuitive naiveté of mind." Schiller, as a medical student, however, questioned some of Haller's views; for example, Haller's

\footnotetext{
${ }^{24}$ Haller believed both that he refuted the opinion that the nerve sheath was the primary functioning part and that he offered support for the idea that the nerves themselves were conveyors of a subtle fluid that communicated sensation rather than that they were oscillating tense cords.
} 
opinion that "euphoria in the moribund derived only from the soul's cheerful awareness of its imminent release from its early confines" did not square with Schiller's direct observation that "the true cause of such euphoria was relief from pain when the nervous system had become so deadened and disrupted that it could no longer register sensation" $(115-116) .{ }^{25}$ In this analysis, the young Schiller was practical and grounded in the natural world. Additionally, in his rejected dissertation, "The Philosophy of Physiology," Schiller explored one of Haller's positions ["into a labyrinth"] only to exclaim, "I cannot analyse this further without taking my reader for a fool . . . . I cannot understand how Haller contrived to be so superficial. Haller is too great for his stature to be diminished by this error. Quandoque bonus dormitat Hallerus" (162). The editors implied that Schiller may have misconstrued Haller's findings, a very unfortunate misunderstanding for a student desiring to graduate (169 fn 10).

In the same dissertation, however, Schiller (1779) based his argument upon correlations made by Haller between emotions and physiological processes; he used the hypothesis that nerves were microtubules of dynamic subtle fluids and he extended Haller's above definition of sensitivity to include that notion of force. ${ }^{26}$ "[F]inally," he wrote regarding the influence of matter on mind, "there must be a force at work that mediates between mind and matter [through the senses]."

${ }^{25}$ As Buffon wrote: "if you do not know how to die, do not worry; Nature will inform you immediately, completely, and sufficiently; she will do exactly that work for you; do not let that affect your life" (in Roger Buffon 172).

${ }^{26}$ This extension was a typical fate of Haller's experimental results at the hands of later vitalists, and Schiller himself evolved and changed over the years until his Mittelkraft became the Spieltrieb in 1794. 
A force which can be altered by matter and which can alter the mind. This would be a force which is spiritual on the one hand and material on the other, an entity that is penetrable on the one hand and impenetrable on the other. Is such an entity conceivable? Of course not!....

Be that as it may, a force in fact exists between matter and mind ....

The transmutative force resides in the nerve...After profound doubt I have reached the firm conclusion that the transmutative force resides in an infinitely subtle, simple and mobile substance, which flows through the nerve, its channel and which I call not elemental fire, not light or ether, nor electrical or magnetic matter, but nerve spirit. And from now on I shall refer to the transmutative force by this term (Schiller in Dewhurst 150, $152,154-5)$.

Schiller's middle force [Mittlelkraft], his transmutative force present in the sense organs, nerves and brain, was responsible for changing perceptions to "material ideas;" these ideas then could be absorbed and transformed by the mind (soul) into true cognitions (171). ${ }^{27}$ As indicated by Schiller's inclusion of Haller's research, the trajectory of its use was secular: to Haller's dismay - he was a pious man - his research forwarded a vitalism without a religious connection; his discoveries lent themselves to an increasingly natural and historical tradition, one Schiller participated in and one that Haller fought in another arena, that of the generation controversy. ${ }^{28}$

\footnotetext{
${ }^{27}$ Like the other vital forces hypothesized during that time, Schiller's early vital force was not entirely of matter in the same way that later forces, like Blumenbach's Bildungstrieb, Herz' Lebenskraft or his own Triebe, would be.

${ }^{28}$ La Mettrie (writing as Demetrius) and the materialists also hijacked Haller's research; they "used irritability as an argument against the very existence of a spiritual soul. Haller ... was highly indignant at De La Mettrie who in his writings moreover had ridiculed him and made him the laughing stock of all Europe" (Temkin Intro to Haller 653). Haller: "The deceased M. DE LA METTRIE has made Irritability the basis of the system which he advanced against the spirituality of the soul ... without ever having made the least experiment about it" (695). La Mettrie, the job of satirist made easy by an inflated target, would have been thrilled by Haller's arrogant irascibility.
} 


\section{The Generation Controversy}

From the last part of the seventeenth century, because observation was dependent on skill with a microscope and the activity of the imagination, competing and ambiguous discoveries fueled battles about generation. Individual researchers sought proof of their own hypotheses - particularly in this intensely interesting area. At first discoveries were associated with the ovist and spermist controversy within a larger theoretical position, preformationism (also called evolution or later encapsulation). ${ }^{29}$ Within that context, the

${ }^{29}$ Kant summarized the generation controversy in $\$ 81$ of the Kritik der Urteilskraft (Critique of the Power of Judgment) (290-293). The following detail with respect to preformationism may be helpful. Preformation was the ground upon which ovists and animalculists fought. This theory, summarized in a review article from 1691, held that "it seems most probable, [that] the Stamina of all Plants and Animals that have been, or ever shall be in the World, have been form'd ab Origine Mundi, by the Almighty Creator, within the first of each respective Kind" (Garden quoted in Sloan "Buffon German Biology" 110). Each group felt that evidence of preformed individuals had been discovered in the products of one, either the male or female parent. Spermists like Anton Leeuwenhoeck discovered animalcules in male semen, and after much debate among themselves and in the greater community, established that they were not evidence of infection, whether from creation or by disease. Animalcules however were too terribly abundant to be the carriers of preformed individuals: such a possibility seemed wasteful beyond the bounds of a providential system. Ovists believed that eggs (which were far, far less numerous) were the female's own and not the combination of both female egg and male sperm. They gained their ascendency in the late 1600's when the belief in the spontaneous generation of insects succumbed to the proof of their emergence from eggs and when, by the use of analogy with birds, eggs were sought and discovered in viviparous animals. As preformationists, they prevailed beyond the middle of the eighteenth century. William Harvey, an enthusiast of the microscope as well, pronounced "Omnia ex ovo," a succinct expression of many different interpretations of known facts about female anatomy. The following written in 1665 serves as an example: in all females, "there are seeds ... like eggs - so named either in the proper sense or by analogy, - which are fertilized through union with the male; among these eggs, some are laid before the fetus has been produced ... and others are retained until the fetus emerges from them, living and formed" (Deusing in Roger Life 207). Ovism established that females contributed something other than menstrual blood to the process of generation. Arguments against ovism generally developed around interpretations of female anatomy - questions about the actual existence of eggs on the ovaries and about the capacity of the Fallopian tubes to transport eggs. Cultural beliefs in the primacy of the male (in actual fathering) or in the failure of analogy from male structures characterized other arguments. 
opinion of the ovists prevailed and the dispute progressed to arguments about the development of the embryo and fetus. Preformationists believed development was actually the growth (enlargement) of preformed miniscules, an evolutionary unfolding of individuals first formed at creation. Their opponents held that embryos developed by gradually gaining form from undifferentiated matter in a process directed by unknown forces. This last position, this alternative theory to preformation, was epigenesis.

Preformationists believed that the new life was present in the seed of one of the parents, deposited there at creation, an event outside of or at the outset of time. This theory preserved the mechanistic view of reality - passive matter, the agency of a Creator - and the account of creation in Genesis. It was, on the other hand, unwieldy: it raised more questions than it could provide answers, and was difficult to square with the known facts. The ease with which it lent itself to satire may have actually prolonged its life: authors enjoyed provoking readers' imaginations about being co-eternal with parents, grandparents and Socrates, if he were an ancestor. They encouraged imagining the tight fit, being scrunched into the tiniest possible space with all the people ever to come into existence, a space which got successively more commodious as more and more individuals moved toward the moment of birth. As a seed developed, it simply grew larger, unwrapping itself like a peony. Besides working within the established paradigm, this theory explained the activity of the Creator (as non-occasional in his interventions) and the stability of species. It also precluded having to explain how organisms came into being and changed in time. Leibniz, for example, depended on it. 
Performationists were left with one question to be answered: what part did each sex play in generation, and more specifically, what role did the following play - the "animalcules" or spermatozoa in male semen and eggs and the fluids of the female?

The alternative, epigenetic theory, though known from classical times, did not gain wide notice until the mid-eighteenth century, and it figured prominently in the midcentury upheaval and the late Enlightenment. Epigenesis described reproduction as development progressing from unorganized matter. Older epigenetic arguments posited that one parent (usually the male) provided the stimulation or some sort of principle of activation for organization or, alternatively, that he infused the matter provided by the female with form. The theories of mutual production of fluid or seed which posited the equal importance in action and involvement of the two sexes were known throughout history and were revived by Buffon and Maupertuis for epigenesis at mid-century. Epigenesis made reproduction, the creation of a new being, a historical event. As such epigenesis would become central to the Enlightenment vitalists' exploration of nature its polarities, middle spaces and life forces. Such a theory allowed generation to be reproduction and development to be transformational; it accepted organisms as selforganizing in time. It, however, raised a terrific difficulty: such a theory necessitated hypothesizing a principle (or force) of life to begin and sustain the direction of new being's development to adulthood in a particular species, an apparent goal-directed activity. And it demanded the necessity of at least one event of spontaneous generation of life in the history of the earth, one too many for the Enlightened. 


\section{Maupertuis, the Generation Controversy and Schiller's Use of Reproduction}

Pierre-Louis Moreau de Maupertuis (1698-1759) was a mathematician and

astronomer who became interested in biological problems and probability studies. ${ }^{30}$

A strong proponent of the experimental method, he observed and dissected both

salamanders and scorpions. As a result of his research, he believed in the dynamic

constancy of nature: "no matter how great the variety of nature," he wrote, "the heart of

things is always about the same. We all know what advantages are to be derived from

comparative anatomy; the perfect knowledge of a single body is perhaps no more than the

price one pays for the impossible examination of all the bodies in nature" (Maupertuis

"Intro" xiv-v). He was France's first Newtonian, and in an effort to prove a Newtonian

hypothesis about the shape of the earth - that it was flattened at the poles - led an

30 "Might one not say that in the chance combination of nature's productions, since only those endowed with certain relations of suitability could survive, it is no cause for wonder that this suitability is found in all species that exist today? Chance, one might say, produced an innumerable multitude of individuals; a small number turned out to be constructed in such a fashion that the parts of the animal could satisfy its needs; in another, infinitely greater number, there was neither suitability nor order: all of the latter have perished; animals without a mouth could not live, others lacking organs for reproduction could not perpetuate themselves; the only ones to have remained are those in which were found order and suitability; and these species, which we see today, are only the smallest part of what blind fate has produced" (Maupertuis qtd. in Roger Life 381). Regarding this excerpt, Roger wrote: "I would like to state here once and for all that it is absolutely impossible to see in this text an early anticipation of Darwin's theory of natural selection. For Lucretius, as for Maupertuis in this text, for La Mettrie in the Système d'Épicure (397-98), and for Diderot in the Lettre sure les aveugles, what was involved was the disappearance of beings incapable of living or reproducing for reasons of malformation. Competition with other species did not enter into the matter. . . But having been a disciple of Lucretius's does not suffice to make one a precursor of Darwin (Life $652 \mathrm{fn} 66$ ). Cf., this excerpt's use by Bentley Glass in Forerunners, 57-58. 
expedition to Lapland in order to measure an arc of the meridian there. ${ }^{31}$ When it was realized that his measurements supported the theory of a foreigner (worse, an Englishman) an unpleasant and irrational dispute ensued, and in 1740 he accepted an invitation from Frederick the Great to reorganize the Berlin Academy of Sciences. Before he could begin, while trying to find Frederick in the midst of a campaign, Maupertuis accidentally crossed the battle lines, was captured during the Battle of Mollwitz and taken to Vienna as a prisoner of war (Hankins 35). Finally in 1745, he assumed the Presidency of the Academy. Conflict however followed him: he was accused of taking credit for the discovery of the Principle of Least Action when the honor should have been accorded to Leibniz, and his old friend Voltaire was enlisted against him. From that satirist, Maupertuis was granted another life in print: he was excoriated in "Diatribe of Dr Akakia," "Micromegas" and in numerous epigrams about his sexual escapades (Boas in Maupertuis xx).

According to Jacques Roger, "a minor social event - the presence in Paris of an albino African child who was being exhibited in the salons," offered Maupertuis the opportunity to write two occasional works on reproduction," one of which, $\underline{\text { Venus }}$ Physique (The Earthly Venus 1745), was read throughout Europe (Life 383). The Earthly Venus affirmed the reciprocity of human sexuality, the pleasure of both sexes, and postulated the equal contribution of both to reproduction. In its pages, the generation controversies were described and the epigenetic theory of reproduction was popularized

\footnotetext{
${ }^{31}$ He was also an avid follower of Leibniz while opposing the rigid Wolffian interpretation of him. Cassirer: "It was especially Maupertuis who brought Leibniz to France" (86).
} 
by a graceful, bright and somewhat seductive manner of explanation. ${ }^{32}$ By presenting a pedigree chart of a family with polydactyly, Maupertuis introduced proofs of heredity involving both parents. Recording of genealogical data was a radical innovation, and its use by Maupertuis destroyed both the ovist and spermist positions (Boas in Maupertuis xxv). Though he knew that, in saying the fetus was formed from the mixture of two seeds, he really hadn't explained this formation at all, Maupertuis couldn't help himself; he augmented epigenetic theory in the following way. He held that 1) in the seminal fluid of every species were innumerable particles which perpetuate that species. 2) Each individual also had particles, more in number, which perpetuated individual traits, and 3) each particle produced germs that have the capacity to induce development of a specific organ or structure (53, "Intro" xxix). ${ }^{33}$ He theorized that chemical attraction of particles

32 "The real merit of Maupertuis in this matter lay in his having reestablished the principle of epigenesis; in other words, in having brought the problem of generation back into the domain of secondary causes and having restored to science a question that had been abandoned to metaphysics. But the philosophical character of the undertaking was uncomfortably evidenced by the absence of any new fact .... After this, it would have been prudent not to purpose any system, and, indeed, Maupertuis was careful not to. $\mathrm{He}$ went on however to present some 'vague thoughts' and 'questions for examination,' which turn out in fact to be a theory of generation based on a mixture of the two seeds [male and female] ..." (! 385).

${ }^{33}$ In considering the assortment of particles in reproduction, Maupertuis wrote: "a uniform and blind attraction spread out through all parts of matter can no longer serve [making an analogy along the lines of gravity for generation] .... we must have recourse to some principle of intelligence, something similar to what we call desire, aversion, memory.... The elements suited to the formation of the fetus swim in the seeds of the father and mother animals; but each, extracted from the part similar to the one it is to form, keeps a kind of memory of its prior placement; and it will resume it again when it can, in order to form the same part in the fetus" (Maupertuis quoted by Roger Life 390). Roger believed that Maupertuis "contributed to the extraordinarily important evolution leading from the Leibnizian idea of a soul added to matter to the idea of a 'dull sensitivity' granted to matter itself, an idea to be encountered again in La Mettrie and Diderot" (392). 
in the two seminal fluids, each for the other, on the basis of the shared structure that would develop from them, allowed for proper assortment and reproduction of a new individual.

Like Maupertuis' theory of the contribution of active particles by both sexes, in Schiller's drive theory, sense and reason as forces each made active contribution to human nature. Their union, as Schiller had Reason trumpet it in his text, reads like a marriage of the sexes, like a union of sex, particularly if Aristotelian bias is admitted:

Let there be a bond of union between the form-drive and the materialdrive; that is to say, let there be a play-drive, since only the union of reality with form, contingency with necessity, passivity with freedom, makes the concept of human nature complete .... Let humanity exist .... (XV.4).

As alluded to above, in Schiller, the generation of the play drive has an Aristotelian element, the (female) material drive is substance for the (male) form drive. Maupertuis summarized Aristotle for the readers of The Earthly Venus as follows:

The ancients believed that the embryo originated from the mixture of the seminal fluids given off by the sexes. That of the male, when propelled into the womb, combined with that of the female. After this mingling had taken place, the Ancients found no difficulty understanding the creation of an animal. The operation was due to Generative Force. Aristotle, as may well be believed, was not more puzzled than others by the problem of generation. He differed only in believing that the generative principle came solely from the male. The female fluid's only function was providing food and growth for the fetus. To use Aristotle's terms, it supplied the matter while the male supplied the form (8).

The format of Maupertuis' theory then had several features congenial to Schiller's point of view. From a meta-perspective, his theory helped establish the vitalistic paradigm of the creation of a third, that is, of polarities joining to produce a new entity without losing their own existence. Through an analogy from epigenesis, Schiller displayed this same intense interest in managing the polarities of human life and the 
active forces of the personality in his psychology (W\&W Appendix III). He emphasized the reciprocity of processes and forces in his theory of the drives that join to create the play drive, harmonizing without losing the character of the originals - i.e. two opposing forces which do not annihilate each other but create a third 'mixed' capacity.

The sense-drive demands that there shall be change and that time shall have a content; the form-drive demands that time shall be annulled and that there shall be no change. That drive, therefore, in which both [the form-drive and the sense-drive] work in concert [I call ... ] the play-drive ... [which is]directed towards annulling time within time, reconciling becoming with absolute being and change with identity. (XIV.3)

In $\underline{L}$ 'histoire naturelle (1749) one of the most widely read and owned series of books about nature in the eighteenth century, Georges-Louis Leclerc, Comte de Buffon posited a similar generation theory, with the addition of a moule intérieur [internal mold] to act as a template of sorts, as a limiting dynamic archetype. ${ }^{34}$ In his article on the horse, Buffon placed the internal mold in the original of the species and in each individual:

There is in Nature a general prototype of every species, upon which each individual is modelled, but which seems, in its actual production, to be depraved or improved by circumstances; so that, with regard to certain qualities, there appears to be an unaccountable variation in the succession of individuals, and, at the same time, an admirable uniformity in the entire species. The first animal, the first horse, for example, has been the external and internal model [moule intérieur; Kastner: innerliche Form], upon which all the horses that have existed, or shall exist, have been formed. But this model, of which we know only copies, has had, in communicating and multiplying its form, the power of adulterating or of improving itself. The original impression is preserved in each individual. But, among millions of individuals, not one exactly resembles another,

\footnotetext{
${ }^{34}$ Many late eighteenth century theories are revitalized ideas from past traditions or are based on imports from specific natural philosophers. Maupertuis' and Buffon's theories of generation have Galenist origins (Terrall, Sloan); Sloan saw in Buffon's emphasis on the physical and his internal mold as a recovery of a William Harvey treatise on Aristotle's eidos, species as form (Sloan, "From logical universals to historical individuals; Buffon's Idea of Biological Species"). Vitalism itself resonated alchemic and animist positions (van Helmont (1648), Stahl, (1660-1734)).
} 
nor, of course, the model from which they sprung. This difference, which shows that Nature is not absolute, but knows how to vary her works by infinite shades, is equally conspicuous in the human species, in all animals, and in all vegetables (Buffon Trans. Smellie 344).

According to Reill, "Buffon's formulation established a rhetorical strategy that used Newtonian vocabulary but transformed its general meaning .... [Using a paradox to explain moule intérier, Buffon wrote that it appears to] 'join two contradictory terms . . one, the idea of form' applied 'only to surfaces.' The other, 'inner' or 'internal,' was usually applied to mass ...." This mediating thought form, the moule intérier, "became the physical symbol of the 'extended middle,' a formation designed to transcend binary forms of argumentation" (Vitalizing 46). Known to both Kant and Goethe, Buffon's conception of reproduction and his synthetic process was basic to Schiller's natural philosophical perspective.

\section{Buffon, Classification and Species Definition, and the Use of Species in Schiller}

Buffon, who maintained a research forest and a menagerie of animals on his own estate, produced - with Daubenton's assistance - thirty-six volumes of the Histoire naturelle, générale et particulière between 1749-1788. Jacques Roger, Buffon's biographer, wrote that "in this immense work, he transformed the way of understanding nature. He did not give new answers to traditional questions; he opened new fields of research; he suggested a new way of conceiving natural history by his audacity and often by his mistakes. $" 35$ In The Growth of Biological Thought, Ernst Mayr marked Buffon's "monumental and fascinating" work:

\footnotetext{
${ }^{35}$ Roger continued, "I have not ignored his inadequacies, knowing they added to his genius and to a system of thinking in which one must find the internal logic; in addition, had he been a 'model scientist' he would have been in what Thomas Kuhn calls 'normal science,' and he never would have had so many new ideas" (Buffon xvi).
} 
It is no exaggeration to claim that virtually all the well-known writers of the Enlightenment, and even of later generations, in France as well as in other European countries were Buffonians, either directly or indirectly. Truly, Buffon was the father of all thought in natural history in the second half of the eighteenth century (330).

Buffon's ideas evolved over his long literary career. Citing his "versatile, indeed almost mercurial mind," Mayr described Buffon as a scholar who "looked at many subjects from so many different sides that he not infrequently contradicted himself" (330). And, because of the political situation, many scholars believed that Buffon could not write with total candor. Roger, particularly, noted that Buffon wrote conventionally in introductory pieces and in articles that might come under the scrutiny of the Sorbonne, hiding his controversial theories about man, for example, in articles about animals. Buffon was not always appreciated: close observers like Bonnet (who was attacked by Buffon for anthropomorphizing his beloved bees) and the empiricist and mathematician d'Alembert both complained of his generalities, his Buffonades, seeing him more as a popularizer than a scientist. As noted earlier, it was Albrecht Haller who introduced his work into Germany; Kant and Herder carried his theories from natural philosophy to philosophy there.

Given the three dozen volumes written over decades and his penchant for changing his opinions with new evidence or theoretical constructions, Buffon (especially mediated through Kant whose natural historical base and opinions changed over the years as well) was a tremendous source of indeterminacy - a compendium of points-of-view - for a synthesizer like Schiller. Most theories illuminated part of the picture; they both answered questions and raised further difficulties, and the discoveries and experiments 
both overturned assumptions and were put to polemic use by all sides of a controversy. In the Aesthetic Letters, Schiller's concepts show the variability, inconsistency and possibility of an author synthesizing disparate and controversial theories, usages and understandings. Schiller played with classification, with the reality of the individual, species and genus, sometimes using the later two in a systematizing (rationalizing) way, sometimes striving for natural classification based on Buffon's concept of relation. In other words, some sense was to be made, but from Schiller's point of view, it was to be done in the combination of the theories, in the bending of concepts and the re-application of the known to human nature. Buffon was part of the milieu, a compendious source of form and content.

Buffon, particularly in the early volumes and the Initial Discourse, fractiously opposed Linnaeus' system and espoused an iconoclastic nominalism: classification, he wrote, "is at the very most only a convention, an arbitrary language, a means of mutual understanding. But no real cognizance of things can result from it" (Lyon Trans. 152). ${ }^{36}$ “It is a 'metaphysical error,' [Buffon] insists, to search for a basis for systemization in nature. The more divisions a would-be systematizer makes in nature, the closer he approximates 'truth." This 'biological calculus' brings humans closer to reality, for "the order we eventually find in nature is more the subjective result of the workings of the human mind and will than a reflection of objectively existing reality; for nature proceeds by imperceptible nuances or gradations ..." (Lyon paraphrasing Buffon, 134, 136). In a passage where Buffon arbitrarily multiplied Linnaeus' classes in an ironic application to improve accuracy of a system by atomizing it, he wrote:

${ }^{36}$ Lyon noted that Buffon later modified his nominalism significantly ("Intro" 134). 
For, in general, the more one augments the number of divisions of the productions of nature, the more one approaches the truth, since in nature only individuals exist, while genera, orders, and classes only exist in our imagination (Lyon trans. 164).

It is significant that Buffon did not include the category species in the above products of imagination. That exclusion is purposive: he contended that species as a group of related individuals can be biologically defined.

Like Buffon, Schiller had nominalist inclinations. In an argument about the natural State as mechanical, as not functioning with the complex reciprocal relations of an organic entity, he saw classification as a straight-jacket that obscured reality and feedback:

the State remains for ever a stranger to its citizens since at no point does it ever make contact with their feeling. Forced to resort to classification in order to cope with the variety of its citizens, and never to get an impression of humanity except through representation at second hand, the governing section ends up by losing sight of them altogether, confusing their concrete reality with a mere construct of the intellect (VI.9 my emphasis).

Buffon proposed a new way of classifying organisms by relation in nature - in that way, he separated living forms from minerals, concepts or diseases. Living things were remarkable in their relationship to each other. Believing that a true classification must be based in nature and reflect this connectedness, Buffon proposed that the real relationship between animals was relation by historical descent from common origin.

However marvelous [the individual] appears to us, it isn't in the individual that we find the greatest marvel. It is in the succession, in the renewal and in the duration of species that Nature appears almost inconceivable ... (Buffon quoted in Sloan "From logical" 120).

Buffon contended that animals (including men) belonged to the same species if they had ancestors in common and breeding, produced fertile offspring, i.e. formed a historical 
fertile lineage. This stance made species spatiotemporal and it gave history a different evidentiary status (if real relation could be proven). It also implied that the moule intérieur (as the carrier of the eidos, physical form of the species) perpetuated the species in the individual. As a concept it held species and individual in polar tension as Schiller often did in his argument for play.

Hiding his speculations in an article on the ass, Buffon reiterated the possibility that organisms showing "great anatomical similarities are related as one natural famille derived from a single archetype" (Sloan "Buffon-Linnaeus" 372).

There exists, at the same time, a primitive and general design, which may be traced to a great distance, and whose degradations are still slower than those of figure or other external relations: For, not to mention the organs of digestion, of circulation, or of generation, without which animals could neither subsist nor reproduce, there is, even among the parts that contribute most to variety in external form, such an amazing resemblance as necessarily conveys the idea of an original plan upon which the whole has been conceived and executed (Buffon, trans. Smellie "The Ass" 400, my emphasis). ${ }^{37}$

Buffon's contention that the biological species is the only reality in nature ("the individual is nothing in the Universe ... The species are the sole beings of Nature, perpetual beings, as ancient and as permanent as it is") is held in tension by his insistence on the reality and the importance of the individual:

But Nature proceeds by unknown gradations ... passing, as she does, from one species to another species, and often from one genus to another

${ }^{37}$ Kant on archetypes [Urbilde]: "Many animal species resemble one another according to a certain common scheme, which scheme seems to lie at the foundation not only of the structure of their bones but also of the order of their other parts, so that the proliferation of species might arise according to a simple outline .... This analogy of forms - insofar as they seem to have been produced, despite their differences, according to common archetypes [Urbilde] - strengthens the suspicion of a real relationship of these forms by reason of their birth from a common, aboriginal mother [Urmutter]" (Kant A363-364, B368-69 in Richards, "Kant and Blumenbach" 28). 
genus, by imperceptible shadings; so that there will be found a great number of intermediate species and of objects belonging half in one class and half in another. Objects of this sort, to which it is impossible to assign a place, necessarily render vain the attempt to a universal system .... In general, the more one increases the number of one's divisions, in the case of natural products, the nearer one comes to the truth; since in reality individuals alone exist in nature, while genera, orders, classes, exist only in our imagination. (Buffon, 1(1749)13,38 as qtd. by Lovejoy in Glass 90)

Another Buffonian idea, that the species are fixed in time but can degenerate because of nutrition, climate and other environmental factors (which appears just above and in Buffon's considerations about the horse) allowed Schiller to claim by analogy that play is archetypal to the human species, that each of us carries it as potential, but a potential that can both be lost historically and be recovered individually. In his developmental history of play, he showed this sense of species, including in the implication that development is actually restoration of the full archetypal potential - a possibility because of degeneration and restoration to type.

Just as Maupertuis posited particles for maintaining the species as well as particles for expressing individuality, Buffon hypothesized moule intérieur, and Kant required both Keim and Anlagen, Schiller synthesized as well. He combined the power of species inherited unchanged from generation to generation with the development of highly variable individual characteristics. In an implied theory of reproduction, his theory of play depended on a sort of modified preformationism involving species-defining characteristics (like our general morphology and the full capacity to play, rather than a tiny unfolded eternal self passed down from generation to generation). He added an epigenetic developmental sequence that included those stable species-determining seeds and the individualizing traits (subject neither to the same necessity, nor to the simple workings of chance). Play, as the product of a separate form drive [Formtrieb] and a 
separate sense-drive [Stofftrieb], was both epigenetic (i.e. unformed matter develops form) and Aristotelian, but the birth was an entirely new one: the resulting play drive was species-specific to humans. On the other hand, Schiller's developmental sequence can be read as allowing for successive, reciprocally-developing and transforming interactions between the sense-drive and rudimentary reason to produce intermediate play drives; these intermediates then interacted with the drives of sense and reason again (and all the while, reason increased its strength and breadth due to interaction, from self-awareness, to empathy, to use of the play drives representations, heightening its productions from material ideas to cognition). Each change was a transformation; that is, the capacity to play developed in history to develop us.

In the Aesthetic Letters, Schiller worked with concepts of the human species, reflecting the taxonomical controversy raging at the time. He also juxtaposed humanity as a genus or species [Gattung, Art] and the individual human being in order to bring into reciprocal relationship the potential inherent in the species and the capacity in the particular individual for development, freedom and a graceful moral character.

\section{The Classification Controversy}

Reason does indeed demand unity; but Nature demands multiplicity; and both these kinds of law make their claim upon man (IV.4)

Throughout the early eighteenth century there was growing acknowledgement that the representation of nature, by words and the concepts, did not approximate the object itself. Things were not fixed as words made them, not species, not individuals: time had to be accounted for, time and its products, the historic individual, the biological event. Linnaeus' useful system itself was artificial: it depended upon identifying characteristics that suited human senses, structures that humans could not only see but count without any 
special apparatus other than a magnification devise. The tight fit with human needs and capacities was the Linnaean system's strength and its genius: anyone could be involved in the great natural historical project. The system itself however was rigid; over and above its dependence on certain countable traits, it required that each organism be lodged in seven hierarchical categories, species, genus, family, class, order, phylum and kingdom, an extraordinarily neat work of classification, good for curiosity cabinets and museums but not representative of living organisms' relationships to each other through common ancestry.

Buffon opposed Linnaeus and his system and proposed the development of a natural system to replace it. The concerns about classification that led him into this controversy are best understood in the context of these intellectual changes at mid-century: first, man joined nature and came to be seen as sharing the limitations of physicality, in particular, the extent of his capacity to know the world and himself. Secondly, man's experience of time was changing. Many late Enlightenment natural historians worked to understand the dimension of time in the light of discoveries about life. A new appreciation of time and the historical record beyond the history of man evolved gradually into a capacity to perceive and describe nature's dynamism. No longer a static and harmoniously balanced entity, nature with all her living productions was recognized as continuously varying in time: the balance of nature became a dynamic tension of continuous change and adjustment, of constant reciprocal adaptation.

From this perspective, then Buffon's biological definition of species, which he proposed in opposition to the static and task-friendly Linnaean system, proved prescient but impractical. As noted above, he identified an individual as a member of a species if it 
were related through historical reproductive events to others in the group and if it were able to reproduce with a member of the species. According to Buffon, "[t]his power of producing its likeness, this chain of successive individuals . . constitutes the real existence of the species." (Buffon qtd. in Lyon 170 my emphasis).

This definition, hailed by Kant and others, still could not dislodge Linnaean classification, even among Buffon's admirers. Why? because it raised insurmountable practical problems. How could such events be observed and traced? How could relationship be discovered in history? Achieving the natural method that Buffon called for but could not fully conceive of would be the work of centuries. Such a shift required the inclusion of evolution into classification, a development that would require more than a hundred years; it awaited carbon dating of archeological finds, only possible after radioactivity in the earth was recognized in 1902. Also necessary to a natural system was analysis of DNA and RNA across species, a capacity that required as a prerequisite the recognition and isolation of those substances in the 1950's, and finally the establishment of cladistics, the system of classifying according to common ancestry (this science of establishing and diagramming homologies only became dominant in the 1990 's). ${ }^{38}$

${ }^{38}$ There were classification difficulties inherent in the Linnaean system and naturalists felt the need to represent the real biological relation between beings over time, their connection through common ancestry. These motivations coupled with the explosion of technology capable of making such a project a reality provoked a revolution in classification, the details of which are being worked out now (e.g. birds and dinosaurs have common ancestry as do whales and hippopotami) The new scientific system, cladistics, classifies organisms based on evolutionary relationships, on common ancestry. A clade is a group consisting of a single (hypothetical) common ancestor and all its descendents. As late as 1976, John Lyon wrote: "The search for a natural system of classification in botany or zoology is somewhat like the chemists' - or alchemists' search for the philosopher's stone. Though the goal is never reached, useful things are picked up along the way. And without an imaginary goal we would never set out at all" 
One of the difficulties pointed out by Buffon, the subtle gradation of living things in nature, cannot be properly represented by classificatory systems. It is a fact that the differences between beings - often so great within a species - can in fact be negligible and seem inconsequential or circumstantial (based on climate, nutrition or geographic isolation) when comparison is made and classification attempted between two individuals of a different species (even assisted by comparison with a third). As many traits are chosen for classification based on the ease with which humans can distinguish them, the hierarchy of their importance was potentially arbitrary. There were always intermediate forms, exceptions, beings that defied easy pigeon-holing and in fact called the assumptions of classification systems into question. Such a being was the Hydra, the fresh water polyp: its discovery and manipulation through experimentation by Abraham Trembley in the early 1740 's created classificatory and theoretical havoc at mid-century.

\section{Trembley, the Polyp and Schiller's Idea of Organic Wholeness}

We really do not know nature: causes hidden in her bosom may have produced everything. Take your own look at Trembley's polyp: does it not contain in itself the causes that give rise to its regeneration?

La Mettrie, L'homme machine (La Mettrie trans. Thomson 24).

Abraham Trembley (1710-1784) was a children's tutor who noticed polyps while sitting beside a pond. What followed from this observation was a series of experiments and a publication considered by many to be "a classical model for a detailed biological investigation," a work that merited the Royal Society of London's prestigious Copley Medal for "those curious and surprising Discoveries ... entirely unobserved in the Animal Creation, and indeed never so much as thought of, till they were brought to light,

(Buffon trans. Lyon 142). But now the goal of a natural system of classification is within reach. 
and made manifest by ... diligent and exact Enquiries" (Lenhoff Hydra ix). Trembley's research on the fresh-water polyp (published 1744; Linnaean Hydra 1746) shocked his contemporaries because his observations and manipulations described a new kind of being, one outside the accepted classification of living organisms. ${ }^{39}$ In addition, it called theories of generation like preformation into question. Acknowledging the world-viewshifting possibility of his research, he began by setting out the model for investigation involving life forms:

the little creature whose natural history I am about to present has revealed facts to me which are so unusual and so contrary to the ideas generally held on the nature of animals, that to accept them demands the clearest of proofs .... It is not enough to say, therefore, that one has seen such and such a thing. This amounts to saying nothing unless at the same time the observer indicates how it was seen, and unless he puts his readers in a position to evaluate the manner in which the reported facts were observed (Trembley (1744) in Lenhoff Hydra 1-2). ${ }^{40}$

\footnotetext{
${ }^{39}$ Vartanian noted that, in addition to playing a significant role in shaping La Mettrie's vital materialism, Trembley's discoveries and experiments had made an impact on so many, particularly on Buffon, Bonnet, Maupertuis, Lyonnet and Rousseau. (The last "listed its manner of multiplication among the six or seven leading problems of science and philosophy in his Discours sur les sciences et les arts," a classic Schiller read.) Diderot's Reve de D'Alembert included human polyps living on Jupiter and Saturn, and the Encyclopédie referenced this "'insect singulier et merveilleux' . . . perhaps the most fascinating single curiosity of natural history in the 1740's" (Vartanian "Trembley" 498). Maupertuis incorporated Trembley's research into Venus Physique [The Earthly Venus 1745]: "An aquatic worm, called polyp, has even more surprising means of multiplying. As a tree sprouts new branches, a polyp sprouts young polyps. When these have reached a certain size, they drop off, but often, even before leaving the main trunk, they themselves produce new polyps and all these descendants of various generations still hold on to the common ancestor .... In order to multiply itself, one of these animals only needs to be cut in pieces. The part with the head grows a tail, while the end with the tail produces a head, and those parts that have neither head nor tail produce both .... This Hydra, more wonderful that that of the fable, can be split lengthwise or mutilated in every way and soon all is repaired and each part has become a new animal. What can one think of this strange kind of generation - of this life-giving principle spread throughout the animal?" (Maupertuis 38-9).

${ }^{40}$ Details about Trembley's methods of experimentation by tissue grafting are also available in a short article (Lenhoff "Tissue Grafting in Animals").
} 
Prior to Trembley, polyps were thought to be plants. Green as the algae that lived in them, they, however, behaved like animals. They moved and reacted to light but, then, they also regenerated lost parts like plants. They were real primitives, one of the missing links between plants and animals. After his initial observations, Trembley began a series of experiments; he amputated parts and divided the little creatures; he watched them and found that they regrew lost parts, or reconstituted themselves if, for example, he turned them inside out. He also diced polyps and saw that they developed into as many separate organisms. These series of experiments (even before their publication) sent the equivalent of a seismic shock wave through the intellectual system supported by the preformation theory. As Johann Georg Sulzer wrote in his Untrredungen über die $\underline{\text { Schönheit der Natur, Moralische Betachtungen über besondere Gegenstände der }}$ Naturlehre (Moral Reflections on Certain Topics of Natural History 1745):

I speak of the POLYPUS, the 'Many-footed,' a kind of worm that lives in water. This curious beast manifests qualities that declare war ... on all human reason. Polypus teaches us (if it were capable of pedagogy) that the man who would imagine it must be a dreamer, an enthusiast intent on mocking the universe - yet experience actually supports him. In this creature, of which everyone au courant has received notice, we have discovered a miraculous aptitude. The animal is divided into innumerable parts ... each fragment does not just survive, but it generates ... a whole new creature as perfect as the one from which it was severed (Sulzer 116).

The preformation theory supported both Newtonian and Leibnizian mechanism: creation, ensoulement, embodiment and any new complex organization were thereby put outside time - saving the passivity of matter. As noted above, the theory posited that one parent contributes an embryo, one that has existed from the beginning of time. Like Russian dolls, embryos were, complete but miniaturized and enfolded, awaiting the stimulation or nutrition from the other parent's fluids to begin development. Naturalists, philosophers 
and theologians alike found it hard to believe that Trembley's behavior could have been anticipated from the beginning of time and equally hard to believe that so many souls for the oddly-created polyps were at the ready for such an eventuality - all of which seemed necessary for the vindication of preformation theory.

The power of the simple organism to create itself, to create wholeness (and change a system of thought), was a perfect metaphor for Schiller's understanding of the early Greeks and their states, and for the potential for modern humans to be returned to a contemplative unity (the unity possible in a more complex human nature) in the aesthetic state through play. The little polyps appear in an extended description of the Greek States, valorizing their autonomy:

That polypoid character [Polypennatur] of the Greek states, in which every individual enjoyed an independent existence but could, when need arose, grow into the whole organism, now made way for an ingenious clock-work, in which, out of the piecing together of innumerable but lifeless parts, a mechanical kind of collective life ensued (VI.7 my emphasis).

Schiller's use of the polyp underscored the primitive perfection, the capacity of Greek states for an autonomy that would be impossible in modernity, and also it referenced the historic loss of flexibility of political institutions (indicated by a mechanical metaphor): those small states did not go on to develop the kind of cohesion and cooperation typical of a more complex organic body ${ }^{41}$ For Schiller, each primitive Greek individual was characterized "by a simplicity to which our age is a stranger;" the Greek mind

${ }^{41}$ Others interested in the polyp or its metaphorical uses included Voltaire who examined "this natural process with all the attention [he] could muster," but nevertheless asserted "that this production called a polyp resembled an animal less than a carrot or an asparagus did" " (Roger Life (158). Roger used Voltaire's remarks to illustrate the change in natural history by 1750 : by then "scientific observation was no longer accessible to mere amateurs"). 
did indeed divide human nature into its several aspects, and project these in magnified form into the divinities of its glorious pantheon; but not by tearing it to pieces; rather by combining its aspects in different proportions, for in no single one of their deities was humanity in its entirety ever lacking. How different with us Moderns! With us too the image of the human species is projected in magnified form into separate individuals - but as fragments, not in different combinations, with the result that one has to go the rounds from one individual to another in order to be able to piece together a complete image of the species .... we see not merely individuals, but whole classes of men, developing but one part of their potentialities, while of the rest, as in stunted growths, only vestigial traces remain (VI. 3).

The trouble with moderns is the same trouble with complex living beings - if they are divided they cannot regenerate missing parts. Many must function only as parts of themselves or die if a function necessary for life cannot be performed. Healing is possible but the result will be imperfect, a scar or a "stunted part." The early Greek, as individual, simple as a polyp, could stand for the whole and could project wholeness into representations: for Schiller "the individual Greek [was] qualified to be the representative of his age, and ... no single Modern [could] venture as much" (VI.4).

\section{Summary}

After the 1750's the dualism of the mechanical system collapsed into avid exploration of living nature through observation, experimentation and theorizing. The very mechanical philosophy that had failed to accommodate the discoveries about life and the growing understanding of life and its processes became the ground upon which scientists built other conceptual frameworks - materialism, neo-mechanism, and vitalism. Amateur and professional natural philosophers who had been deluged with things to describe and classify continued to seek a transformative empirical surface but did so in the service of examining the phenomenon of life. The geometrical spirit that created the architecture of the mechanical systems broke into mathematical pieces, and there rose the 
promise, through calculus, that probability would emerge as the future empirical language. The contribution of the medical community gave some access to explanations of "how things work" through anatomy and physiology: vivisection coupled with experimentation allowed several life actions to be discovered and described. But even the real-time experimentation had not answered quandaries about generation, maintenance and development, functions of life with quasi-teleological qualities. These capacities became more and more the focus of attention.

After mid-century, history had more dimensions - not just Biblical time (6000 years) or personal time based on the our experience of seasons, years and personal milestones or retrospection into human history, but deep geological and cosmological time as well as the relative time of other natural entities, the aphid, the dog, or the animals represented in the fossil record. The facts were plotted between two axes: that of space - "Of all the lessons derived from the idea of space, perhaps the latest had to do with relativity. Perspectives changed" (Hazard 11) - data from travel and travel literature, from the description of all those exotic places, of all things in nature, large and microscopic, and the varieties of human society that were encountered. ${ }^{42}$ Not just space but also time time had changed. It had grown relative, suddenly lengthened by discoveries on the strata of the earth's surface, suddenly shortened with respect to the amount of change that could be perceived over a lifetime. The context of experience involved a

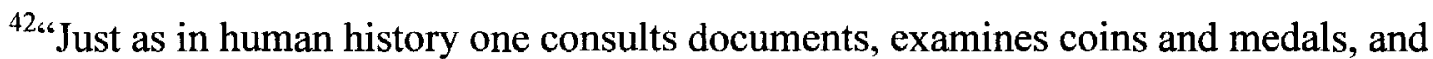
deciphers ancient inscriptions in order to determine the revolutions and epochs in the intellectual life of man, so in natural history one must search the archives of the world, unearth the oldest relics, collect remnants, and unite all signs of physical changes which are traceable to the various ages of nature into one corpus of evidence. This is the only way to determine any fixed points in the infinity of space and to leave behind a few milestones on the unending pathway of time" (Buffon qtd. in Cassirer 79-80).
} 
combination of sensibility about life forms and the restlessness of reality, a new understanding of the dynamism of life and of the complexity of the environments inhabited by all life forms. Mechanistic science's description of matter did not encompass what was available to observation and description, partly because the connection between life and time was a felt experience: "It was just that living things have been affected ... by historical processes .... The results of those processes are systems different in kind from any nonliving systems and almost incomparably more complicated" (Simpson in Mayr 35). Life-deposition and its maintenance, once considered either an occasional intervention or an infusion outside of time, was after midcentury regularly conceived of as an historical event and a capacity of life. No longer outside of history, the beginnings of life could and would be studied like any other phenomenon in nature. Reality looked less like a ladder spanning to perfection and more and more like a net spread on an ever-moving sea. 


\section{CHAPTER IV}

\section{SCHILLER AND LATE EIGHTEENTH-CENTURY VITALISM}

From mid-century, living nature was increasingly described as a complicated, balanced system of complexly organized individuals with singular capacities for reproduction, self-development and self-sustenance. In the last part of the century, an understanding had developed about life: living organisms were reciprocally affecting, not only in a spatial economy, but in a historical one. Each individual was not only complexly-organized, self-developing and directing, but each was an instantiation of forces within matter, unique in history.

Fueled by accumulating data and opinion, the acrimonious classification controversy and the dispute about generation continued throughout the period. Many with concerns about classification focused on the human species, on the question of the unity and varieties of mankind, while other researchers provoked new interest in the generation controversy and in epigenesis as the development of life from unformed matter. With contributions of Maupertuis and Buffon as ground, with Haller's work near to hand, a new generation of natural historians in Germany, working as embryologists, marshaled evidence favoring epigenesis. This ascendency of epigenetic theory made not only spontaneous generation a distasteful logical necessity but it also made a postulate of something within matter to begin, guide and promote the development of new life. This something was a force-in-matter. Throughout the rest of the century, the possibility of 
forces in matter was explored repeatedly and understood variously by both natural historians, like Caspar Friedrich Wolff and Johann Friedrich Blumenbach, and physicians, like Théophile Bordeu and Jean Barthez of Montpellier as well as Marcus Herz and Johann Christian Reil in Germany. ${ }^{1}$ It was within this active environment of research, publication and discussion that Schiller hypothesized about play as a speciesspecific force [Spieltrieb] rising from the interaction of two originating polar forces (the material- or sense-drive and the form-drive).

The interest in epigenesis (which put origins within time) and the efforts to apply the species concept to humanity combined with an expanded experience of history itself to provoke Jean Jacques Rousseau and Johann Gottfried Herder to projects of developmental human history. Schiller, emulating and amending their accounts, wrote into the Aesthetic Letters a history of man as developed through play and beauty.

All these advances in the study of life took place within the context of a broad field of competing positions, from animism through vitalism to materialism. In Germany, particularly, the fertile natural philosophical ground was a vitalistic one.

\section{Vitalism?}

The true essence of nature is not to be sought in the realm of the created (natura naturata), but in that of the creative process (natura naturans). Nature is more than mere creation ... the dualism between creator and creation is thus abolished. Nature as that which is moved is no longer set over against the divine mover; it is now an original formative principle which moves from within (Cassirer 40-41).

"Vitalism" is a word like "play," freighted with historical meanings that are not value-neutral. Just as "play" in both English and German culture is an example of a

'Blumenbach's insight into the developmental force [Bildungstrieb] included yet another appearance by the polyp and Trembley's experimental techniques. See page 146. 
concept which popular understanding has captured, "vitalism" is a designation in biology that is laden with historical meanings and connotative values. A problem of language use became a complicated hermeneutic problem: the term "vitalist" was used as a designation for some ancient theories of life, for characterizing the philosophical positions of many early modern physicians and natural philosophers as well as some nineteenth- and twentieth-century biologists; it pooled everyone who "felt that a living organism had some sort of constituent that distinguished it from inert matter. These people were customarily lumped together ... even though ... they held widely differing views of what that constituent might be" (Mayr, Toward 9-10). ${ }^{2}$ The difficulty in nuce was this: the terms "vitalism" and "vitalist" have been applied to a broad range of positions, persons and theories, some of which could profitably be distinguished from one another.

The meaning of the concept, "vitalism," depends on two parameters, the period under discussion and the time period of the commentary. Francois Duchesneau (1985), seeking "an exact and limited meaning of "vitalism"' in order to situate some vitalists of the Enlightenment, referred the problem to a split that occurred after the turn of the century. At that time, an anti-reductionist trend (Naturphilosophie) became identified as vitalism, and the physiology of the nineteenth century - one that reacted violently against Naturphilosophie and defined itself in opposition to it - gained approbation as science, as the legitimate science. ${ }^{3}$ This "standard dual model," vitalism vs. reductionism, was then

${ }^{2}$ For example, Harvey, the discoverer of the heart's action and circulation was labeled a "vitalist" in some texts (e.g. Westfall); and in the twentieth century, vitalism emerged in new forms - in Bergson's philosophical system and in organismic biology (Hein).

${ }^{3}$ I have included the publication dates for many of the articles and books that follow because they evidence a watershed and a change in perception of the past. Roger's sense 109 
applied to other historical periods. For this reason, Duchesneau wrote, "connotations of 'vitalism' should be spelt [out] into a variety of meanings according to the historical period and to the specific blend of methodological principles and ontological presuppositions involved in the historically situated theories" (259-60).

For much of the modern period - and that included the eighteenth century - vitalists were not considered scientific: painted with a broad brush, they were the ones that postulated something extra for life. Commenting on this trend, Ernst Mayr wrote in 1985 that vitalism had become "so disreputable a belief in the last fifty years that no biologist alive today would want to be classified as a vitalist" (Toward 13). On that account, when he sought to define a legitimate scientific tradition of life studies in the eighteenth century, Peter Hanns Reill took himself somewhat to task for choosing to name it "Enlightenment vitalism" (Vitalizing (2005) 9). Others had felt the need to explain the terms they coined, like "teleomechanism," "vital materialism" or "vital mechanism," all in an effort to avoid the same pejorative associations. ${ }^{4}$ In short, all who have attempted

was that "biology did not appear suddenly at the end of the eighteenth century, as Athena sprang from Zeus's forehead;" it had antecedents and one of those important antecedents was the eighteenth-century vitalist tradition (Rousseau 277). After 1980, many science historians focusing on the eighteenth century researched natural philosophers and natural historians who, because of their 'vitalist' inclinations, had not been considered in the scientific mainstream. They had no status as precursors of the modern life sciences.

${ }^{4}$ Reill suggested his revision as early as 1995 in "Anthropology" and used it in a number of his publications up to and including Vitalizing Nature in the Enlightenment (2005). Others carving out parts of vitalism for science with the above terms include Lenoir, Larson, Roger and Vartanian, for example. 
to explore the middle ground between materialism and animism needed to manage ideology and connotation by qualifying their terms. ${ }^{5}$

Beyond the general devaluation, there was a problem with "vitalism," its specificity, its power to designate particular content. So Reill, as noted above, followed the custom of classifiers; he used "vitalism" as a genus and he added "Enlightenment" as a species designation, fully aware that there were varieties. ${ }^{6}$ He believed the use of "vitalism" as a mediating term between animism and materialism began with Dumas' history of physiology (1807) and credited the mid-century ferment, the popularizers and the researchers, the natural philosophers and historians, with its generation (295-6 fn 6). Within the enlarged middle between animism and materialism, some of those vitalists merged toward animism, seeking a non-material addition to life, a spirit or an essence;

\footnotetext{
${ }^{5}$ Using technical words with ideological uses and connotative or emotive qualities is seen as a problem for translators, but it is also a problem of word use in the history of science and the history of ideas (Love).

${ }^{6}$ On taxonomy and the division of knowledge: "Living forms - their production, growth, organization, modifications, characters, affinities, and distributions - were the central concern of natural history and physiology throughout the century. The sciences of living form included two branches of taxonomy: the primary divisions of the plant and animal kingdoms and the study of species and their modifications. A separate but related inquiry studied the organization of the living world as a whole, the distribution of natural forms. These sciences, separate divisions of natural history, took the Gestalt of living forms as their point of departure. The science of formation, Bildung, was part of physiology and studied the principles and mechanisms of organic generation. Naturalists and physiologists treated these inquiries as largely independent ..." (Larson, Interpreting 7). (Note that Bildung denoted physical before it referred to cultural development.) One of the innovations of the Linnaean classification was the general use of binominal nomenclature, the combination of a genus name and another term: the two together uniquely identify each species of organism. Research on cultural naming and folk taxonomies found that reliance on two names for accuracy is extremely common (See Carol Kaesuk Yoon, "Reviving the Lost Art of Naming the World," New York Times Science Section, August 10, 2009).
} 
others aligned toward materialism, simply seeking an enlargement of the concept of

matter, an extension that would include components, functions or organizations

characteristic only of living forms. Many sought in this broad space an opportunity to

explore solutions to the problem of life by using the hypothetico-deductive method: in

that research force acted as a sort of placeholder until an epistemological or technological

breakthrough carved away part of the unknown. ${ }^{7}$

${ }^{7}$ With each development in vitalism, another history grows that presents the development of the idea of matter itself. There is then a sort of homeostasis, a maintenance of environment between the polarities of matter and the unknown (something more) as postulated by life scientists: what the vitalists are able to describe aptly by analogy is integrated into matter through technology over time; the analogy is then obsolete in terms of knowledge production for those who accept the new definition of matter. In general, the term "vitalism" has had a long history, a history of hypothesizing something more to the current understanding of matter. The following example illustrates that history, one where "vitalism" can be observed changing like Proteus. In his The Strategy of Life: Teleology and Mechanics in Nineteenth-Century German Biology, Timothy Lenoir began a short survey of vitalism with Stahl: "Vitalistic positions assume in some form or other the existence of an agent which actively selects and arranges matter in the organism," he wrote. "Some vitalist approaches assume furthermore that this agent, which may be a rational soul, can exist separately from matter and that the organism is in a healthy, functional state so long as the vital agent remains in control. Such a position was defended by Georg Ernst Stahl, for instance." This "vitalism" (more accurately designated animism, but described as Lenoir did above) and its practitioners complemented the Cartesian view of matter as defined by passivity, uniformity and extension in space. This position was the one that Haller marshaled his experimental evidence against. Lenoir continued, "A vitalistic position similar to this renounces the role of a rational, purposeful agent but continues to acknowledge special vital forces, such as sensibility and irritability. These forces are characterized as the organic analogues of Newtonian forces." Here Lenoir separated out the work of Haller (See Chapter III), an early vitalist who espoused an empirical epistemology. "This [type of vitalism's] 'scientific' status depended very much on the prevailing confusion in the characterization of Newtonian forces; for many capable scientists treated forces as active powers superimposed upon inert matter," he continued, positing the next development as an accidental movement away from the old epistemology to an idea of emergent forces. "This position was only slightly removed from one version of teleological argument ... [which restricted] the specific vital force [to dependence] upon the organization of the constituent elements of the organ exhibiting it. The force was not to be conceived [of] as some independent entity but rather as an emergent property dependent upon the specific 
Again, in the late twentieth century, the received wisdom around which historians circled was the position that natural philosophy (which included the popular spectator sports of electrical and magnetic demonstrations and phrenological mapping) along with its cultural hybrid, vitalism, was not really a part of the history of science. In his 1985 Messenger Lecture at Cornell University, delivered just as renewed interest in the order and arrangement of the components" (Strategy 9). Lenoir argued for the next transformation, one that included the work of Schiller's contemporaries, Reil and Blumenbach, as a "teleo-mechanist research program" he believed originated in Kant's philosophy of biology, one fundamentally different from Naturphilosophie. Caron called Lenoir's work a "major historical reconstruction, lending a new richness to our knowledge of German life sciences in the nineteenth century" (238); however, many came to feel that Lenoir incorrectly suggested that such a tradition started with metaphysics rather than with active natural historical and physiological research. Some thought as well that he had misjudged the impact Blumenbach and Kant had on one another. (Caneva, Huneman, Larson, Look, Richards ("Kant"), Sloan ("Performing"), Smith and Zammito "Genesis")). Lenoir to his great credit took the late eighteenthcentury and early nineteenth-century life science seriously, drawing attention and controversy to a neglected area. Another example of rehabilitation of a strand of the "vitalist" natural philosophy is found in the seminal work on Julien Ouffray de La Mettrie by Aram Vartanian (1960). He, recognizing the vitalist aspects of the argument in L'homme machine, categorized La Mettrie's project as follows: "His idea of the 'living machine,' defined hypothetically by its purposive self-motion, may thus be said to express a "vitalo-méchanisme à base dynamique." Vartanian appeared intent on distinguishing a type of vitalism, one specifically separate from the vitalism that at the time of his writing included what came to be identified as animism. "The biological philosophy implicit in this view of things cannot, properly speaking, be classed as either mechanistic or vitalistic [i.e. now animistic] in a restrictive sense, for it really represents an attempt to combine those two traditionally opposed attitudes into a unified standpoint. La Mettrie has by no means neglected the specifically vital characteristics of the organism; but at the same time he remains entirely convinced that these are knowable to science only insofar as they are seen sub specie machinae" (La Mettrie's 20). Vartanian placed La Mettrie with Haller in the early phase of an emerging vitalism. Just as Lenoir's distinctions tease out a "teleo-mechanism" within vitalism in an effort to legitimize eighteenth-century science to a twentieth century epistemology based on the physical sciences, others - using appellations like "vital materialism" - also tried to bypass vitalist difficulties, letting compounds do the work of agency, of life/form causality. As will be evident, this idea of forces emergent from the organization of matter was but one of the positions regarding forces represented in Enlightenment vitalism. 
vitalism of the Enlightenment was beginning to produce a wave of publications, Ernst Mayr (1985) summarized the classical vitalist position as follows:

The classical vitalist ascribed life to the organism's possession of a tangible thing, a real object, whether called a vital fluid, life force, or Entelechie. He believed that this vital force was outside the realm of physico-chemical laws; in fact, it had a rather metaphysical flavor in the writings of some vitalists. All attempts to substantiate the existence of this force failed, and the need for it became obsolete when the phenomena it had tried to explain were eventually accounted for by other means, for example, the genetic program.

Other vitalists, he added, "rejected the idea that [the force mentioned above] was a nonmaterial force; rather, they view life as an organizational property of certain material systems" (Toward 12-13). In the years that followed, these latter efforts - expressed analogically - provoked comparison to the mid-twentieth century discovery of DNA in terms of function and properties, and Kant's interpretation of Blumenbach's Bildungstrieb as an "as if" [als $o b]$ construction was seen by some to bridge the gap between vitalism and genetics. ${ }^{8}$ Of the developmental force [Bildungstrieb], Blumenbach himself wrote with epistemological delicacy (perhaps intended to appeal to Kant) that it, "like names applied to every other kind of vital power, of itself, explains nothing: it serves merely to designate a peculiar power formed by the combination of the mechanical principle with that which is susceptible of modification." In terms of time, Blumenbach and Kant were at the heart of the Enlightenment vitalism that Reill carved out between

${ }^{8}$ The reciprocal relationship of Kant's and Blumenbach's theories and the (mis)understanding between two men is the subject of considerable controversy, cf. Richards "Kant," Lenoir, and Reill (Vitalizing 304-5n28). See page 195 fn 30.

${ }^{9}$ Blumenbach as qtd. in Helmut Müller-Sievers 43. Blumenbach: "Vital forces are merely terms given to effects known a posteriori, such as Nisus formativus [Bildungstrieb]" (Larson, Interpreting 164). 
Newtonian mechanism and Naturphilosophie; they also were basic to the teleo-mechanic research program that Lenoir described, as well as the vitalistic mentality that Roger identified as in need of investigation. And they were also a part of the tradition which, according to Robert Richards, communicated to Darwin that experience of nature necessary for his theory of evolution by natural selection. And, as coupled in $\S 81$ of the Third Critique, they were part of Schiller's study before he wrote the Aesthetic Letters.

One of the great values of the vitalistic philosophy of Schiller's time, however, was its ambiguity, its capacity to be the holding environment of a contemplative "expanded middle." As a large, fractious and competitive group, the vitalistic natural philosophers and physicians worked with an indeterminacy that allowed research to progress in spite of the lack of technical capacity or community agreement. They sometimes misunderstood one another, yes, but they practiced by maintaining the unknowns in a milieu of epistemologic modesty. Whether the constituent associated with life were a substance, a force, an unknowable or yet-to-be discovered property of matter resulting from complex organization and boundary conditions or whether it be simply (!) a regulative idea necessary to human conceptualization of life, it was a subject of speculation rather than knowledge for the vitalistic natural philosophers and natural historians of the late Enlightenment. ${ }^{10}$

${ }^{10}$ Larson's article "Vital Forces" explored these options. History makes strange bedfellows in such a wide bed: researchers, medical practitioners, natural philosophers and historians identified as eighteenth-century vitalists (of various stripes by various historians and in various degrees of contention with one another) include Barthez, Bichat, Blumenbach, Bordeu, Buffon, Cullen, Diderot, Forster, Girtanner, Goethe, Haller, Herder, Herz, the Humboldts, Hume, Hunter, later Kant, Kielmeyer, Kölreuter, La Mettrie, Lavoisier, Maupertuis, Monro, Müller, the incipient Naturphilosophen, Needham, Pallas, Rousseau, Reil, Stahl, Caspar Wolff, Whytt and Schiller. The tradition 
As a participating historian, Roger (1980) described the new approach to the study of

the life sciences during the eighteenth century this way:

What interests us [now] . . . is the slow and complicated process which led from the Cartesian bio-mechanism and the Stahlian animism that prevailed at the beginning of the century, with all their metaphysical implications, to a vitalism that abandoned neither the mechanical nor the chemical explanations but recognized the originality of living beings and made possible a more phenomenological approach. As far as theories are concerned we may summarize that development by the sequence: Cartesian bio-mechanism, Newtonian biomechanism, and vitalism" (Rousseau 277 my emphasis).

Given the big tent of vitalism, Schiller was a vitalist. As Mayr summarized, the term can be "attached to anyone [in the eighteenth and nineteenth centuries] who did not accept the ... dogma that matter in motion is an adequate explanatory basis for all aspects of life, and that organisms are simply machines. [Again] all those ... were united in their belief that a living organism has some sort of constituent by which it can clearly be distinguished from inert matter" (Toward 12). Vitalism ascribed to living matter both a qualitatively and quantitatively different level of complexity than did mechanism, animism, or materialism. Mechanism and animism are dualist; materialism is monistic, and vitalism inhabited an expanded middle where its practitioners found "force" or "vital principle" variously single or multiple, from "additional to the soul and body" (Barthez) to inseparable from matter (Schiller, Blumenbach). ${ }^{11}$ As Reill explained, "Enlightenment

is traced to Leibniz through Maupertuis and Buffon, and includes Rousseau and Herder as philosophers with a deep commitment to natural history.

${ }^{11}$ It is helpful to keep in mind the current understanding of life and status of the various theories today. According to Mayr: by the 1930's "biologists almost universally rejected vitalism . . . . First because it virtually leaves the realm of science by falling back on an unknown and presumably unknowable factor, and second, because it became eventually possible to explain in physico-chemical terms all the phenomena which according to the 
vitalists sought to bridge or dissolve this dichotomy [force/matter; mind/body] by positing the existence in living matter of active or self-activating forces, that had a

vitalists 'demanded' a vitalistic explanation .... The rejection of vitalism was made possible by the simultaneous rejection of a crude 'animals are nothing but machines' conceptualization. Like Kant in his later years, most biologists realized that organisms are different from inanimate matter and that the difference had to be explained not by postulating a vital force but by modifying rather drastically the mechanistic theory. Such a theory begins by granting that there is nothing in the processes, functions and activities of living organisms that is in conflict with or outside of any of the laws of physics or chemistry. All biologists are thorough-going 'materialists' in the sense that they recognize no supernatural or immaterial forces, but only such that are physico-chemical. But they do not accept the naïve mechanistic explanation of the seventeenth century and disagree with the statement that animals are 'nothing but' machines [my emphasis]. Organismic biologists stress the fact that organisms have many characteristics that are without parallel in the world of inanimate objects. The explanatory equipment of the physical sciences is insufficient to explain complex living systems and, in particular, the interplay between historically acquired information and the responses of these genetic programs to the physical world" (Growth 52). In the late Enlightenment, however, "falling back on an unknown and presumably unknowable factor," i.e. holding to a modest view of what can be known and how it might be known, allowed for research to continue, allowed the "naïve mechanistic explanation of the seventeenth century," the impoverished view of matter, to be superseded and amended. According to the historical narratives about the science of the late eighteenth century fashioned after the publication of the Growth of Biological Thought, vitalistic hypotheses allowed the characterization of life processes to continue and very likely to contribute to Darwin's insight into evolution by natural selection. Mayr continued: "Attempts have been made again and again to define 'life.' These endeavors are rather futile since it is now quite clear that there is no special substance, object or force that can be identified with life. The process of living, however, can be defined [as follows, by paraphrase of Mayr] .... Living organisms possess certain attributes" including: complexity and organization, chemical uniqueness, qualitative (relational) phenomena, uniqueness and variability (individuality), genetic programming, historical nature, derivation by natural selection and indeterminacy (impossibility of temporal prediction due to great complexity and unexpected novelty (emergence) (53-59). Many of these attributes were empirically and intuitively grasped by Schiller and his contemporaries. In the late twentieth century, the mechanism/ vitalism controversy was addressed by Hilde Hein, who saw the dispute as a perennial one that actually pitted two non-rational perspective types against one another. Julius Elias found the practical Schiller making the same point about the impossibility of agreement on certain basic philosophical issues, i.e. because there are two basic personality types, the realist and idealist. It seemed Hein then followed Schiller (the German classical tradition) in her reasoning. 
teleological character. Living matter was seen as containing an immanent principle of self-movement or self-organization whose sources lay in active powers, which resided in matter itself" (Vitalizing 7 my emphasis).

\section{Vitalism in the Late Enlightenment: The Schillerian Mittelgrund}

Vitalism appeared very soon, that is, in the 1760's, in nearly all fields of research, and almost simultaneously in England, France and Germany. Unfortunately, we still have no comprehensive study of the phenomenon, whose importance was enormous, not only in the history of biology but in the general history of ideas as well (Jacques Roger (1980) in Rousseau 275).

Vitalism was a recognized position in the eighteenth century, but as a scientific tradition it had neither been described nor systematically explored until the late twentieth century. ${ }^{12}$ Then, historians of science began to turn their attention to the elaborating study of life, finding there, a coherent program, an autonomous tradition with all the hallmarks of science. According to Thomas Kuhn, such changes come about through novelties of fact and through inventions, novelties of theory:

Discovery commences with the awareness of anomaly, i.e. with the recognition that nature has somehow violated the paradigm-induced expectations that govern normal science. It then continues with a more or less extended exploration of the area of anomaly. And it closes only when the paradigm theory has been adjusted so that the anomalous has become the expected. Assimilating a new sort of fact demands a more than additive adjustment of theory, and until the adjustment is completed -

\footnotetext{
${ }^{12}$ Then, some of those scholars working in the Enlightenment period on individuals their careers and contributions - began writing with a broader view. Earlier in the twentieth century, while Arthur Lovejoy, through the history of an idea, and Bentley Glass, through tracing the beginnings of evolutionary theory in the eighteenth century, sought continuity in the life sciences, Jacques Roger, James L. Larson, Timothy Lenoir, Peter Hanns Reill, Phillip Sloan and many others focused on the life science tradition in the eighteenth and early nineteenth century and, finally, on vitalism itself. As mentioned earlier, Robert Richards also traced a lineage to Darwin from eighteenth-century vitalism and Naturphilosophie through Goethe.
} 
until the scientist has learned to see nature in a different way - the new fact is not quite a scientific fact at all (Structure 52-53).

"Until the scientist has learned to see nature in a different way - the new fact is not quite a scientific fact at all": the natural historians and philosophers of the time recognized life as an anomaly vis $\dot{a}$ vis the mechanical philosophy, and the historians of a later period in turn recognized their new approach to nature.

In his asșessments, Kuhn concentrated on language and representation of nature, an emphasis that served as a conduit between the science and the humanities. Adopting Kuhn's schema and building on a score of his own individual studies and the research efforts of many others, Peter Hanns Reill took as his task the description and characterization of a language of nature at the end of the eighteenth century. This tradition he named "Enlightenment vitalism," and from his perspective, it represented a scientific revolution according to Kuhn's own criteria. In the following, Kuhn's intuition the basic characteristics of scientific revolution, of the basic structure (Urtyp!) of paradigm change, is summarized. In Kuhn's view of paradigm change, changes cannot be made piecemeal: "In revolutionary change one must either live with incoherence or else revise a number of interrelated generalizations together." There are not therefore changes, but change, and change is holistic. Paradigm change involves a "change in the way words and phrases attach to nature." Not only do the words change (and "the criteria by which terms attach to nature") but the referents are different as well, "the set of objects or situations to which those terms attach." As a consequence, there is "a change in several of the taxonomic categories prerequisite to scientific description and generalization." This change requires either the creation new categories or the 
redistribution of objects/ideas into new categories (Kuhn "What" 18-21 my emphasis).

In all, the new paradigm provokes a "major change of metaphor, analogy, or model; that is, the basic juxtapositions one used to bring things together in a pattern of understanding and recognition were irredeemably transformed" (Reill Vitalizing 118 my emphasis).

Reill himself described Enlightenment vitalism as a scientific language of the late eighteenth century, the use of which began in the ferment at mid-century and culminated in the work of the Humboldt brothers. ${ }^{13}$ He argued that the natural philosophy relating to living matter developed into a coherent tradition, a paradigm, during the last half of the eighteenth century. As a "reanimation of nature" and a "naturalization of humanity," Enlightenment vitalism was for him a cultural system and a way of perceiving the world ("Anthropology" 245). And from his perspective and that of many contemporary

${ }^{13}$ Reill's work is a culmination of years of labor on a variety of individuals, including the Humboldts, Herder, Buffon, Goethe, and Schiller, and of scientific trends in the late Enlightenment. I found his organization of the material both invaluable and reassuring, as I had come to see Schiller's sources much as he described the tradition. Reill's understanding apparently evolved from his research into the change in historical consciousness during the Aufklärung, the German Enlightenment. He found that the Enlightenment historicism fostered, among other things, a concept of development and an idea of individuality. These, as dynamic transformations of Leibniz's idea of perfectibility and his theory of the monad, were part of a new intuitive and historicized experience of living organisms: for Reill, they became the wheels and track-bed for the sciences of life in the late eighteenth century (214). In many ways, Enlightenment vitalism functions as a deeply-felt defense of the value of the Enlightenment project: it captures the Counter or late Enlightenment for the period, as distinctly and incontrovertibly Enlightenment, rather than proto-Romantic or modern. Reill, who like Schiller is determined to save the enlightenment project, countered the "instruments taken directly from Foucault's toolbox," Foucault's characterization of the time by discipline, control, dehumanization and colonial exploitation with descriptive categories of Enlightenment vitalism. He proposed that harmony and free play trumped discipline, goal-directed development refined control, humanization displaced dehumanization and levels of reciprocal control in complex organization eclipsed colonial exploitation - in terms of serving our understanding of the period. In essence, his formulation described a late Enlightenment scientific correction (Vitalizing 4, 252-3). 
historians of science, those vitalists inhabited the middle ground between mechanism and animism, and they approached the unanswered questions about life with a lively, abiding interest and a keen sense that the known physico-chemical laws fell short of describing the phenomenon of life. They developed their knowledge based on a modest epistemology and a specific methodology. That vitalism's vocabulary and its worldview extended beyond its practitioners to the broader culture, yet that these extensions were limited to the particular time of the late Enlightenment, were profoundly important to its characterization.

A short but extremely fruitful program, Enlightenment vitalism was distinguished by its basic understanding of nature and individual organisms including man. As a tradition it organized around the description of the particular attributes of life. These recognized hallmarks of life were complex organization, a dynamic and harmonious structural balance in nature and in the individual, and in-dwelling forces that promoted, through reciprocal relations, the functions specific to life - self-creation, nutrition, sensitivity, irritability, generation and development. ${ }^{14}$ Implicit in this description is life's relation to time. For vitalists, life was change. Life was extension in time as history. And history as a consequence was reciprocally affected by vitalism: it became developmental, complexly organic - replete with forces, economies, types and special functions - and attained a potentially different epistemological status.

${ }^{14}$ Life forms not only self-sustained, self-created and developed; they degenerated, became ill and died as well. Part of defining life was distinguishing the state of death: because of the questions and the intellectual uncertainties about what makes an organism alive, there was a wave of angst about being taken for dead [Scheintod] and buried alive. Because of Jewish customs surrounding death required quick burial of the body, Moses Mendelssohn and Marcus Herz, in particular, were active in this controversy, counseling delay (Cf. Reill, Vitalizing 170-82). 
Late Enlightenment vitalism valued methods of discovery that included observation, experimentation, comparison, extension by analogy and determination through probability. It encompassed a way of thinking about life forms, their structure and function, that would provide more information in the following way: typically hypotheses defined a problem in terms of polarities and then carved out a third, ambiguous space, a complex issue identified by an unknown - be it a force, an energy, potentiality or substance - to hold the incompletely understood aspect of life, to allow observation, experimentation and comparison to continue.

Many of Enlightenment vitalists were academicians and independent scholars in the German states but, as the life science disciplines themselves had yet to be demarcated, many educated persons were familiar with, fascinated by and involved in a wide range of knowledge-developing and codifying activities related to living forms and human nature. Accessibility and active participation made the intermingling of ideas, their language and metaphor, inevitable. The light of the Enlightenment was "a sociable light. It was not the inner light of mystical vision, but rather the outer light of letters, lectures, treatises, memoirs, novels, journals and conversations" (Daston in Clark 497). ${ }^{15}$ The intercalation of philosophy (including natural philosophy) and art provoked hypotheses by creative analogy and discovery by technical innovation. Science was then part of the humanities, perhaps even a forward position. Until the beginning of the nineteenth century (yet long enough to create a tradition that would promote evolutionary biology), life science and

${ }^{15}$ Schwab: The modern "reader is surprised by the degree of compactness and intimacy of the lively universe that existed in Europe just before the vast mushrooming of population during the past two centuries. A very large percentage of the men of letters knew one another well enough to be great friends or to hate one another" (In d'Alembert, "Translator's Introduction," xiii.). 
the humanities were intimately connected in an expanded middle - and the physical sciences and the arts were the poles. Within, at the center of activity and interest, the emerging life science disciplines, the new way of "doing" history and the coalescing social sciences germinated and began to develop. And Schiller spanned this center: as physician, natural and political philosopher, aesthetician, playwright and poet, he both contributed to and exploited the breadth of knowledge available in his time.

Vitalism then was everywhere evidenced in intellectual culture. Art, philosophy, history and study of the life sciences all contributed reciprocally to the gradual intermingling of mechanical metaphors favored by the early Enlightenment with organic metaphors that would come to characterize the Romantic period. Mechanical metaphors, significantly, continued through vitalism and often had special functions. At first, one of those functions was to guard against the assumptions of animism. Words like "assemblage," "aggregation," or "sum," for example, might be used in building a description about an organism; they often signaled a rejection of "a single universal organizing principle, logos, soul, or spirit. Life was not, for Enlightenment vitalists, a uniform attribute of all the parts of the body" (Reill, Vitalizing 138). A second and more common use of mechanical imagery signaled an acceptance of the view that physical and chemical processes supported life: mechanical functions were the foundation upon which transformation by organization, complexity or generation occurred.

What made living organisms distinct - their complexity, their internal organization (within which operated a variety of reciprocally-interacting, hierarchical and coordinated systems that functioned harmoniously), their forces, their connection with the greater environment, their wholeness and function, growth and development - contributed to a 
growing organic metaphor system. This analogy encompassed not only life forms, but their parts, not only the human body but also the mind, its unity and creativity, and all its social and political products. At the time, such a system was reciprocal: physiologists, historians, philosophers and artists incorporated the theories and information about discoveries into their projects, adjusting for their own purposes. Facts became examples, old structures of meaning were atomized and then emerged like developing embryos, and old world-views burst like exoskeletons in the process of metamorphosis.

Human creations and productions were represented by metaphors and analogies from living nature. For Schiller, while the state (when functioning as it should) and art (when participating in our aesthetic Bildung) merited elaborate organic metaphors, the State had another function as well - it was also the objective, the empirically observable, stand-in for human nature:

Every individual human being, one may say, carries within him, potentially and prescriptively, an ideal man, the archetype of a human being .... This archetype, which is to be discerned more or less clearly in every individual, is represented by the State, the objective and, as it were, canonical form in which all the diversity of individual subjects strive to unite ..." (IV.2 my emphasis).

The state was, then, potentially a life-like entity in its own right and an appearance (more than an analogue) of human nature. As such it had a mechanical ground, basic functions that by necessity continue, and something more as well: layers of complexity, of balanced reciprocity and self-generated action associated with life. For the state then, basic services were mechanical just as in human nature; many instinctual or maintenance functions were natural and arbitrary. At the level of organic metaphor, the state provided for individual freedom and full potential, for aesthetic education and moral behavior. When it functioned fully, it performed transformatively in a manner the mechanical 
simply could not. It allowed for autonomous human functioning under reciprocal regulation of self and society (like organs and the body); it fostered the extensive development of the individual over and above his mere survival, and it encouraged the co-ordination of nature's necessities and moral duties. In short, it honored man "at last as an end in himself" (V.2). Likewise, the representation of the state reflected on human nature. Just as the state could create the circumstances that made individual development a more likely possibility, a fully functioning human being - if he thought for himself and acted as a citizen of the world [Selbstdenker; Weltbürger], if he applied himself to the problems of his age - might raise "himself from an individual into a representative of the species" (II.4).

"Imagine ... [how] man existing in time can coincide with man as Idea, and in consequence, just [how] the State can assert itself in individuals: [in one way,] ... the ideal man [would] suppress empirical man, and the State annul . . . individuals (IV.2). When things go wrong, the state might enforce a uniformity of function and behavior that disregarded the individual. Men would be pigeon-holed for the good of the whole; they would become their jobs and be limited to repetitive and reflexive existence. Likewise a man could martyr himself, limiting his being to a fragment of his potential. Particularly if a state were not dedicated to a reciprocal development of its parts, without the support of society and the capacity to manage and develop himself, "man [would end up being] at odds with himself in two ways: either as savage, when feeling predominates over principle; or as barbarian, when principle destroys feeling. The savage despises civilization, and acknowledges Nature as his sovereign mistress. The barbarian derides and dishonours Nature, but, more contemptible than the savage, as often as not continues 
to be the slave of his slave" (IV.6). ${ }^{16}$ Schiller saw savages and particularly contemporary barbarians behaving without consideration for the whole: they neglected the contributions each must make for society to function - i.e. they behaved like rogue or damaged organs, tissue and systems in an organism.

When Schiller introduced terms like the "complex machinery of State" (VI.6), he related those functions to the unconscious operations of life, the ones that sustained and maintained the organism. ${ }^{17}$ And, when survival was at stake, Schiller was extremely practical. The nuanced co-operative social powers came into play and could be counted on only after safety and security are assured. ${ }^{18}$ In the face of civil violence or catastrophe (like the aftermath of war, revolution, earthquake or tsunami, epidemic or famine - all of which could serve as examples in his century), there was danger of a failed state and of

${ }^{16}$ The passage continues introducing a third type, the cosmopolitan, who develops himself within society: "The man of Culture [gebildete Mensch], makes a friend of Nature, and honours her freedom whilst curbing only her caprice."

${ }^{17}$ In an Aristotelian system such functions would be provinces of the vegetative or animal souls. The rational soul of that system is infused with the organic imagery and is brought into matter as a force. Alternatively, the human anima became localized to the sensorium communis and, in turn, physiologized into the medullary brain mass with extension to the whole nervous system by Haller and others around mid-century. In a letter to Goethe, Schiller wrote about the dependency of humans on the elemental forces of nature: "How tied we are, for all our vaunted independence, to the forces of Nature! And of what avail is our will if Nature leaves us in the lurch? What I have been fruitlessly brooding over for the last five weeks has been released within me by a warm ray of sunshine within three days" (as qtd. W\&W xl).

${ }^{18}$ Schiller made this observation of play - that it only occurs in security and abundance, when basic needs are met. "It is true that Nature has given even to creatures without reason more than the bare necessities of existence, and shed a glimmer of freedom even into the darkness of animal life. When the lion is not gnawed by hunger ..." (XXVII.3). 
devolution to chaos. In such a situation, governments [Naturstaaten] must sustain

themselves at a mechanical or arbitrary level for the sake of all the individuals involved.

Can the State be blamed for having disregarded the dignity of human beings as long as it was still a question of ensuring their very existence? Or for having hastened to divide and unite by the [mechanical] forces of gravity and cohesion, while there could as yet be no thought of any [organic] formative principle from within? ... [F]or society, released from its controls, is falling back into the kingdom of the elements, instead of hastening upwards into the realm of organic life (V.4 the addition of [organic] and [mechanical] by Wilkinson \& Willoughby). ${ }^{19}$

Here Schiller depended on the mechanical for basic functions just as his contemporaries, the theorizing physicians and embryologists, did. When he used mechanical imagery in the example above and the one that follows, he underscored the difficulty of broad reform or any sudden change in government. ${ }^{20}$ In such a case, there was the imperative for continuous functioning: basic services must be provided. Like an organism, the state must maintain itself throughout change and development. The passage also implied that the development of the human being must be aesthetic, i.e. rise naturally out of the fabric of the self. The jarring inadequacy of mechanical repair (described below) to any historic

${ }^{19}$ Wilkinson and Willoughby added the clarifying words "mechanical" and "organic" to reiterate Schiller's polarizing language, "to bring out the implied contrast between the State conceived as mere physical mechanism and the State conceived as living organism. The forces of gravity and cohesion belong to the Newtonian world-picture of mechanical forces; the formative drive (nisus formativus was a term used by the contemporary biologist, Blumenbach) reflects the interest of the late eighteenth century in the newer sciences of living things" (229). The original German text: "Das er eilte, durch die Schwerkraft zu scheiden and durch die Kohäsionskraft zu binden, wo an die bildende noch nicht zu denken war? . . Die losgebendene Gesellschaft, anstatt aufwärts in das organische Leben zu eilen, fällt in das Elementarreich zurück."

${ }^{20}$ Schiller's contention was that Reason is not so reasonable when she seeks to institute a state of principles for one of forces. Before man "has had time to cleave unto the Law with the full force of his moral will, [Reason] would have drawn from under his feet the ladder of Nature" (III.3). 
institution carried Schiller's judgment. The self-maintenance of an organism was vastly to be preferred to a watch reduced to its parts, lying on a jeweler's bench:

When the craftsman has a time piece to repair, he can let its wheels run down; but the living clockwork of the State must be repaired while it is still striking, and it is a question of changing the revolving wheel while it still revolves (III.4).

When harmoniously dynamic, the entity's parts function as organs, semi-autonomous units in reciprocal communication with and subordinated to the purposes of the whole: for "just because the State is to be an organization formed by itself and for itself, it can only become a reality inasmuch as its parts have been tuned up to the idea of the whole" (IV.5). The solution for these ills, then, in the state and in the individual was a harmoniously-balanced equilibrium, the aesthetic state. Within such an environment, the parts and the whole were each other's means and ends. When and if the State would not only respect "the objective and generic character in its individual subjects; ... [but] also honour their subjective and specific character, and in extending the invisible realm of morals take[s] care not to depopulate the sensible realm of appearance" (IV.3), the individual(developing aesthetically) could become a self-correcting dynamic equilibrium of feeling and thinking, of sense and morality. Man then, in a situation of reciprocal development, might more easily weave an extensive (internal and external) space of personal freedom out of necessity and possibility. The situation mimicked a spiral in nature: "Wholeness of character must... be present in any people capable, and worthy, of exchanging a State of compulsion [Staat der Not] for a State of freedom" (IV.7).

Primitive wholes, according to Schiller, broke down; more complicated entities devolved grotesquely: they sickened and became disabled. They decayed and died. The 
organic problem of sickness, decay and death, for him, was a modern problem, again, a problem of complex societies and complex individuals. In the scheme of things, then, perhaps the ancient Greeks were to be envied in their dissolution. They (simple organisms that they were) were apt to disintegrate into mechanical parts. "It was scarcely to be expected that the simple organization of the early republics should have survived the simplicity of early manners and conditions," wrote Schiller, "but instead of rising to a higher form of organic existence it degenerated into a crude and clumsy mechanism" (VI.7).

When a modern state self-destructed, the result was a rotting mess (V.2), and Schiller's deep concern of course was with the fate of the French organism - and by extension, the rest of Europe. Because of modern fragmentation and the breakdown of the reciprocal relations in society, the European states were subject to decay, "to disintegrate into a state of primitive morality, in which public authority has become but one party more, to be hated and circumvented by those who make authority necessary, and only obeyed by such as are capable of doing without it" (VI.9). In a sort of Jeremiad, Schiller lamented the "repugnant spectacle of lethargy, and of depravation of character which offends the more because culture itself is its source .... As some philosophers say, 'The nobler a thing is, the more repulsive it is when it decays"'(V.5).

Schiller's Aesthetic Letters is full of both mechanical and organic metaphors that attest to the vitalistic ground. For his theory of human nature, Schiller also imported concepts and hypotheses into his text, complete with their natural historical and philosophical details (and their epistemological ambiguity). With them he constructed a representation of nature and a representation of human nature, of man placed firmly 
within nature itself. ${ }^{21}$ One of the most fruitful concepts for Schiller was force. The vitalistic theories of forces-in-matter, bespoke the unity of the psyche, of mind and body, and of the economy of Nature. Forces and drives were part of Schiller's objective reality and his subjective understanding of himself and others.

\section{Schiller and the Panoply of Vitalistic Forces}

Theories of forces in living organisms were abundant during Schiller's time. Natural historians, natural philosophers and metaphysicians, many of whom were experimenters themselves, had data at their disposal, results of efforts at analysis of the special problems of life. Their active interest in the capacity of organisms to reproduce, develop, grow, and self-sustain generated research work, theories, and publications about forces-inmatter. By their lights, forces appeared responsible for effects, for the functions of life, and these forces, whatever their ontological status, became the default explanatory concepts in vitalism.

In medicine and natural history, a number of forces were represented. Some were principles or emergents of organization within structures, powers of particular body systems like the nervous system, and others were drives or forces to solve the dilemma posed by epigenesis, life or developmental drives (whether for plants or animals). The first group of forces appeared to be the outcome of organizational complexity; these forces worked in reciprocal, hierarchal (sometimes co-operative, sometimes conflictual) dynamism, coordinating within tissues, organs and systems in bodies. Theories about

${ }^{21}$ The epistemology of vitalism will be addressed in Chapter V and the organic nature of works of art, specifically the Aesthetic Letters (as an organismic whole showing complexity of organization, polar structuring of rhetoric and conceptual content, and reciprocal relations with the environment, its readers), in Chapter VI. 
these forces emphasized the complex, dynamic interiority of organisms and designated boundaried complexity as a precondition of transformation or emergent entities.

Hypothetical forces specific to particular organ systems, particularly the nervous system, developed out of physiological and anatomical study. The site of the mind, the mind/body connection, and the actual mechanics of the animal capacity to relate to the environment through sensation had long been subjects of interest. During the eighteenth century the nervous system became the "bridge between the philosophical/psychological inquiry into the soul and nature of man and animals on the one hand, and the anatomical/physiological study of their structure and function on the other" (Figlio 178). For the vitalists, especially the physicians, that bridge became a habitation. An empirical experimental data base about nervous system anatomy and function (complete with theories about the precise action and involved constituents) had been established by Haller: he did not exactly locate the seat of the soul, but an anatomical sensorium communis, the medullary structures of the brain. ${ }^{22}$ The next generation of researchers, (and this group included the young medical student and Zwitterart Schiller), furthered the union of matter and force, moved mind more into matter in terms of psychosomatic medicine and struggled with the "the simple model" of sensation. This simple model, the impression theory, held that nervous fluid (force or some substance) reacted to mechanical impact by movement. The vibration or pressure was transmitted to the brain, where the "mind was a passive recipient of the powers of bodies to impress sensations

${ }^{22}$ For Haller and others, the soul was "present" to the sensorium; " "presence' was a common and suggestive way to specify the location and manner of interaction of the incommensurable substances which could neither be located in the same terms, nor affect each other" (Figlio 182). 
upon it" (195). For the philosophers of the late Enlightenment, the mechanical analogy was completely unsuitable as explanation of the various, active capacities of mind.

At the height of vitalism, in the scientific literature of German States, the word Geist most often indicated "mind," an undivided entity. Schiller used Geist frequently in the Aesthetic Letters (over seventy cognates): there, it entailed the whole human mind, the active aspect of mind, or an active spirit in an individual, people or time period.

Occasionally Schiller opposed it to the sense-drive as a part of human nature. Its use was closely related to the concept of freedom. For example, in exploring the play of the imagination, Schiller wrote:

From this play of freely associated ideas, which is still of a wholly material kind, and to be explained by purely natural laws, the imagination, in its attempt at free form, finally makes the leap to aesthetic play. A leap it must be called, since a completely new power now goes into action; for here, for the first time, mind [Geist] takes a hand as lawgiver in the operations of blind instinct... (XXVII.4).

"Soul" [Seele], by comparison, Schiller used only a half dozen times and in every case, it connoted passivity, an aesthetic whole with all its relational emotionality. ${ }^{23}$

As the sensorium communis, Geist became a part of nature, referencing the anatomical nervous system's central structures. These terms came to be understood phenomenologically, as a way of representing experience: the mind was not known empirically, but it was known subjectively and intersubjectively. What was not known

23 "Hence the abstract thinker very often has a cold heart, since he dissects his impressions, and impressions can move the soul [Seele] only as long as they remain whole" (VI.10). "But not everyone whose soul [Seele] glows with this ideal was granted either the creative tranquility or the spirit [Sinn] of long patience required ..." (IX.6), and "[r]eleased from its dark bondage, the eye, less troubled now by passion, can apprehend the form of the beloved; soul [Seele] looks deep into soul [Seele], and out of a selfish exchange of lust there grows a generous interchange of affection" (XXVII.7). 
(perhaps, what could never be known precisely), however, many still considered a province of the study of nature. "By the end of the eighteenth century," summarized Karl Figlio, "the nervous system had become not just the transmitter of external reality to the place of the mind, but a physiological common substrate in which the union of mind and body was accomplished" (190-191).

The other type of force was a postulate demanded by epigenesis. Given pure epigenesis, something had to do the organizing of unformed matter (or something, the explaining about organic developing from inorganic precursors). Such a force must have organizing power, the capacity to transform elements into structure in space and to develop rudiments to wholes in stages in time. It functioned as if it were an agent of planned change. ${ }^{24}$

The site of Schiller's theory about human nature was the nervous system. Schiller's description of his originating drives (the material-drive and the form-drive) followed the paradigm of interacting forces even as it participated in the type of a developmental drive. His material-drive [Stofftrieb] and form-drive [Formtrieb], as polar drives, perhaps both in sympathy and synergy, as reciprocally coordinated and organized, combined and

\footnotetext{
${ }^{24}$ Not only are the forces themselves many and varied, but their ontological nature is inconstant: whether they are constructs, descriptors of relations, regulative principles, entities or placeholders has been difficult to distinguish; often like Schiller who used words in any number of ways to stress their different connotations, authors themselves seemed to drift and readers throughout history have misjudged meaning repeatedly. Richards suggested and it is now generally accepted that Kant's commendation of Blumenbach on his conception of developmental force [Bildungstrieb] and Blumenbach's acceptance of the compliment were based on mutual misunderstanding (Richards ("Kant and Blumenbach"), Huneman (Intro) and Smith). How this new nature is to be known and if it can be completely known are deeply concerning to those who hypothesize forces. The developing and open-ended epistemology of vitalism is represented in Chapter V.
} 
promoted a higher third function, the play drive [Spieltrieb]. But, in this case, form took on matter and developed it as well. The play drive also functioned as a developmental drive, the second type, and not only of the individual's potential (himself) but also of human products and productions, of the species and of itself, continuously renewing and developing in the individual and throughout cultural history. Schiller's theory of human nature flowed naturally out of this cultural hypothesizing tendency: his Aesthetic Letters, published in the protected environment of (and following the intentions he outlined for) the Horen, imported both empirical research and speculation about these forces into literature.

Schiller had access to the natural history, natural philosophy and medicine of his time and he had an array of forces from which to choose. Research and hypotheses were available to him through his experience in medicine, but they were also available to the public through abstracts. He was deeply immersed in Kant, whose philosophical arguments were filled with examples of and allusions to both Newtonian science and the new life studies. He was well-versed in Rousseau who followed Buffon and the Encyclopédistes, and finally he had the company of Herder and Goethe. Well-known at the time was the work of physicians Théophile Bordeu and Paul-Joseph Barthez of Montpellier, who emphasized the place of forces in the organization of living beings, and the theories of Marcus Herz and Johann-Christian Reil, also physicians, who focused on the nervous system and tried to work within Kant's epistemology with the concept of force in the mind. The studies of natural historians, Caspar Friedrich Wolff and Johann Friedrich Blumenbach, who posited developmental forces made logically necessary by the current theory of epigenesis, were a source of German pride. 
The following short vignettes are intended to show the variety of thought and research about forces and the growing commitment to naturalism. They are examples of problems that attracted researchers and consumed the attention of the Enlightened public (particularly interested Germans [Aufklärunger]). They are an effort to explain what was learned through painstaking observation and experiment and what sort of clinical observations and practice promoted theory. They also attempt to speak to the variety of ideas about forces in play as well as to the many individual concerns about those ideas' real relation to data each researcher had collected. These exemplary men grappled with problems without the theory and technology that would finally lead to their simplification. Schiller posed the same problems to himself: he imported forces from contemporary theories of life or the mind and struggled with epistemological issues, ones Kant attempted to clarify.

\section{Forces from the Medical and Natural History Traditions: Source-Drives for Schiller's Human Nature}

Educated at Montpellier, Théophile Bordeu (1722-1776) spent a decade in the further study of anatomy and physiology and in clinical hospital practice before settling in Paris, where he attended the powerful, including King Louis XV in his last illness. A friend of the Encyclopédistes, Bordeu was immortalized as the physician character in Diderot's D'Alembert's Dream [Le Reve D'Alembert $]$ and in medicine as the father of

endocrinology. ${ }^{25}$ Another portrait of him, written by a clinician more recently, described

${ }^{25}$ This work has a scofflaw's amazing history of reverses and recoveries: written around 1769 , it was denounced by one of its characters, thrown into the fire, poorly reconstructed, found in copy, rehabilitated, hidden, spirited to Russia, stolen and in copy 
him as the possessor "of a high degree of [of] Intuition, that faculty more artistic than scientific, which in Medicine consists in seeing the patient from the inside, in assessing rapidly his total personality, physical and mental and thus ... understanding the whole ... because patients are not Hearts or Stomachs but are human problems" (Cawadias 95).

His publications show a synthetic approach to illnesswith emphasis on the integrated organization of nervous and endocrine systems. ${ }^{26}$ He wrote:

We are led to believe that every organ has an impulse coming from the brain, which itself is so constituted that its different parts have different functions and corresponding nerves, so that what takes place in the organs is but the effect and image of what first occurs in the brain. In a word, we believe that functions first begin in the brain, which is divided into as many compartments as there are organs .... [And each] of the organs serves as a factory and laboratory of a specific humor .... Every organ sends ... continuous emanations and thus the blood caries in its torrent extracts of all organs, which are indispensable for life as a whole ... (Bordeu qtd. by Cawadias 95-96).

The mind, as an aspect of the nervous system, was included in Bordeu's emphasis on interrelationship of body organs. Bordeu was a practitioner of psychosomatic medicine; he understood health as a working connection between mind and body, and illness as a disordered relation. This approach characterized by his principles of constitutional medicine: first, he held that the whole human being was affected in health and disease. The body is a whole and acts as a whole; disease, as a psychosomatic reaction, affects the whole body, including the mind. The second principle concerned the etiology of

sent to Paris, and there published in 1830 (Preface, 89-91). Diderot introduced Bordeu's concept of force-as-sensibility into the Encyclopédie in 1765 (Haigh 40).

${ }^{26}$ Among others, Recherches anatomiques sur la position des glandes et sur leur action (1751) and Recherches sur quelques points d'histoire de la medecine (1764) had wide circulation. 
disfunction: disease, he felt, is a combination of environmental and individual constitutional factors. Third, he recognized a principle of natural healing powers. Cure was based on the natural, self-regulating power of the organism and its efforts to restore its own balance (Cawadias 97). Bordeu approached the human being as an individual, a sensible being, and while taking into consideration the environment, centered attention on the man's organic interior.

As a theoretician, Bordeu was committed to protecting two frontiers, the autonomy of vital phenomena over and against the soul and the "autonomy of vital phenomena vis à vis mechanical phenomena." In his presentations and writing, he intended to elaborate "a pattern of organic matter [of "ceaseless reciprocal interaction ... in complex dynamism"] that would explain the nature and the different aspects of life in reliable and verifiable terms" (Moravia, "From Homme" 52-54). From his research on the nervous system, he hypothesized that the whole body had a sensorium for which the brain was responsible but that the organs of the body, including the glands, had their own functions which were relatively autonomous and unconscious. ${ }^{27}$ Though the brain with the nervous system constituted the residence of the vital force, Bordeu considered that, as consciousness, it was not in a position of control like a monarch. His vitalism was a "federation of organs" (Moravia 56).

\footnotetext{
${ }^{27}$ According to Moravia, Bordeu's empiricism was based on Hippocratic experimentalism, as well as on Bacon and Locke (51). The soul in his system was restricted to a rational and conscious physiological role, and automatic functions were dependent upon another "vital sensibility," a sort of dual control, one external to matter (the soul) and the other somehow part of living matter. (Haigh 38).
} 
Schiller used this theory of organization in a republican metaphor in his final letter.

There, he described the autonomy of the imagination but placed it within the organization of nature, independent but subordinate.

Like the bodily organs in man, his imagination, too, has its free movement and its material play, an activity in which, without any reference to form, it simply delights in its own absolute and unfettered power. Inasmuch as form does not yet enter this fantasy play at all, its whole charm residing in the free association of images, such play - although the prerogative of man alone - belongs merely to his animal life . . is still of a totally material kind, and to be explained by purely natural laws ... (XXVII.4 my emphasis). ${ }^{28}$

Paul-Joseph Barthez (1734-1806) was an extraordinarily active polymath. A physician and physiologist of Montpellier and later conservative aesthetician, he contributed to the Encyclopédie, authored Nouveaux éléments de la science de l'homme (1778) and was considered the originator of the "principal model of French vitalism" (Reich 16). In his research, he focused on describing the variety of interactions he thought were orchestrated by a governing vital principle. This explanatory principle coordinated the actions of different organs and systems of the body. Regarding

all functions of the animal oecomony, [he wrote] certain conditions prevent their being resolved into mere mechanical or chemical phenomena, as well as their being explained by simple vital reaction .... $[$ A]ctions composing those functions are continually directed by a higherorder cause which links, coordinates, adjusts them to an end, and induces on organs modifications needed to adapt them at all times to the actually required mode of action (Barthez qtd. in Duchesneau 261).

\footnotetext{
${ }^{28}$ Reil (see page 144) like Bordeu used republican metaphors: "The animal body is like a large republic, which consists of many parts. These parts, of course, stand in a determinate relationship with one another and they contribute to the maintenance of the whole. But each part operates through its own force and possesses its own perfections, deficiencies, and failures independently of the other branches of the body" (qtd. in Richards, "Rhapsodies" 710).
} 
Given that the vital principle is responsible for the "autonomous correlation of the motive and sensitive forces [that constitute] the genuine dynamic unity of the living body," Barthez focused particularly on relations among the functions governed by the principle. These he termed sympathies and synergies (Duchesneau 263). Synergies promoted organismic stability (keeping up the normal activities of life), while sympathetic reactions were responses to environmental challenges (like stress) and were by their nature episodic and idiosyncratic. Barthez identified the latter complexly interactive response-forces as productive of new perspectives into the animal economy. Based on his observations, taken from the standpoint of past, present and potential states, the organism proved to be a dynamic, responsive unit both with respect to the external environment and within itself. ${ }^{29}$

From his medical school days, Schiller believed in the reciprocal action of mind and body, a stance reflected not only in the tradition of Montpellier but carried forward in Germany as well. Intensely interested in psychosomatic medicine, Schiller was committed to a united psyche. He was sensitive to polarities and conflicts and often expressed himself dualistically; nevertheless, he was, according to Wilkinson and Willoughby, impelled to seek and represent a "wholeness of personality, conceived as a changing pattern of behavior in time." They warned that "to dismiss him as a Kantian dualist has been a recurrent failing of Schiller scholarship: it has obscured his life-long inclination to think of the psyche as an organic unity" (xxx). For him, the human

${ }^{29}$ For the physicians of Montpellier, the autonomy of the individual was paramount: "free individual agency characterizes alike the vital actions in living beings, the unique liberties of the human soul, and the cultures in which mankind creates itself" (Reich 21). 
personality was not to be understood "in terms of simple antithesis, common enough in his day, between a mechanical 'aggregate of elements' and a living 'organized whole' not even with the added rider "in which part and whole are reciprocally means and end." The whole person was one of the "living forms," where interacting forces of mind, in a real body functioning in a real environment, displayed characteristics of "imbalance, asymmetry, dominant principle and hierarchical subordination" and participated in the unstable harmony of transformation through the synthesizing play drive (W\&W lxxxiv).

In health, Schiller saw harmonious function; in disease he saw derangement by force in both directions, either through ideas affecting the function of the body (e.g., Grammont's melancholia and his religious enthusiasm [Schwärmerei]) or through bodily illness (e.g., infectious fever) affecting mental capacities. He envisioned his program of education through beauty as a prescription for bringing the independent reciprocal forces into a dynamic balance. In the medical sense, then, Schiller's cure for man's divided state is his capacity to play, to approach the beautiful (Dewhurst, 354).

Marcus Herz (1747-1803) - physician, philosopher and correspondent of Kant and friend of Mendelssohn - was extremely influential through his medical practice and his interest in Kantian philosophy. He practiced out of the Jewish hospital in Berlin and gave informal lectures to the community on medicine, experimental physics and Kantian ideas. Particularly interested in teaching from and applying the First Critique, he, in addition to his other occupations, oversaw the details of publication and distribution for Kant.

Herz was also quite influential through the social milieu of his wife's salon. Henriette Lemos Herz' salon brought Jews and women into the mix with Lessing and other older literary figures and scientists, with Johann Christian Reil, Goethe, the 
Humboldts, Schlegel and Schleiermacher among others. Because of the difference in age, temperament and preferences of Herz and his young wife, the salon, as a gathering of overlapping circles of influence and acquaintance, was itself a "metaphor for the transition from Aufklärung to romanticism." (Hansen "From Enlightenment" 43, passim).

In his own work and like Schiller, he focused on the relationship of the mind, the emotions and the body, approaching this interest from his background in clinical medicine and physiology. Efforts to apply Kantian categories to medical problems left him in a state of contradiction; as a philosopher he could not justify positing hypothetical nervous fluid, but as a "theoretically inclined physician, he could not do without [it]." $\mathrm{He}$ was "forced to postulate the existence of a nervous fluid that travels through the nerves to the brain, ... which is the 'heart' of the system, the origin and final destination of all the nerves, [and] the source of the living force [Lebenskraft] that maintains the constant motion of the nervous fluid through all parts of the body" (Hansen, "From Enlightenment" 49,48$).{ }^{30}$ For Herz, the brain was the place of meeting for mind and body, and the Lebenskraft, which can be stimulated mentally by ideas or physically by sensation or motion, the regulator of nervous fluid. On a clinical level, disturbances in Lebenskraft were the cause of symptoms of mental illness; in this Herz was one of the first to associate boredom with pathology (55). In 1791, Herz also hypothesized "material ideas," organic (yet at once composites of real and ideal) substances that

${ }^{30}$ Schiller used Lebenskraft in the Aesthetic Letters as a synonym for the sense-drive: "For there is, after all, a moment in which the life-impulse [Lebenskraft], just because the form-impulse $[$ Formtrieb] is not yet running counter to it, operates as nature and as necessity" (XX.3). In the late eighteenth century, life-force was used more generally to denote the vital capacity associated with a living body or in reference to Hallerian irritability of tissue (A. Humboldt in Reill Vitalizing 299 fn 79). Illness diminished and death finally destroyed Lebenskraft (171-182). 
functioned in the brain as intermediaries to mind. Further, for Herz, the mind itself was an active power, its ability to represent to itself things or ideas, the Vorstellungskraft. All other capacities were modifications or aspects of this single force, whether they be will, imagination or understanding. Herz held that the fundamental law of the human mind was that perception of perfection is identified with happiness. This, a familiar ground of German aesthetics, Herz further particularized: he suggested that certain relationships create liveliness and pleasure. These relationships included the perception of unity and diversity, similarity and contrast, order (harmony and symmetry) against disorder and, very importantly, causality (53).

Herz published his work (including the above considerations) in the professional literature, in essays about the causes of medical illness like vertigo or in the form of letters to physicians. Such a pattern of publication exemplified how very blurred "the lines between epistemological concepts, their psychological equivalents and their physiological embodiments" had become (57). ${ }^{31}$ Herz felt this situation very personally. In a letter to Kant, he shared a self-representation, one that resonated with Schiller's characterization of himself as a zitterart. $^{32}$

You see, dearest sir, that I am not entirely disloyal ... [but rather like] a deserter who still wears your uniform and who, while associating with

${ }^{31}$ Briefe an Ärzte $(1777,1785)$ and Versuch über den Schwindel $(1786,1791)$. The letter to Kant related to the publication of the latter; it is dated 27.viii.1786.

${ }^{32}$ See Chapter I, page 3. Schiller also expressed to Goethe (in a letter dated 16.x.1795) that he, in order to write philosophic poems, had "been forced to keep both these powers [of poetic imagination and philosophic abstraction] at full stretch, and only by a constant movement within himself been able to maintain the two heterogeneous elements 'in einer Art von Solution' [in a species of solution, an apparent chemical analogy]" (qtd. in W\&W 223). 
other[s], is still in your service .... I enjoy wandering around the border towns of both countries, philosophy and medicine, and it gives me joy when I can make arrangements for their common government. I think it would be a good thing if similar border areas between philosophy and its neighboring territories were diligently visited by philosophers as well as by people in practical studies and artists of all sorts. The one would avoid thereby the frequently valid charge of useless mediation, the others, that of empiricism (51). ${ }^{33}$

Johann-Christian Reil (1759-1813), professor at Halle and Berlin, personal physician to Goethe after 1802, psychiatrist, anatomist and physiologist, was an admirer of Schiller and Goethe who "began to intermix his lectures on therapy and diseases of the eye with poetry from Schiller and Goethe, so that the delicious fruits of his research were hidden among flowers" (Binder 1094). ${ }^{34}$ Known later in life (from 1802) for his shocking switch from the materialistic edge of vitalism to Naturphilosophie and for his creative but idiosyncratic theories about the causes and treatment of mental illness, he was in the late eighteenth century, committed to the work of moving medicine more in the direction of science. ${ }^{35}$ In an effort to advance medicine as a theoretical discipline

33 "There is only one way to unite the great branches of learning and end the culture wars. It is to view the boundary between the scientific and literary cultures not as a territorial line but as a broad and mostly unexplored terrain awaiting cooperative entry from both sides" (Wilson 137).

${ }^{34}$ Reil, according to Binder, was one of the first to recognize the need of physicians assistants or auxiliaries in areas of limited access. His legacy includes many named anatomical features and pathologies - several heart and brain structures, insula of Reil, Reil's band, ansa, triangle, sulcus and ribbon, and two pathological changes in the digits of the hand.

${ }^{35}$ He wrote Rhapsodies on the Application of Psychological Cures for the Mentally Ill [Rhapsodieen über die Anwendung der psychischen Curmethode auf Geisteszerrüttungen]. He was known for treatments that included the theatre and the tongue-in-cheek call for a cat piano, an instrument whose cat-yowl notes brought the mentally ill back to reality. Reil's conversion had some relation to his study of the gravid 
(over and above its practical clinical aspects), he published the first journal of physiology in Germany, Archiv fur die Physiologie (1795). In its first number, he critiqued the use of the concept of force which he limited to a regulative role:

Force $[$ Kraff $]$ is a subjective concept, the form according to which we think the connection between cause and effect. If it were possible for us to think clearly of each body as it is - simultaneously of the nature of its constituent elements and their connection, of their composition [Mischung] and structure [Form], then we would not find the concept of force necessary, a concept that produces so many erroneous conclusions (qtd. in Binder 1092).

Because he followed the essentially Newtonian epistemology of the First Critique, "Reil advanced a quite ... mechanistic conception of organic processes. The fundamental operations of assimilation, growth, and reproduction occurred by way of the elective attraction of external matter (in the form of food) to the right parts of an animal body and then to the chemical alteration of nutrient material to tissue through a kind of 'crystallization of animal matter."' This inorganic metaphor served "his fundamental assumption that organic life derived from basic chemical and physical forces," and it developed a life of its own in Naturphilosophie's opposing camp, nineteenth-century reductionist physiology (Richards 709).

Caspar Friedrich Wolff (1734-1794) served as a military physician before becoming an academic in Berlin and then St. Petersburg. Wolff's doctoral dissertation, Theoria generationis (1759), formed the platform for his lifelong research. In it, he proposed

the ability of plant and animal fluids to solidify, and a force, which he named the essential force [vis essentialis]. According to his system the

uterus, its remarkable capacity to be both means and end, i.e. a natural purpose (Richards, "Rhapsodies" 706-710, 728-731). 
origins and subsequent formation of the embryonic plant or animal are produced through the secretion of fluids which then solidify into structures .... As each part begins to solidify, it becomes 'organized,' acquiring vessels and vesicles, which are produced by the fluid to the new part .... What else but a force could cause this movement? 'It must be assumed [to exist],' Wolff contends, 'if plants and their nourishing liquids are supposed, which is confirmed through experience: This is sufficient for the present purpose, and it will be called by me the essential force of plants' (Roe, "Rationalism" 6-7).

In the case of animals, the flow is through the umbilical area, and the same force, the vis essentialis, "transform[s] inorganic matter into organic through the formation of vessel and cells" (Larson, "Vital" 240). Force plus unformed matter led to solidification of structures.

Wolff's remarkable work on the formation of chick embryo intestines was considered at once the crowning proof of epigenesis and the coup de grâce administered to eighteenth-century preformationism (Aulie 125). It was also an outstanding example of exacting and protracted observation and experimentation. Wolff, who "occupied himself with natural science and chiefly with observations on the procreation of animals, in which he was indefatigable," discovered by serial and sequential observations and dissections that the intestine was formed from a flat sheet of tissue. The folding of this flat structure into a tube was evidence of a development of a temporary part into a structurally complicated organ (Roe, "Rationalism"11). This painstakingly documented discovery answered the complaints by preformationists that observability in Wolff's system was existence. As a result of this discovery, Wolff could and did counter that it was not the "parts [that were] hidden because of their infinite smallness thereafter gradually emerging" as opponents had charged, but rather that, if generation by preformation came about through the enlargement of a miniscule whole, one "should not 
be able to see its constituent parts before one sees the complete structure" (10). "Time and cost were not spared" in his work and neither was logic (11). One of his former student's wrote of Wolff that he "lectured on logic better than it had perhaps ever been taught before, and used it with excellence in medicine, creating through it, as it were, a new spirit in his numerous listeners, so that they now could grasp and digest his other teachings more easily" (Mursinna qtd. in Roe 4-5).

Johann Friedrich Blumenbach (1752-1840) was a natural historian and philosopher, a comparative anatomist, embryologist and the father of anthropology. While he was still a very young man, his $\underline{\text { Uber den Bildungstrieb }}$ (an extension of some considerations from his dissertation, "On the Natural Varieties of Human Beings" (1775)) and his subsequently published Handbook of Natural History (1779) (which went to eleven editions) brought him immediate and sustained recognition. Originally not a partisan of epigenetic theory, he developed his life work on epigenesis with the energy and enthusiasm of a convert. He was but one more eighteenth-century naturalist affected by an encounter with the Hydra. While on vacation he, sitting beside a pond, noticed the little polyps; he collected and examined them and then repeated Trembley's classic experiments (Larson "Vital," Richards "Kant" 17-18), Such experimental activities provoked the following insight about all living things:

there exists in all living creatures, from men to maggots and from cedar trees to mold, a particular inborn, life-long active drive [Trieb]. This drive initially bestows on creatures their form, then preserves it, and, if they become injured, where possible restores their form. This is a drive (or tendency or effort, however you wish to call it) that is completely different from the common features of the body generally; it is also completely different from the other special forces [Kräften] of organized bodies in particular. It shows itself to be one of the first causes of all generation, nutrition and reproduction. In order to avoid all misunderstanding and to 
distinguish it from all other natural powers, I give it the name of Bildungstrieb (Nisus formativus). (qtd. by Richards "Kant" 18). ${ }^{36}$

In Blumenbach's explanatory system, this one drive, the Bildungstrieb, was responsible for generation, that is, it accounted for reproduction, maintenance and restoration together. ${ }^{37}$ It was also the source of all other necessary drives, vital forces that accounted for motion in tissues and the nervous system (vis cellulosa and vis muscularis, and vis propriae and vis nervea) (Larson "Vital" 238). After the late 1780's, possibly in light of Kant's critique of his work, Blumenbach identified the Bildungstrieb as a more explicitly teleo-mechanical principle, a combination of physic-chemical (mechanistic) explanation within a teleological framework (Richards, Duchesneau). As Blumenbach conceived it, Bildungstrieb was a force acting upon unformed matter that manifested a "comprehensive architectonic character: it directed the formation of anatomical structures and the operations of physiological processes of the organism so

\footnotetext{
${ }^{36}$ Lenoir suggested that Blumenbach's change of heart resulted from a consideration that the paternal contribution to a new organism had to be greater than simple agitation. Additionally, Blumenbach recognized that hybrids would be impossible in a preformationist world: not only had Kölreuter adequately proven the existence of fertile hybrid plants, but his own research of all varieties of mankind (as fertile) forced the same conclusion (Lenoir "Kant" 82).

${ }^{37}$ Later in 1798 , Blumenbach offered principles to assist readers in the interpretation of his system: 1) the name Bildungstrieb distinguished the developmental forces from all other orders of vital forces, and did not explain the cause of generation "since I believe that it is buried in the utmost darkness." It was a mere name imposed on an effect known a posteriori. 2) The drive was however more than a mere mechanical force, and 3) it consisted "in the conjunction of two explanatory principles on the nature of organic bodies, the physic-mechanical and the purely teleological (paraphrased from qtd. material in Duchesneau 271).
} 
that various parts would come into existence and function interactively to achieve the ends of the species" (Richards 19). ${ }^{38}$

Like many vitalists, Blumenbach was concerned about the epistemological status of hypothetical force, particularly his own:

I hope it will be superfluous to remind most readers that the word Bildungstrieb, like the words attraction, gravity, etc. should serve, no more and no less, to signify a power whose constant effect is recognized from experience and whose cause, like the causes of the aforementioned and the commonly recognize natural powers, is for us a qualitas occulta.

What Ovid said pertains to all of these forces - causa latet, vis est notissima [the cause is hidden, the force is well recognized]. The service rendered by a study of these forces is only that one can more carefully determine their effects and bring those effects into general laws (Blumenbach qtd. by Richards "Kant" 24).

In spite of his caveat, the Bildungstrieb often functioned in his system and for others as a real cause with a real effect. ${ }^{39}$

\footnotetext{
${ }^{38}$ Duchesneau also emphasized the architectonic, quoting Blumenbach: "In the first place, there needs have been an acting nisus formativus, before we can become certain enough of the very existence of the embryo. Almost immediately, in the jellylike body of the initial embryo contractility intervenes. Then, as soon as the muscular parts have been effected, irritability takes place in their very motive fibres. Then, in . . . organs [as well]. Finally, in man after birth there is beside those forces also sensitivity" ( $274 \mathrm{fn}$ ). Richards considered Blumenbach's concept of Bildungstrieb seminal for Herder who "frequently cited Blumenbach" and followed his reasoning about epigenesis: "one speaks improperly if one talks about a seed [Keim] that only unfolds, [wrote Herder] or of an epigenesis according to which limbs form by an external power. Bildung (genesis) is an effect of an inner force that forms the mass prepared by nature and in which it will be manifest" (Richards "Kant" 23 fn. 53).
}

${ }^{39}$ And Bildungstrieb found its place in the Aesthetic Letters: Schiller, concerned about the possibility that a man of feeling would act in response to political circumstances without consideration, wrote that "not everyone whose soul glows with this ideal was granted either the creative tranquility or the spirit of long patience required to imprint it upon the silent stone, or pour it into the sober mould of words, and so entrust it to the executory hands of time. Far too impetuous to proceed by such unobtrusive means, the divine impulse to form [gottische Bildungstrieb] often hurls itself directly upon present- 


\section{Polarity, Conflict and Resolution}

Another component of the concept of force in vitalism involved the perception of dynamic opposition and conflict. The appearance in nature may be one of balance, but that balance was often violently obtained. Herder, for example, believed in dynamic polarity. Such opposition was "spread throughout the whole world order. Everywhere two forces [are] set against one another which nonetheless must work together and in which only by the combined and appropriate influence of both emerges the higher reality of a wise order, development, organization, life" (Herder, quoted in Zammito 319). In the following example, taking as his ground Haller's description of the property of irritability (varying it a good bit for his own purposes) and Maupertuis' manner of presenting human sexuality in the context of natural history, Herder wrote about love as an irritation, a union of polar beings (the sexes), one that produces a third.

Finally, the deepest irritation, as it is the mightiest hunger and thirst: love! That two beings mate, feel themselves one in their need and yearning, that their shared stirring, the whole fount of organic forces, is reciprocally one and becomes a third in their shared image - what an effect of irritation in the whole living $\mathrm{I}$ of animal beings! Animals have still been able to mate without a head, just as a torn-out heart still beats on irritably for a long time. The deep abyss of all organic irritations and forces seems to be in reciprocal overflow; the spark of creation kindles and there comes into

day reality and upon the life of action..." (IX.6). In Letter XXVI.7, where he described the development of the play-drive, Schiller wrote: "And as soon as the play-drive begins to stir, with its pleasure in semblance, it will be followed by the shaping spirit of imitation [Bildungstrieb], which treats semblance as something autonomous." And again in XXVII.8: "In the midst of the fearful kingdom of forces, and in the midst of the sacred kingdom of laws, the aesthetic impulse to form [Bildungstrieb] is at work, unnoticed, on the building of a third joyous kingdom of play and of semblance...." In the three instances of Schiller's use, the artist's aesthetic impulse mimics the epigenetic Bildungstrieb: the artist (author) shapes unformed materials mentally in a manner that is not understood, but the results are known. The translators (1967) did not do justice to the word's contemporary significance in late Enlightenment natural history. 
being a new I, the mainspring of new sensations and irritations, a third heart beats (Trans. Forster 193). ${ }^{40}$

Schiller, who was very familiar with Herder, forged a model of the mind that combined two theoretical positions on force. The first, one of synthetic union and production of a transformational third, he introduced as follows: "Let there be a bond of union between the form-drive and the material drive; that is to say let there be a playdrive .... Let humanity exist ... [and] Let there be beauty" (XV.4) The second position, an intuition of polarity, allowed him to emphasize and elaborate on the conflict of forces. For Schiller, while human nature is a synthetic process of interacting feeling and reasoned judgment, of sense and reason, the original drives are polar forces reciprocally working toward transformation. Of these drives, he wrote:

At first sight nothing could seem more diametrically opposed than the tendencies of these two drives, the one pressing for change, the other for changelessness. And yet it is these two drives which, between them, exhaust our concept of humanity, and make a third fundamental drive which might possibly reconcile the two a completely unthinkable concept. How then, are we to restore the unity of human nature which seems to be utterly destroyed by this primary and radical opposition? (XIII.1)

According to Wilkinson and Willoughby, Schiller's emphasis on the conflicting polarities developed right out of his sense of himself; "the very violence with which Schiller tries to heal the dichotomy of modern man is further evidence of the reality of his own" division. They counted as one of the most important contributions to our understanding of human nature "his insight into the dynamic interplay - and interstrife - of opposing forces in the life of the psyche." And as Goethe scholars, they had only to compare the two friends to highlight the difference:

${ }^{40}$ See Chapter III, Haller and Trembley, pages 77 and 100. 
Goethe [they wrote] sees the collaboration of the faculties as mutual aid; all is interrelation and overlapping of function, as between members of a family ... needing each other, helping each other out, synthesizing, permeating .... For Schiller, a fruitful 'collaboration' is only to be achieved through hostile forces holding each other in check; all is antagonism and arrogation of authority, the maintenance of a strict watch over frontiers and the invocation of immutable laws against trespassers $(\mathrm{xxx})$.

In another comparison, they cited Schiller's view of the famous friendship as "a dramatic encounter between two diametrically opposed types, meeting each other exactly half-way, and modifying each other by exactly proportional concessions and approximation ..." $(\mathrm{xxx}){ }^{41}$

\section{From State of Nature to Developmental Stages in History}

"A history is a continuously moving statistics, a statistics is a halted history" (Schlözer as qtd. in Reill, "Buffon" 673).

The development of vitalism during the late eighteenth century was fostered by Time, time as a force, time as a current of thought, as a previously incompletely represented perception of the world. The intentional incorporation of history, the deliberate focus on the flowing stream instead of the configuration of the river, affected descriptions of organisms and provoked more dynamism in exploratory theories about living nature. This change was profoundly important to Schiller and to his argument in the Aesthetic Letters. As history itself began to move - to deepen, lengthening to cosmology, geological history, and archeology, and to broaden, overflowing with the addition of synchronic cultural perspectives and context to political chronicling, the early

\footnotetext{
${ }^{41}$ Goethe, they were quick to add, "saw it in terms of two different 'cycles of feeling, thought, and activity, which in part coincide, in part remain tangential'; it was for him not so much a question of altering the other as of bringing out the best that was in him, and warning him when he showed signs of becoming too one-sided" (xxx).
} 
eighteenth century state-of-nature tableau (an elaboration of Genesis) gave way to developmental histories. The meditations of Pope changed to the speculations of JeanJacques Rousseau; these in turn were antimonies against which Johann Gottfried Herder argued his developmental histories of mankind and language. Schiller's developmental narrative of humanity as the maturation of the play drive participated in this dynamic. He used its conventions and assumptions to raft his theory of human nature through the late Enlightenment intellectual rapids. ${ }^{42}$

Jean-Jacques Rousseau (1712-1778) was something of a vagabond autodidact before he came to public notice by winning the Prize of the Academy of Dijon (1750) with an essay on the pernicious effects of the sciences and arts on happiness and morality. ${ }^{43}$ In his Second Discourse (1755) he enlarged on his original themes by providing a developmental history of humanity, documentedly indebted to Buffon's

\footnotetext{
${ }^{42}$ These developmental histories had the same hypothetical quality as the vitalist forces; they were meant to stimulate and free thought and establish a possibility of choice and action for their readers. Rousseau explicitly stated that "this 'state of nature' is not to be thought of as an historical reality" and Schiller did not mince words about the necessity of this operation and its purpose (W\&W 225): "And even thus does [modern man], in his maturity, retrieve by means of a fiction the childhood of the race: he conceives, as idea, a state of nature, a state not indeed given him by any experience, but a necessary result of what Reason destined him to be; attributes to himself in this idealized natural state a purpose of which in his actual natural state he was entirely ignorant, and a power of free choice of which he was at that time wholly incapable; and now proceeds exactly as if he were starting from scratch, and were, from sheer insight and free resolve, exchanging a state of complete independence for a state of social contracts" (III.2 my emphasis).

${ }^{43}$ Schiller followed the argument of this First Discourse to explain the stalled Enlightenment: feelings (which are the motivations) were not accounted valuable and consequently knowledge did not find its way into behavior and action. The failure of the French Revolution, the violence of which marked the lack of preparation for freedom, was precipitated by the inorganic lack of feedback and integral involvement among the groups of citizens divided from one another by functions, interests and knowledge (the arts \& sciences).
} 
L'histoire naturelle as well as to travel literature and popular accounts of feral humanity. According to Hulliung, just as energetically as he enlisted scientific arguments (e.g. the genetic method) to his projects, Rousseau pursued his own natural historical studies through observation of the natural world and human beings, especially himself. Most of Rousseau's work took as background the grand tropes of natural man and developmental history, but Schiller drew mainly from his Discourses and from the epistolary novel, $\underline{\text { Julie }}$ ou la Nouvelle Héloïse for his own history of play.

Johann Gottlieb Herder (1744-1803), one of the most significant contributors to the philosophy of history and languages, a pillar of early anthropology, a student of Kant, and a champion and elaborator of pre-critical Kantian positions, was avidly involved in natural history and natural philosophy, not as an experimenter, though he extolled experiment, but as a conduit of knowledge about living nature. Known for setting out the "fundamental principles concerning an intimate dependence of thought on language which underpin modern philosophy of language," for developing modern hermeneutics, and for laying the foundation of the modern anthropology and for making "vital contributions to biblical scholarship," Herder (with Kant) incorporated Buffon into German philosophy. He appreciated Buffon's epistemology, using his argument from analogy and his template of gradual developmental history in his explanation of the origins of both language and humankind. ${ }^{44}$ John Zammito summarized the innovative

\footnotetext{
${ }^{44}$ Description of Herder's contributions are Michael N. Forster's, from the Introduction to his translations (vii). Regarding Herder's relation with the natural sciences, Palti wrote: "Actually, we meet here a kind of 'hermeneutical circle': the study of the natural sciences of his time clarifies fundamental aspects of Herder's historical view, and conversely, the analysis of Herder's philosophy allows us to better understand how the above-mentioned process of redefinition [of historical constructs like "organicism,"
} 
thinker's commitment to do more than understand and then explain the world; for Herder, the task of a philosopher was to change it: "by analogy, metaphor, observation and experience, [Herder endeavored to bring] thought back down to earth and [turn the Enlighteners'] concern to the whole man (Birth $309-310) .{ }^{45}$ Herder was also intimately involved in the progress of German aesthetics and was highly critical of the late eighteenth-century developments in theory, regarding the play of faculties, the disinterestedness of the observer and the "purposeful purposelessness" of art forms, particularly as presented in Kant's Critique of Judgment and as taken up by Schiller in the Aesthetic Letters. Herder undertook a history of language development and, in the Reflections on the Philosophy of the History of Mankind [Ideen zur Philosophie der Geschichte der Menschheit] (1784), attempted to provide "a pure natural history of human powers, actions, and drives in space and time" (Reill Vitalizing 196). ${ }^{46}$

animism to vitalism through epigenesis, and "evolution," preformationism to transformationism, during and after Herder's time] took place" (323).

45 "If I were worthy and able to be such a philosopher, what my book would be is a book about the human soul, full of observations and experiences! I would like to write it as a human for humans: it should instruct and cultivate! The foundations of psychology, and after the development of the soul as well ontology, cosmology, theology and physics! It should offer a living logic, aesthetic, historical science and theory of art! [It should show] how from every sense a fine art develops. And from every power of the soul a science arises. And from all this a history of scholarship and science in general! and a history of the human soul in general, by ages and peoples! What a book!" (Herder (1769), manic, qtd. by Zammito Birth 315).

${ }^{46}$ Reill noted that Herder had antipathy toward the mechanical philosophy (in spite of using mechanical metaphors when referring to the body) rather than more generally to the Enlightenment and that he was widely read in the natural history and philosophy of his time: "he mastered this new [vitalistic] language of nature extremely well. His knowledge of contemporary chemical theory, the life sciences, and natural history was encyclopedic" (Vitalizing 187). Again, "Herder never attempted to separate the historical from the natural sciences and . . . certainly did not reject late Enlightenment science; 
Identifying the animal condition and the subsequent developments that indicated and established the human species is vitally important to all three thinkers. To this end, the two philosophers, sources to Schiller for his developmental history of play (as it is couched in the Aesthetic Letters), emphasized several positions in their own developmental histories, including the gradual transition from the animal to human state and the importance of certain human acquisitions, like language, to distinctiveness of the genus. Together, these positions constituted the type of natural man. This hypothetical construct was the site of a transformational zone from animal to man for them - and for Schiller, from the physical state toward aesthetic being. For all, humanity depended on the development of representation. For Rousseau and Herder, representation through language is the crux; for Schiller, creating visual representations of the self (beginning in self-adornment) and valorizing the symbolic generally ranked with language. Though he unquestionably drew upon both Herder and Rousseau, Schiller used several of Rousseau's devises and concepts in particular as part of his argument. Rousseau, in order to emphasize that man's present condition is neither rational nor natural, revised the idea of man in a state of nature. The common cultural ideas of natural law and natural right (Hobbes, Grotius, Pufendorf, and Locke) grounded his speculations; upon them, he created a hypothetical history of natural man that he justified by referencing Buffon's cosmology. Herder and Schiller, given lee-way by the ascendency of a looser

quite the contrary, he used it as the ground upon which to construct what he considered a sufficient science and philosophy of history. ("Herder" 13). Reill listed eighteen natural philosophers and natural historians cited by Herder, including ones highlighted in this paper: Haller, Maupertuis, Buffon, and Blumenbach. I have found in my reading that references to Haller figure prominently in the arguments of two of his papers (Vitalizing 309). 
epistemology, followed his lead. It all began, however, with this beginning: man was (just about) an animal.

Man, according to Rousseau, began an animal:

l'homme sauvage commencera par les fonctions purement animales. Apercevoir et sentir sera son premier état, qui lui sera commun avec tous les animaux. [His life, in short, was] that of an animal limited at first to mere sensation, scarcely profiting by the gifts which nature held out to him, and not even dreaming of seizing anything from her. (qtd. in Lovejoy $16-17){ }^{47}$

But Rousseau's mankind began in a hardy animal state - he had a healthy body, acute senses, (especially of sight, hearing and smell) and simple capacities suited to the necessities of nutrition, sex and protection. He was first an animal without language of course. Considering man, Rousseau wrote, "as he must have come from the hands of nature - I see an animal less strong than some, less agile than others, but all things considered, the most advantageously organized of all" (105). As such, man had two capacities: a rudimentary reason (like other animals) capable of organizing ideas about self-protection and survival, and sensitivity, an ability to feel simple compassion for fellow creatures. For Rousseau the "first and simplest operations of the human soul" were

two principles anterior to reason, of which one interests us ardently in our well-being and our self-preservation and the other inspires in us a natural repugnance to see any sensitive being perish or suffer, principally our fellowmen .... In this way one is not forced to make man a philosopher before making him a man .... as long as he does not resist the inner impulse of commiseration, he will never harm another man or even another sensitive being, except in the legitimate case where, his

${ }^{47}$ From the French: "In the beginning, primitive man was endowed with purely animal functions. Feeling and seeing were his first conditions, these he holds in common with other animals." 
preservation being concerned, he is obliged to give himself preference $(96){ }^{48}$

Rousseau's natural man was adjusted to his environment. Because he had senses, he had ideas like those of other animals, and as an animal, a physical being, he was "an ingenious machine to which nature has given senses in order to revitalize itself and guarantee itself." He was unlike other animals only in the following way: nature functions for other animals through instincts and man must contribute through free agency to his well-being (113). In all, "Nature treat[ed man] precisely as the law of Sparta treated the children of citizens: it render[ed] strong and robust those who are well constituted and makes all the others perish" (106). Schiller expressed a similar relation for man with regard to nature: "Nature deals no better with Man than with the rest of her works: she acts for him as long as he is as yet incapable of acting for himself as a free intelligence"(III.1). The surviving human, therefore, was not timid or stupid. According to Rousseau, "living dispersed among the animals and early finding himself in a position to measure himself against them, [man] soon [made] the comparison" and, based on his appraisal of circumstances, "he always [had] the option of accepting or leaving the encounter and the choice of flight or combat" (107-108). Rousseau found his human to be natively non-moral, but a good-natured brute. Like other animals, he was not malicious or cruel; his needs were modest, his horizon short.

For his part, Herder attributed to animals the capacity to connect thoughts obscurely and clearly but not distinctly, and the ability to display memory and much recollection,

48 "It seems, in effect, that if I am obliged to do no harm to my fellow man, it is less because he is a reasonable being than because he is a sensitive being: a quality that, being common to beast and man, ought at least to give the one the right not to be uselessly mistreated by the other" (ibid). 
based on sense. Man in nature therefore was not "a great, clumsy, helpless machine ...

[or someone who came] from Plato's cave," not

a naked, instinctless animal, ... [not] weak and succumbing, abandoned to the contention of the elements, to hunger, to all dangers, to the claws of all stronger animals, to a thousandfold death, [not] lonely and alone ... ! He was from the first moment on the freely active, rational creature which was destined to help itself, and inevitably had the ability to do so .... All his shortcomings and needs as an animal were pressing reasons to prove himself with all his forces as a human being ... [these were] his nature (trans. Forster 128-9).

\section{The Human Difference: "It is reason that makes a man, but feeling that guides him." $" 49$}

For Rousseau and Herder particularly, man's difference and his perfectibility was based on his the capacity for language. "Man's first language, the most universal, most energetic ... [was] the cry of nature," Rousseau wrote, [and] "this cry was elicited only by a kind of instinct in pressing emergencies, to beg for help in great dangers, or for relief in violent ills" (122). In the ordinary course of living, Rousseau theorized, gesture which "requires attention rather than stimulates it" was gradually replaced by vocalizations, actions more serviceable in the dark and requiring no direct line of vision. In reinforcing both the importance and the difficulties attendant on the development of communication, Rousseau challenged his readers to a thought experiment:

Let us consider how many ideas we owe to the use of speech; how much grammar trains and facilitates the operations of the mind; and let us think of the inconceivable difficulties and the infinite time which the first invention of languages must have cost .... how many thousands of

${ }^{49}$ The epigraph (which appears only in the Horen, used by Schiller is "Si c'est la raison, qui fait l'homme, /c'est le sentiment, qui le conduit" is from Rousseau's Julie ou la Nouvelle Héloïse (III.7). Schiller called for this epistolary novel during his final revision of the Aesthetic Letters (To his wife: "Don't forget to bring me ... the Héloïse ...") (W\&W, Commentary 221). 
centuries would have been necessary to develop successively in the human mind the operations of which it was capable (120).

Given man's situation, that "the human being is a freely thinking, active being, whose forces operate forth progressively," Herder exclaimed: "Therefore let him be a creature of language!" (127 Trans. Forster). And, as far as Herder was concerned, man's language developed in purely natural human terms. Language was man's "center of gravity, the main direction of his soul's efficacies, [and it] fell as much on this understanding, on human awareness [Besonnenheit], as with the bee [who] falls immediately on sucking and building. ...the first moment of taking-awareness [Besinnung] was also the moment for the inward emergence of language" (128). Therefore,

the genesis of language is as much an inner imperative as is the impulse of the embryo to be born at the moment when it reaches maturity. [Like a hard labor! t] he whole of nature storms at the human being in order to develop his senses until he is a human being. And since language begins from this condition, the whole chain of conditions in the human soul is of such a kind that each of them forms language further (128 my exuberant inclusion).

For Herder, development progressed on the tracks of language.

[T] he sense of feeling does not rule but the whole center of [his] nature falls on finer senses, vision and hearing, and these constantly give . . . language, it follows that taken as a whole, 'there is also no condition in the human soul which does not turn out to be susceptible of words or actually determined by words' .... [and, consequently,] 'the progressive formation of language turns out to be as natural for the human being as his nature itself (132). ${ }^{50}$

Rousseau's true child of nature was not an ideal; he was not even particularly attractive. Part of what developed him was the natural economy, the distinctly conflictual environment, a dynamic competing ecology of needs - his own and those of attacking

${ }^{50}$ Herder put his laws in quotes. 
carnivores, for example. With the success of the species, increasing population provoked competition for food not only among different species but also within the human group (Lovejoy 23). Under this kind of pressure, man showed his difference. Man had the capacity to develop, and this capability was for Rousseau what separated him from the other animals. His faculty of self-perfection was the "specific characteristic of the human species," something, Rousseau recognized, that was not part of other animals' repertoire. Neither the pongo nor the orangutan, animals that otherwise were considered to have "striking conformities with the human species and lesser differences than those which could be assigned between one man and another," showed the slightest capacity in this regard (207).

But if the difficulties surrounding all these questions [the discovery of anthropomorphic animals in Africa and Asia for example] should leave some room for dispute on this difference between man and animal, there is [a] very specific quality that distinguishes them and about which there can be no dispute: the faculty of self-perfection, a faculty which, with the aid of circumstances, successively develops all the others, and resides among us as much in the species as in the individual (114 my emphasis).

According to Herder, man differed from animals in that he was able to generalize experience for the improved condition of the whole species. Animals were confined to something of a behavioral reflex arc - the more reflexive, "the narrower the circle is," the more uniform the behavior. The law of nature that governs the succession of human ideas, however, is different: it is awareness:

[The human being is] the most ignorant creature when he comes into the world, but immediately he becomes nature's apprentice in a way that no animal does; not only does each day teach the next, but each minute of the day teaches the next, each thought the next. It is an essential knack of his soul to learn nothing for this moment, but to marshal everything either along with what it already knew or in readiness for what it intends to link with it in the future.... And in this way the soul becomes a force of steadily collecting. Such a chain continues on until death. [He is,] so to 
speak, never the whole human being; always in development, in progression, in process of perfection (Trans. Forster 130). ${ }^{51}$

Man "came from the hands of nature, with his forces and fluids in the freshest of conditions, and with the best immediate disposition to develop himself from the first moment," (128-9). And, as "the end of our present existence is the formation of humanity, to which all the meaner wants of the Earth are subservient, and which they are all contrived to promote, ..." Herder continued, "Humanity is the character of our species, which, although innate, is only a project" (qtd. in Palti 338).

For Rousseau, Herder and Schiller, man's potentiality, his perfectibility, his wholeness, is made possible by the combination of passion with reason. Rousseau believed that it is by the activity of the passions that reason is perfected. "[W]e seek to know only because we desire to have pleasure; and it is impossible to conceive why one who had neither desires nor fears would go to the trouble of reasoning" (116). The Aesthetic Letters itself began with an epigraph from Rousseau, a call to combine reason with feeling: its prominent inclusion signaled the work Schiller meant to do in uniting these eighteenth-century polarities. ${ }^{52}$ For him, man's potential depends on this senseand-reason synthesis. As a result of the reciprocal interaction of the sense-drive and the form-drive, of thought and feeling as forces, man has and develops a play-drive. This

\footnotetext{
${ }^{51}$ Herder on Kraft: "I do not say that I explain anything thereby; I have not yet known any philosophy which explains what 'force' $[K r a f t]$ is, whether it is active in one or more beings. What philosophy does is notice, arrange, clarify, after assuming force, stimulus, and effect, from the very beginning" (qtd. in Palti 334).

52 The epigraph in French: "Si c'est la raison, qui fait l'homme, /c'est le sentiment, qui le conduit."
} 
play-drive is his pluri-potential capacity, and through it he has a future full of possibility.

Essentially, man - as individual and species - can make of himself whatever he will.

What makes him Man is precisely this [wrote Schiller] that he does not stop short at what Nature herself made of him, but has the power of retracing by means of reason the steps she took on his behalf, of transforming the work of blind compulsion into a work of free choice, and of elevating physical necessity into moral necessity (III.1).

In his developmental history of man, Schiller established "three different moments or stages ... though which both the individual and the species as a whole must pass, inevitably and in a definite order, if they are to complete the full cycle of their destiny." Man begins an animal, develops into a rational animal and then, becomes truly human through encounters with beauty. "Man in his physical state merely suffers the dominion of nature; he emancipates himself from this dominion in the aesthetic state, and he acquires mastery over it in the moral" (XXIV.1). ${ }^{53}$ As the human being develops aesthetically, his reason also enlarges, and the use of reason is freed through interaction with feeling in play just as play also perfects itself. The final moral stage however "is problematic": it, as an ideal, is never fully gained but is always to be attempted, to be approached (III.3).

${ }^{53}$ At first, man was as near to an animal as he could be. Schiller's first stage is a stage without Beauty, "a monotonous round of ends, a constant vacillation of judgements; selfseeking, and yet without a Self; lawless, yet without Freedom; a slave, yet to no Rule. At this state the world is for him, merely Fate, not yet Object; nothing exists for him except what furthers his own existence .... In vain does nature let her rich variety pass before his senses; he sees in her splendid profusion nothing but his prey, in all her might and grandeur nothing but his foe ... conscious of his own savage greed, he fears it in every creature which resembles him. He never sees others in himself, but only himself in others; and communal life, far from enlarging him into a representative of the species, only confines him ever more narrowly within his own individuality" (XXIV. 2). This is a construct, wrote Schiller, "purely an Idea," because man was never purely animal nor has he escaped from the animal condition. 
In Schiller's developmental schema, man began with the common reason upon which survival depends, a capacity to connect cause to effect mandated by the need for nourishment, protection and reproduction. Then he slowly developed the capacity to represent himself internally, not just as a body as animals do, but as an idea, a selfconsciousness (XI). Then a sense of others grew in him, the capacity for empathy. ${ }^{54}$ This power was not Rousseau's sympathy (which animals have), the recognition of the physical state and the broad intention of fellows of one's own kind (for protection and companionship mandated by survival) or the recognition by visual and auditory cues of agent-enemies (for recognizing intent to harm), but the development of a theory of mind (XXVII.5) ${ }^{55}$ In Schiller, these representations came with other very important changes brought by a rudimentarily functioning play-drive. The play-drive fostered a reciprocally developing desire and capacity to use language and the desire to represent reality both by one's own agency as well as to symbolize one's own thoughts by real objects (to make

\footnotetext{
54 "When a man walking ahead of me stumbles, my body immediately espouses the attitude that this man should adopt to keep from falling. We can hardly witness the suffering of others without feeling a part of the pain. Often our reactions are more acute than those felt by individuals under fire and sword. This is one of Nature's means of binding men to one another. She induces sympathy in them only when feeling similar pains. Pleasure and suffering are the world's two masters. Without the first, few would bother to continue the species of man, and if it were not for fear of the latter, many would not care to live" (Maupertuis 49).

55 "It would be no less difficult to determine which does more to impede the practice of brotherly love: the violence of our passions which disturbs it, or the rigidity of our principles, which chills it - the egotism of our senses or the egotism of our reason. If we are to become compassionate, helpful, effective human beings, feeling and character must unite, even as wide-open senses must combine with vigour of intellect if we are to acquire experience. How can we, however laudable our precepts, how can we be just, kindly, and human towards others, if we lack the power of receiving into ourselves faithfully and truly, natures unlike ours, of feeling our way into the situation of others, of making other people's feelings our own? (XIII.4 fn *2).
} 
outside inside and the inside outside) (XI.9). These primitive efforts at representation [Schein] included, for example, adorning one's body or enjoying objects in the world without reference to their utility (XXVII.5-6). This play, putting form to matter in terms of shaping reality by conceptions, developed humans and also further develops the species.

The aesthetic mode (stage, state and capacity) characterized by the functioning of the play-drive is a gift of nature -"the favour of fortune alone can unloose the fetters of that first physical stage and lead the savage towards beauty" (XXVI.1) ${ }^{56}$ For Schiller, the species developed in this way, and it is in this way that the individual must develop as well. Such development cannot mandate what a man will become; it only makes the allimportant moral reflection and behavior possible. By "means of aesthetic culture, the personal worth of a man ... remains completely indeterminate; and nothing more is achieved by it [other] than that he is henceforth enabled by the grace of Nature to make of himself what he will - that the freedom to be what he ought to be is completely restored to him" (XXI.4). In fact, that freedom to be human (his very humanity) "must be restored to him each time anew through the life of the aesthetic." In that way by the grace of the play-drive and the aesthetic state, he "possesses ... humanity in potentia before every determinate condition into which he can conceivably enter" (XXI.5). For Schiller, this organic pause made contemplation the natural result of attending to and living into beauty. Out of that state flowed grace, morality and creativity. Always

${ }^{56}$ For Herder as well, "Reason and reflection [Besonnenheit] were emergents from nature, not transcendental interventions ....'Both in theory and in practice, reason is merely something acquired [Vernommenes] and learned, a proportion and direction of man's ideas and faculties [Kräfte] to which he was predetermined by his organization and way of life"' (Zammito Birth 316, $476 \mathrm{fn}$ 43). 
potentially available through beauty, the aesthetic state (of active-inactivity) destined a man for wholeness, but only if he could tolerate the following: a period of experienced indetermination, a state of aesthetic limitlessness during which time, there is no push to action and every choice is equal in the balance. Man must also be able to combine the aesthetic capacity with a sense of reality. This combined work is not a small task for each moment or for a lifetime (XXI.5 fn).

Schiller addressed the same concerns as Rousseau and Herder did: modern man's state is an unhappy one; he is in a condition that knowledge does not improve. His culture does not encourage or guarantee virtue - quite the contrary - man's present condition seems to deny coexistence for knowledge and morality. The remedy for this complicated condition, one that inquiry into the true nature of mankind is meant to disclose, is a return to his nature and, thereby, to the active possibility of his potential. For Rousseau, that potential was the species-specific capacity to perfection ("the faculty of perfectibility"); for Herder it was man's development, a corrected enlightenment infused with the knowledge given by feeling. And for Schiller, of course, that capacity for developing full human potential was renewed in the aesthetic state and given by play.

Rousseau's faculty of self-perfection also had the unintended consequences of Schiller's play drive (undirected by ideal beauty). With all its potential for development it carried with it an alternate propensity; it could potentiate degeneration.

[T]his distinctive and almost unlimited faculty is the source of all man's misfortunes .... [I]t is this faculty which, by dint of time, draws him out of that original condition in which he would pass tranquil and innocent days .... [I]t is this faculty which, bringing to flower over the centuries his enlightenment and his errors, his vices and his virtues, in the long run makes him the tyrant of himself and of nature (115). 
Likewise, according to Schiller, men can fail in two ways: man can and does lose himself by becoming perseverative - staying directed toward stockpiling things - then he falls to the service of the tyrant appetite and loses his freedom (XXVII.2). ${ }^{57}$ Or he can be subject to play's own illusion and elaboration, and can thereby lose reality and the capacity to be free. In spite of all his intensely expressed criticism, Rousseau, like Schiller, encouraged an approach of realistic optimism:

Far from thinking that there is no longer any virtue or happiness attainable by us, and that Heaven has abandoned us without resource to the depravation of the species, let us endeavor to draw from the very evil from which we suffer the remedy which shall cure it (qtd. in Lovejoy 35).

And, isn't play just that, the hair of the dog?

\section{Summary}

Late Enlightenment vitalism was a tradition of studying the whole of nature and the living organisms within it based on an enriched concept of matter that included force(s). Some of these vital forces emerged from complex organization, representing capacities of organs or organ systems, and others interacted in complicated ways to produce a transformative third, usually a type of developmental force. All were identified with

${ }^{57}$ Part of the issue with the physical or natural state is the relative indolence of the appetite-driven life. Rousseau captured the extremes of need-driven activities followed by periods of languor and sleep, and Schiller registered the animality of early play this way, that the first inclinations to play occur as - unusual displays mostly in immature animals - overabundance of energy, an active superfluity of unnecessary acts, the experienced purposive purposeless, play. As man became more active and labored in agriculture, land seemed an entitlement, his own private property. As a result, society, according to Rousseau, became Hobbesian, and man had to deliver himself to a social contract in order to live in community. For Schiller, man was never really an isolate, and the physical State, that government assuring basic survival needs and conflictual but less destructive internal function, would be the transition zone to a more collegial form of government. 
function, with movement, and it is little wonder that, at the same time, steady nature became steadily more historicized, and reality itself was transformed into epigenetically conceived, continuous change.

The speculative emphasis on forces focused attention on connection and reciprocal relations between polarities and an expanded middle. As a result, within life study as well as in late Enlightenment culture as a whole, mechanical and organic metaphors functioned together to describe a two-tiered nature. At one level, nature was necessity and reflex; at another, it was the nature of transformations, a zone of complex function and potential choice. These descriptions of nature were applied to biological forces, functions and reactions; they were incorporated into understandings of human nature, human productions and institutions. Metaphors of vegetable life and animal economy naturalized human possibilities like creativity or development; they made human products like the state and art organic. Mechanical metaphors remained as the bedrock, but organic tropes, which first clung to those rock out-croppings like primitive plants, soon grew wildly, transforming the bare and jagged landscape to verdant terrain.

This descriptive language system signaled a way of perceiving, a mentality: the natural philosophical tradition, Enlightenment vitalism, had fully matured by the time of Schiller's Aesthetic Letters. There had been new births - discoveries and theories - into this system, ones that were disseminated and elaborated by artists, historians and philosophers. Schiller was one of the disseminators and creators; his work teemed with vitalistic metaphors and the information from observation, collection and experimentation in medicine and natural history, and it depended on hypotheses arising from empirical evidence. Synthesizing the enormous variety of materials available to him, Schiller 
formed a theory of human nature based on species-specific drives, forces-in-matter. His theory included a human development history of gradual acquisition of reason and aesthetic capacity that, at the same time, allowed for instantiation of the pluri-potential human archetype.

Not only human nature, not just human productions, but history itself was transformed by its being perceived and experienced organically. As vitalism matured, organic complexity in descriptions of living matter and medical theories of the body's coordinated functioning were integrated into historical narrative and the philosophical experience of time. Nature as dynamic, life as characterized by change and human institutions as organically-described entities were all carried along by a new intuition of history as epigenetic, as developing from unformed materials (rather than just unfolding out of itself). The concept of history as a system, an organized body, rather than an aggregate of events, lent new relational emphasis: cultures and nations became organs with internal dynamics, reciprocally co-operating and conflicting forces. They were seen as systems impacted by the external forces of nature, the climate and geography, and affected by the normal function and dysfunction of other entities through development, decay or dissolution. History had multiple foci and, as such, was as continuously interactive and complex as the world's weather system - some clear bright times, but many shifting and unpleasant conditions, banking clouds and sheer wind, sleet and fog. Adam Ferguson, a thinker influential to the young Schiller through his professor Abel, expressed his understanding of organized bodies as "progressive natures," as structures transmuted to stages. Ferguson wrote that such natures, like cultures, institutions or governments, or history 
are subject to the vicissitudes of advancement or decline, but are not stationary, perhaps in any period of their existence. Thus, in the material world, [organized] subjects, . . . being progressive, when they cease to advance, begin to decline .... . [Stationary (mechanical) bodies] are described by the enumeration of co-existent parts . . . . subjects progressive are characterized by the enumeration of steps, in the passage from one form of excellence to another (as quoted in Reill, "Buffon" 671).

Such ideas suited Schiller's sense of human potential.

Vitalism too was an approach to the unanswered questions about life that incorporated the legacy of the past century and struggled to respond to the turmoil of recent discoveries and controversies. The zeal for discovery and categorization was unabated, and it was accompanied by a critique of systems and a critique of the human capacity for knowledge. As a result of these activities, a new epistemology - a loose, more open conception about knowledge of organism - developed over the last part of the century, one that Kant endeavored to bring under control. A more modest epistemology and an expanded methodology helped researchers and metaphysicians cope with the dynamic universe, not only with its particulars, but its classes and theories. The particular epistemology was part of a cultural movement of thought that ushered the conception of man from man-as-the-rational-being toward man as defined by his speciesspecific (and peculiarly limited) reason and, at last, to man as a being of sense and reason. Man became complete, understood anthropologically and aesthetically by the end of the century. Many sought to hold on to these developments without premature closure.

During the later part of the century, an understanding was established that forces-inmatter - ones the current physico-chemical laws were inadequate to explain and perceptual methods were unable to isolate and examine - were responsible for the 
phenomenon of life. How was this understanding to be addressed? What was its status? The Great Chain of Being had tipped and dropped. A partly-cleared path of stepping stones remained, disappearing in the distance as it traversed the undulating terrain of Time. ${ }^{58}$ Where was the map?

${ }^{58}$ Herder referred to "Maupertuis' ladder," to the "idea of the great chain of being . . . in the immanent and genetic sense that Maupertuis, Buffon and Diderot were developing over the 1750's" (Zammito Birth 317). 


\section{CHAPTER V}

\section{A MODEST YET DARING EPISTEMOLOGY}

[O]ur first question must be what kind of objects is commensurate with, and determinable by, our knowledge. But the solution of this question... cannot otherwise be attained than by examining the whole extent of its realm and by tracing the whole course of its development from its first elements to its highest forms. Thus the critical problem has its roots in a generic problem. A really adequate explanation of the human mind is only to be found in its evolution. Hence psychology is designated as the foundation of epistemology (Cassirer 93).

Schiller had a problem: he was deeply committed to the freedom of the individual but saw the difficulties attendant on anyone's developing autonomy. His evidence for those difficulties was garnered by observation - modern man in all his particularity was a barbarian whose banal use of the benefits of culture dishonored its martyrs. Modern states as well proved recalcitrant: their neglect of individual potential and their dependence on force to establish basic security did little to foster complete human beings. For him the motivating catastrophe was the failure of the French Revolution, a leap toward Enlightenment values born out of the hopes of reason and killed by the excesses of it. He wrote the Aesthetic Letters to support those values and provided a definition of human nature that allowed for a development toward the full realization of the promise of the species in the individual. Even though enlightenment appeared to be held in such esteem, development [Bildung] proved to be a difficult process. In Schiller's experience, human beings must first conceive an ideal before they can actualize their desire for betterment. Then, to move toward it, they need audacity, they need drive, and the support 
of an environment that favors such change. In fashioning the Aesthetic Letters as a philosophical treatise enforcing the Enlightenment hopes for man, Schiller meant to motivate. He intended to provide a contemplative object, an argument within the frame of art, which - after it was experienced and participated in - would promote action (VIII). He hoped for the action of self-development in its readers and their involvement in promoting a culture of autonomy in their world.

Schiller, arguing, worked hard. And he asked his readers (and they complained) to work as well. ${ }^{1}$ The difficulty was his manner of argument: in an attempt to adhere to a scientific epistemology, a vitalist one recently jiggered by Kant, and to a method of philosophizing, also modeled by the great thinker, he confined himself to an analytic process applied regulatively to discover simple concepts. Luckily, he also advanced his claims through facts and historical narrative like d'Alembert or Rousseau, recollected his material and his readers through circular inclusivity like Buffon and Goethe, surprised with occasional exuberance like Herder, and all the while remained the poet he was. All these stylistic strategies, moves and feints of genius, incorporated methods of passing

\footnotetext{
${ }^{1}$ Referring to himself, Schiller commented: "They'll oppose him now, I'm afraid; but in a few years they'll be plundering him without acknowledgement." In fact, "negative reactions outnumbered, even if they did not outweigh, the positive .... Klopstock apparently dismissed [the Letters] as pretentious 'non sens,' Herder abhorred them as 'Kantische Sünden [Kantian sinning]."' Garve wrote, "I would have thought they made heavy weather of things that are in fact very simple," and Ramdohr remarked that the lot contained "half-truths on poetical stilts, as in all Schiller's philosophical writings." An anonymous letter-writer informed Schiller that he had failed as an editor and an author to live up to his new journal's promise "to present the results of 'science' in a simple and agreeable form for the benefit of the common reader." Another wrote that "'obscurity" of style ... held him up on every page;" another that his " metaphysisch-asthetische Sprache'... simply resulted in 'an uninterrupted and distasteful mixture of learned abstractions and fine phrasing, one long series of rhetorical sophistries and wearisome antitheses." Some offered to translate the work of the "philosophische Querköpfe" into German (W\&W cxxxiii ff).
} 
from the particular to the general, and from the general back to the particular; they applied a modest but daring epistemology to a dynamic and subjective phenomenon, the nature of man.

The foundational rational and empiricist strains of this vitalist epistemology were summarized at mid-century by the French Encyclopédistes, especially by Jean Le Rond $\mathrm{d}^{\text {'Alembert in the Preliminary Discourse. }}{ }^{2}$ The "invention and use of a new method of philosophizing" outlined in the Encyclopédie was fundamental to the study of life. Its firm connection of the "careful examination of Nature and the grand study of mankind" was imperative to progress in the sciences (xxiv, 62). It upheld the centrality of doubt as a disposition; it reaffirmed the observation, experiment and analysis of Newton. It extolled mathematics, but saw probability rising from empiricism as the only certitude in time. And as such it was a map of knowledge about human nature that the mariners of mid-century carried with them when they set off. It was a beauty too: an architectural rendering of Bacon's columns adorned it, opening the way to the unknown, and

\footnotetext{
${ }^{2}$ D'Alembert (1717-1783), the author of this "manifesto of the French Enlightenment," was a precocious mathematical genius. The natural son of an aristocrat and a renegade nun, abandoned on a church doorstep, he was well-educated through the support of his father. He published work on Newtonian mechanics and contributed to mathematics before gaining place and position as a spokesman for the philosophes as a result of the appearance of the Preliminary Discourse in 1751 (Schwab in d'Alembert xv-xix). The Encyclopédie, which the aforementioned introduced, totaled 28 folio volumes, 71,818 articles, and 2,885 plates (Heilbron in Frängsmyr 20). Of rationalism and empiricism: "We may define 'rationalism' as an intellectual orientation (particularly notable in the metaphysical systems of the late seventeenth century) which assumes the existence of certain absolute principle or truths instinctively or clearly felt to be true, through which the chief truths of phenomena can be deduced, judged, or explained. 'Empiricism' is an intellectual orientation ... based on the assumption that 'hard facts' of experience, experimentation, and physical sensations are the essential elements from which our valid ideas are derived and which are the source of all true knowledge" (Schwab in d'Alembert xxxii).
} 
admonishments of the other English philosophers, Locke and Newton, filled two of its corners. Scrolled along its bottom edge were the words: "Nothing is in the intellect which is not first in sense."3 And Descartes peered out from the fourth corner, reminding the explorers to question. "Doubt is the beginning of science; he who doubts nothing, examines nothing; he who examines nothing, discovers nothing; he who discovers nothing is blind and remains blind" (Chardin qtd. in Hazard 12).

\section{Empiricism: Observation, Experimentation and Analysis}

Our first object, which we should never lose from sight, is the study of the human mind - not to discover its nature, but to learn to know its operations, to observe how they are combined and how we ought to use them in order to acquire all the intelligence of which we are capable. It is necessary to go back to the origin of our ideas, to work out their generation, to follow them to the limits which nature has prescribed for them, and by these means to establish the extent and limits of our knowledge and renew all of human understanding (Condillac qtd. in d'Alembert 5 fn 8 my emphasis). ${ }^{6}$

For d'Alembert, Newton was the originator of scientific physics and Locke, the creator of scientific philosophy (Cassirer 99). The author of the Preliminary Discourse

\footnotetext{
${ }^{3}$ Diderot expressly stated: "nothing is proved in metaphysics and we know nothing either concerning our intellectual faculties or concerning the origin and progress of our knowledge, if the old principle: nihil est in intellectu, etc., is not evidence of a first axiom" (as qtd. Cassirer 99).

4 "Descartes dared at least to show intelligent minds how to throw off the yoke of scholasticism, of opinion, of authority - in a word, of prejudices and barbarism .... If he concluded by believing he could explain everything, he at least began by doubting everything, and the arms which we use to combat him belong to him no less because we turn them against him" (d'Alembert 80 my emphasis).

${ }^{5}$ Jean Chardin the traveler, here quoted by Paul Hazard, was mentioned in Rousseau's Second Discourse [Discours sur l'inégalité] and in Montesquieu's Lettres persanes (Still 365 fn 4).

${ }^{6}$ Étienne Bonnot de Condillac (1715-1780), d'Alembert's colleague, was a celebrated mathematician, a champion of Locke and generally a critic of systems.
} 
therefore based his mid-century epistemology on the tried-and-true methods of the mechanical philosophy and on Locke's analysis of the contents of the mind. He also revered Bacon, whose tree of knowledge the Encyclopédistes used as a model for their endeavor, for his empiricism and his method of induction - however difficult it was to progress from particulars to general principles through the use of it. ${ }^{7}$

Part of Schiller's heritage through the French Enlightenment figures and through Herder, Humboldt and Goethe was a respect for the Chancellor Francis Bacon (15611626), his project for the re-organization of knowledge, his belief in the advancement of learning and his empirical and inductive system. ${ }^{8}$ Bacon's valorization of practical

${ }^{7}$ General principles of natural science cannot arise from "mere induction in the sense of a simple aggregation of individual observations" wrote Cassirer reflecting on Tetens' work. Forms of relations require "what we call judging and combining, or inferring and concluding, [and these operations are] different from arranging ideas in sequence and connection; it is more than simply observing similarity and agreement among them." Comparison contains the continuously developing relation with a third entity which assorts objects to a hierarchy of organization as well. (129-131). Bacon's parable of the ants as empiricists, spiders as systems builders and bees as scientists that both gather and produce (develop) theories gave a sense of what he felt induction had to offer (Novum Organum Book I, Aphorism 95: "Those who have treated of the sciences have been either empirics or dogmatical. The former like ants only heap up and use their store, the latter like spiders spin out their own webs. The bee, a mean between both, extracts matter from the flowers of the garden and the field, but works and fashions it by its own efforts. The true labour of philosophy resembles hers, for it neither relies entirely or principally on the powers of the mind, nor yet lays up in the memory, the matter afforded by the experiments of natural history or mechanics in its raw state, but changes and works it in the understanding. We have good reason, therefore, to derive hope from a closer and purer alliance of these faculties, (the experimental and rational) than has yet been attempted" (my emphasis of a concept, beloved by Schiller and all vitalists).

${ }^{8}$ Goethe's interest and emulation of Bacon's empiricism is well-documented in his own reflections: H.B. Nisbet referred to Goethe's essay "Der Versuch als Vermittler von Objekt und Subjekt" (which I quote at the end of the chapter) as a recommendation for Baconian induction, and states that Goethe, aware of the pronounced empiricism of his thought, sought philosophical backing for his work on color from the "father of British empiricism, Francis Bacon, whose thought he described as a decisive influence on his own philosophical development (Gespräche II, 1105-6)" (Sharpe Goethe 226, 228). 
knowledge and its accumulation (as the advancement of learning) was elaborated into the Enlightenment idea of progress by d'Alembert and his second generation colleagues. Bacon's inductive method countered deductive systems: he proceeded from laborious observation of and experiment with particulars, working by a gradual ascent to more general axioms. In addition to focusing on the data of experience, Bacon counseled vigilance against certain intellectual errors. He cautioned against what he termed "idols of the tribe," that is, epistemological problems of the species. Humans, according to Bacon, have natural tendencies and limitations. Our senses are limited; we impose organization or order where there is none, we find what we want to discover and we make premature judgments. ${ }^{9}$ He also identified "idols of the cave," idiosyncratic reasoning problems of the individual. Being a creature of a certain point-of-view, a disciple of a master or distorting reality according to one's own narrow life experience: these, for example, can be summarized as failures to think for oneself. They are errors that drew the Enlightenment polemic against immaturity, against the lack of courage to

Daniel Steuer mentioned Goethe's understanding of Baconian science in his chapter "Goethe's natural investigations and scientific culture" in the same reference (Sharpe Goethe 176). The Humboldts' appreciation of Bacon is the subject of Dettelbach's “"Baconianism' in Revolutionary Germany: Humboldt's Great Instauration." Schiller was quite actively interested in all three of his friends' scientific researches.

${ }^{9}$ Cassirer: As a result of their studies of the senses, the philosophes concluded that "[e]ach sense has its own world, and there is no other alternative than to understand and analyze all these worlds in a purely empirical manner without attempting to reduce them to a common denominator." The spaces they define "all possess equal validity; none can claim higher degree of certainty, objectivity, and generality than any other" (115 cf. Gulliver's Travels). "Our mind seems to be destined to reason only from facts discovered by our senses. Microscopes and glasses have, as it were, provided us with new senses quite beyond our own normal capacities. They should belong rightfully to higher intelligences and often confuse our limited faculties" (Maupertuis 28). 
counter conventional claims, to explore difficult problems or posit new hypotheses. ${ }^{10}$ "The idols of the marketplace" are the errors created by language. Abstractions and reification, according to Bacon, were continued by mutual encouragement and thereby gained a life of their own. For d'Alembert, while "we owe many errors to the abuse of words," it is perhaps the same with axioms. A proposition can be dispatched through a chain of reasoning, and as language is "imperceptibly altered, so that the proposition was successively expressed in different ways ... each of these states would be recognized in the one immediately neighboring it; but in a more remote state we would no longer make it out" (28). The concept "force" is an example of a cluster of meaning that changed through use and nuance during the late Enlightenment (a situation that drew Kant's attention). Bacon's last, the "idols of the theatre," are pitfalls of culture. Here Bacon cautioned against systems of thought - whether they be abstractly argued and speculative, narrowly empirical or a mixture of metaphysics and theology. As d'Alembert wrote: "it is by thoughtful study of phenomena, by the comparisons we make among them, by the art of reducing, as much as that may be possible a large number of phenomena to a single one that can be regarded as their principle .... This reduction which, moreover, makes them easier to understand, constitutes the true 'systemic spirit.' One must be careful not to mistake this for the 'spirit of system"' of the type that Bacon condemned (22-23; 7477).

${ }^{10}$ See page 209. Kant: "Our age is, in especial degree, the age of criticism, and to criticism everything must submit ... . [They that seek exemption from it] then awaken just suspicion, and cannot claim the sincere respect which reason accords only to that which has been able to sustain the test of free and open examination" (qtd. in Schmidt 371). 
The empirical methods of observation and experimentation clarified by analysis,

were brought to stunning success in Newton's synthesis of mathematics applied to

physics. ${ }^{11}$ Newton's great accomplishments, wrote d'Alembert,

gave philosophy a form which apparently it is to keep. That great genius ... banish[ed] conjectures and vague hypotheses from physics, or at least [thought] to present them only for what they were worth, and [saw too] that this science was uniquely susceptible to the experiments of geometry .... [He] invented calculus ... whose applications are so extensive ... in explaining the complicated effects one observes in Nature, where everything seems to take place by various kinds of infinite progressions .... But perhaps he has done more by teaching philosophy to be judicious and to restrict within reasonable limits the sort of audacity which Descartes had been forced by circumstances to bestow upon it (81).

This union of empiricism and analysis, coupled with eschewing all but the most careful hypothesizing, was carried forward by the Preliminary Discourse in the company of Locke's "historical, plain method." 12

${ }^{11}$ Both d'Alembert and Buffon emphasized the demonstration of Newton's theory. Buffon: "The most beautiful and felicitous use to which this method [the union of mathematics to physics] has ever been applied is to the system of the world. We must admit that if Newton had only given us the physical conformations of his system without having supported them by precise mathematical calculations they would not have had nearly the same force;" then speaking as a vitalist he continued, but "at the same time one ought to be aware that there are very few subjects as simple as this, that is to say, as stripped of physical qualities as Newton's universe" ("Initial" 176).

${ }^{12}$ Newton's famous "non fingo hypotheses" occurred in this context: "But hitherto I have not been able to discover the cause of those properties of gravity from phænomena, and $I$ frame no hypotheses; for whatever is not deduced from the phænomena is to be called an hypothesis; and hypotheses, whether metaphysical or physical, whether of occult qualities or mechanical, have no place in experimental philosophy. In this philosophy particular propositions are inferred from the phænomena, and afterwards rendered general by induction. Thus it was that the impenetrability, the mobility, and the impulsive force of bodies, and the laws of motion and of gravitation, were discovered. And to us it is enough that gravity does really exist, and act according to the laws which we have explained, and abundantly serves to account for all the motions of the celestial bodies, and of our sea" (Principia my emphasis). 
"So many philosophers having written the romance of the soul," wrote Voltaire, but "a sage has arrived who has modestly written its history. Locke has set forth human reason just as an excellent anatomist explains the parts of the human body." (qtd. in Cassirer 94, 99). In An Essay Concerning Human Understanding, John Locke analyzed the operation of the mind as follows:

Let us then suppose the mind to be, as we say, with paper, void of all characters, without any ideas; how comes it to be furnished? Whence comes it by that vast store, which the busy and boundless fancy of man has painted on it, with an almost endless variety? Whence has it all the materials of reason and knowledge? To this I answer, in one word, from experience: in that all our knowledge is founded; and from that it ultimately derives itself. Our observation employed either about external, sensible objects; or about the internal operations of our minds, perceived and reflected on by ourselves, is that, which supplies our understandings with all the materials of thinking.... First, our senses, conversant about particular sensible objects, do convey into the mind, several distinct perceptions of things, according to those various ways, wherein those objects do affect them: and thus we come by those ideas [of] sensible qualities .... This great source, of most of the ideas we have, depending wholly upon our senses, and derived by them to the understanding, I call SENSATION (33-34).

There, according to d'Alembert, the results of Locke's own self-examination

provided a starting point for studies of human beings. In doing so,

he reduced the metaphysics to what it really ought to be: the experimental physics of the soul - a very different kind of physics from that of bodies, not only in its object, but in its way of viewing the object. In the latter we can and often do, discover unknown phenomena. In the former, facts as ancient as the world exist equally in all men .... Reasonable metaphysics can only consist, as does experimental physics, in the careful assembling of all these facts, in reducing them to a corpus of information, in explaining some by others, and in distinguishing those which ought to hold the first rank and serve as foundation (84).

Laurence Sterne's Tristram described Locke's Essay as “'a history-book,'-a history ... 'of what passes in a man's own mind"' (Locke "Intro." xv); as such it gave d'Alembert leave to construct his own history of knowledge beginning with "physical 
sensations, material facts, and the demands of the body." Direct knowledge, he summarized, comes from sensations and these sensations convince us of our existence and the existence of everything else: indeed, "all our knowledge is ultimately reduced to sensations that are approximately the same in all men" $(6-8,31)$. The body, "that most complicated machine," is insistent and it

turns our attention to itself, because of the necessity of providing for its endlessly multiplying needs. The care for its preservation must be directed either toward preventing the evils that threaten it or toward remedying those that have attacked it .... Stimulated as they were by so engrossing an aim as self-preservation, these men ... are able . . . to make some progress along the path of knowledge $(24,14-15) .{ }^{13}$

D'Alembert elaborated on this need structure by underscoring pleasure as the source of motivation (with the corresponding relief or avoidance of pain) and by recommending curiosity as a passion. "Moreover, in the hierarchy of our needs and of the objects of our passions," he continued, "pleasure holds the highest places, and curiosity is a need for anyone who knows how to think, especially when this restless desire is enlivened with a sort of vexation at not being able to satisfy itself entirely" (16). Need and passion had pushed knowledge forward historically and they would continue to do so: the Encyclopédie itself was a pledge of progress in the arts and sciences. ${ }^{14}$ Since the study of

${ }^{13}$ Marie Jean Antoine Nicolas de Caritat, marquis de Condorcet (1743 -1794), mathematician and political scientist, a student of d'Alembert's, enlarged on this theme: "The first fruits of continuous association are a number of arts, all concerned with the satisfaction of simple needs. They include the making of weapons, cooking and the construction of the utensils necessary for cooking, preserving food and providing against those times of the year when fresh supplies are unobtainable ..." (qtd. in d'Alembert 15 fn 28).

14 "Everything is related to our needs, whether from absolute necessity, or from convenience and pleasure, or even from custom and caprice. The more the needs are remote or difficult to satisfy, the slower the knowledge intended to satisfy them will be in making its appearance" (43). 
nature provided both necessities and amusement, however, d'Alembert believed that our active pursuit of it approached the limits defined by the capacity of abstraction to remain relevant to the natural world and by our own limits in understanding ourselves. To that end, study of the mind had progressed as well: the mind was considered by mid-century to be an active principle, not just a receiving surface for the imprint of sensations nor the scene for assembling retrieved ideas from memory in order to reason, to compare or judge. Its imagination created ideas (51). As catapulting to abstractions and creativity, loaded with perceptions and memories, yet circumscribed by specific sense capacities and moved by the passions, the mind was a problematic instrument of knowledge. The study of it by itself had proven difficult: "[t]he nature of man, the study of which is so necessary and so highly recommended by Socrates, is an impenetrable mystery for man himself when he is enlightened by reason alone; and the greatest geniuses, after considerable reflection upon this most important matter too often succeed merely in knowing a little less about it than the rest of men" (26). The best we can do in difficult investigations, is to "collect as many facts as we can ... arrange them in the most natural order, and . . . relate them to a certain number of principal facts of which the others are only the consequences. If we presume sometimes to raise ourselves higher, let it be with that wise circumspection which befits so feeble an understanding as ours" (23-4 my emphasis). ${ }^{15}$

Psychology was a part of natural philosophy: "Its highest ideal was to become the 'analyst of the soul' just as chemistry is the analyst of the inorganic world, and anatomy

\footnotetext{
${ }^{15}$ Condillac held that the only legitimate system was one that explained facts by facts, and the best system was one in which one fact would explain all the others ( $29 \mathrm{fn} 37$ ).
} 
of the organic world"- and so by his metaphors you shall know him(Cassirer 94).

Schiller. Just as Newton "made the properties of light known to men by breaking it up into its constituent parts," into the colors of the spectrum, and as Locke analyzed the contents of the mind into simple ideas derived from sense, Schiller analyzed human nature into its original forces and its species-specific drive, the play-drive. ${ }^{16}$ But he did so most reluctantly. ${ }^{17}$ The following complex of mechanical and organic imagery

\footnotetext{
${ }^{16}$ In his analysis, Schiller created the antimonies Person/Condition, Independence/ Dependence, Noumena [reiner Intelligenz]/Phenomena, as well as Form/Matter, highlighted above. Immediate philosophical sources for the analysis are considered to be Fichte and Kant; drives in the philosophic and aesthetic literature included Reinhold's Trieb nach Form and Trieb nach Stoff. Ramdohr's Charis (1793), which Schiller read, "applied the concept of play in a broader ethical and anthropological sense." Ramdohr's drives were two: a drive toward the fulfillment of basic needs and a drive toward freedom (Beiser 137-9, 143).
}

${ }^{17}$ "The spirit of philosophical inquiry itself is wresting from the imagination one province after another, and the frontiers of art contract the more the boundaries of science expand" (II.2). D'Alembert, however, pointed out how necessary the imagination was for analysis: "Imagination acts no less in a geometer who creates than in a poet who invents. It is true that they operate differently on their object. The first shears it down and analyzes it, the second puts it together and embellishes it . . . Of all the great men of antiquity Archimedes is perhaps the one who most deserves to be placed beside Homer. I hope that this digression by a geometer who loves his art will be pardoned, and that he will not be accused of being an excessive enthusiast; and I return to my subject" (52). The trouble with analysis, however, especially mathematical analysis according to Buffon, is that "one is obliged . . . to make suppositions which are always contrary to nature, to strip the subject of most of its qualities, and to make of it an abstract entity which has no resemblance to the actual being. And after long reason and calculation on the connections and properties of this abstract entity, and after having arrived at a conclusion equally abstract, when it appears that something real has been found, the ideal result is transferred back upon the real subject. This process produces an infinity of false consequences and errors" (178). Goethe: "every analysis presupposes a synthesis .... Thus modern chemistry depends largely on separating what nature has united. We do away with nature's synthesis so that we may learn about nature through its separate elements. What higher synthesis is there than a living organism? Why would we submit ourselves to the torments of anatomy, physiology, and psychology if not to reach some concept of the whole, a concept which can always restore itself to wholeness no matter how it is torn to pieces?" (Scientific 49). 
captured Schiller's own ambivalence about this chosen method of argument in the Aesthetic Letters. ${ }^{18}$ If including the graphic metaphor allowed Schiller to register his dismay about the unintended but inevitable consequences of the analytic method of philosophizing (Kant's method as well as Newton and Locke's), it also exemplified the synthesizing function of vitalism, its acceptance of mechanism, of the known physics and chemistry as partially explanatory of life, while insisting on something more built on that foundation as specific to life. The analytic method revealed the parts of the whole; as such, Schiller's original drives represented constructs; the method did not uncover a situation found in nature, but the planks and beams of an explanatory model. It is the same with the play-drive: its effects are part of nature, but it is a concept. And it is for Schiller a necessary one.

After indicating his method of argument Schiller wrote in the first Letter, "For alas! intellect must first destroy the object of Inner Sense if it would make it its own. Like the analytical chemist, the philosopher can only discover how things are combined by analyzing them ..."(I.4). The eighteenth-century reader might think immediately of Lavoisier, recently beheaded in the Terror, the famous analytical chemist [Scheidekünstler] who experimented with air and water (these once thought to be elements), separated them into their elementary components and then - and this will not do for Schiller - reconstituted the original compounds! What happened with nonliving compounds cannot occur in living nature. In mid-sentence, Schiller (who began in the

\footnotetext{
${ }^{18}$ The benefit of a machine metaphor system is apparent today as well: the analogy of the computer and all its projections is extremely generative not only in biology but in cognitive science. Mechanical metaphors prove useful in describing processes that were empirically available, and they make some complex systems more accessible. As such, information technology adds a layer of complexity to machines and the machine metaphor system.
} 
sentence above) changed the comparison from chemistry to vivisection and intensified it emotionally:

... the philosopher can only discover how things are combined by analyzing them, only lay bare the workings of spontaneous Nature by subjecting them to the torment of his own techniques. In order to lay hold of the fleeting phenomenon, he must first bind it in the fetters of rule, tear its fair body to pieces by reducing it to concepts, and preserve its living spirit in a sorry skeleton of words (I.4 my emphasis). ${ }^{19}$

His analogy escalated from chemistry to iatromechanical physiology and experimental vivisection with which he was certainly familiar from his medical education and from Goethe's descriptions of recent forays to the anatomy laboratory with the Humboldt brothers. Within it, the unnatural divisions or distorting actions of reason were indicated by the actions of the anatomist in vivisection or necropsy, implying that

${ }^{19}$ In his famous paper De partibus corporis humani sensibilibus et irritabilibus (read in 1752 , published in 1755), Haller used similar language in describing his experimental use of vivisection: "I have examined several different ways, a hundred and ninety animals, a species of cruelty for which I felt such a reluctance, as could only be overcome by the desire of contributing to the benefit of mankind, and excused by that motive which induces persons of the most human temper, to eat every day the flesh of harmless animals without any scruple" (657). In his procedure, Haller subjected living animals to "being burnt, tore, pricked, or cut till ... [certain parts were] quite destroyed" in an effort to promote a reaction "for it is very well known, that an animal, when it is in pain, endeavours to remove the part that suffers from the cause that hurts it; pulls back the leg if it is hurt, shakes the skin if it is pricked, and gives other evident signs by which we know that it suffers" (659). He described his procedure as follows: "I took living animals of different kinds, and different ages, and after laying bare that part which I want to examine, I waited till the animal ceased to struggle or complain; after which I irritated the part, by blowing, heat, spirit of wine, the scalpel, lapis infinalis, oil of vitriol, and butter of antimony. I examined attentively, whether upon touching, cutting, burning or lacerating the part, the animal seemed disquieted, made a noise struggled, or pulled back the wounded limb, if the part was convulsed, or if nothing of all this happened. The repeated events of these experiments ..." (559-60). He, however, made no experiments on the sensitivity of bones because "in that cruel torture which is unavoidable in order to lay bare the bones, it is very difficult to distinguish the new pains thereby produced" (666). 
analysis precludes a surviving, much less restored, subject. The method, though it may gain clarity, will miss the whole, its dynamic organic functioning.

\section{Vitalist Epistemology: Comparison, Analogy and Hypothesis}

Unity of person necessarily presupposes the unity of a sentient being .... $[T]$ he senses are not the cause but the occasion of all our knowledge. For it is not the senses which perceive; it is rather the mind which perceives when modifications of the bodily organs take place. We must carefully observe the first sensations of which we become aware; we must discover the foundation of the first operations of the mind, watch them in their development, and pursue them to their extreme limits. In short, as Bacon said, we must, as it were, create the whole human mind anew in order really to understand its structure" (Condillac qtd. in Cassirer 101-102).

Enlightenment science historian, Sergio Moravia, presented a schema for understanding the vitalists' method. He found that late Enlightenment vitalism was characterized by "epistemological liberation," a character of exploration and discovery that allowed for a panoply of "epistemological options." The changes that ushered in this loosening, indicative of the effort to describe and orient toward a much enriched understanding of matter, included the following: a rediscovery of the importance of elemental facts and empirical description, the rehabilitation of sense and a pluralization of cognitive strategies. They involved as well a movement from formal and deductive approaches to empirical, inductive construction of explanatory models, and a retraction of mathematical privilege ("Enlightenment" 248). ${ }^{20}$ These changes not only transformed the study of life, they brought the "whole man down to earth": they placed "human being and human action within the coordinates of reality accessible to the instruments of science ... not only the body but the thought itself; not only the physique but also the moral; not only the nervous sensibility, but also the passions, emotions and higher

${ }^{20}$ For the "rehabilitation of sense," see Chapter VI. 
psychic operations." This development fostered the redefinition of "human corporeity," opening to intensive study "the corporeal organization of man - in order to prove that such organization contained within itself all the forces necessary to organs for the correct functioning of vital, psychic and mental phenomena, none excepted." The body came to be seen as capable without a soul and able to produce autonomously even the most sophisticated and complex human acts. Finally, by valorizing only natural explanations, this new tradition placed the human being as body in his environment [the Umwelt], connecting him to the natural world by a complex web of relations $(250-253,256)$.

There were so many favorable references to observation (as implicitly visual) that this approved method of knowledge was a virtual "epistemology of sight" (Moravia 249). Buffon counseled: "begin the study of nature by very broad observation . . . almost at random," and as you are observing, observe yourself, " . . allow your mind to follow its lead, to get to know itself' (146). The next step, then, is description, a function that entails more than observation of an individual. It involves comparison, a function as old as having two ears separated by the space of one brain (for time), or two eyes by a nose (for space). Side-by-side observation of two and then comparison with a third are basic to our judgments: "Nothing is well-defined but that which is exactly described. Now, in order to describe exactly, it is necessary to have seen, reviewed, examined, and compared the thing which one wishes to describe. And it is necessary to do all this without prejudging things and without an eye to systemization" (157).

According to Moravia, comparison "is one of the principal cognitive acts of the modern human science. It is quite significant that it was worked out in the Enlightenment" (250). For the scholars of the late eighteenth century, it was a sort of 
middle road between observation and abstract formalization. They knew what they were doing: those who compared understood

that reality is made up of discontinuous and individualized data, which are not, however, completely unrelated among themselves and, indeed, are susceptible to being juxtaposed and connected. They kn[e]w, in addition, that they [could] not be content with the mere visual inspection of the single datum, but that they must institute interfactual relations capable of penetrating to the meaning of the facts themselves, and eventually of constituting certain structures or constants useful for pursuing investigation (250).

D'Alembert acknowledged that the mind moved from individual to the general through comparison: "We cannot repeat too often that nature is composed merely of individual things which are the primary object of our sensations and direct perceptions. To be sure, we note in these individual things common properties by which we compare them and dissimilar properties by which we differentiate them" (48-9). But Buffon believed that the method of natural history should build on this natural capacity of mind and he incorporated it in his description of the ideal natural historian: he should gather facts, then rise to "combinations of observation, the generalization of facts, linking them together by the power of analogies .... [Then] we can judge that particular effects depend upon more general ones; we can compare nature with herself in her vast operations; and finally, we are able to open new routes for further perfection of the various branches of natural science $(171-2){ }^{21}$ This emphasis naturally led to the emergence of morphology and the intuition of "type."

21 "Analogy frees our mind from having to imagine new things and from an even greater worry, that of remaining uncertain. It pleases our mind, but does it please nature as much?" (Maupertuis 32). 
Mathematics lost some cache as life became more and more defined by qualities that were difficult to distill. Buffon reminded his readers that as unnatural and abstract, as products of human invention, "[m]athematical truths are only exact repetitions of definitions or suppositions ... [they represent only an] identity of ideas [that] has nothing of the real about it. Truths of the physical sciences, on the other hand, are in no way arbitrary, and in no way depend on us, instead of being founded on suppositions which we made, they depend only on facts." Truth itself then was redefined, by Buffon and others, in a way that related to the dynamic reality of the physical world. For them, "a sequence of similar facts or, if you prefer, a frequent repetition and an uninterrupted succession of the same occurrences constitute the essence of this sort of truth. What is called 'truth' in the physical sciences is thus only a probability, but a probability so great that it is equivalent to certitude" $(173-174) .{ }^{22}$

Combining all these functions and recalculating the value and reliability of each mental operation in relation to the others was necessary to a new system of knowledge. According to Buffon:

The true method of guiding one's mind in such research is to have recourse to observations, to gather these together, and from them to make new observations in sufficient number to assure the truth of the principal facts, and to use mathematics only for the purpose of estimating the probabilities of the consequences which may be drawn from these facts. Above all, it is necessary to try to generalize these facts and to distinguish well those which are essential from those which are only accessories to the

\footnotetext{
${ }^{22}$ See page 182 (fn 17) for Buffon's attack on (mathematical) analysis. D'Alembert saw the change coming: "evidence is the result of the operations of the mind alone and is related to metaphysical and mathematical speculations .... [C]ertitude is more appropriate to physical objects, the knowledge of which is the fruit of the constant and invariable testimony of our senses. Probability applies principally to historical facts and generally to all past, present, and future events that we attribute to a kind of chance because we cannot perceive the causes of them" (44).
} 
subject under consideration. It is then necessary to tie such facts together by analogies, confirm or destroy certain equivocal points by means of experiment, form one's plan of explanation on the basis of the combination of all these connections, and present them in the most natural order. This order can be established in two ways: the first is to ascend from the particular effects to more general ones, and the other is to descend from the general to the particular (178). ${ }^{23}$

Buffon issued a warning, a premonition of the heightening concerns during the late Enlightenment, about the limits of human knowledge. He recognized the particular spin on reality that is natural to us, and he fixed his readers with a rhetorical glance: "Here is the most delicate and the most important point in the study of the sciences: to know how to distinguish what is really in a subject from what we arbitrarily put there in considering it, to recognize clearly the properties which belong to it and those which we give to it. [T] his appears to me to be the foundation of the truth method of leading one's mind in the way of the sciences" (178).

\section{The Hypothesis and the Unknown}

The French vitalist Barthez' premier research interest was to 'investigate the laws by which the vital principle in each living being creates and commands bodily structures and

${ }^{23}$ Buffon saw that these approaches stemmed from different personalities: "the love of the study of nature supposes two qualities of mind which are apparently in opposition to each other: the grand view of the ardent genius who takes in everything at a glance, and the detailed attention of an instinct which concentrates laboriously on a single minute detail" (145). Nevertheless, there was "need for a [combined] methodical approach to guide the mind, ... for that method which sustains the very order of things, guides our reasoning, enlightens our views, extends them, and prevents us from being led astray" (172). Such a natural method was needed and sought throughout the century. According to Zammito, "Kant, [for example] taking up impulses from Buffon, intended to displace this [heuristic and classificatory natural history with Naturgeschichte] with a real and genetic conception of the order of living forms (Naturgattungen in place of

Schulgattungen), and therewith to make history central to the project of the life sciences. [In Kant's colleague's words] the new research program would ask ...'what the primal form of each ancestral species of animals and plants originally consisted of, and how the species gradually devolved from their ancestral species" ("This inscrutable" 79). 
events to achieve its own intent." In that endeavor, he was deeply committed to process, to careful methodology. He recommended that "Science of Life . . . abandon all premature attempts to define the final cause of this occult force, naming it by some 'unknown expression' like "vital principle"” (Reich 18). He continued:

The names of occult faculties are useful to simplify the computation of phenomena, and to give it more extension. [But if $t$ ] hese names [are] used as letters in algebra, no prejudiced opinion hampers the search for the proximate and immediate causes of facts. Thus one obtains much more easily and directly formulas or general expressions of the analogies of the facts (Barthez in Duchesneau 266).

This formulation was one of the clearest representations of force speculations as placeholders for the data of future scientific study. Duchesneau developed Barthez' position as follows:

The algebraic $x$ in physiological analysis would have a specific meaning and role. It would signify the heterogeneity between the laws of vital functions and those of inorganic nature, as well as between the laws of vital functions and determinations of the psychological agent. It would afford a new combinatoire of phenomena showing the specific physiological connection involved, an intrinsic connection, and more fundamental than the order arising from anatomical, mechanical or chemical determinations. Indeed the experimental cause is hypothesis, but it should be framed on the ground of an 'analytic computation of phenomena.' Barthez considers that scientific knowledge can develop only once an adequate principle or experimental cause has been posited. The experimental cause represents [a] common 'area of research'.... Barthez's experimental cause makes it possible to locate in the phenomena significant facts, that is faits-principes serving as grounds for explanatory analogies ..." (266-7 my emphasis).

In this recommendation Barthez both cleared hypotheses of confusing concepts, took from the questions their already embedded answers, and he reminded his readers of the great value of hypothesis itself. ${ }^{24}$

${ }^{24}$ Reflection on this development based on recent philosophy of biology: to characterize science by "the rigor of its methodology, the possibility of testing or falsifying its 
This hypothetico-deductive method moved easily from physics and physiology into the developing science of life and science of man, and it was also eagerly taken up by the broader culture. Rousseau, for example, commented in his Second Discourse that he was making an hypothetical history "not unlike those our physicists are in the habit of making every day" (Rousseau; also W\&W xlvi). For his part, Schiller proposed that the play drive has a goal, Beauty, an Ideal: in essence he hypothesized that, unlike other animals whose goals are hard-wired (for example, goals like reproduction, development, maintenance), human beings, as a species, are characterized by an additional non-specific capacity, an ability to fix individual goal(s) by pleasurable attention. Human goals are potentially freely chosen and human nature pluri-potential in terms of its possible actualization. The species is therefore fixed though its flexibility - and it is culture as an environment that, in reciprocal relation with the individual, promotes increasingly

conclusions, and of establishing non-contradictory 'paradigms' (systems of theories)" establishes a baseline, but it is one that must be understood in the context of discovery. According to Mayr, science is no longer considered to progress by Baconian induction, by observation, description and notation of experience without prior theorizing, but is seen historically to progress by the hypothetico-deductive method: observation leading to speculation that frames observation and dictates hierarchies of experience (i.e. what fits, what falsifies, what leads to other speculations). This way of proceeding valorizes scientific relativism, the anticipation of impermanence of findings and the activity that has conclusions continually tested. That facts give rise to questions, problems and theories rather than supplying answers gives science a dynamic quality. Evolutionary and other branches of biology with dependence on historical material have additional methods of inquiry beyond experimentation in real time: these biologists use observation and comparison (Growth 25-32). Historically, this basic epistemological change occurred during Schiller's time: then, according to Mayr and others, the geometrical and mathematical ideal of proof was challenged by a probabilistic model of evidence; the inductive method was edged out by the hypothetico-deductive method, and observation and experiment were augmented by comparison. During the eighteenth century, the probabilistic approach to truth and empiricism's connection to hypothesis found their way into fiction and into the considerations of fiction: "in Tristram Shandy, Laurence Sterne could declare that "it is in the nature of an hypothesis, when once a man has conceived it, that it assimilates every thing to itself" (Bender 16). 
compelling and fulfilling goals. These goals are ideals, ones each person can strive toward, but never reach.

Combining the results of the various techniques, from observation, experimentation, comparison and analogy into the frame of a hypothesis allowed for indication of the direction of further study. It focused attention by giving form to a problem, by creating a bounded area for the search. Hypothesis imposed on knowledge-making an organization worthy of a vitalistic analogy: the working hypothesis functions as if it were in a developmental drive. It creates an organism of intelligence out of both preconceived notions [Keim und Anlagen] and unformatted data. It uses some materials and discards others from the world in order to create an autonomous individual, a self-developing and self-maintaining environment for ideas. It continues to change, to develop and to grow as long as it is viable. For the reader it is like play, like contemplating or creating a work of art: author and reader's attention is framed and focused, and in the space that is created, each can contemplate the whole, each form and mature their judgment. If it is not beautiful, if something does not fit, is distorted or deadened, if there is an anomaly, the reader (even if he be the author) will rebel and dare to apply a new frame.

\section{Kant \& Goethe: A Representation of Inquiry and Portrait of a Natural Historian [Naturforscher]}

Questions about human ability to interface with nature, then, immediately arise and, since Schiller took in both Kant and Goethe's organization of natural history and their stances of our epistemological relation to nature, he worked toward presenting his hypothesis in a way to satisfy both their claims. He followed the Critiques and audaciously used Kant's regulative category to hypothesize broadly about play, and he 
used Goethe's intuitive technique to reassure himself about his own observations regarding human nature. ${ }^{25}$

\section{Kant: Regulative Ideas and the Labyrinth of Unknowns}

It is absurd to hope that another Newton might one day arise who would make conceivable to us so much as the production of a blade of grass according to natural laws unordered by any intention (Kant $\underline{\text { Judgment }}$ $\S 75)$.

Immanuel Kant (1724-1804) had a long and fruitful involvement with natural philosophy. ${ }^{26}$ He was a "shrewd student of the life sciences who followed their development since the $1750 \mathrm{~s} \ldots$. [and] one of the very few who followed - and understood the implications of - Buffon's distinctions" (Larson 170). From Buffon, Kant received a sense of the value of a natural system of classification and a concomitant appreciation of the importance of history to our understanding of living forms, particularly with respect to the definition of natural species. ${ }^{27}$ Throughout his academic life, Kant lectured and published in natural philosophy and anthropology, and he

${ }^{25}$ The analogy of epistemology to a map and our relationship to the map is, of course, a representation: Kant was the surveyor and Goethe, the boon companion: "Kant was proud to have 'not merely explored the territory of pure understanding, and carefully surveyed every part of it ... but also measured its extent, and assigned to everything in it its rightful place" (Müller-Sievers 65). Goethe was a master of journeys of becoming: he had his own experience of an Italian journey and worked on the composition of an "epitome of epigenetic literature," a Bildungsroman, Wilhelm Meisters Lehrjahre, during the time Schiller was involved with the Aesthetic Letters (Muller-Sievers compared Tristram Shandy as a tome based on preformationist theory to Goethe's coming-of-age novel as a work that claims "a free cause and formation of self." 20 ).

${ }^{26}$ There is a virtual academic industry of information about Kant's interest in, involvement with and influence on the natural sciences: see Huneman, Larson, Sloan, Steigerwald and Zammito.

27 "Every species, every succession of individuals, who reproduce and cannot mix, shall be considered and treated separately; and we shall employ no other families, genera, orders, and classes, than what are exhibited by Nature herself" (Buffon, "The Ass" 406). 
participated in major confrontations and controversies about the explanatory use of natural science, theories of generation and the species concept. He railed against "aesthetic" philosophers, the "speculative empiricists" like Herder, demanding a responsible use of the discoveries of natural history. ${ }^{28}$ In controversies about the application of data in theory, in the species controversy, he held the position against Kames and Forster that mankind was a single genus and species, that species were fixed and that Buffon's idea of natural species, however correct it might be, was empirically unworkable. Regarding reproduction, he posited a modified preformationism, one that allowed species characteristic to be inherited through germ material [Keim und Anlagen..$^{29}$ As an appreciator of the epigenetic theory (but an opponent of hylozoism), he followed the work and initiated a correspondence with the natural historian Blumenbach regarding his hypothesis of a developmental force. Kant believed that Blumenbach, in positing a mechanical force that functioned as if it were teleological,

${ }^{28}$ Kant: "Would not the whole of this learned industry be better off if those who are accustomed, as the public taste demands, to purvey a mixture of the empirical with the rational in all sorts of proportions unknown even to themselves and who style themselves independent thinkers, while giving the name of hair-splitters to those who apply themselves to the purely rational part, were to be given warning about pursuing simultaneously two jobs which are quite different in their technique, and each of which perhaps requires a special talent that when combined with the other talent produces nothing but bungling?" (Zammito Genesis 186). Having been a spectator to the flamethrowing between Herder and Kant that produced this salvo and recently enamored of Kant, Schiller certainly kept his eye on the latter - in an effort to avoid being considered one of the careless.

${ }^{29}$ Sloan's "Buffon" includes evidence for Buffon's acquaintance with Leibniz, Kant's acquaintance with Buffon (though he did not own any of Buffon's works), and Girtanner's study of Kant through Reinhold, who was also Schiller's explanatory source. 
created a regulatory or place-holding concept in the study of generation. ${ }^{30}$ For Kant, who adhered to the necessity of describing nature in all its manifestations within the frame of nature itself, and with reference to known mechanical (and chemical) laws, Blumenbach's refusal to attribute life's structure to a supersensual cause (e.g. the soul), to any action outside of history (by prior creation), or through some change in raw matter, seemed to support his own thinking about life and the epistemological problem it provoked. He celebrated what he considered to be Blumenbach's careful use of the vitalist concept of force. In other words, Kant founded a "new method of argumentation and legitimization" by favoring the "epigenesis of the categories: generatio aequivoca ... [to] the gradual growth of inorganic matter into organisms (or of empirical knowledge into knowledge a priori), and preformationism, the creation of all natural forms since the beginning of the world (or implantation of categories into the mind by 'our maker')" (Müller-Sievers 47, 90).

In the Critique of the Power of Judgment, Kant presented the principle of purposiveness without purpose as an a priori transcendental principle of judgment necessary for us because it "governs, justifies, and makes possible our aspirations to

\footnotetext{
${ }^{30} \mathrm{He}$ commended Blumenbach's work as follows: "No one has done more for the proof of this theory of epigenesis as well as the establishment of the proper principles of its application, partly by limiting an excessively presumptuous use of it, than Privy Councilor Blumenbach. He begins all physical explanation of these formations with organized matter .... [H]e leaves natural mechanism an indeterminable but at the same time also unmistakable role under this inscrutable principle of an original organization, on account of which he calls the faculty in the matter in an organized body (in distinction from the merely mechanical formative power [Bildungskraft] that is present in all matter) a formative drive [Bildungstrieb] (standing as it were, under the guidance and direction of that former principle)" $(\$ 81,292)$. For the references to the interaction of Blumenbach and Kant, the issues about mechanical forces with teleological appearances, including their possible misunderstanding, see page $114 \mathrm{fn} \mathrm{8,} \mathrm{146-48.}$
} 
empirical knowledge" with regard to two subsidiary forms of judgment: teleological judgment concerning organic behavior and aesthetic judgment of natural beauty. In the second part of that work, the "Critique of the Teleological Power of Judgment," Kant approached the problems of the scientific understanding of organisms. He saw that, from our point of view, organisms (in their being and action) were not satisfactorily explained according to known mechanical or chemical laws:

An organized being is thus not a mere machine, for that has only a motive power, while the organized being possesses in itself a formative power, and indeed one that it communicates to the matter, which does not have it (it organizes the latter): thus it has a self-propagating formative power, which cannot be explained through the capacity for movement alone (that is, by mechanism) $(\$ 65)$.

Further, it was difficult for humans to conceive of natural explanations of their existence, complex structure and functioning. We see organisms as both being purposive and as purposes of nature, as agented products. According to Kant, the principle that pertains to the above, that of purposiveness, is a reflective judgment: it "is a merely subjective principle, one needed and employed by subjects, but not properly applicable to objects; we may judge objects...only as if they are purposive." ${ }^{, 31}$ More, natural

${ }^{31}$ An analysis of "teleology" by Ernst Mayr demonstrated the importance of isolating the word's connotations and uses today: Mayr found that historically, particularly in the description and explanation of living systems, several meanings were necessarily conflated in one term. Teleological language marshaled the following meanings endorsement of theological or metaphysical doctrines, a rejection of the physico-chemical explanations for biological phenomena, a perception of causation of the present by the future, or the connotation of anthropomorphic purpose and intention. He solved these issues to his and others' satisfaction by noting the natural differences between the processes described. His distinctions are useful to our understanding of the difficulties faced by the Enlightenment vitalists, who lacked both the knowledge to make these particular differentiations. He analyzed the heterogeneous concept as follows: its meanings included teleomatic processes in inanimate nature and teleonomic processes in living nature. 1) Teleomatic processes are simple consequences of natural laws, "enddirected only in a passive automatic way, regulated by external forces or conditions." 
philosophers studying organisms, "not only do, but must, employ the concept of a natural purpose in their investigation" (Zuckert 1-2). To be clear, "Kant identifies purposiveness not as an ontological characteristic of objects or nature, but as an epistemic principle that governs the unity of representations or judgments" (Zuckert 9-10 my emphasis). In other words, natural purposes [Naturzwecke] as organisms or organized beings [Organisierte Wesen] are our constructs; they are the only way we can understand life. Not what-it-is but what-humans-see-and-think-of-it constitutes life. And, as a principle of knowledge, presupposition or "regulative use" allows us to recognize the differences in living organisms without committing to a research program outside of the methods of natural history or physiology. Kant's summary of this function is as follows:

Nevertheless, teleological judging is rightly drawn into our research into nature ... but only in order to bring it under principles of observation and research in analogy with causality according to ends, without presuming thereby to explain it. It thus belongs to the reflecting, not to the determining power of judgment. The concept of the combinations and forms of nature in accordance with ends is still at least one more principle for bringing its appearances under rules where the laws of causality about the mere mechanism of nature will not suffice. For we adduce a teleological ground when we ascribe causality in regard to an object to a concept of the object as if it were to be found in nature (not in us), or rather we represent the possibility of the object in accordance with the analogy of such a causality (like the kind we encounter in ourselves), and hence we conceive of nature as technical through its own capacity; whereas if we did not ascribe such an agency to it, we would have to represent its causality as a blind mechanism. If, however, we were to base nature on intentionally acting causes, hence were to ground teleology not merely on a regulative principle for the mere judging of appearances ...

The end is a result. 2) "A teleonomic process or behavior is one which owes its goaldirectedness to the operation of a program." Program and end-point. The program, Mayr pointed out, may be coded in the genes as the developmental sequence of the nervous system which, functioning executively, enables the organism to, say, perceive food and eat it, or choose materials and make a nest (Toward 45). Mayr also distinguished human agency but found no place for cosmic teleology in biology: it is crucial to him that evolutionary theory be clearly understood as non-teleological. 
but rather on a constitutive principle for the derivation of its products from their causes, then the concept of a natural end would no longer belong to the reflecting, but to the determining power of judgment $(\S 61)$.

For Kant, teleology was "an a priori principle about the relation between the human mind and the nature that surrounds it, including other human minds, that can give us confidence in the validity of our judgments without directly giving us new concepts of objects" (Guyer in Kant xxi). Kant argued his position with reference to the advances made in the study of life, from the work of the embryologists, the anatomists, the physiologists and the naturalists, Buffon, Maupertuis, Haller, Wolff and Blumenbach. From his familiarity with their publications, he judged that the life sciences of the time needed grounding, needed an epistemology that at once extended to them an authority based on past testing and success (empiricism composed of observation and experiment in physics) and one that gave a level of autonomy and encouraged an open-ended program for discovery through theory-building. ${ }^{32}$

Schiller imbibed Kant in a three-year period of study, a terrific luxury (paid for by the Duke of Augustenburg) for a writer who had supported himself with his pen and lived much of his life hand-to-mouth. He took Kant's philosophy into his head and his heart, particularly the Third Critique, its emphasis on beauty, freedom and on mankind as an end of nature. When he disagreed, his variance was a movement toward the anthropological and the aesthetic, a shift underneath the fluttering flag of Kantianism. ${ }^{33}$

${ }^{32}$ For complete argument see Huneman, "Introduction."

${ }^{33}$ An example of Schiller's method of affirming Kant while distancing his own position from any "misconception" the reader might have: "In the Transcendental method of philosophizing, where everything depends on clearing form of content, and obtaining Necessity in its pure state, free of all admixture with the contingent, one easily falls into thinking of material things as nothing but an obstacle, and of imagining that our sensuous 
He also took in Kant's epistemological distinctions with regard to organisms and art and made an effort at rigorous philosophizing according to Kant's standards. In the middle of his analysis, the thirteenth letter of the Aesthetic Letters, Schiller included a footnote deploring the effects of preconceived notions of goals in natural philosophy. There, Schiller publicly lamented the use by some physiologists, physicians and natural historians of concepts like force as reifications, as designations of principles in nature that function outside known laws (whether mechanical or chemical), uses that would force the hypothesis of new laws or function as an appeal to a cause outside of nature. In it he also provided a gloss: his use of his drive concept should be read as adhering to Kant's explanation of organisms as natural purposes and products of nature. ${ }^{34}$ The following excerpt of the footnote functions as an introduction to the intuitive scientist:

One of the chief reasons why our natural sciences make such slow progress is obviously the universal, and almost uncontrollable, propensity to teleological judgments, in which, once they are used constitutively, the determining faculty is substituted for the receptive. However strong and however varied the impact made upon our organs by nature, all her manifold variety is then entirely lost upon us, because we are seeking nothing in her but what we have put into her; because, instead of letting her come in upon us, we are thrusting ourselves out upon her with all the impatient anticipations of our reason (XIII.4 fn 2 my emphasis). ${ }^{35}$

Much as he valued Kant, and though Schiller presented drives regulatively, he did not use concepts that imply purpose, plan or agency, (the drives) abstemiously - as Kant

nature, just because it happens to be a hindrance in this operation must of necessity be in conflict with reason. Such a way of thinking is, it is true, wholly alien to the spirit of the Kantian system, but it may very well be found in the letter of it" (XIII.2 fn *2).

${ }^{34}$ In this reading I am at odds with Wilkinson and Willoughby who take Schiller's critique as one against scientists who would posit an agent outside of nature to explain the specific qualities of life (W\&W "Commentary" 247).

${ }^{35}$ The rest of the footnote is discussed with reference to Goethe on page 202. 
had specified - but much as others used them at the time, audaciously, to justify speculating about the unknowns in the vitalistic research program, including the nature of man. For Schiller, the epistemological value that resided in teleological concepts, otherwise without ontological stature, then, was that the 'as if' posture allowed him to move the argument of the Aesthetic Letters forward. He developed the argument analytically in spite of his preference for empirical and historical evidence and for objective rather than subjective observation (if only they were possible). He judged human potential as if our natural constitution (a product of nature alone) were itself a natural purpose (developed as if according to a plan, not accounted for by known laws and internal to itself), one that behaved according to expectations (normative standards) (Ginsborg). All this he posited based on his understanding of archetypes and drives. And based on Kant's regulative concepts, including the presuppositions of the purposiveness of organism as products of nature, organisms as natural purposes, and species and genera as natural categories not subject to demonstration, Schiller approached humanity as one species but in two ways: he presented human nature itself as a an organization in the individual and he saw the species that functioned "as if" it were an agent of its own potentiality (cause and effect of itself). ${ }^{36}$ Like many during the time, Schiller made the theoretical effort: he set out to explore the labyrinth of human nature, with his boon companion Goethe, unlocking the gate of the unknown with Kant's own

\footnotetext{
${ }^{36}$ The following sections are referenced $\S \S 64-68,75,77,78,81$; comparisons: bird $\S 61$; hexagon $\S 65$; thread/labyrinth $\S 72$. I am following Hannah Ginsborg's discussion of products of nature and purposive organisms as following normative laws.
} 
keys, carrying a rucksack filled with information from the natural historians and

physicians, packed by Rousseau and Herder. ${ }^{37}$

\section{Johann Wolfgang Goethe Experience and Intuition [Erfahrung und Anschauung]}

"A man can stand anything except a succession of ordinary days" (Goethe).

What a force Goethe was, energetic and self-correcting: he led the German Counter Enlightenment [the charge of Empfindsamkeit] from Sturm und Drang to the end of the Romantic era, beginning with exuberantly written and popularly received poems, plays and a misunderstood self-parody (The Sorrows of Young Werther), a cautionary tale about his own depression. Then he engineered his own recovery with work and structure at Weimar, and indulged in some rowdying with the ruler Carl August. Then for the sake of his own Bildung he redirected himself by means of a two-year Italian journey. The trip led to another book, a renewed interest in classicism as well as some field work in botany (looking for the Urpflanze), in anatomy (developing the insight that the bones of the head are modified vertebrae) and a unitary theory of natural philosophy based on archetypes. He wrote at Faust, Part I for years, finishing in 1808: too late for his good friend Schiller (1759-1805) and others who could not "hear what now I bring, belated, Who listened to the early tunes I made: /Gone is the throng by love so animated,/Dead the responsive tribute that they paid" (trans. Wayne 29). Altogether his works fill 143 volumes.

${ }^{37}$ Rousseau found himself in a analogous position regarding the status of the "historical fact": he, "keenly interested in tracing the succession of phases through which man's intellectual and social life has passed[,] . . . recognized that the knowledge of his time permitted only raisonnements hypothétiques on the subject" (Lovejoy EII 18). Schiller adopted the same stance with respect to his developmental history. 
This polymath, poet, artist, scientist, administrator, also most probably had bipolar disorder. He was sometimes exuberant - a man of great energy and high ambition, of unapologetically eccentric lifestyle ${ }^{38}$ in whom impulse and feeling were controlled by the structure of living and the forms of art - but also someone who was profoundly and repeatedly depressed. He wrote in a letter of bereavement, "I know full well what it cost me then, in effort and in resolution, to escape the waters of death, even as I have had since then to save myself from many another shipwrecks by toiling effort and difficult recovery." ${ }^{39}$ Goethe's character Faust and his foil Mephistopheles play out many of Goethe's own character struggles (implied above) - temptation by curiosity, knowledge and sensuality, struggle against melancholy and cynicism with monumental programs of distraction and dissipation, working through guilt (sinning against innocent affection) and the redemption of a narcissistic Romantic hero through that same love.

In "The Experiment as Mediator between the Subject and the Object," Goethe summarized the stance of the researcher into nature [Naturforscher]:

when a person's thirst for knowledge kindles in him a desire to view nature's objects in their own right and in relation to one another ... he loses the yardstick which came to his aid when he looked at things from the human standpoint; i.e., in relation to himself. This yardstick of pleasure and displeasure, attraction and repulsion, help and harm, he must now renounce absolutely; as a ... true botanist [for example, he] must remain unmoved by beauty or utility in a plant; he must explore its formation, its relation to other plants. Like the sun which draws forth every plant and shines on all, he must look upon each plant with the same quiet gaze; he must find the measure for what he learns, the data for judgment, not in himself but in the sphere of what he observes (Scientific 11).

\footnotetext{
38 "Thomas Mann remarked that schoolboys learn [Goethe's] love-affairs by heart, like Jove's" (Faust Trans. Wayne 13).

${ }^{39}$ In a letter to Zelter in his bereavement (qtd. in Faust Trans. Wayne 20).
} 
Goethe recommended "the calm exercise of the powers of attention" directed to an object in its natural context in order to develop a clear concept of the object, its parts and relationships. Goethe was not sanguine, however, about human seeing: "The scientific researcher strives to grasp and keep the definite aspect of what he beholds" but he "never sees the pure phenomenon with his own eyes, rather much depends on his mood, the state of his senses, the light, air, weather, the physical object, how it is handled, and a thousand other circumstances." He found it useful to consider three states of seeing: the empirical phenomenon (what everyone sees in nature), the scientific phenomenon, produced under controlled circumstances and conditions, and the pure phenomenon, which is what stands before us as a results of all our observations and experiments. It can never be isolated, but it appears in a continuous sequence of events. To depict it, the human mind gives definition to the empirically variable, excludes the accidental, sets aside the impure, untangles the complicated, and even discovers the unknown (Scientific 24-25).

He extolled experimentation, a species of comparative analysis, as part of what produced the scientific phenomenon, but an experimentation that was careful, repetitive and narrow in scope in order that it not be overinterpreted. A group of experiments may illuminate an aspect of a problem, but Goethe believed that it took an extensive series of intentionally reproduced empirical evidence, under varied circumstances and different hands, to create an order that conforms to nature. In Goethe's system, the best course is to view the result of each experiment as isolated, as a kind of contemplation, to avoid the enthusiasm humans have for "hypotheses, theories, terminologies, and systems," a tendency, "to prove some relationship not fully perceptible to the senses but expressed 
through the creative power of the mind" (14)..$^{40}$ Ideally, not to direct the experiment to prove a hypothesis but to "follow every single experiment through its variation is the real task of the scientific researcher." In this way he follows nature, for everything in nature, "especially the commoner forces and elements, work incessantly upon one another; we can say that each phenomenon is connected with countless others just as we can say that a point of light floating in space sends its rays in all directions" (15-16). In short, we cannot exercise enough care, diligence, strictness, even pedantry, in collecting basic empirical evidence; here we labor for the world and the future. But these materials must be ordered and shown in sequence, not arranged in some hypothetical way nor made to serve the dictates of some system (17).

These steps were the steps to the pure phenomenon and, in spite of abstraction, it was a phenomenon for Goethe, the end of the "practical and self-distilling processes of common human understanding as it ventures to apply itself to a higher sphere" (25).

\section{The Schiller-Goethe Fortunate Encounter}

"Science was the common ground on which the two men first met, nor was it ever left during the ensuing time.",41

For Goethe, his intuition about plants and animals, that is, his deep understanding of their form and structure, was the product of patient and repeated observation and experimentation. Goethe's intuitions were developed out of a rational empiricism (as described above), a profound attention to what the senses (particularly vision) collect, and a research program based on repetition (as a statistical method for increasing probabilities), on swinging back and forth between the phenomena and his collected

40 "We often find that the more limited the data, the more artful a gifted thinker will become."

${ }^{41}$ Rudolf Magnus qtd. in Heinz Norden. Goethe as a Scientist. New York: Henry Schuman, 1949, 23. 
experience of them, in a spiral of correction and reinforcement, allowing a subsequent imaginative grasp [Anschauung] of the essence of the phenomena. This method of discovery allowed Goethe to elaborate the study of morphology, of dynamic form (Bildung and metamorphosis), and to a theory of plant and animal types. ${ }^{42}$ For example, in collecting and examining plants, he came to an understanding that many of their

${ }^{42}$ In addition to Buffon, Maupertuis (as Dr. Baumann), Diderot, Robinet and Bonnet recognized either Platonic or Aristotelian forms exemplified by living things. Many of these researchers, as well as the early Herder, considered man as the model in the theory of types (as microcosm, hieroglyph) and sought similarities to him in lower animals. By the early 1780 's, Herder and Goethe reversed that organization: working from an empirical ground, they observed a pattern present in lower animals and sought the same physical formation modified in man or specialized in other animals, "[for] the lower levels of material and organization are represented in man, as well as the higher ones which are peculiar to him." (Nisbet "Type" $83 \mathrm{ff}, 101$ ). Herder applied the theory not only to the skeleton, but to the anatomy of the whole organism (morphology, the common outward form), but also to the forces within the natural type, forces he regarded as "manifestations of the creative 'Urkraft' within all nature" (89). Goethe, in intimate communication with Herder and familiar with his manuscripts, followed Herder's more empirically-based constructs about plant and animal form quite closely. Additionally, both Herder and Goethe believed that the theory of types could be extended to physiology, to function, to the abilities and the drives [Geschicklichkeiten und Triebe]. Goethe, although he confined his experiments to anatomy and therefore to generating empirical data relating to morphology, theorized not only an outward form but a correspondent inner type of forces: "The type, regardless of size, includes a certain aggregate of forces" (100). Both describe the animal type as an Urbild, and both were involved in recognizing Urpflanze and noting the similarities of plants, but Goethe did not seek a fundamental type for all living forms. Goethe differed as well in having an intense interest in applying the idea of types to organs, to leaves in plants and to the bony frame of the vertebrates, and in both placing the prototypes in the past (Urtier, Urpflanze) and seeking them in the present, as on his trip to Italy. He continued to develop his theories of type for plants and animals from the 1780's, and he published actively in the 1790 's, including during the period of his early intimate relationship with Schiller. Goethe's publications during the 1790's were indications of what scientific issues were on his mind: Metamorphose der Pflanzen (1790), Erster Entwurf einer allgemeinen Einleitung in die gleichende Anatomie (1795), Vorträge über die drei ersten Kapitel des Entwurfs [continuation of the comparative anatomy] (1796), and the poem "Metamorphose der Tiere." 
structures were modified leaves, ${ }^{43}$ and he then sought the archetypal plant, an Urpflanze. This particular commitment to the original plant form (the living form, the dynamic plan of a plant) was the subject of Schiller and Goethe's first intimate interaction. They had both attended a meeting of the Natural History Society of Jena [Naturforschende Gesellschaft zu Jena] in 1794 and continued talking as they left. Goethe shared one of his favorite obsessions. He said that he had had an experience of the archetypal plant, which he then drew for Schiller. ${ }^{44}$ Schiller cried out that it was not an experience [Erfahrung] that Goethe had had, but an Idea [Idee $]^{45}$ As it happened, one of Schiller's own Ideen, and he had many, was that human beings are at base playful and that this playfulness is the key to their development. In other words, Schiller, who made countless observations of mankind over the years (just as his friend had of plants), had the Goethean "experience" that man is "fully human only when he plays," that human nature is archetypally playful. His idea of a human Urtyp was an intuition [Anschauung] of type, one he came to by moving back and forth between the particular and the general,

${ }^{43}$ The root, the stem, the bud, the bloom, the pistil, the stamen ... the seed.

44 "I gave an enthusiastic description of the metamorphosis of plants, and with a few characteristic strokes of the pen I caused a symbolic plant to spring up before his eyes." The translator clarified his translation in a footnote directly following "symbolic plant": the footnote reads "the "archetypal plant"' and then refers the reader to another footnote with a passage from the Italian Journey describing the "primordial plant" (Scientific Trans. Miller 20, 321,328).

${ }^{45}$ July 20, 1794. Schiller's words: "Das is keine Erfahrung; das ist eine Idee!" (Goethe Scientific 18-21; Richards, Romantic 1-2). Richards: "The individual who exercised the greatest impact on Goethe's intellectual and artistic life was undoubtedly Friedrich Schiller. Their intense friendship, which began in 1794 and ended only with Schiller's death in 1805, encompassed many dimensions of their lives": the pleasure of friendship and comfortable domesticity, constructive criticism of major works, exchange of poetry, mutual writing projects including the Horen, sharing Goethe's scientific interests, and agreement around the Third Critique (420-27). 
between the individual as embodiment of a natural species and species as a concept of combining heritage and destiny.

After the encounter, Goethe included the two aspects in his description, calling the type "one part concept/one part experience" [theils aus dem Begriff, theils aus der Erfahrung, 107], a movement toward a more regulative view of type. ${ }^{46}$

In one of the footnotes to the Aesthetic Letters, Schiller paid tribute to an unnamed scientist (who was Goethe). He used the following portrait to argue against rationalizing, against looking at the evidence with a theory already in mind (i.e. unconscious cherrypicking) and saw his ideal researcher of nature as empirical first and then intuitive, respectful of the subjects of his interest, and intent on the apprehension of connectedness, of real relation. In it can be recognized Goethe's commitment to Baconian science, his conforming to a mentor, from whose methods and manner he sought justification. In this example, too, the binaries of form and content as well as a harmonious way of bringing them together for the advancement of knowledge represent the vitalistic understanding of antimonies participating in a harmonious whole:

\footnotetext{
${ }^{46}$ In Goethe's discussion of the scientific process, he noted that the company of others is the greatest help for two reasons: first, different people bringing different experience and expertise to the task, helping to edge the entrenched researcher out of his rut. He also recognized that "the greatest discoveries are made not so much by men as by the age" and saw that science (unlike art) benefited from early, even premature, exchange of information: "it is useful to publish every bit of empirical evidence, even every conjecture; indeed, no scientific edifice should be built until the plan and materials of its structure have been widely known, judged and sifted" (12-13). Both Goethe and Schiller, like the Encyclopédistes valued the company and "work of a society of men of letters" (d'Alembert 3). D'Alembert mentioned frequently the "incontestable advantages in being able to convey and receive ideas easily in mutual intercourse" (32), remarking further that "ideas which are acquired from reading and from association with others are the germ of almost all discoveries .... It is like the air one breathes without thinking about it, to which one owes life ... (61).
} 
If, then in the course of centuries, it should happen that a man tries to approach her [Nature] with his sense-organs untroubled, innocent and wide open, and, thanks to this, should chance upon a multitude of phenomena which we, with our tendency to prejudge the issue, have overlooked, then we are mightily astonished that so many eyes in such broad daylight should have noticed nothing. This premature hankering after harmony before we have even got together the individual sounds which are to go to its making, this violent usurping of authority by ratiocination in a field where its right to give orders is by no means unconditional, is the reason why so many thinking minds fail to have any fruitful effect upon the advancement of science; and it would be difficult to say which has done more harm to the progress of knowledge: a sensefaculty unamenable to form, or a reasoning faculty which will not stay for content (XIII.4 fn 2).

In the late eighteenth century as Goethe used it, the theory of types was grounded in the empirical experience of observing, collecting, experimenting and comparing. Then its analogical power and epistemological value was at its height. At that time analogy's use as a function of knowledge-development was full of different degrees of relatedness. It contained the recognition of comparability between similar parts with similar function as well as the more rigorous (and in the nineteenth century differentiated by Owen) comparability of parts showing exact anatomical correspondence. Both these degrees of similarity were then revised much later: by definition homology came to mean resemblances due to common ancestry. Some eighteenth century comparisons and extended analogies then actually contained or were identical with evolutionary homologies, relations of biological relatedness, and consequently, these insights were validated by twenty-first century technologies. Because of its approximation to reality both dynamic nature and the processes of human understanding - the metaphor of animal or plant type was extremely fruitful in generating both evidence and theory. The hiddenness of homology (relatedness through a common ancestor) within the class of all 
analogies, on the other hand, explains both the creative value and erratic accuracy of analogy itself.

Is Schiller's positing of a theory of play as archetypical of human nature an intuition of biological relatedness? Like the vertebrae, several of which transmute over eons into the specialized structure of the cranium, does play, as a structural net in the brain and as a behavior in the environment, change over time with the evolution of mammalian social species, ending in the capacity to play with self-consciousness, empathy and representations? ${ }^{47}$

\section{Epistemological Modesty to Epistemological Audacity Sapere aude! Dare to Know}

Enlightenment is mankind's exit from its self-incurred immaturity. Immaturity is the inability to make use of one's own understanding without the guidance of another. Self-incurred is this inability if its cause lies not in the lack of understanding but rather in the lack of the resolution and the courage to use it without guidance of another. Sapere aude! Have the courage to use your own understanding! is thus the motto of the enlightenment" (Kant in Schmidt 58).

From mid-century, researchers, writers and philosophers often called for courage from their fellows, not just courage to break with tradition and think for themselves but also courage to delve, actively explore, and hypothesize about the nature of life and the nature of man:

It takes a peculiar kind of genius and courage of spirit to be able to envisage nature in the innumerable multitude of its productions without losing one's orientation, and to believe oneself capable of understanding and comparing such productions" (Buffon 145 my emphasis).

Buffon's words reflected not just on his own capacities and his colossal project but they aptly described his contemporary, Maupertuis. Zammito wrote that "it is hard for one to underscore too heavily the novelty, the epistemological audacity represented in [Maupertuis'] conceptions. Of course these hypotheses were very crude and they were

${ }^{47}$ In posing this question, I am taking play behavior in birds to be a phenomenon of convergence. 
[at the time] incapable of experimental confirmation. Nevertheless..." (Francois Russo qtd. "Kant's Early"). Among other things, Maupertuis opined the following:

May we not say that, in the fortuitous combination of the productions of Nature, since only those creatures could survive in whose organization a certain degree of adaptation was present, there is nothing extraordinary in the fact that such adaptation is actually found in all those species which now exist? Chance, one might say, turned out a vast number of individuals; a small proportion of these were organized in such a manner that the animals' organs could satisfy their needs. A much greater number showed neither adaptation nor order; these last all perished.... Thus the species which we see today are but a small part of all those that blind destiny has produced (Maupertuis qtd. by Glass Forerunners 57-58).

Julien Offray de La Mettrie's work itself was an example of that cultural audacity. Theories of forces in living organisms were abundant during Schiller's time: they filled the black box of the unknowns to bursting. A labyrinth of speculation, home of the possible sublime - whether machine-man or an animal-man hybrid - drew in all the eighteenth-century natural philosophers and metaphysicians who dared. And many ventured in, because "to dare" was a strong value in the late Enlightenment. L'homme machine (1749), La Mettrie's controversial and satirical materialist tract, got everyone's attention including in time Goethe's and Schiller's. It was intended to be offensive, in the sense of audacious, and it was. La Mettrie believed that "to know things as they are and without distortion, such methods as logical reasoning, empirical observation, experimental inquiry, while indispensable, [did] not necessarily suffice." What was needed was audacity, [hardiesse], a way of speaking truth [vérité hardie] to power that breaks through the censorship of pre-conceptions and assumptions. And his bluntness began with an attack on self-censorship which "no less than outside censure, blurs and blunts the reflex of objectivity." Because the self-education of the l'homme machine proceeds like a "surgical operation carried out by the patient on himself, audace is the 
quality" that allows the necessary mentality for detachment (La Mettrie qtd. by Vartanian

Science 54). From Vartanian's prospect, La Mettrie was first and foremost a physician, a humanist whose goals for man were not "merely good health but the good life." He was, therefore,

predisposed ... to perceive the human being as an organism .... an individual, viewed biologically, [that] had a determinate and specific mode of being - an intransigeant tendency to be, like all physical objects, what it is .... This 'what it is' [precedes] temporally and cognitively, the innumerable myths, fictions, desires, fantasies, beliefs, custom, values, representations and prejudices with which the human race has a remarkable talent for clothing its underlying nakedness (Science 48).

And man in his nakedness was La Mettrie's true object of study.

Schiller had a use for courage too: his meditation on the difficulties of

Enlightenment, of the progress of truth, ended in a call to a battle.

There must ... be something in the disposition of men which stands in the way of the acceptance of truth, however brightly it may shine, and the adoption of truth, however forcibly it may convince. A Sage of old felt what it was, and it lies concealed in that pregnant utterance: sapere aude. Dare to be wise! It is energy and courage that are required to combat the obstacles which both indolence of nature and cowardice of heart put in the way of true enlightenment. Not for nothing does the ancient myth make the goddess of wisdom emerge full armed from the head of Jupiter. For her very first action is a war-like one (VIII.5-6). ${ }^{48}$

\footnotetext{
${ }^{48}$ La Mettrie's use of "animal machine" or "organic machine," in addition to its capacity to rivet attention, actually had the effect of vitalizing mechanism. According to Aram Vartanian, La Mettrie's "primary task was to vitalize the Cartesian 'dead mechanism' approach to biology. In order to lift the homme machine beyond the reach of animistic criticism, La Mettrie had first to show that purposive motion could be a property of organized matter as such, or put differently, that the man-machine was automatic in a manner that no man-made machine, requiring direction from without, could truly duplicate." Such organic activity like irritability apart from the central nervous system was "taken by La Mettrie as conclusive proof of his contention that organic activity is not caused by any kind of soul .... The biological philosophy implicit in this view ... represents an attempt to combine ... traditionally opposed attitudes ... . La Mettrie has by no means neglected the specifically vital characteristics of the organism; but at the same time he remains entirely convinced that these are knowable to science only insofar as they are seen sub specie machinae. His idea of the 'living machine,' defined
} 
"Dare to know" demanded Schiller of his readers, as Kant most famously did before him. ${ }^{49}$ And Schiller was as bold as he dared his readers to be: he audaciously proposed that human nature itself was grounded not in reason but in play. And playing off the certainty that he would garner attention, shocked attention, by suggesting an exalted place for "mere play," he explained that his play would, through the pleasures of attention and fixed on beauty, bring out what is best and most noble in humanity (I.1). Schiller dared contend that the aesthetic and only the aesthetic would make human wholeness possible.

\section{Summary}

Goethe's character Faust, in an agitated mood, began a translation:

"In the beginning was the Word" - thus runs the text.

hypothetically by its purposive self-motion, may thus be said to express a 'vitalomecanisme à base dynamique" (Vartanian in La Mettrie's 19-20).

${ }^{49}$ See above page 209. Regarding the history of the admonition: according to Eric Miller, translator of Sulzer's Dialogues on the Beauty of Nature and Moral Reflections on Certain Topics of Natural History, the frontispiece of that work's 1770 edition featured an illustration of Athena in battle dress with the motto "Sapere aude!" (Sulzer vii). That illustration matched the description of Athena in Schiller. Kant's famous use of "Sapere Aude!" in "An Answer to the Question: What is Enlightenment?" (1784) probably was Schiller's source: as Wilkinson and Willoughby put it, it was "no doubt ringing in Schiller's ears, if not lying on his desk. By the same token, of course, in other ears, or on other desks too!" (lxxv). That essay also references La Mettrie: "When nature has, under this hard shell, developed the seed for which she cares most tenderly, namely the inclination and the vocation for free thinking, this works back upon the character of the people ... and finally even on the principles of government, which finds it to its advantage to treat man, who is now more than a machine, in accord with his dignity" (Kant in Schmidt 63, my emphasis). The earliest occurrence in the eighteenth century of "Sapere Aude!" used as a motto apart from its course appears to be that of a medal struck in 1736 for the Society of the Friends of Truth in Berlin. A volume on numismatics found in Goethe's library included a reproduction of the medal (W\&W lxxv). Horace is the original author; the phrase occurs in Epistles 1.2.40 (Schmidt, 63-64). The words "daring" and "audacious" are often used to describe the work of the researchers and philosophers after mid-century by others as well, e.g. Hulliung of Rousseau's First Discourse: a "remarkably daring essay" (173). 
Who helps me on? Already I'm perplexed!

I cannot grant the word such sovereign merit,

I must translate it in a different way

If I'm indeed illumined by the Spirit.

"In the beginning was the Sense [Sinn]." But stay!

reflect on this first sentence well and truly

Lest the light pen be hurrying unduly!

Is sense in fact all action's spur and source?

It should read: "In the beginning was the Force [Kraft]!"

Yet as I write it down, some warning sense

Alerts me that it, too, will give offense.

The spirit speaks! And lo, the way is freed,

I calmly write: "In the beginning was the Deed [Tat]!" 50

This struggle with meaning, and the work to get it right, can be applied to the history of epistemology in the eighteenth century. Concepts and words, as authorities, as descriptors or as guarantors, were discredited by the English philosophy - by Bacon, Locke and Newton. As Maupertuis remarked after disproving a legend of the incombustible salamander, "Whatever shame a physicist may have in doing a silly experiment, this is the price he must pay in order to destroy opinions consecrated by the ancients' accounts" (in Roger 155). "Everything from sense" worked as generator of data through observation and experiment and as a battle-cry, but it did not provide a basis for understanding. To take advantage of experience, even a scientific epistemology needed a way to augment Baconian induction with methods of organization, with comparison, analogy and, finally, with force as a regulative concept and by the force of hypothesis. Still, nothing works better than the combination of all: the action of the mind put to particulars, focusing attention, performing experiments, simplifying by analysis, creating hypotheses out of this frame. The sum of experience, the intuition, is really a deed of

\footnotetext{
${ }^{50}$ Faust finished in 1801, published 1808. Faust Part One was accomplished with considerable encouragement from Schiller (English: Trans. Arndt 34; German, 41).
} 
perception, a necessary creative insight into the nature of things. And then there is the necessary mustering of audacity to act upon it, of course.

Life posed epistemological problems that authority, reason and mechanical models of matter, force and motion could not engage: all organisms had histories and were a part of history - individual life was described by time. And in the case of mankind, the Germans of the late Enlightenment and especially Schiller, had intense concern that freedom of agency in action, free human acts, be carved out between the two necessities - physical and moral. Individual actions, deeds, done by a free rational agent in science were critical to establishing facts and their relation to each other, and scientific action associated with the study of life involved deeds of observation, comparison and experimentation by an investigator working toward an intuition of nature through hypothesis. ${ }^{51}$

\footnotetext{
${ }^{51}$ But what of the poodle? The scene in Faust's study was not the scene of a soliloquy: there were two beings there. There is great danger when a self-authorizing system concentrates great power into the present and acts, whether that system is an autonomous human being, a discipline or a nation. Jacques Roger, in his Preface (1993) to The Life Sciences in Eighteenth-Century French Thought, reflected on the development of the sciences and the importance of understanding their history. "The problem is all the more serious in that science and the technologies deriving from it give man an unheard-of power over nature and over himself .... [I]t is becoming urgent to impose norms upon the exercise of that power. If all that is possible must be actualized ... which is one of the guiding maxims of the technological system, our civilization is in danger of going mad. The historical study of this evolution in Western thought, and of the forms of resistance that it has elicited, can possibly provide some enlightenment, and this too is part of the history of science." (Roger xxxvii). From the perspective of Faust's wager, it is vitally important to recognize the drive-like urgency of scientific activity, "that man's sense of curiosity about the world and himself is every bit as compelling as his need for clothing and food" (Laudan 225). Like the play drive that Schiller hypothesized, scientific curiosity too must be programmed by an ideal, lest "[c]ivilization, far from setting us free, in fact creates some new need with every new power it develops in us" (V.5). Such management by form also involves what Roger (after Laudan and consonant with insights expressed by d'Alembert in the Preliminary Discourse) calls 'rational choice,' a stance of the agent. He wrote that even though the problems posed by
} 
Vitalism's modest epistemology was a map of the strengths and limitations of human nature's interface with nature, of what can be known by the human mind, and of the great expanse of the unknown. Schiller used it, accepting the primacy of empirical knowledge, of observation and experimentation. He extended observation to self-observation, the "objects of the Inner Sense" and the subjectivity of others, admitting Kant's proviso that these operations lacked epistemological status. ${ }^{52}$ He imported the data of the physician-

scientists change, the real object of scientific research, nature, is permanent and the equipment of the observer, human rationality, is stable as well. "Rational choice,' [is] the choice used by the scientist in all periods of history [and it does not change]. What changes historically is not the nature of this choice, but its terms - that is, what the scientist must take into account .... [A] scientific explanation must meet two conditions: first, resolve the problem 'rationally'; then, create the least number of possible 'conceptual difficulties' that is, be in accord with the reigning philosophies of nature, ideologies, and even mentalities" (Laudan qtd. in Roger xxiv). This is not to say that there is not an evolving scientific rationality, but that there might be both grace and dignity in scientific endeavor.

${ }^{52}$ Re: Schiller's "Inner Sense." Locke wrote that the "fountain [other than sensation], from which experience furnishes the understanding with ideas, is the perception of the operations of our own minds within us, as it is employed about the ideas it has got; which operations, when the soul comes to reflect on, and consider, do furnish the understanding with another set of ideas, which could not be had from things without: and such are perception, thinking, doubting, believing, reasoning, knowing, willing, and all the different actings of our own minds; which we being conscious of, and observing in ourselves, do from these receive into our understandings, as distinct ideas, as we do from bodies affecting our senses. This sources of ideas, every man has wholly in himself: and though it be not sense, as having nothing to do with external objects; yet it is very like it, and might properly enough be called internal sense. But as I call the other sensation, so I call this REFLECTION, the ideas it affords being such only, as the mind get by reflecting on its own operations within itself" (34). Schiller's contemporary Karl Philipp Moritz, author of the psychological novel, Anton Reiser, and founder of the one of the first psychological journals, Magazin zur Erfahrungsseelenkunde als ein Lesebuch für Gelehrte und Ungelehrte (Journal of Psychological Experience, a Reader for Scholars and Non-Scholars), gave self-observation a "more secure foothold in secular German thought .... [His aim was] to offer 'observations of oneself for the improvement of others' ... [and his method was] distanced, dispassionate self-observation." According to Moritz, in this self-observation, "it is necessary to shelter from the 'whirlwind' [Wirbel] of one's desires and attain disinterestedness, 'to play the cold observer for a while, without being in the least bit interested in oneself" (Bell 91). 
physiologists and natural historians about development and the nervous system, information upon which their hypotheses about force were based, and upon which he fashioned his own hypothesis about the forces of the human mind. He used comparison, metaphor and analogy. Before embarking on the hypothetical developmental history contained in the Aesthetic Letters, he commiserated with his readers, "Resign yourself therefore to one more brief sojourn in the sphere of speculation, in order thereafter to leave it for good, and proceed, with steps made all the more sure, over the terrain of experience" (XXVII.5). This map needs color and it is the German aesthetic tradition that will allow us to add that color, to vivify it with a "complete, anthropologic" view and to gain a full understanding of the place of the senses and feeling to the completion of human nature. 


\section{CHAPTER VI}

\section{AESTHETICS AND ANTHROPOLOGY: THE WHOLE MAN}

I am drawing ever nearer the goal toward which I have been leading you by a not exactly encouraging path. If you will consent to follow me $a \mathrm{few}$ steps further along it, horizons all the wider will unfold and a pleasing prospect perhaps requite you for the labour of the journey (XV.1 my emphasis).

Put down the map; come into the garden. Come in, through the gate - a fine primitive one it is - dry stack masonry with a low arch, grass volunteering on top. Mind your head! Schiller would have had to. The planning stakes are out, and some new plantings just in. Quite the landscape, almost wild. Mature trees, uneven ground, its own natural rock outcroppings, surrounded by hills. What a prospect! ${ }^{1}$

\footnotetext{
${ }^{1}$ Among the holdings of the National Goethe Museum is an etching of "Schillers Garten bei Jena" by Jakob Wilhelm Christian Roux. Schiller found and purchased this land in 1797. The etching shows a low horizon, a house, garden shed and flat-topped hill to the far left. Above them Howard-like clouds hang and ride. There is high ground with a tall tree foregrounding the work on the right. The garden itself has a natural aspect with rock outcroppings and a variety of tree and plant species; it appears to spill over a wild edge beyond the tree. The gate is piled stone, rustic and narrow and, near it, a person kneels, weeding or planting. The garden plan appears to be in the process of execution. No labyrinthine ruins are represented. Where is Schiller? He is often ill and needing to conserve his energy, but perhaps we will see him approaching the garden on a donkey, a slouchy hat on his head and his long legs dangling almost to the ground (Schuster 745). The art of pleasure gardens, wrote Kant, "a beautiful depiction of nature [as well as a] beautiful arrangement of its products [is]. . given only for the eye, like painting" (Third $\S 51$ ). Kant was fond of architectonic metaphor, and Beth Lord suggested that the Third Critique functioned as a landscape garden that connected the two edifices on Kant's vast property, theoretical and practical reason. The garden itself also represented "the Enlightenment project to build an ideal community of rational beings in tune with nature" (263).
} 
In late eighteenth-century Germany, philosophical interest in landscape architecture flourished both in the development of gardens and in the theorizing about that activity. Applied to the art of gardening, the patriotic sentiments of Empfindsamkeit and Sturm und Drang cultivated a Mittelweg, a synthesis of French and English styles that defined a home-grown German tradition - and provided a "topography of thought" relating to its practice (Lee 5-6). Identifying the "burst of attention that the garden received ... in the two decades immediately following Kant's Third Critique" as unique in landscape architecture's history, Michael Lee described past German gardening styles as cyclical, moving between formal and informal approaches, broken by periods of eclecticism (Lee 10,11 ). Into this narrative, a new synthetic theory, expressed in Kantian idiom, was presented by Friedrich Schiller in his review of "Über den Gartenkalender auf das Jahr 1795." This reviewer (writing in the fall of 1794 while editing the Aesthetic Letters) applied his own theory about the middle state, the aesthetic Zustand, to landscape architecture. According to Schiller, the garden, an object of art, should be representationally complete, a whole in dynamic and harmonious balance. As a product of human nature, however, it was prone to the same distortions as the psyche. Under the influence of the tensed and overbearing form of the French [Baukunst] style, for example, the natural elements of the garden gave up their higher organic nature, exchanging their 'beautiful autonomous life' (schöne selbständiges Leben) for a 'soulless symmetry' (geistlosen Ebenmass). The English, or Poetik, style, on the other hand, has a tendency to extend freedom to the point of willfulness and caprice, often flaunting a 'disorderly license' (regellos Lizenz)" (Schiller qtd. in Lee 138-139). For Schiller, the formal style emphasized both physical necessity and rational purposes and, thereby, reified the 
connection between understanding, purpose and order. It was the style of human agency. The opposite pole in garden art, the informal style, valorized the evocation of feeling through nature. Its landscape scenes [landschaftliche Szenen] were enjoyed as products of free nature [Werke der freien Natur]: they were, in a word, completely natural. ${ }^{2}$ Schiller gave the two poles equal value - just as he did the antimonies in his theory of human nature, just as he juxtaposed reason against feeling, necessity (whether moral or natural) against freedom, and art against nature in the creative opposition of the original form- and sense-drives. He demanded from the art of German gardening, the Mittelweg, an acknowledgement of the power of both poles and a commitment to balanced economy created by their reciprocal interaction. By the active mixture of styles and by "conforming to the demands of sound agriculture," Schiller wrote, a garden might be fashioned that represented "a characteristic whole meant as much for the Eye as for the Heart and the Understanding" (Schiller qtd. in Lee 141 my emphasis).

Welcome to Schiller's garden, an art object, an aesthetic space, an analogue of graceful human nature. His garden of aesthetics was planned and planted by Baumgarten and the rationalists and by the proponents of Empfindsamkeit as well as by the synthesizers Herder, Goethe and Kant. A place of contemplation for all humanity, it was reworked and transformed - then contemplated and enjoyed - by Schiller himself.

\section{The Science of Man: Early German Anthropology, Psychology and Aesthetics}

Here then is the only expedient, from which we can hope for success in our philosophical researches, to leave the tedious lingering method, which we have hither to followed, and instead of taking now and then a castle or

${ }^{2}$ For Schiller, a Garten was a work of art wherein Kunst is apparent, and Gartenlandschaft was one where all evidence of human agency had been artfully removed, an illusion of artlessness (Lee 139). 
village on the frontier, to march up directly to the capital or center of these sciences, to human nature itself; which being once masters of, we may every where else hope for an easy victory. From this station we may extend our conquests over all those science, which more intimately concern human life, and may afterwards proceed at leisure to discover more fully those, which are the objects of pure curiosity (Hume "Treatise" xvi). ${ }^{3}$

In the Enlightenment, the study of man, the "science of man," was the principal preoccupation. Through the various late eighteenth-century science traditions, whether materialism or vitalism, the whole man came down to earth. Human beings were more and more described as products of nature. ${ }^{4}$ The recognized hallmarks of life, the new understandings of nature and individual organisms, were applied to man. He was seen as a complex organism, a dynamic and harmonious balance of reciprocally relating parts situated in a similarly interactive environment, characterized by in-dwelling forces that promoted the functions specific to life - nutrition, sensitivity, responsivity, generation and development. This organismic description synthesized from medicine, natural history and natural philosophy encompassed not only man's physicality and the human

${ }^{3}$ And this: "I have difficulty conceiving how, in a century taking pride in splendid knowledge, there are not to be found two closely unified men - rich, one in money and the other in genius, both loving glory and aspiring to immortality - one of whom would sacrifice his wealth and the other ... years of life in order to study, not always stones and plants, but for once men and morals, and who, after so many centuries used to measure and examine the house, should finally make up their minds to want to know its inhabitants" (Rousseau 212).

${ }^{4}$ "Much of this theorizing - and this is of immense importance for Schiller's thesis of education through art - had taken place within the wider context of investigation, empirical and speculative, into the natural history of the human mind. However much they may have differed on points of detail, or even in their basic convictions, Diderot and the philosophes, Hume, Rousseau, and Herder, German psychologists and logicians such as Tetens and Lambert who, in the wake of Leibniz, took the creation of art as a paradigm of the general formative activity of the human mind - they all in their several ways helped to replace the picture of the psyche as a collection of discrete faculties by a picture of the psyche as a unity and continuity" (W\&W xxvii). 
mind, but all his relations and connections - with his species, his products (including art), and nature at large. ${ }^{5}$ Developed out of previously institutionalized disciplines, this perspective was enlarged by information and theories reintroduced at odd new angles and under new organization.

Early in the century for example, a burgeoning psychology [Seelenlehre, Psychologie], fueled by the terrific interest in the mind, grew active and became institutionalized in Germany. ${ }^{6}$ Just as his philosophy had directed much of the science-

${ }^{5}$ Blumenbach: "the whole collective assemblage of all the faculties and laws ... by which the functions of the human body are performed and regulated from the opening, to the closing pulse of life, is called human nature, or the nature of man; from whence arouse the name physiologie" (Reill 138).

${ }^{6}$ Psychology, like all the human sciences of the eighteenth century "developed through a rather complex historical process, full of theoretical détours and ambiguities," the origins of the discipline as obscure as interest in the mind and its nature, ancient (Moravia qtd. in Vidal 91). The word itself was coined by sixteenth-century theologians and so carries old connections of "soul," the rational, the immortal and immaterial. At first psychology was the study of "the nature of the human spirit or logical," the animus (spiritus, the immaterial, immortal soul) which was not the form of the body (i.e., it was distinguished from the anima, the life principle joined to the body). Treatises about the vital principle were not psychological but rather of the science of nature. Similarly, anthropology appeared in the early sixteenth century, sometimes designating the study of purely physical, the human body. In the eighteenth century, Buffon (who presented nine articles on anthropology in Histoire Naturelle and a monograph on man) and Blumenbach participated in the project of moving the philosophy of man to a science of the human species (Blanckaert "Buffon"). From the end of the seventeenth century through the early eighteenth century, "psychology" denoted the study of monads in general and pneumatology, "the science of intelligent monads, the human mind in particular" (Vidal 91-93). Often the psychological was divided into logical, based on the empirical study of the understanding, and the metaphysical disciplines: in reference to this confusion, Hume wrote that the "sole end of logic is to explain the principles and operations of our reasoning faculty, and the nature of our ideas .... [that to be incorporated] into the 'science of Man' upon which all other sciences would have to depend (Hume qtd. in Vidal 93). In Wolff's system empirical psychology was an experiential, observational, study of the soul (the mind), and his rational psychology involved constructing proofs of the soul's immortal nature. According to Vidal, Wolff distinguished between "“historical' (a posteriori, 'empirical') knowledge of existing things and events, from 'philosophical' (a priori, 'rational')." In his system, history alone was not scientific, not "a marriage of reason and experience." It was the philosophical or rational psychology 
[Seelen-Wissenschaft] that was scientific, the "science of possibles insofar as they can be" of the human soul; empirical psychology [Seelen-Geschichte] "established principles through experience" using observation and experimentation to be used by rational psychology (Wolff qtd. 98). In the Encyclopédie, the entry "Psychologie" was Wolffian in content, but it functioned as a Trojan horse through which to introduce more controversial views. Because of its historical etymology, empiricists and sensationalists (like Hume or Condillac) refused to use the term "psychology." The Encyclopedia Britannica of the late eighteenth century challenged the multiplicity of terms:

"Anthroposophy [anthropology], Psychology, and Pneumatology, if they be not words expressive of distinctions where there is not difference, seem to be at least very needlessly disjoined from each other ..." (97). Locke, of course, radically redefined it, reducing "psychology" "to what it really ought to be: the experimental physics of the soul" (Locke see page 179). In Germany beyond Wolff, according to Vidal, "psychology" was a term familiar to the academics of the Aufklärung; it acquired traction there in relation to questions about the education of man (109). There was also a culture (exemplified by Moritz) of self-observation and self-experimentation for scientific purposes in the late eighteenth century, but the epistemology of such endeavors is controversial. Kant varied in his outright rejection of the possibility of a psychological science: he was quite critical of such claims, but his statements are not "all of a piece." In the Metaphysical Foundations of Natural Science, for example, he wrote "empirical psychology must always remain outside the rank of a natural science properly so-called" (due to the impossibility of mathematization?); in the First Critique he required that psychology should not be mixed with logic, and then rejected "rational psychology." Kant "could imagine that psychology can become a science if only we could develop such a [chemistry-like] law for the attractive and repulsive forces governing alterations of, say, our perception." But, according to Strum, "he takes that it be impossible: 'The territory of psychology is forever restricted to inner sense, to which the full range of categorical principles, most notably causality, is not cognitively applicable. For that causality be applicable to a set of phenomena, we must be able to distinguish objective from subjective successions of appearances (see A193/B238). But such a distinction requires the determination of objects of outer sense. It follows that genuine causal relations cannot be attributed to psychological phenomena'" (a paraphrase of Kant in Sturm 163, 168). Rudolf Makkreel followed the fluctuations and ambivalence of Kant's attitudes toward human studies, psychology, anthropology and history. While these were sometimes labeled by him, Menschenkunde, i.e. studies of such low informational level that they do not deserve the designation of sciences, he continued to teach them. As an empirical observational discipline, psychology was subject to doubt and, as far as he was concerned, "[s]elf-observation is difficult, unnatural, can lead to revision and must not last long." In fact, Kant believed self-observation to be unhealthy at base: "the more attention one gives to oneself, the more hypochondriacal one becomes." The benefit of anthropology was that it is not merely the observation of the soul, but of objective traits of human nature. It was like geography and history, a historical science. "The world as an object of outer sense is nature, the world as an object of inner sense is the human being" (Kant qtd. in Makkreel 186, 187). Schiller, I believe, read Kant as making an impossibility claim and proceeded regulatively: he took Kant's position to be that 
of-life theorizing (especially in France), Leibniz' theories about the human mind and the monad grounded German psychology as it was carried forward by Wolff. Liebniz' conception of the mind as an active rather than a passive entity was a counterpoise to the passivity postulated by empiricist and sensationalist philosophers. He conceived of the monad as an ultimate substance, each determined to represent the universe in its own way. It was a "windowless" entity operationally opposed to the tabula rasa of empiricism. And as a whole, each monad was capable of development by appetition, the desire to improve its own representations. Monads were hierarchical with respect to perfection; the lowest class was capable of perception, the next feeling and memory; the highest reason - a corollary to the faculties of sense (or desire), feeling, and reason. For Leibniz then, the psyche was "a single unit, powered by a single force (appetition) and grounded in a single activity, the production of representations" (Bell 18). At the lowest level of its activity, the psyche was involved with obscure and confused sensations, petites perceptions:

To give a clearer idea of these minute perceptions which we are unable to pick out from the crowd, I like to use the example of the roaring noise of the sea which impresses itself on us when we are standing on the shore. To hear this noise as we do, we must hear the parts which make up this whole, that is the noise of each wave, although each of these little noises makes itself known only when combined confusedly with all the others, and would not be noticed if the wave which made it were by itself. We must be affected slightly by the motion of this wave, and have some perception of each of these noises, however faint they may be . . these minute perceptions ... constitute that je ne sais quoi, those flavours, those images of sensible qualities, vivid in the aggregate but confused as to the parts; those impressions which are made on us by the bodies around us

psychology was not a science, and, therefore, Schiller's hypotheses about the mind were made only "as if" data were empirical and "as if" scientific understandings could be applied. 
and which involve the infinite; that connection which each being has with the rest of the universe. It can even be said that by virtue of these minute perceptions the present is big with the future and burdened with the past, that all things harmonize ... (Leibniz 54-55).

Leibniz set the perimeters; Wolff wrote the texts, and by Schiller's time, Karl Philipp Moritz had begun the first German journal of psychology. This interest of course was also furthered by medicine, not just in the study of the anatomy and physiology of the nervous system, but in the practice of psychosomatic medicine and the theories about it. The young Schiller was a practitioner of this infant psychiatry (Fink 54-65; Dewhurst; Hansen "Metaphors," Diss.; Richards "Rhapsodies").

Another new perspective was provided by aesthetics, the "science of the senses." German aesthetics began in the philosophy and the philosophical psychology of the early eighteenth century which had, up to that time, emphasized the importance of reason and the mind's higher faculties as the site of our humanity, of knowledge discrimination and production (to the exclusion of sense). In spite of this emphasis, Leibniz and Wolff still found value in the experience of beauty, in art or in nature, because it was a pleasure. Their natural theological ground placed the pleasure of finding the agency of a perfect Creator at the center of the new discipline. From early in the tradition, then, in addition to producing a valuable physical response (that is pleasure), art was judged to have a positive impact on man's moral aspect (attractive perfection): the pleasure came from the perception of perfection in nature or in art, and the pleasure was in perfections that mirrored the perfection of God. ${ }^{7}$ Humans, by perceiving God's perfection, attained perfection and thus fulfilled their function in creation.

\footnotetext{
${ }^{7}$ Schiller's "Ode to Joy": "Pleasure was given (even) to the worm ..." [Wollust ward dem Wurm gegeben].
} 
The German feel for the individual was also carried forward by Leibniz's monad theory; his idealism paradoxically opened out an appreciation of difference based on the particularity of each individual, his sense organs, his environment and his past life experience. This value was held in tension with experience of a common sense of taste among men as a species. Then, while this concept of a standard of beauty was maintained by the further Leibnizian commitment to harmony and the premise that individuals reflected the essence of the cosmos in as far as each was able, a new, dynamic experience of history and its application to nature, society, and language pressed the case for a more nuanced stance toward standards over time and across cultures. History, released from the restraint of Judeo-Christian affirmation and the chronicling of power, provided this perspective and provided as well numerous developmental hypotheses about mankind. These histories, ones like those of Rousseau, Herder and Schiller, found human beginnings very close indeed to animal life and posited our difference to be flexibility and perfectibility. Even Kant, who came late from the physical to the life sciences, taught an anthropology (in the 1770's) that was grounded in the understanding that man as single species developed from a four-footed ancestor (this theory, significantly, explained the occurrence of varicose veins and hemorrhoids). ${ }^{8}$ In this determination, he followed Buffon's rule [Büffonsche Regel] (as did Herder), defining species by fertile descent from fertile ancestors. These endeavors were pressed forward by discoveries in ethnology and by all the popular but uneven accounts of primitive peoples and cultures. Interest in the human species as a biological phenomenon

${ }^{8}$ The boundaries of the science of man at the time were such that when Kant prepared his Anthropology course in the 1770's, he used Baumgarten's "Psychologia Empirica" chapter as text and taught principally about aesthetics (Guyer in CPJ xvi). See page 221 fn 5 . 
potentiated an enthusiasm for similar animals, the apes, for their description and comparative anatomy. The rudiments of both physical and cultural anthropology consequently can be traced back into the Enlightenment, back beyond their titular father, Johann Blumenbach. Archeological discoveries contributed to reexamination of past cultures; the enthusiastic gathering of data and artifacts from newly discovered and excavated sites at Herculaneum (1738) and Pompeii (1748) flooded the late eighteenth century with descriptions, casts and engravings, fresh perspectives and relativistic interpretations. These were avidly assimilated into both anthropology and the study of aesthetics. ${ }^{9}$

In Germany, aesthetics was a discipline that sought to include all of man - all his powers, all his products and all his relations. By the time Schiller crafted his treatise on aesthetic education for the whole man, all the sciences of man and a bouquet of different aesthetic theories were available to elaborate that art of living. ${ }^{10}$

\footnotetext{
${ }^{9}$ Herculaneum was first discovered in 1706; systematic excavations began in 1738 . The information about the excavations was disseminated through Le Antichità di Ercolano Esposte [The Antiquities discovered in Herculaneum], published in 9 volumes from 1755 to 1792. Many illustrations in the above were based on the work of Karl Jakob Weber, a Swiss architect and engineer in charge of the first organized excavations at Herculaneum, Pompeii and Stabiae. Pompeii was rediscovered in 1748 as the result of plundering by the Spanish treasure-seeker Rocque Joaquin de Alcubierre. Karl Weber again directed the first scientific excavations; after his death in 1764 military engineer Francisco la Vega continued the archeological work.

${ }^{10}$ In letters exchanged between Schiller and Körner in 1793, Schiller's aesthetics reading was partially enumerated. Schiller: "I already possess Burke, Sulz[e]r, Webb, Mengs, Winckelmann, Hume, Batteux, Wood, Mendelssohn and five or six others." Körner recommended Hogarth, Hagedorn, Duclos, Lessing, Herder, Reynolds and Moritz among others $(11,18$. i.1793 Schiller-Körner on line). Wilkinson and Willoughby also recognized Baumgarten, Goethe, Home, Mirabeau, Rousseau and Diderot as sources. Schiller mentioned Kant, Fichte, Burke, Mengs and Herder by name in the Aesthetic Letters (W\&W lxxiv).
} 


\section{Alexander Baumgarten, Father of Aesthetics}

The intention of the founder of aesthetics, Alexander Gottlieb Baumgarten (17141762), was not to write a philosophy of art: what he attempted was "to provide an alternative approach to the philosophy of human knowledge, experience, and perception that [went] beyond the purely rationalist, empiricist, and sensualist approach. In short, Baumgarten transcend[ed] the old opposition between rationalism and sensualism. His core theme [was] the improvement [perfectio] of human knowledge and cognition and the ways to reach this goal" (Gross 403). ${ }^{11}$ His work countered the objection, the early Enlightenment cultural stance, that "impressions received from the senses, fantasies, emotional disturbances, etc., are unworthy of philosophers and beneath the scope of their consideration." He believed, rather, that "the philosopher is a man amongst men and it is not good for him to think that so great a part of human perception has nothing to do with him" (Baumgarten "Prolegomena" Harrison 490). Further,

[p]hilosophers might still find occasion, not without ample reward, to inquire also into those devices by which they might improve the lower faculties of knowing, and sharpen them, and apply them more happily for the benefit of the whole world. Since psychology affords sound principles, we have no doubt that there could be available a science which might direct the lower cognitive faculty in knowing things sensately ("Reflections" Harrison 488). ${ }^{12}$

His rationalism was based not only in the philosophies of Leibniz and Wolff, but in a negotiation of the polarities of German Pietism. Raised in Pietism, Baumgarten was

${ }^{11}$ As late as 2002, there was no complete modern edition/translation of Baumgarten, whether in German or English (Gross 404).

${ }^{12}$ The passage is part of Baumgarten's inaugural dissertation, Meditationes philosophicae de nonnullis ad poema pertenentibus 1735 ("Philosophical Meditations on some Matters pertaining to Poetry" published as Reflections on Poetry). The previous quote's source is the "Prolegomena" of the Aesthetica 1750) 
aware both of its attractive emphasis on feeling, interiority and authenticity and of its unenlightened absolutism (exemplified later in the dismissal from Halle of the popular professor of natural philosophy and mathematics, the rationalist Christian Wolff). This juxtaposition made him interested in the claims of sense and alert to avoiding its abuses. While Baumgarten's brother became a renowned cleric (Voltaire called him the "crown of German scholars"), Baumgarten became, according to Herder, "the real Aristotle of our time" and the one of Wolff's pupils who "really mastered the logical technique which Wolff taught and by which he first gave German philosophy a definite shape of its own" (Cassirer 338). ${ }^{13}$ His thorough understanding of logic made him quite realistic about the exercise of reason as well. He was uniquely aware of the "limits of every human approach to the real world [man's Grenzbewusstsein]" (Gross 407 my emphasis).

According to Cassirer, Baumgarten

was not only the outstanding scholastic logician who was a master of all aspects of this discipline ... [but] through his mastery of the subject he became especially conscious of both the intrinsic and systematic limitations of formal logic. As a result ... Baumgarten was able to make his original contribution to the history of thought, which lay in the philosophical foundation of aesthetics .... Thus aesthetics evolves from logic [and in this] Baumgarten does not remain a mere 'artist of reason'; in him that ideal of philosophy is realized which Kant called the idea of the 'self-knowledge of reason.' He was a master of analysis; yet his mastery does not lead him to overestimate its value but rather to define clearly, and to distinguish sharply between, the means and the ends of analysis. The highest development of analysis stirs it into productivity again, bringing it to the point where, as if by itself, a new starting-point appears and a new intellectual synthesis opens up (339). ${ }^{14}$

\footnotetext{
${ }^{13}$ Herder wrote that Baumgarten "looked down into the abyss of the human psyche to the point where the feelings of the animal turn into the feelings of the human being" (W \&W $\mathrm{xxi})$.

${ }^{14}$ Kant, whom Cassirer noted referred to Baumgarten as an "excellent analyst," doubted his approach to aesthetics in the First Critique, only to embrace it in the Third. "The Germans are the only people who at present use this word to indicate what others call the critique of taste. At the foundation of this term lies the disappointed hope, which the
} 
The Leibnizian-Wolffian system from which he received a model of the mind distinguished higher and lower faculties. Higher faculties "housed" reason, the producer of "real" knowledge, of distinct ideas, those that led to the achievements of mathematics and natural sciences. The lower faculties were associated with aistheta, sensual perceptions that managed only indistinct concepts [cognitio confusa] (Gross 407). Baumgarten's new science of aesthetics demanded recognition for a new kind of knowing, the knowing of the lower faculties, and that knowing included as its object, beauty. From Cassirer's perspective, that human capacity and its new science of aesthetics

abandon[ed] itself to sensory appearance without attempting to go beyond it to something entirely different, to the grounds of all appearance. For [any] such step ... would not explain the aesthetic content of appearance, but destroy it .... [B]eauty can be perceived only by undivided observation, by pure contemplation of the ... whole. Only the artist, the painter or the poet can reflect this totality and put life into every feature of his representation" (Cassirer 343-344). ${ }^{15}$

eminent analyst, Baumgarten, conceived, of subjecting the criticism of the beautiful to principles of reason, and so of elevating its rules into a science. But his endeavours were vain. For the said rules or criteria are, in respect to their chief sources, merely empirical, consequently never can serve as determinate laws a priori, by which our judgement in matters of taste is to be directed. It is rather our judgement which forms the proper test as to the correctness of the principles. On this account it is advisable to give up the use of the term as designating the critique of taste, and to apply it solely to that doctrine, which is true science - the science of the laws of sensibility - and thus come nearer to the language and the sense of the ancients in their well-known division of the objects of cognition into thought and sense [aiotheta kai noeta], or to share it with speculative philosophy, and employ it partly in a transcendental, partly in a psychological signification" (Critique of Pure Reason A 21 note).

${ }^{15}$ Beauty, wrote Schiller, as the object of the Inner Sense was a phenomenon revealed by the common sense: "[f]or the whole magic resides in its mystery, and in dissolving the essential amalgam of its elements we find we have dissolved its very being" (I.5). Goethe: "Fluttering the fountain nigh/ The iridescent dragonfly/ An hour mine eye has dwelt upon/ Now dark, now light alternately/Like the chameleon;/ Now red, now blue,/ Now blue now green/ How would its hues appear/ If one could but come near/ It flits and however, resting not - / Hush! on a willow bough it lights;/ I have it in my fingers 
The goal of Baumgarten's cognitio sensitiva, reached through sensitive perception and the cultivated powers of representation, "is the grasp of the special, the particular, in the diversity and complexity of its relations and connections." This confused representation possesses 'extensive clarity,' and in order to preserve that quality, things must be dealt with as the complex assemblages they are (Gross 409-10). Then Baumgarten's abundance, magnitude, truth, clarity, light and certainty, all the wealth of meaning and significance, are preserved in the impression of the "life of knowledge" (Cassirer 347). ${ }^{16}$ Wilkinson and Willoughby reiterated the holistic aspect of Baumgarten's innovation but with a slight change of perspective: they experienced him as attending to a kind of knowledge that mediated between the lower faculties' ideas of sense and the higher "distinct" ideas, those analyzable to the truth behind appearance by reason. In the end, it came to the same thing: Baumgarten turned to "a mode of perception in which wholes are neither cursorily recognized for practical purposes and cursorily dismissed, nor yet subjected to the analytical procedures of science and philosophy, but dwelt on in their sensible and undivided appearance for the sake of the insight and delight such contemplation may afford" (W\&W xx-xxi). For both Cassirer and the translators of the Aesthetic Letters, the etymology of confusa was key to

caught,/ And now I seek its colors true/ And find a melancholy blue -/ such is thy lot, dissector of delights!" (qtd. in Cassirer 344-5).

${ }^{16}$ Schiller used this concept in his idea of extensivity: "The more facets his Receptivity develops, the more labile it is, and the more surface it presents to phenomena, so much more world does man apprehend, and all the more potentialities does he develop in himself." Extensivity is a way of taking in content (passively), of suspending activity toward things. This cast of mind quality must be balanced by intensiveness: "The more power and depth the Personality achieves, and the more freedom reason attains, so much more world does man comprehend, and all the more form does he create outside himself" (XIII.3). 
understanding the value of sensate perception. An exploration of the word's meaning also connected the intuition of wholes to the human experience of organisms, life forms seen as complex and boundaried.

If the realm of aesthetics can be characterized by the expression "confused perception," this can only be done on the condition that we understand this expression in its strictly etymological sense. This would mean that in all aesthetic intuition a confluence, a fusing together, of elements takes place, and that we cannot isolate the individual elements from the totality of the intuition. But such a confluence creates no disorder; for this complex presents itself to direct perception as a definite and harmonious whole. According to the fundamental thesis of Baumgarten's aesthetics, no such organization is attainable solely by means of concepts .... These "inferior" cognitive forces also have their rational principle, and for them too a special epistemology, an "inferior knowledge" [gnoseologia inferior] is requisite" (Cassirer 346 my emphasis, also W\&W xxi).

A definite and harmonious whole that included all its relations and connections.

The significant ideas that organize Baumgarten's work as the science of man are his concepts of beauty [pulchritudo] and of completion [perfectio]. These concepts work reciprocally to create a new idea of the human being, an anthropological image, felix aestheticus. "Baumgarten upholds the validity of sensibility; he [did] not, however, merely seek to release sensibility from all restraint but rather to lead it to its spiritual perfection. This perfection cannot lie in enjoyment but only in beauty. Beauty is pleasure, but this pleasure is specifically different from that other kind which is derived from mere sense impulses" (Cassirer 356). Beauty is the perfection of the sensate; through perfectio, pulchritudo aims at the whole, the all [Ganzheit], "the whole with all its connections and relations." ${ }^{17}$ And the aim of the discipline of aesthetics is to develop and improve human sensitive knowledge, wrote Baumgarten, adding, this too is beauty.

${ }^{17}$ Gross emphasized that this conjunction gave Baumgarten's aesthetics "an extraordinary dynamic." This dynamic was timely: it fit well with the change in the vitalist experience of history, taken forward by Herder. 
Through perfectio, human capacities are improved and perfected. It followed then that it is a human duty to be mindful of the object, to think beautifully, i.e. "to be aware of and sensitive to the object, and not to the object alone but to all the relations of that object" (Gross 410-411). Because it is impossible to grasp the whole from any limited position, the possibility of knowledge from numerous perspectives both limits knowledge claims and makes each point-of-view significant. The art of thinking beautifully also made demands of the arts and specifically poetry. Poetry should "convey not only form but color; not only objective truth but sensitive force; and not only correct but vital insight," and the poet ought to use words, not as paint, but in order to provoke his readers to create their own "clear and vivid sensuous ideas." This position allows for a participatory creativity and a grounded contemplation of objects, a transformation through the use of abstract symbols. Like the philosopher, the artist must be "a man among men: nor does he rightly think so great a part of human knowledge alien to himself." Both must strive for totality: "the 'beautiful sciences' now form no longer simply a relatively independent province of knowledge; they 'activate the whole man' and are indispensable to man's realization of his true destiny" (Cassirer 348-353). In requiring philosophy to be more humanistic, Baumgarten spoke for the whole new science of man - for the psychological and anthropological sciences in their infancy. "The two faces of Baumgarten's aesthetics - theory of knowledge and philosophical anthropology - mirror each other," wrote Gross. "To think beautifully, that is, to grasp the object in a way that acknowledges its embeddedness in the various relations that constitute its specific character, unavoidably presupposes a person in a continual process of developing all his powers and senses, and exploring them in all possible dimensions" (412). 


\section{The Force of Feeling}

$[T]$ he way to the head must be opened through the heart. The development of man's capacity for feeling is, therefore, the more urgent need of our age, not merely because it can be a means of making better insights effective for living, but precisely because it provides the impulse for bettering our insights (VIII.7).

The positive valence of pleasure made all of human physicality of interest to German philosophers: pleasure became important scientifically, artistically and culturally, not just as the possibility of another kind of knowledge but as a product of the senses and the ground and corollary of emotion. As the harbinger of the Enlightenment's neglected pole of feeling opposed to reason (animal/rational, sense/understanding, nature/art), it represented the undervalued aspect of humanness, sensibility - with all its perceptions and emotions. If sensitivity were restored - and with it humanity to equilibrium Enlightenment hopes and values might be salvaged.

But before sense was restored to equality with reason, it was acclaimed and advanced as the remedy to every problem, the cure of ills and the cause of all that was sublime in human nature. Creativity, genius and spontaneity of mind, not to mention motivation for any purposive action, arose from feeling: the restatement of physicality and the rehabilitation of sense began with a vengeance. Physicality was carried into aesthetics through the English empiricists, and it moved even the rationalist theorizers toward the register of emotion and to subjects of creativity and genius. Psychology and art mixed to present the dramatic characters of Sturm und Drang, the man of violent action [Kraftkerl, Kraftmensch, urkräftiger Mensch] and the suffering woman [leidendes Weib] (Bell 54, Leidner Impatient 47-62). 
"In Germany, the emancipation of the senses led to a repudiation [of dualism] that promoted the rise of the discipline of 'anthropology' as the empirical science of the 'whole man' in the latter part of the century" (1016). After the 1750's, the importance of the capacity for powerful, integrating feeling (Empfindsamkeit), including pleasure, was posited as a good in itself. According to Catherine Minter, this wave of sensualist philosophy, Empfindsamkeit, was carried forward by two impulses: the understanding of sensibility in its physical sense (derived from neurophysiology and current ideas about the functioning of the nervous system) and the valorization of moral sensibility, of the capacity to be powerfully emotionally affected.

On one hand, moral Empfindsamkeit, the capacity to experience and be deeply affected by emotion, had an immensely positive valence as a late Enlightenment correction of reason with feeling. The goals of enlightenment after the Sturm und Drang period came to depend on both an autonomous reason and a vigorous life of feeling, upon the whole man. They depended on the feeling's participation in motivation and man's free agency in the world of action; they required the maintenance of a capacity for accurate perception and the development of an energetic emotional life. These became urgently important undertakings. Again, the physiological psychological model of the nervous system as the quick and vigorous processor of sensations by means of nerves ("similar to electricity or magnetism" which is "ccleverly' contained in the nerve," according to Schiller's mentor Jakob Friedrich Abel), was central to descriptions of the "speed and power of emotions and ideas" (Dewhurst 129; Minter 1020). Emotions and passions grew by association and sympathy, and "typically, the bonds between friends and lovers were conceived of as physical forces, usually of a magnetic or electric nature" 
(1022). There also developed an ideal of vigor, "of manly energy [that] informed and overlapped with a particular conception of sensibility." Vigor was associated with an [equally active drive toward an] "eminently healthy, invigorating type of solitude," a situation to be used constructively to consolidate inner strength [Geistesstärke, Festigkeit] and to ward off melancholy [Nervenzufälle, Kraftlosigkeit] (Minter 1023). The physiological model endowed "emotions with holistic potential because ... transitions between sensations, emotions and ideas are fluid" and interactive; in it, emotions and passions also had the capacity for transmutation and growth, and they, as active expressions of inner states and spurs to action, were testimony that "a person could be empfindsam without being a passive victim of emotion" (Minter 1024). Human minds were active, capable of incisive ideas and sublime imaginative constructions, generative of great deeds.

As the most sensitive (and most widespread) part of the organism, the nervous system was conceptualized in late eighteenth-century Germany according to the popular understanding of Haller's studies on sensitivity and irritability and according to the psychosomatic traditions from Montpellier and England. From the medical (pathologizing) perspective, the influence of the psyche was also experienced as powerfully pervasive and capable of causing imbalance; consequently, descriptions of unhealthy or excessive feeling, including its symptoms and situations, found their way into professional and popular literature. The Sorrows of Young Werther and Karl Moritz's thinly disguised self-portraits in Anton Reiser and his journal are examples of 
the period's fascination with this type of nervous illness. ${ }^{18}$ Grammont's premorbid personality as described by the medical student Schiller (see page $274 \mathrm{fn} 58$ ) and reproduced in his character Julius show the linear entry of physicalism (psychosomatic medicine) into literature. ${ }^{19}$ The symptoms of the unhealthily empfindsam, documented in patients in a case study or attributed to a character in a sentimental novel, included, for example, nervous fever, unrealistic aspirations to write poetry and cloying sentimentalization or over-sexualization of relationships. ${ }^{20}$ Female characters are depicted as particularly prone, because of a perception of women's exaggerated capacity

${ }^{18}$ Goethe confided that he wrote "Werther ... to free himself from a "stormy element' that threatened to destroy him." What worked for him didn't appear to work for his readers: in the reprinted version of 1775, he added the warning, "Sei ein Mann, und folge mir nicht [Be a man: don't do as I do]" (Leidner Impatient 29, $115 \mathrm{fn} \mathrm{1).}$

${ }^{19}$ G.S. Rousseau cautioned against considering this transmission one-way, only from science to literature. Introducing a study about the interface of English literature and psychology, Fox elaborated on that observation: "the flow can also move the other way, especially in an age when many doctors ... wrote for popular audiences and considered themselves men of letters, or when 'literary' authors like Samuel Johnson wrote articles for Dr. James's Medicinal Dictionary (1743). In 1768, J.F. Zückert, physician and physiologist, note[d] that Richardson provide[d] a textbook case in Clarissa of the morbid effects of 'heart-break' - 'slow consumption,' gradual wasting away of the limbs, and death" (R. qtd. in Fox 10). Diffusion is confused; it must be considered in all its connections and relations.

${ }^{20}$ It is worth noting that Simon-Andre Tissot (1728-1787), a physician who made his way in the world by elaborating on the dangers of masturbation to health, was invited to address the young men at Karlsschule while Schiller was a student. "Although Tissot condemned all sexual excesses, he stressed in particular that the unnatural loss of semen was most likely to cause innumerable disorders such as debility predisposing to consumption, visual deterioration, disorders of digestion and impotence. But its most serious effect was to produce an increased flow of blood to the brain, distending and weakening the nervous system and eventually causing insanity" (Dewhurst 42-43). In his chapter, "Onanism," Vidal described Tissot and his system of naturalistic ethics (based on health consequences), opposing it to Kant's morality of duties to oneself (Daston and Vidal 254-281). Vidal's work included a sequential illustration: in it the young man grew more and more debilitated with each frame, and finally appeared moribund, succumbing to consumption as a result of his unhealthy habit. 
for sympathy, to assimilating physically the qualities of whatever they saw or to transplanting their emotions to the site of their sense organs, a sort of "heart on one's sleeve" phenomenon. "Relocalization of the soul to the senses," wrote Catherine Minter, "is at least nourished by the vitalistic neurophysiology of Empfindsamkeit, which makes fast and fluid transitions possible throughout the body and opposes polarization of body and soul, of sensations and ideas" $(1018-20,1021)$.

Sense was established in two camps then, as a rationality all its own and as a neglected aspect of our nature, the contribution of our physicality to humanness. Both traditions, the theoretical and the experiential, made claims for the rehabilitation of sense for the benefit of the whole man. If it can be said that Baumgarten sought to establish the senses from the top down, by securing for them a reason and an epistemology, Herder can be seen as enforcing the value of the senses and emotions, empirically, from the bottom up. And his effort at aesthetics, the science of feeling, was in the service of complete humanness. "A man who desires to be solely head," he wrote, "is just as much a monster as one who desires to be only heart; the whole, healthy man is both. And that he is both, with each in its place, the heart not in the head and the head not in the heart, is precisely what makes him a human being" (Aesthetics 3$).^{21}$

\footnotetext{
${ }^{21}$ From Daniel Dahlstom's perspective, Hamann, Herder and Schiller were among those most responsible for the holistic turn in German thought - the Counter-Enlightenment correction (Ameriks 76). In this series of men, each fifteen years the other's junior, the whole man's plunge to earth is quite dramatic: for Hamann, natural man is divine; in Herder natural man stands in relation to God and his purposes, and in Schiller natural man is secularized. Hamann was convinced that "highest act of reason, which embraces all Ideas, is an aesthetic act, and that truth and goodness are brothers only in beauty" (Bernstein viii-ix). This idea descends intact through the genealogy. Herder struggled to balance Haman and Kant's influence in his intellectual life, while Schiller lived the synthesis of Kant and Goethe.
} 
Herder, much as he admired Baumgarten, felt that in the end the father of aesthetics had managed his subject abstractly and from a distance. He insisted on bringing aesthetics down to the particular, to philosophizing about beauty, taste and aesthetic education in the flow of sense, feeling and emotion. So, he wrote, "I feel! I am!" (Aesthetics 14). Led by Winckelmann's study of Greek sensuality and Lessing's understanding of the art object as directly presented to the intuition, Herder moved the emphasis from systematic aesthetics to philosophical anthropology (Moore in Herder Aesthetics 5, Cassirer 353). He proceeded empirically; he did research, examining artifacts and tracing the artworks back to their cultures and periods. In doing so he stressed both the subject's entire experience (whether artist or perceiver) and the object's sensuous properties. He upheld genius as a power, a force, and taste as the judgment or ordering of that power. He proselytized for education by belles lettres, beginning in childhood.

Herder was the protagonist in the establishment of emotion as central to healthy, more, sublime individuality. The understanding of emotion as part of the active life of man, not only in terms of motivation, but in a vibrant internal environment, found expression in his theories of force. For him, the essence of life and of organism was force. "Genius is an aggregation of natural forces" he wrote; genius is a second creator, one who imitates nature organically, and only nature. He developed themes (and metaphors) made popular by Edward Young, whose Conjectures on Original Composition had two separate German translation by 1760 . Young wrote, "An Original may be said to be of a vegetable nature; it rises spontaneously from the vital root of 
Genius; it grows, it is not made" ( $11 \S 43$ Young, on line). ${ }^{22}$ Herder made force the essence of art as well. He believed that in poetry force is responsible for the transmission of the meaning of arbitrary signs to the reader. An analogue of natural forces, this power of words (transformed) acts like the "force [that is] responsible for charging a storm cloud with electricity and discharging it through lightning" (Moore in Herder $\underline{\Lambda \text { esthetics }}$ $10)$.

After mid-century, genius loomed large; charisma was all, and great deeds formed a correction of a muted enlightenment. Then taste opposed feeling, originality, creativity and genius; taste was derivative, reasoned and conventional. In the midst of Strum und Drang, "the worship of genius meant also a one-sided celebration of 'feeling,' and the denigration of taste signaled a rejection of the rational culture [Verstandeskultur] of French neoclassicism and the Enlightenment" (Moore in Herder Aesthetics 21). Then, Herder entered the fray to safeguard "the equilibrium of human powers." He balanced individual force in his aesthetic philosophy through the identification of a drive-like empathy basic to human life, the common feeling for other human beings, Mitgefühl. Consideration of past cultures, of great ages, led him also to value taste as a part of genius creation, to see the reciprocity between the creative artist and his community. Herder enthusiastically tended the vegetable metaphor to make his point: the vegetable genius must come first, then taste cultivates him and his fellows:

So if taste can arise only through geniuses - that is through natural powers that operate quickly and vivaciously - then taste must also desire to persist in them; otherwise it is nothing but reverberation in the air, an echo. An abundance of trees, plants, and meadows makes a garden; and once the garden exists, then order, taste, and landscaping can develop. But without

\footnotetext{
${ }^{22} \mathrm{He}$ continued: "Imitations are often a sort of Manufacture wrought up by those Mechanics, Art, and Labour, out of pre-existent materials not their own."
} 
a garden we cultivate air... [Only a] dunderhead [could fail to] use or comprehend it; taste is only order in the application of powers of genius, and hence taste without genius is an absurdity. Conversely, the more powers a genius possesses, the quicker the powers operate, then the more necessary is the mentor of good taste, so that the powers do not overwhelm and destroy one another... (Aesthetics 310).

Taste then was not simply an instinctive or intuitive judgment, but judgment applied to life and living one's particular life. "Only when genius is exercised in conjunction with what Herder calls true reason does that order of our instinctive powers arise which constitutes taste. Only the misuse of reason, only pedantry and irrationality can ever corrupt taste. Finally, taste and virtue overlap but are not identical: taste is the order of our sensuous nature, but virtue is the equilibrium of all the powers of the mind" (Moore in Herder Aesthetics 21).

Herder was committed to aesthetic education. The experiences of belles letters, should begin early. They must

cultivate the so-called lower faculties of the soul, sensuous cognition, the wit, the imagination, the sensuous appetites, enjoyment, the passions and inclinations. Is not this very definite sufficient proof that they therefore exert the finest and best influence on the higher sciences, which concern themselves with judgment and understanding, the will and convictions? .... [A] sound understanding is impossible without sound and wellordered senses, a decisive judgment is impossible without an imagination tamed and heedful of its duty, a good will and character are impossible without passions and inclinations in good order. Hence it is both wrong and foolish to cultivate the higher sciences without the belles lettres, to plow the air when the soil lies fallow (Aesthetica 338).

Studies in literature and the arts are, in short, a school of the senses. The humanities help human beings to avoid premature and narrow specialization; they "inspire and nurture in us the feeling of humanity by which we realize ourselves and develop our potential to its fullest extent." The result is a balanced human being; like the felix aestheticus of 
Baumgarten, a reasoned thinker who is in love with the sensory world (Aesthetics 23, 24).

Schiller incorporated Herder's synthesizing achievements into his anthropology: sense came first to the human being who was an amalgam of sense and reason. Genius had a high value for Schiller as well, but taste was the objective indication, the outward and visible sign of our common humanity. From that perspective, humans in community make beauty. And Schiller, of course, looked to aesthetic education as the means to the end - and as the end as well, but as the approached, never gained end of man. For man to develop toward wholeness,

[h]is education will therefore consist, firstly, in procuring for the receptive faculty the most manifold contacts with the world, and, within the purview of feeling, intensifying passivity to the upmost; secondly, in securing for the determining faculty the highest degree of independence from the receptive, and within the purview of reason, intensifying activity to the upmost. Where both these aptitudes are conjoined, man will combine the greatest fullness of existence with the highest autonomy and freedom, and instead of losing himself to the world, will rather draw the latter into himself in all its infinitude of phenomena, and subject it to the unity of his reason" (XIII.3). ${ }^{23}$

Schiller concurred with Herder, then, when he wrote, "[t]his much is settled: by itself the principle 'imitate Nature!' leads mostly to arid observations. But the principle 'pursue sensuous perfection!' concentrates, as it were, all the rays of Nature in my soul and is nothing other than the application of the oracular injunction $\mathrm{O}$ mortal! Know thyself!" (Herder in "A Monument to Baumgarten" Aesthetics 46).

${ }^{23}$ On the education of man: "Thus man, when he reflects, can conceive of Virtue, Truth, Happiness; but man, when he acts, can only practice virtues, comprehend truths, and enjoy happy hours. To refer these experiences back to those abstractions - to replace morals by Morality, happy hours by Happiness, the facts of knowledge by Knowledge itself - that is the business of physical and moral education. To make Beauty out of a multiplicity of beautiful objects is the task of an aesthetic education" (XVI.2). 
Just as Herder intended to apply a new experimental method [Beobachtung und Erfahrung, observation and experience] to the study of man in the form of a genetic psychology, a developmental history of the species, Schiller intended to do the same and to extend the work. He added his own subjective capacities, sharpened through the necessities of characterization in drama, that is, his intensified self-awareness, empathy and capacity for representation, to analyze the human type and the inner drives that organize human nature and human experience.

"All the powers of our soul are only one power," wrote Herder (Aesthetics 338). Schiller too sought the unity of the psyche. He followed "the thread which will guide us through the whole labyrinth of aesthetics," the dynamic course that connects matter and form, negotiates passivity and activity, and leads to where feeling and thought meet. His intent was to "make this union complete; and to do it with such unmitigated thoroughness that both these conditions totally disappear in a third without leaving any trace of division behind in the new whole that has been made; otherwise we shall only succeed in distinguishing but never in uniting them" (XVIII.4 my emphasis). In his search for a unifying state, one of the organizers for Schiller was his conception of beauty in terms of its situation. He held that beauty brings the sensuous man to form and thought, and the conceptualizer down to the particulars of reality, to a unity of the aesthetic state. ${ }^{24}$ On an individual level, this aesthetic state provides for free choice by allowing man to contemplate, to pause and disengage from what determines him. Within this pause, an individual has the opportunity, in essence, to start over once again, before he emerges.

${ }^{24}$ From Herder's perspective, "art activates the totality of the organism; it is produced by the cooperation of our sensuous, imaginative, and intellectual faculties, by our interaction with the world around us, and so an analysis of art will inevitably shed light on the complexities of human nature and experience" (Moore in Herder Aesthetics 3). 
Schiller believed that a society full of such (aesthetically developing) individuals would also have the potential to develop and transform.

In the midst of the fearful kingdom of forces, and in the midst of the sacred kingdom of laws, the aesthetic impulse to form is at work, unnoticed, on the building of a third joyous kingdom of play and of semblance, in which man is relieved of the shackles of circumstance, and released from all that might be called constraint, alike in the physical and the moral sphere (XXVII. 8). ${ }^{25}$

For Schiller, beauty and humanity then were conditions of each other's existence:

without humans, no beauty, and without beauty no humans. Humans not a human being.

Why? The development of the aesthetic requires society, culture in collaboration with

each individual, and beauty also is upheld by a sense of commonly held judgment: the judgment of beauty is a reciprocal relation with other minds.

To watch over these, and secure for each of these two drives its proper frontiers, is the task of culture, which is, therefore, in duty bound to do justice to both drives equally; not simply to maintain the rational against the sensuous, but the sensuous against the rational too. Hence its business is twofold: first, to preserve the life of Sense against the encroachments of Freedom; and second, to secure the Personality against the forces of Sensation. The former it achieves by developing our capacity for feeling, the latter by developing our capacity for reason (XIII.2)

\section{Theories of Art and Schiller's Theory of Art}

The whole labyrinth of aesthetics (XVIII.3)

Beauty, then, is indeed an object for us, because reflection is the condition of our having any sensation of it; but it is at the same time a state of the perceiving subject, because feeling is a condition of our having any perception of it. Thus beauty is indeed form, because we contemplate it; but it is at the same time life, because we feel it. In a word: it is at once a state of our being and an activity we perform. (XXV.5)

\footnotetext{
${ }^{25}$ Throughout the Aesthetic Letters, Schiller, in moments of self-observation, recognized that his manner of argument, analysis, seemed paradoxical to his solution. In all he sought unity, but a unity gained by indirection: "Nature (sense and intuition) always unites, Intellect always divides; but Reason unites once more" (XVIII.4ftn). A reason that includes aesthetic judgment, that is.
} 
Schiller's larger stance was that aesthetic education is education for life, and the Aesthetic Letters was an exhortation to each of its readers to develop himself toward wholeness while being active in the life of the community. In order to orient the development he encouraged, Schiller was determined to establish some perimeters for beauty in nature, in art and in graceful humanity. His intent was wholeness: $a$ whole species united by the play drive, an archetype of humanity open to potentiality through beauty. He envisioned a developing individual seeking wholeness in a potentiating society, a person seeking his own freedom and that of others, not compartmentalized by civic claims on his talents and time. And he sought a unified psyche in balanced tension and equilibrium, graceful in virtue. He would have beauty to be a whole as well - like an organism with its connections and relations - subject and object, genius and communal taste, sense and emotion coupled with judgment.

As a synthesizer, Schiller struggled to abstract the value of several classes of aesthetic theories with which he was familiar and to combine those elements in a formulation that stressed the sensual and the consensual. He incorporated features from the British empirical and French sensationalist thinkers, ideas from the tradition of Leibniz, Baumgarten and Mendelssohn, and methods, distinctions and metaphors from Kant's theory, itself a synthesis of all the former views. These he described in Letter XVIII: some theories, he wrote, remained at the level of the beautiful experience as a whole, at what would be synthesis if only analysis had been performed. Other theories succeeded in analyzing the components of the beautiful, the parts of the experience of both the subject and the object. Such theories presented the results of an analysis, which beauty did not survive; this theory-type's synthetic component was inadequate and could 
not account for the whole. In other words, the former credited feeling and sense in order to protect beauty as a (dynamic) force, and the latter knowledge and intellect in order to preserve the logic of beauty. ${ }^{26}$ The first he associated with Edmund Burke, who identified beauty with sensations and feelings. In this English empirical tradition, beauty was its sensual effect on us, the pleasure it brings. Its pleasure differed, however, from desire which includes possession. ${ }^{27}$ Burke, who noted that "when we go but one step

\footnotetext{
${ }^{26} \mathrm{~W} \& W$ noted in their commentary that Schiller felt Letter XVIII was one of the most important for understanding what he is about, "analyzing as it does the two basic, and basically opposed, approaches to the problem of beauty, and proposing his own resolution of the conflict between them." In a much earlier letter to Körner, 25.i.1793, he had actually distinguished three possible ways of explaining beauty: "the sinnlichsubjectiv (Burke and many others); the subjectiv-rational (Kant); the rational-objectiv (Baumgarten, Mendelssohn, and the whole tribe of 'beauty = perfection types'). The fourth way, his own, was to be the sinnlich-objectiv" (W\&W 257). In the Kallias Letters, Schiller wrote: "It is impossibly difficult to construct an objective concept of beauty and to legitimate it completely a priori out of the nature of rationality, in such a way that experience may confirm the concept, but that such confirmation from experience is not necessary for its validity [and if I cannot do so, Kant will be right about taste always remaining empirical] .... It is worth noting that my theory is a fourth possible way of explaining the beautiful. Either one declares it subjective or objective; and either subjective sensual (like Burke and the others), subjective rational (like Kant) or rational objective (like Baumgarten, Mendelssohn and the whole crowd of men who esteem perfection), or, finally sensuous objective; a term which will mean little to you at this point, save if you compare the other three forms with each other (Bernstein Trans. Stephan Bird-Pollan 145-6). Beiser translated sinnlich as "empirical" and worked through different ways of approach, finally opting to "construe . . . loosely and liberally" (53-57).

${ }^{27}$ Burke: "By beauty I mean, that quality or those qualities in bodies by which they cause love, or some passion similar to it. I confine this definition to the merely sensible qualities of things, for the sake of preserving the utmost simplicity in a subject ... from the direct force which they have merely on being viewed. I likewise distinguish love, by which I mean that satisfaction which arises to the mind upon contemplating any thing beautiful, of whatsoever nature it may be, from desire or lust; which is an energy of the mind, that hurries us on to the possession of certain objects, that do not affect us as they are beautiful, but by means altogether different. Which shows, that beauty and the passion caused by beauty, which I call love, is different from desire ..." (83).
} 
beyond the immediately sensible quality of things, we go out of our depth" (117), confined his explanation of our attribution of beauty to the action of our senses.

[S]ince [Beauty] is no creature of our reason, since it strikes us without any reference to use, and even where no use at all can be discerned, since the order and method of nature is generally very different from our measures and proportions, we must conclude that beauty is, for the greater part, some quality in bodies, acting mechanically upon the human mind by the intervention of the senses. We ought therefore to consider attentively in what manner those sensible qualities are disposed, in such things as by experience we find beautiful, or which excite in us the passion of love, or some correspondent affection (102).

Schiller accepted the participation of the sensual part of human nature, a part that included the nervous system with its senses, the principals being sight and hearing, and our feelings, our passions. ${ }^{28}$ He wrote to Körner: "The Burkian is completely justified in insisting on the unmediated quality, on the independence of beauty against the Wolffian; but he is in the wrong against the Kantian to insist that beauty be posited as a mere affectation of sensuousness" (Bernstein 146). ${ }^{29}$ In his Philosophical Enquiry, Schiller summarized later, Burke "makes beauty into mere life" (XV.5 fn).

The rationalists, Schiller's analyzers, reached a kind of perfection themselves in Moses Mendelssohn (1729-1786). An aficionado of Jewish mediaeval philosophy and mediaeval Aristotelianism, mentored by Torah and Maimonides scholars, he was

${ }^{28}$ Schiller on the importance of seeing and hearing: "In the case of the eye and the ear, she [Nature] herself has driven importunate matter back from the organs of sense, and the object, with which in the case our more animal senses we have direct contact, is set at a distance from us. What we actually see with the eye is something different from the sensation we receive; for the mind leaps out across light to objects ... Once he does begin to enjoy through the eye, and seeing acquires for him a value of its own, he is already aesthetically free and the play-drive has started to develop (XXVI.6).

${ }^{29}$ Burke against function: the structure of a watch, "for all the perfection of its parts and their fitness to the whole, yet it is not beautiful - whereas its engraved case may be so, since in beauty "the effect is previous to any knowledge of the use"" (Burke On the Sublime iii.7, qtd. in W\&W 226). 
linguistically competent in Latin, French and English and uncommonly welcoming and well-versed in diverse knowledge traditions. Mendelssohn was a decades-long friend of Gotthold Ephraim Lessing who modeled "the religious tolerance and good will of the protagonist in his dramatic poem, "Nathan the Wise," after his friend. Mendelssohn's own work included numerous essays, philosophical dialogues (including one, "On Sentiments," reflecting Shaftesbury's influence), a piece on probability theory, letters to Lessing on tragedy, a contribution to the debate on the Enlightenment, and a work elaborating a theory of beauty in opposition to Batteux and Hutcheson, "On the main principles of the fine arts and sciences" (Dahlstrom in Mendelssohn ix-xxiv). ${ }^{30}$

Mendelssohn valued the life of feeling: "We are called in this life not only to improve our powers of understanding and willing, but also to educate feelings by means of sentient knowledge and to raise the obscure impulses of the soul to a higher perfection by means of sensuous pleasures" (140). For him beauty was this perfection of a sensuous cognition, and it followed that the pleasure arose from our own sensuously perfect

\footnotetext{
${ }^{30}$ Mendelssohn's complaint about Hutcheson was that he referenced the Deity in a way that precluded further discussion of the causes of our response to beauty, precisely the question to be explored. Hutcheson posited a "sense of beauty" (and a civic sense as well) and his ideas about aesthetic response appealed to wholes: "Let everyone here consider, how different we must suppose the Perception to be, with which a Poet is transported upon the Prospect of any of those Objects of natural Beauty, which ravish us even in his Description; for the cold lifeless Conception which we imagine in a dull Critick, or one of the Virtuosi, without what we call a fine Taste. This latter Class of Men may have greater Perfection in that Knowledge, which is deriv'd from external Sensation; they can tell all the specifick Differences of Trees, herbs, Minerals; they know the Form of every Leaf, Stalk, Root, Flower, and Seed of all the Species, about which the Poet is often ignorant: And yet the Poet shall have a much more delightful Perception of the Whole; and not only the Poet but any Man of a fine Taste. (Beauty I.XII) (as qtd. in Fox 155). His ideas were incorporated into German theory through translation by Lessing; his speculation about internal senses of man - of beauty and sociability, for example fleshed out the skeleton of Common Sense (See Chapter VII).
} 
representations. ${ }^{31}$ Since "the final purpose of the fine arts is to please ... the essence of the fine arts and sciences consists in an artful, sensuously perfect representation or in a sensuous perfection represented in art" (172-173). As such, the "arts have a mediating role to perform between what a person knows and what he or she desires" (Dahlstrom xxi). For Mendelssohn, the source of beauty's pleasure is three-fold: unity of diversity (sensuous), harmony in the manifold (rational perfection) and enjoyment of our own well-being in the contemplation of it (Dewhurst 122). The three-fold pleasure required of Mendelssohn a three-part model of the soul. In both explanations, his tendency (repeated in other perfection theorists) was to conflate the beautiful and the good:

[b]etween the ability to know and the ability to desire lies the ability to feel, by means of which we feel pleasure or displeasure in some subject matter, approve of it, deem it good, and find it pleasant or disapprove of it, find fault with it, and find it unpleasant.... The goal of the ability to feel is the good. That is, insofar as we possess an ability to feel, we strive to make the objective properties agree with our concepts of goodness, order, and beauty (309). ${ }^{32}$

Though Schiller was critical of Mendelssohn, he may have been a direct inspiration:

his "On Sensations" [Briefe uber die Empfindungen] (1755) seemed to many to be a

31 "Each individual representation stands in a twofold relation. It is related, at once, to the matter before it as its object (of which it is a picture or copy) and then to the soul or the thinking subject of which it constitutes a determination). As a determination of the soul, many a representation can have something pleasant about it although, as a picture of the object, it is accompanied by disapproval or a feeling of repugnance. Thus we must indeed take care not to mix or confuse these two relations, the objective and the subjective" (132). The implication is two-fold: as an activity of mind a representation can be pleasurable purely as "play" of the faculties. But many representations provoke an ambivalent mix of emotions. Prior to the passage, Mendelssohn reflected on the Lisbon earthquake of 1755: after evil has occurred and nothing can be done to prevent or ameliorate it, he wrote, "we are powerfully attracted to the representation of it and long to acquire that representation" (131).

32 "We must not, says Mendelssohn, "confuse the "heavenly Venus" which consists in perfection, in the perfect adequacy of all concepts, with the "earthly Venus," that is, with beauty" (Cassirer 354). 
template for Schiller's presentation of the problems of aesthetic response and their solution. There, Mendelssohn reiterated that the "beautiful object is neither one of mere knowledge or one of mere desire; it slips through our fingers if we try to treat it as an object of knowledge and to approach it by means of scientific method, by the process of analysis and definition," More, he held that the "nature of the beautiful object also escapes us if we approach it from the 'practical' viewpoint, making it the object of wishing or acting, because as soon as an object is desired or striven for, it ceases to be a beautiful object, an object of artistic contemplation and enjoyment." For those reasons, he postulated a faculty of approval [Billigungsvermögen], a faculty for what is special about beauty. For beauty "is contemplated with calm pleasure, ... pleases even if we do not possess it, and if we are ever so far removed from the desire to possess it." ${ }^{33}$ This faculty, with its capacity for contemplation, has similarities to Schiller's aesthetic state (XXV.2).

In spite of Schiller's dismissal of the perfectionists, the rationalist aesthetic tradition contained important considerations for him. Of course, Baumgarten's work had defined the field and the other theorists like Mendelssohn quite simply tilled his ground (as Kant did as well): weeding, pruning or hybridizing their ideas added value to value. Though they focused too consistently on intuitive perfection, their holistic approach to beauty was

${ }^{33}$ (Mendelssohn qtd. and summarized in Cassirer 126; Dewhurst 114-5, 122). Schiller: "Contemplation (or reflection) is the first liberal relation which man establishes with the universe around him. If desire seizes directly upon its object, contemplation removes its object to a distance, and makes it into a true and inalienable possession by putting it beyond the reach of passion .... In his sense there results a momentary peace; time itself, the eternally moving, stands still; and, as the divergent rays of consciousness converge, there is reflected against a background of transcience an image of the infinite, namely form .... as soon as it grows still within him, the storm in the universe abates and the contending forces of nature come to rest between stable confines" (XXV.2). 
absolutely necessary. They underscored the importance of sense, perceptions and feelings, even if they emphasized the particular rationality of the aesthetic faculty and the rational aspects of beautiful objects, specifically perfection, which they identified as a trigger of our response. Their valorization of sense reestablished the possibility of a harmoniously functioning psyche with its polar forces in tension, and allowed for its union, for human wholeness. Schiller reached back into the tradition of German aesthetics for these understandings as well - and Leibniz (and, with Leibniz, Wolff of course), for whom beauty and the power to act were connected, for whom beauty, morality and happiness together attainable, flowed through the tradition.

All intensification of being I have called perfection, [wrote Leibniz] for just as sickness is a diminution of health, so is perfection something which rises above health ... perfection appears in the power to act. Indeed, all being consists in a certain force, and the greater this force, the higher and freer the being. Furthermore, the greater the force, the more we see multiplicity from unity and in unity ... harmony ... beauty, love ... so happiness, joy, love, perfection, being, force freedom, harmony, order, and beauty are all linked together a fact which few people rightly understand (as qtd. in Cassirer 122).

In spite of his objections, Schiller's contention that beauty was our second creatress also involved the rational part of our "sensuo-rational" nature. ${ }^{34}$ How could this be? How could the logical be involved, yet subsumed and transformed? The rational included for Schiller, according to Frederick Beiser, a very broad understanding of reason as the "power of combination or synthesis, a power which unite[d] all kinds of representations among themselves, and even representations with other faculties, such as the will." He continued: "[Schiller's] general concept of reason [was] strategic and

\footnotetext{
${ }^{34}$ Mendelssohn: "Beauty is the self-empowered mistress of all our sentiments, the basis of all our natural drives, and the animating spirit which transforms speculative knowledge of the truth into sentiments and incites us to active decision" (170).
} 
significant: it allow[ed] him to bring all forms of judgment within the general domain of reason" (Beiser 58-59). This domain includes a theoretical reason (knowledge-based concepts or sense-derived intuitions) as well as practical reason (representations for action). Each type of reason corresponded to a judgment: "the application of theoretical reason to concepts [was] a logical judgment ... to intuitions [it was] a teleological judgment, [while] the application of practical reason to free actions [was] moral judgment." Aesthetic judgment was a form of practical reason, "namely that form that appli[ed] its principles to events in the natural world." A counterpart of moral judgment, aesthetic judgment's task was to discern "how freedom appears in the sensible world. In other words, the fundamental principle of aesthetic judgment - the general concept of beauty - was nothing less than the appearance of freedom in the sensible world, 'freedom in appearance' [Freiheit in der Erscheinung], 'autonomy in appearance' [Autonomie in der Erscheinung]," and in the Aesthetic Letters, living form [lebende Gestalt]. (Beiser 59-60; XV.2). In dividing the psyche between reason and sense this way, Schiller placed the sensing of the object of beauty with one drive and the in-forming or typing of beauty with the other drive: only in the combination of capacities can the judgment be made, can the full experiencing of passively sensing and actively creating be had. The object must have sensual aspects that gain and keep our attention; the object as material must be conformable to our drive to externalize ourselves into it.

Beiser anchored his descriptions of Schiller's faculties/forces of reason on the Kalliasbriefe, Schiller's effort to work out an objective theory of beauty in response to Kant's subjectivist stance in the Third Critique. These letters to his friend Körner, exchanged during the winter and spring of 1793, were full of ideas and partial proofs, but 
ones that appeared to one correspondent or the other to be flawed or to open up further difficulties. Through his construction of an objective concept of beauty, Schiller, frankly, had hoped to do what Kant had not done, to become a Newton of aesthetics. But Schiller did not finish that project. Consequently, while Baumgarten laid the foundation of an anthropological aesthetics and "Schiller did not dream of starting his treatise on aesthetic education without first coming to terms with Baumgarten, it was not he who presented him with a challenge. It was Kant." (W\&W xxiii). ${ }^{35}$

Kant accomplished many things necessary for Schiller's art and argument: he solidified the turn toward the subjective into a position (Third $\S 1,8$ ), and then he developed the expression of individual taste into the "form of a universal judgement by subjecting it to the rigour of his 'transcendental' method." Kant further defined that judgment as one "'free of 'interest' as the pure moral act is free of 'motive,' [i.e.] one characterized by disinterested pleasure even as the other is characterized by disinterested duty" ( Third $\S \S 2,6,8$, xxiii). In these operations Kant freed art from subservience to ends, granting it the autonomy dear to Schiller's heart:

for beauty produces no particular result whatsoever, neither for the understanding or the will. It accomplishes no particular purpose, neither intellectual or moral; it discovers no individual truth, helps us to perform

\footnotetext{
${ }^{35}$ According to Beiser, Schiller differed from Kant in the following ways: Schiller rejected the transcendent Christian conception of the highest good, managing human rationality and moral obligation in immanent and secular way. Schiller held that moral worth proceeded from character as well as action. Schiller's concept of freedom was anthropological: it did not entail acting on the moral law "independent of sensibility" but on the freedom to act according to the moral law or not, the freedom to act within the sphere of nature or not, to apply principles and execute ideas $(112,131)$. With reference to judgments about art, Schiller believed that reason should and could be given, reasons referencing the objective qualities of the work. In short, Schiller's "ideal of complete humanity consist[ed] in an aesthetic whole, the harmony of sensibility in grace ... [beauty rising] from the appearance of freedom in the sensible world" (2-4). Schiller of course battled with his own understanding of Kant.
} 
no individual duty and is, in short, as unfitted to provide a firm basis for character as to enlighten the understanding. By means of aesthetic culture, therefore the personal worth of a man, or his dignity, in as much as this can depend solely upon himself, remains completely indeterminate; and nothing more is achieved by it than that he is henceforth enabled by the grace of Nature to make of himself what he will - that the freedom to be what he ought to be is completely restored to him (XXI.4).

In sum, Kant had "crowned what Baumgarten had begun by widening the field of aesthetics to embrace far more than art itself; to embrace not only the beauties of nature but even such phenomena as human conduct, thus opening up possibilities which Schiller was to explore and exploit to the full for his idea of aesthetic education (xxiii).

For all that Schiller valued in Kant's service to freedom of man and the autonomy of art, however, he differed with him with respect to the derivation of beauty, and he held out for a level of seriousness in artistic forms, believing that they could support intensity of life import and still promote the play of the faculties and imagination. He also differed with Kant on the definition of man and opposed his aesthetic man to Kant's man of reason. From Schiller's point of view, beauty was both an objective and a subjective phenomenon: "[b]eauty, then, is indeed an object for us, because reflection is the condition of our having any sensation of it; but it is at the same time a state of the perceiving subject, because feeling is a condition of our having any perception of it" (XXV.5). Kant's subjective bias was "dissatisf[ying]": "like Goethe [Schiller] felt that from it one could learn much about man but all too little about art and beauty" (Third $\S 9$, 34, W\&W xxiv-xxvi). Beauty resided in relation: Schiller followed Henry Home, Lord Kames, in theorizing that "beauty ... for its existence, depends upon the percipient as much as upon the object perceived, [and] cannot be an inherent property of either" (Lord Kames qtd. by W\&W xxvi). 
Schiller also insisted on the capacity of art to represent profound human significance. He wrote Körner that, while many in the German tradition and elsewhere "have tried to situate beauty in intuitive perfection [and thus have caused] the logically good [to be] confused with the beautiful," it was Kant [who] wanted to cut [and succeeded in cutting] precisely this knot" (Bernstein 146). By Schiller's lights, however, when Kant cut the knot, he lost the beautiful again. What Kant had suggested was that "beauty presents itself in its greatest splendor only once it has overcome the logical nature of its object" and he gave as an example an arabesque, a beauty without any logical interest or resistance to be overcome $(\S 16)$. It was this formulation, the loss of beauty replete with human content, that gave Schiller further pause. For, while Schiller celebrated "Kant's demand that in aesthetic experience the psyche should delight in the free play of all its faculties [as] all very right and proper," he firmly believed that free play of the faculties did not preclude vital, serious, even disturbing interests (W\&W xxiv-xxvi.) Wilkinson and Willoughby applied Schiller's metaphor of the balance to this problem: just as genius is encouraged by strong taste, intense content and robust or audacious en-forming will manage each other: for Schiller, "[t]he scales of the balance stand level when they are empty; but they also stand level when they contain equal weights" (xxiv, XX.3).

Likewise he held that humans should act with the whole force of their personalities, develop themselves, completely and fully, and that enlightenment encompassed the whole man, not his rational part. Human actions and products should be "expressive of life as it is felt and thought, in all its concrete uniqueness and irreducibility to categories and abstractions" (xxv).

[For] in the complete anthropological view ... content counts no less than form, and living feeling too has a voice .... Reason does indeed demand 
unity; but Nature demands multiplicity; and both these kinds of law make their claim upon man. The law of Reason is imprinted upon him by an incorruptible consciousness; the law of Nature by an ineradicable feeling. Hence it will always argue a still defective education if the moral character is able to assert itself only by sacrificing the natural (IV.3).

Many of the ideas from those letters to Körner were reworded and incorporated into the Aesthetic Letters; they provided a background for his new analysis of beauty. There, he developed a two-fold theory of beauty. Beauty was the means of aesthetic education of man, the only process through which a complete person might develop. But beauty was not just a means but an end in itself: understood as part of the world and part of human experience, it was for Schiller what we create out of what we sense. It was both dependent our sensate experience of it and necessary to our very humanity. Beauty and humanity then are conditions of each other's existence: without humans, no beauty, and without beauty no humans. From the context of vitalism and aesthetics, Schiller conceived his theories under the influence of Kant's ideas about biology and aesthetics and he developed them in the climate of Goethe's interest in beauty and organism. ${ }^{36}$ As

\footnotetext{
${ }^{36}$ Reill noted that combining and harmonizing the extreme styles of philosophical reasoning and popular fiction, as schöne Schreibart, was Schiller's strategy in historywriting ("Anthropology" 262). Schöner Vertrag below refers to both Goethe's nature writing and Schiller's aesthetic discourse considered as cultural reproductions of natural phenomena through a complex interaction. Goethe was interactive with and supportive of the Aesthetic Letters project, reading it and providing perspectives (Boyce 215-233). About a month after their first meeting, he sent Schiller a short piece, "The Extent to Which the Idea 'Beauty Is Perfection in Combination with Freedom' May Be Applied to Living Organisms": in it he noted that an animal appearing to us to be "capable of manifold and free use of all its members whenever it wishes" engenders a sense of beauty, of repose together with strength, inaction together with power" and that the most "intense feeling of beauty is connected with feelings of trust and hope" (Scientific 23). Regarding beauty, on the singularity of the object and observer: according to Goethe, "When ways of looking disappear from the world, the objects perceived often go missing too. In fact one can say that, in a higher sense, the way of looking is the object." (Stephenson 554, $561)$.
} 
philosopher and artist then, he poured them into a dynamic form, an energy, really - and they metamorphosed into the Aesthetic Letters, an artful philosophy, a beautiful treatise [schöner Vertrag]. ${ }^{37}$ He intended art that holds its community in an aesthetic state. He wished to synthesize all, but to emphasize the relational, and one of the results was an effort to connect the object to our interiority, and another to derive an objective aesthetic or principle of beauty, one that would explain the standard of taste, the fact that we expect judgments about beauty to be normative (X-XVI). For him, the sensate (empirical) was organized both by the world we perceive outside ourselves and by the capacities of the nervous system itself. The mind was already involved and active in perception (though for the most part unconsciously). This judgment circularly conflated our judgment of organicity and human agency as humanly delightful and reinforced our other sensate experiences of the object.

\section{Beauty, Organism and the Aesthetic Letters}

The Aesthetic Letters represents Schiller's theory of art: it reflects the German aesthetic legacy, its reason of sense and its valorization of feeling's part in motivation, its love of the object and its scrutiny of the subject. In spite of his work's debt to Kant, however, its autonomy is clear: through it Schiller dared to make play the ground of our nature instead of reason, and he had the audacity to imagine aesthetics both as the means

${ }^{37}$ An "energy" is a dynamic work of art defined by James Harris as follows: an “"energy' is 'every Production, the Parts of which exist successively, and whose Nature hath its being or Essence in a Transition.' An energetic art operates through time. It does not deliver a complete object that can be surveyed at once; rather, its effect lies precisely in a succession of moments because each moment is effective only as a link in this chain. A 'work,' on the other hand, is 'every Production, whose Parts exist all at once"' (Harris qtd. by Morris in Herder's Aesthetics 9). Herder knew Harris' work; his Three Treatises: The First Concerning Art, the Second Concerning Music, Painting and Poetry, the Third Concerning Happiness was translated into German in 1756. 
to wholeness and as the representation of the whole man. The Aesthetic Letters then functions as a semblance [Schein], an art-form [Gehalt] that transforms life-materials and vital life-interests into a kind of play which "yet has its own seriousness [ein ernstes Spiel]" (W\&W xxvi). ${ }^{38}$ "[E]very genuine work of art presents us with [a] standard; it not only displays a wealth of observations but it masters this wealth" wrote Cassirer, "it molds it and causes its inner unity to appear in the form which results" (345). There is a standard to be found in the Aesthetic Letters. The work, a confused whole with all its relations and connections, is a profoundly relational entity, with connections to its readers, a profound commitment to grave import and a lively and infectious play with representations.

In the late eighteenth century, both art and organism were identified as sites of boundaried complexity and transformational activity. Schiller intended the Aesthetic

${ }^{38}$ In a long footnote to Letter XIII, Schiller described play's first earnestness, its own dynamic of reciprocal relations. The complexity of this interaction between the original drives is a representation of the life of the mind, and the capacity to play is an analogue of life processes described in philosophical physiology. In this formulation, he began by countering Kant: one can't just have subordination of sense. From such a solution, "only uniformity can result, never harmony, and man goes on forever being divided.

Subordination there must, of course, be; but it must be reciprocal. For even though it is true that limitation can never be the source of the Absolute, and hence freedom never be dependent upon time, it is no less certain that the Absolute can of itself never be the source of limitation, or a condition in time dependent upon freedom. Both principles are, therefore, at once subordinated to each other and co-ordinated with each other, that is to say, they stand in reciprocal relation to one another: without form no matter, and without matter no form. How things stand with the Person in the realm of ideas we frankly do not know; but that it can never become manifest in the realm of time without taking on matter, of that we are certain. In this realm, therefore, matter will have some say, and not merely in a role subordinate to force, but also co-ordinate with it and independently of it. Necessary as it may be, therefore, that feeling should have no say in the realm of reason, it is no less necessary that reason should not presume to have a say in the realm of feeling. Just by assigning to each of them its own sphere, we are by that very fact excluding the other from it, and setting bounds to each, bounds which can only by transgressed at the risk of detriment to both" (XIII.2 fn *1 my emphasis. Cf. Herder page 237). 
Letters to be organically complete, an original, a means and an end in itself, "unified and transformed by the dominant intention of presenting art as an educative power." $\mathrm{He}$ intended it to be "[t]ransformed too by [his] evident desire to write not just a treatise on aesthetics but an aesthetic treatise," an example of the new discipline of the "art of thinking beautifully' as well as the 'science of the beautiful'" (W\&W xxviii). ${ }^{39}$

There has always been argument about the unity of the letters (which in fact first appeared in serial fashion, creating a chronological division). In their Introduction, Wilkinson and Willoughby compared the dualism within Schiller's model of the unified psyche and the binary structure of the Aesthetic Letters, noting that both oppositions resolve into a third synthetic entity. In human nature, the sense-drive and the form-drive relate reciprocally in the play-drive; human sense and reason combine in the aesthetic state, making the whole man possible. In the work itself, ideal beauty applied to empirical humanity opened up new possibilities of transformational human experience. Schiller used the same strategy linguistically. When his rhetorical figures, polarities and chiasma, all his dynamic play with polar terms resolved into triads of unity, Wilkinson and Willoughby saw his word and figure use as a "linguistic analogue of the dynamics of the psyche" (xcvii, Appendix III). ${ }^{40}$ They concurred absolutely with "Schiller's own

${ }^{39}$ In an essay that was contained in Goethe's Italian Journey, Moritz wrote, "The concept of beauty, which for us has arisen from the fact that it need not be useful, thus requires not only that it exist as a self-contained whole, but that it be given as a self-contained whole to our senses, or can be grasped as such by our imagination." (Bernstein "On the Artistic Imitation of the Beautiful (1788)" 138). "[T] he work of art is a microcosm, parallel in its structure to that of nature, and like that, 'a self-sufficient whole,' and beautiful only in so far as 'it has no need to be useful,"' continued Abrams paraphrase of Moritz, "The work of art "needs no end, no purpose for its presence outside itself, but has its entire value, and the end of its existence, in itself" (Abrams 327).

${ }^{40}$ For paradigmatic chiasma, see XIII. 2 fn* 1 , partially reproduced on page $257 \mathrm{fn} 38$. 
claim that the structure as a whole was unassailable" reminding readers that he wrote repeatedly to Körner and Goethe of "its unity, simplicity and severity, of its inner consistency ... and of his conviction that it was 'all of a piece"" (xlviii). Finally, for them, unity was attained for the art object when the treatise on aesthetics transformed into aesthetic treatise. ${ }^{41}$ They allowed, however, that the "treatise ... has the shape of a torso. A torso with one arm missing" if we believe that Schiller left out the "energetic beauty" he promised to discuss (lviii). ${ }^{42}$ In short, the translators argued tirelessly for the organic unity of the work. Artistically, structurally, linguistically, etymologically.

Beiser, as noted earlier, argued for the Aesthetic Letters' philosophic unity and the durability of its philosophizing. Admitting that beauty in the essay is both means and end, and that in it as well, "education through art becomes an education to art," Beiser described the work as a treatise on aesthetic education and an analytic of the beautiful

${ }^{41}$ Wilkinson and Willoughby found Schiller to be a borrower in order to construct an original: he pulled in all kinds of materials from his environment for incorporation into his work: he of course inherited a model of the psyche "as a bundle of faculties, divided according to the Leibniz-Wolffian tradition - into an upper and lower storey .... From Fichte ... he borrowed a model of the self and its conditions - reminiscent of the theological doctrine of the Person and His Attributes - which served him for describing the determinations of the psyche in its goal-directed activities. From his colleague at Jena, the philosopher Karl Reinhold, he took a model of the psyche as a complex of interdependent drives - analogous to a field of forces - which provided him with some of the dynamics his other models lacked. And from Herder he appropriated a genetic account of the dawn of self-consciousness, in the individual and the race ... amalgamated no doubt with mystical doctrines of the Swabian Pietists. [It] enabled him to postulate an aesthetic modulation of the psyche in activities not otherwise to be termed aesthetic: to distinguish between the structure of the psyche and its modalities, between the practical, scientific, or ethical value of an act and its overall aesthetic tone or temper" (Model 239).

${ }^{42}$ The justification for its absence is that "energetic beauty" (opposed to "melting beauty" XVI, XVII) may have been considered by Schiller to be "identical with the sublime, [and therefore] was best treated - according to tradition - as a distinct 'genus,' rather than as a 'species' of the beautiful" or. . (lviii). 
united as "an apology for beauty, a defense for the aesthetic dimension of human life" (Gadamer qtd. 120, 123).

Through his work on the Aesthetic Letters, Schiller's understanding of organism changed. The concept of means as end, and end as means, of a harmonious and balanced - autonomous-economy was not completely adequate. The work of art, like an organism, developed and transformed through his effort to apply form to encompass new materials, and through its own history. As a form, therefore, the ideal of "wholeness was only ... achieved as a changing pattern in time, a constantly shifting hierarchy of interests and values and powers, in which the dominant was properly determined by the requirements of the immediate situation" (xxxix). This whole encompassed more tension, more energy, asymmetry, recovery, reach and adjustment. By the end of the century this more dynamic understanding of organism had a life of its own in the larger culture - and that model was applied to art. Such an idea of organism was not the antithesis of the mechanism of lower nature, but a third, a transformational third, created by incorporation of mechanism into the organic. Its metamorphosis promoted the higher order management of imbalance, things tilting toward the future, toward the edges of space (lxxxiv). As a human product, art is an analogue to human wholeness: art objects are harmoniously balanced, yes, but dynamic as well, and they develop in relation with us. As instantiations of beauty, they are reciprocally the means and end of our development. 
Schiller, a man of his century, was directly engaged "the drama of the present time" (II.2, V.3). ${ }^{43}$ The Aesthetic Letters was his response to the current political situation, revolution; it was written in a one-sided epistolary genre that literally reached out to engage its readers. In spite of its groundedness, it also connects the author-and-narratorsubject through the common object (a philosophical work of literary art) to the readersubjects in a reciprocal relation across time. With respect to us, the readers of this century, it is an engagement to play. Right from the outset Schiller shares the results of his exploration of "Art and Beauty" (I.1) with us. As readers, each of us is addressed as someone with a heart "fully sensible of the power of beauty and prompt to act upon it." As an "acute thinker," a liberal citizen of the world [Weltbürger]," are you not willing to engage, are you not willing to be a good sport, to pitch in and do your part? (II.5). Schiller writes to a sympathetic ear, and each of us is suborned. Each of us is playfully, amicably, forced to be the enlightened one to whom he writes. ${ }^{44}$ You are in, and so am I: we are playing with Schiller before we know it. Pulled onto the dance floor, each of us finds himself in the dance and dancing, learning the Kantian steps, the poetic maneuvers:

43 "Let me turn my attention at once to the object most in evidence on this enormous canvass.... The fabric of the natural State is tottering, its rotting foundations giving way, and there seems to be a physical possibility of setting law upon the throne, of honouring man at last as an end in himself, and making true freedom the basis of political associations. Vain hope! The moral possibility is lacking, and a moment so prodigal of opportunity finds a generation unprepared to receive it .... And what a figure [man] cuts in the drama of the present time!" (V.1-3)

44 "The freedom of your mind shall, I promise you, remain inviolable"(I.3), and what "better use of the freedom you accord me than by keeping your attention fixed upon the domain of the fine arts?" (II.1 my emphasis) "What an agreeable surprise if, despite all difference in station, and the vast distance which the circumstances of the actual word make inevitable, I were, in the realm of ideas, to find my conclusions identical with those of a mind as unprejudiced as your own!" (II.5) 
each, perspiring with effort, enjoys. Schiller collects us into a form that, like an English reel of spinning words, makes means ends and ends means (W\&W lxx, cxxxi; Schiller's poem "Der Tanz"). You and I, other readers as well, are enticed into an activity of mind and body, into our own development. This is Schiller's play. He plays with us as if present today and - we play with him. The goal is the activity itself, guided by the beauty and all the possibility of human nature. As he promised, "[y]our own feeling will provide me with the material on which to build, our own free powers of thought dictate the laws according to which we are to proceed" (I.3): the process however is governed by the way our minds work in reality, based on Schiller's intuitive understanding of human beings.

As such, the work's vital functions, its sensitivity and irritability as well as the above mentioned self-maintenance, generation and development, promote transformation of material: the Aesthetic Letters does not just develop narratively in time and spatially as a whole, but itself becomes a developmental force in others. ${ }^{45}$ Generating like a hydra?

${ }^{45}$ Regarding sensibility and irritability: as if poked, questioned or prodded, Schiller checked his reader often. He was especially sensitive to any flagging enthusiasm and aware of the perhaps unreasonable demands of his text. He often provided encouragement and commiseration at the beginning and end of letters: "Have I not ...? That is scarcely the reproach I anticipate ... Such a report, you tell me ..." (VI.1); "[b]ut is this not, perhaps, to argue in a circle?" (IX.1). "I have now reached the point to which all my preceding reflections have been tending" (IX.2). "You, are, then, in agreement with me, and persuaded ..." (X.1). "I am drawing ever nearer the goal towards which I have been leading you by a not exactly encouraging path. If you will consent to follow me a few steps further along it, horizons all the wider will unfold and a pleasing prospect perhaps requite you for the labour of the journey" (XV.1). "But, you may long have been tempted to object, is beauty not degraded by being made to consist of mere play?" (XV.6). "Resign yourself therefore to one more brief sojourn in the sphere of speculation, in order thereafter to leave it for good, and proceed, with steps made all the more sure, over the terrain of experience" (XVII.5). "At this point we must remind ourselves that we are dealing with a finite, not with an infinite, mind" (XIX.9). "You need have no fear for either reality or truth ..." (XXVII.1). And of course, "we" know 
An insect? A plant? An animal? Examples abound: what did Werther create, and how were those new subjects and objects created? A functioning Goethe, separated from his diseased parts? And what of those parts, the unhealthy feeling, the imitation of the characteristic attitude, dress and posture, the sickness unto death? To what metamorphosis, but Torquato Tasso? And what of this work, the Aesthetic Letters? A synthesis of friendship and esteem? What did it generate, but a thousand players playing ${ }^{46}$ This dissertation.

Finally, there are a number of ways to interpret the narrative progress of Aesthetic Letters, to represent its wholeness. For the purposes of example, a medical model will be presented here, a Schein, an epidemiological study that includes individual case presentations. The reason is the excuse. Schiller was a physician of objective and subjective human nature, who witnessed a catastrophe of reason, the French Revolution (II). ${ }^{47}$ The mortality and morbidity were extremely high. The symptom complex of the

many things together, for example, what is necessary for the psyche (VI.10), and that "[o]ur Age is Enlightened; that is to say, such knowledge has been discovered and publicly disseminated as would suffice to correct at least our practical principles" (VIII.4). "Man, as we know, is neither exclusively matter nor exclusively mind" (XV.5). "We can, then, distinguish three different moments or stages of development through which both the individual and the species as a whole must pass ..." (XXIV.1). "We have now been led" (XIV.1) and we ponder together many significant questions: "Can we perhaps look for such action [toward insuring human wholeness] from the State?" (VII); "Is Philosophy then to retire, dejected and despairing, from this field?" (VIII). "How, then, are we to restore the unity of human nature which seems to be utterly destroyed by this primary and radical opposition [the two original drives, the sense-drive and the formdrive]?" (XIII.1). "But how is the artist to protect himself against the corruption of the age which besets him on all sides?" (IX.5). "But does such a State of Aesthetic Semblance really exist? And if so, where is it to be found?" (XXVII.12). And of course, reader: "Dare to be wise!" (VIII.6).

${ }^{46}$ Hegel, Coleridge and the Romantics, Peirce, the twentieth century hermeneuticians, and transplanted German philosophers, for example.

${ }^{47}$ Cf. Albert Camus' The Plague (1947). 
disorder varied in the population: some were sick with a violent illness, one that intensified the emotions, manifested itself in lack of self-awareness, empathy and capacity with symbols, in a word, in unconsidered, reflexive action (i.e. savages IV.6). Others appeared yoked to the ordinary, not alert to the crisis due to muted or overcontrolled feeling, their interests narrowed and their approach to life perversely or apathetically self-serving (that is, barbarians IV.6). Schiller's diagnosis of the times and its ills: the outbreak constituted a crisis of Enlightenment (European human crisisitis). (This affliction was a new illness, unknown in past cultures (VI).) Everyone including Schiller worried about the virulence of the epidemic: would it cross national borders? While most were concerned about savagery, he saw barbarism, as a more subtle but more dangerous, even malignant, manifestation (V.5). ${ }^{48} \mathrm{He}$ recommended safety precautions for caregivers, both the artists (IX) and the scientists (XIII.4 fn 2). He performed an examination of the population, individual by individual, and then generalized his findings. He analyzed mental status in particular and found that basic human dividedness constituted a susceptibility to this disease (XI-XIII). To his relief, however, there was a natural unified state of human nature, one that could be restored and maintained (XIV, XV). The preventative regimen and the cure were essentially the same: restoration to this natural unity, a unity to be regained and maintained by exposure to beauty, by each person's always developing his own potential. (X, XVIII). This treatment was, as Schiller understood it, a life-long one - human beings must learn and relearn how to direct and manage their attention pleasurably, how to allow it to be developed by a

48 "Thus do we see the spirit of the age wavering between perversity and brutality, between unnaturalness and mere nature, between superstition and moral unbelief; and it is only through an equilibrium of evils that it is still sometimes kept within bounds" (V.5). 
sensate ideal. They must free themselves continuously; they must play (XV). The cure might have to be administered homeopathically at first, on an individual basis, and increased as the patient himself developed. Schiller was very well aware of the long history of the medication's misuse as well as its past history of involvement with misconceived host-parasite (subject-object) relations (XVIII). When he reviewed the history of beauty's adverse effects and its side-effect profile, he noted that, while the racemic mixture is the ideal $(\mathrm{X})$, beauty generally came in two enantiomers (mirrorimage stereoisomers), that is, as melting or as energizing beauty. (XVI, XVII). Wrongly administered by a society similarly affected, these cures could be like chemotherapy, as bad as the disease. And often, compounders had gotten and still got the formula wrong; patients became addicted to certain readily available but impure and adulterated products (XVI, XVII). However disappointing these findings were, Schiller was not deterred: he reflected next on the patients and their developmental histories. In them, he found reason to hope: nature seemed on the side of human potential: self-awareness, empathy (sociability), play with its delight in representation developed serially but spontaneously in many a healthy individual - and also in certain populations, societies that encouraged autonomy. He noted that beauty and freedom (and the aesthetic space that conceives, develops and nurtures them) were a part of the history of humanity (XIX- XXII). He ended on an optimistic note: if humans could survive this plague, they would do so transformed by their bold efforts to heal and stay healthy, and they would transform civil society as well (XXVII). 


\section{The Whole Man: Man Playing Toward Wholeness}

"'Art itself is natural to man,' who is 'in some measure the artificer' of his own nature. 'He is perpetuallly busied in reformations.' There is no human state of repose" (Ferguson qtd. in Wokler 128).

Schiller was committed to the complete anthropological and aesthetic view of man, of experiencing human wholeness. According to Wilkinson and Willoughby, he supported this view with several different models and drew on a number of cultural antecedents (Model). He depended on two different representations: first, he proposed a drive theory of human nature that achieved human wholeness through the exercise of the play drive and through repeated access to the aesthetic state. This theory was part of an overall organic model, supported by natural history and philosophy, specifically, vitalism. It also elaborated a metaphor system of living forms and organic growth, one that had ideals to be "'cultivated,' [ideals like] harmony, perfection and consistency" $(240) .{ }^{49}$ Then, he also constructed a speculative history as Hobbes, Rousseau, Monboddo and Herder had done as a model for the development of man's capacity to play.

In addition to these models, others were at the time active and near to hand. One of them, according to Wilkinson and Willoughby, was the Renaissance uomo universal, brought to life again in the Spectator and continued in Germany by Georg Christoph

\footnotetext{
${ }^{49} \mathrm{~W} \& \mathrm{~W}$ noted that "[a]t some stage in the process of turning his epistolary drafts into a treatise in epistolary form Schiller must have learnt a good deal more about the principles of biological organization than the knowledge embodied in such stock formulas as, say, that adopted by his friend Körner for his own 'aesthetic credo' in 1790: that a living organism is distinguished from a mere mechanical 'aggregate of elements' by the fact that in the former 'part and whole are reciprocally means and end.' And it seems plausible that he learnt it from Goethe during those exchanges on natural science in July 1794 which proved the starting-point of their friendship." (Model 249).
} 
Lichtenberg. ${ }^{50}$ Lichtenberg, a contemporary of Schiller's, now remembered principally

as an aphorist, contributed the following, an appreciation of living form:

If anyone in the whole world wishes to etch a rule of conduct upon his hand with the aid of needles and saltpeter, I would propose the one I once read in some number of the 'Spectator': 'The whole man must move together.' Transgressions against this maxim are beyond counting, and the damage arising therefrom great and often irreparable. Under 'man' [Mensch] I include head, heart, mouth and hands. And it takes a master to pursue the art of driving these inseparably together, through wind and weather, right up to the end where all movement ceases (Model 244-5). ${ }^{51}$

Goethe too had an understanding of his own psychic unity, and he developed his insights about self-management and creativity into an extended metaphor. As such it is instructive of his contributions to Schiller's project.

It suddenly dawned on me when I came upon Pindar's words the power of mastery [epikratein dunasthai]. If you stand up boldly in your chariot, and four unbroken horses rear in wild disorder against your curb, and you guide their mettle, whipping the one who steps out of line back into the ranks, the one who rears up and down to the ground again, and drive them, and guide them, and turn them, whip and hold them, and go on driving them, until all sixteen hooves carry you to your goal as if in single step that is Mastery, epigratein, Virtuosity. And what if all I've been doing is to stroll about just taking a peep at this and that. Never really getting hold of anything. To get your hands into a thing, seize hold of it, that is the essence of mastery of whatever kind ("Letter to Herder July 1772" Model 131).

${ }^{50}$ Lichtenberg (1742-1799), a physicist colleague of Kant and Goethe, introduced Franklin's lightening rod to Germany. He was lampooned by his contemporaries for his enthusiasm about physical culture.

${ }^{51} \mathrm{~A}$ number of complete human models emerged in the late seventeenth and eighteenth centuries: for example, Christian Thomasius introduced "bon goût" into German in 1687 in opposition to the pedant or homme galant. The man of good taste "showed discrimination in the affairs of everyday life; he did not slavishly follow fashion or cultivate an air of idiosyncrasy but rather demonstrated decorum, elegance, and selfconfidence" (Moore in Herder Aesthetics 20). Many are the ways of being a man, even one involved in the humanities: Mendelssohn wrote: "For the virtuoso fine arts and sciences are a preoccupation, for the amateur a source of pleasure, and for the philosopher a school of instruction" (169). 
Schiller was much taken with Johann Joachim Winckelmann's contributions, his potent mythology, and particularly with his representation of the early Greeks as living simply and naturally with beauty. ${ }^{52}$ Letter VI reflected Schiller's study of their "noble simplicity and tranquil grandeur" [eine edle Einfalt und eine stille Größe], their expression of the "ideal of humanity, of human completeness and self-sufficiency" (Nisbet German 4). ${ }^{53}$ He used Winckelmann's idealization, "the natural humanity of the Greeks" as a counterpoint to contemporary forms of humanity. The Greeks "were wedded to all the delights of art and all the dignity of wisdom, without however, like us, falling a prey to their seduction. The Greeks put us to shame not only by a simplicity to which our age is a stranger; they are at the same time our rivals, indeed often our models" (VI.2).

Winckelmann himself was something of a model. Though Goethe may have used Winckelmann as a foil to write about himself and his own responses to the natural world, Goethe nevertheless found the occasion (an elegiac essay in 1805) to valorize healthy

\footnotetext{
${ }^{52}$ Winckelmann (1717-68) spent many, miserable years before becoming a research assistant to a Count near Dresden and gained access to an excellent library. He studied literature and religion systematically and converted to Catholicism before moving to Rome in 1755. His "Thought on the Imitation of the Painting and Sculpture of the Greeks" (1755), from which the quote below is taken, began the German love affair with Hellenism. Once in Rome, Winckelmann became an eminent scholar of classicism and connoisseur of Greek art; he was appointed to the office of Prefect of Antiquities and held a position at the Vatican Library.

53 "Finally, the universal and predominant characteristic of the Greek masterpieces is a noble simplicity and tranquil grandeur, both in posture and expression. Just as the depths of the sea remain forever calm, however much the surface may rage, so does the expression of the Greek figures, however strong their passions, reveal a great and dignified soul. Such a soul is depicted in the face of Laocoon ..." (Winckelmann in Nisbet 42).
} 
connectedness not only as a state of the body and mind, but as a way being -joyously in the world:

Winckelmann brought to his life a genuinely antique spirit ... not only to enjoy happiness but to endure misfortune: for just as healthy fibres resist disease and rapidly recover from every attack of illness, so also can that healthy sense which distinguished the ancients recover quickly and easily from internal or external accidents .... When the healthy nature of man functions as a totality, when he feels himself in the world as a vast, beautiful, worthy, and valued whole, when a harmonious sense of wellbeing affords him pure and free delight - then the universe, if it were capable of sensation, would exult at having reached its goal, and marvel at the culmination of its own development and being. For what is the use of all the expenditure of suns and planets and moons, of stars and galaxies, of comets and nebulae, of completed and developing worlds, if at the end a happy man does not unconsciously rejoice in existence? (Goethe qtd. in Nisbet German 237-8). ${ }^{54}$

With the Greeks and with Winckelmann, "[h]owever high the mind might soar, it always drew matter lovingly along with it; and however fine and sharp the distinctions it might make, it never proceeded to mutilate" (VI.3).

Schiller's own achievement was to weigh many values and synthesize them all: organic humanity, graceful organic movement as lebende Gestalt, and the dignity of mastering of all one's powers and circumstances with equanimity, even happiness. His over-arching consideration was, however, "the possibility of each and every man becoming 'whole' within his own limits of endowment and situation - an essentially democratic possibility which was central to [his] theory of education" (246). His image of the "whole man" focused on unity through movement and development: it was a dynamic model that stressed on-going co-ordination, balance, harmony and symmetry of

${ }^{54} \mathrm{H}$. B. Nisbet: "The exemplary and historic significance which he attributes to Winckelmann in the essay ... belongs in even greater measure to Goethe himself: he has overshadowed German Literature for the last two hundred years" (235). Goethe in conversation with Eckermann on Winckelmann: "One learns nothing on reading him, but one becomes something" (qtd. in Nisbet 7). 
the human psyche within the aesthetic space. Schiller's respite, the aesthetic space, was the default position, the reboot for goal-directed activity, a starting-block for actions that followed yet another model, one that captured Goethe's sensitivity to irreversible growth, a dominant principle, and combined subordination, hierarchy, imbalance, and asymmetry (249).

Again Schiller's model was the complete anthropological view [die vollständige anthropologische Schätzung] that "every individual human being carries within him, potentially and prescriptively, an ideal man, the archetype of a human being, and it is his life's task to be, through all his changing, manifestations, in harmony with the unchanging unity of his ideal" (IV.2) The failure of his fellows to live fully and to fulfill their potential plagued Schiller: "[b]ut can Man really be destined to miss himself for the sake of any purpose whatsoever?" Aesthetic education provided humans the opportunity "to restore by means of a higher Art the totality of our nature which the arts themselves have destroyed" (VI.15). Based on experiences with beauty, its project was to deepen and broaden capacities for self-awareness, empathy and representation in each person. It was also a program "designed to make men - all men - willing and active participants in the political community, but without forfeiting their inalienable right to the full development of their unique and unrepeatable individuality" as well (Models 238).

It is, then, not just poetic license but philosophical truth when we call beauty our second creatress. For although it only offers us the possibility of becoming human beings, and for the rest leaves it to our own free will to decide how far we wish to make this a reality, it does in this resemble our first creatress, Nature, which likewise conferred upon us nothing more than the power of becoming human, leaving the use and practice of that power to our own free will and decision (XXI. 6). 


\section{The Man Himself: Portrait of a $Z$ witterart}

O Aesthetics! in which cavern of the Muses is sleeping the young man of my philosophical nation destined to raise you to perfection[?]

(Herder Aesthetics 2).

What is man? What is a whole man, but a work of art in time? (cf. Kant Third §10). Here is the life of a man working toward wholeness; it is the life that was poured into the Aesthetic Letters. Beauty and freedom, autonomy and art were the benchmarks of its development. Johann Christoph Friedrich Schiller, one of the greatest German literary figures, poet and philosopher, wrote almost continuously from his school years. He crafted poetry most consistently, but also authored an unfinished novel, a short story and ten plays including the trilogy Wallenstein. He also completed an anonymous review of one of his own plays, a philosophical dialogue, occasional essays, histories of the Thirty Years War and the revolt of the Netherlands, and several substantial philosophical essays on aesthetics, one of which is the occasion of this dissertation. He often moved back and forth between creative endeavors and technical ones, in an effort to reenergize himself. ${ }^{55}$ It was this tendency that set him studying history and philosophy after his disappointment with both the process and product of his play, Don Carlos (1787). A period of particularly intense attention to Kant's Critiques between 1792-94, provoked the development of his own ideas within a Kantian structure and produced his major philosophical works between 1793-96. The Aesthetic Letters was a part of this project.

${ }^{55}$ Once, in 1784 in "The Effect of Theatre on the People" (also called "The Theatre considered as a Moral Institution" [Vom Wirken der Schaubühne auf das Volk]), Schiller asked his fellows the question, "whether the business to which we are devoting the best part of our mental powers is compatible with the dignity of our spirit," that is, are we, am I, following my true vocation? His movement back and forth between creator and critic, artist and philosopher, physician and patient, allowed for the perspective of ubiquity: it empowered him to answer with self-correction (Reed Schiller 33). 
He wrote plays again only after the publication of "On Naïve and Sentimental Poetry," a final philosophical essay that, though an explication of a duality in human nature, paradoxically signaled a hard-won unity of his own self-experience and the resolution of anxiety about his mixed nature.

Schiller's life as narrative is a developmental history of his spiral movement in and out of the aesthetic state, from determinability to determination, from contemplation to project, from freedom in play to necessity - followed by release to reflection once again. In beauty's gift, the aesthetic state, was his second mother's loving gaze and her safe lap, a holding environment for recalibration (Winnicott).

[By means of the aesthetic] the personal worth of a man, or his dignity, inasmuch as this can depend solely upon himself, remains completely indeterminate; and nothing more is achieved by it than that he is henceforth enabled by the grace of Nature to make of himself what he will - that the freedom to be what he ought to be is completely restored to him .... True, he possesses this humanity in potentia before every determinate condition into which he can conceivably enter. But he loses it in practice with every determinate condition into which he does enter. And if he is to pass into a condition of an opposite nature, this humanity must be restored to him each time anew through the life of the aesthetic .... It is then, not just poetic license but philosophical truth when we call beauty our second creatress. (XXI. 4-6)

At fifteen, Schiller matriculated at Karlsschule (1775-80), the Duke of Württemburg's Military Academy at Solitude. His invitation to attend the academy was a recognition of his father's service to the Duke as forester, a consideration proffered to a subordinate which could not be regretted. There then he was sent. There, Schiller, who longed for a theological education, made a forced choice - first to study the law and then medicine. ${ }^{56}$ Within that curriculum however there was a species of freedom: the students

56 "[H]e wanted to be a preacher, dedicated to the cure of souls" (W\&W xxxi). When Schiller transferred from law to medicine, he gave up intensive study of languages (Greek 
were offered incredible diversity, an extensive acquaintance with philosophy - the ancients, Descartes, Leibniz, the Wolffians, the philosophes, Locke, Shaftesbury, the common sense school of Ferguson, Hutcheson and Reid, and the contemporary Germans including Sulzer, Garve, Herder Lessing and Mendelssohn. The medicine taught there was philosophical as well, oriented toward psychosomatic interpretation. Schiller's two dissertations indicated that bias: the rejected "Philosophy of Psychology" ["Philosophie der Psychologie"] (1779) and his "Essay on the Connection between the Animal and the Spiritual Nature of Man" (1780) reflected Schiller's search for a ground in the physical nature of man for the possibility of freedom (Dewhurst 38, W\&W xxxi). ${ }^{57}$ According to Wilkinson and Willoughby, "The notion of the human mind as an organic growth, reciprocally related to the physical organism, was and remained a genuine interest, as genuine as his unshakeable belief in the freedom of the human spirit" (xxxiii).

There at Karlsschule, Jakob Friedrich Abel (1751-1829) was his mentor, and this mentor's method was "reasoning from experience" (xxxi). Keenly interested in the new psychology, Abel directed Schiller's attention to Shakespeare and to forensic psychology, his avocation. There too, Schiller spent a good deal of time in the Infirmary where he wrote The Robbers [Die Raüber] for the desk drawer, expressing in the characters and the plot his experience of the tyranny of his Duke, who supported his extravagant lifestyle by

and Latin) for the study of physiology, anatomy, pathology, osteology, chemistry and natural history (Dewhurst 34).

${ }^{57}$ The French figures included La Mettrie and Helvétius in addition to the Encyclopédistes. Directly after an example from Shakespeare, Schiller included a passage from The Robbers in his dissertation, a nose-thumbing reference from the "Life of Moor, a Tragedy by Krake, V.1" (Dewhurst 273). 
selling troops to fight in the American war and who refused Schiller and other cadets family visits. By proxy, the Duke ran a claustrophobically regimented institution. ${ }^{58}$

After graduation Schiller, who needed an additional year of education in order to practice autonomously, was limited to Duke Karl Eugen's employ. From him, he received an undistinguished appointment as a regimental physician in Stuttgart. Schiller's responsibilities were light, and the work was unchallenging and repetitive. According to Abel, who was his correspondent, Schiller had difficulty managing his money and occasionally his alcohol, gaining something of a reputation for dissipation and "addiction to conviviality" (Dewhurst 66). A contemporary found him living in "picturesque disorderliness" but, beneath it all, Schiller was aware of his capacities. He had The Robbers printed at his own expense (July 1781) and prepared a stage adaptation for Dahlberg's Mannheim Theatre. Then, in January 1782, Schiller, without permission, left his duty station to see his own play produced. An eyewitness reported the behavior of spectators after the play:

${ }^{58}$ For very good reason Schiller was spectacularly unhappy at the institution: the Duke's idea of discipline created an extremely oppressive atmosphere of constant supervision. Pupils were required to wear uniforms and wigs and to request permission to perform the most basic functions. It was an inhumane environment as well: he, for example, met his two younger sisters only after graduating in 1780 . As part of the medical curriculum he was assigned to companion his school friend Grammont during that student's bout of depression. Confined to the infirmary (June 1780), Grammont was isolated, treated with emetics and subject to clinical observation and reportage. Schiller's assessment was clinical depression, a condition that seemed partly situational, arising from the cold and restrictive institutional environment, homesickness [Heimweh], and distressing nausea and anorexia (the side-effects of treatment). In his encounters with Grammont, he practiced an empathic psychotherapy but was countermanded from further contact because of his "indulgent methods." Grammont's pleas to leave the "repugnant" institution were poignant: the patient "longed for the freedom to enjoy the beauty and solitude of nature." Grammont was released from the Academy in December 1781; he was reported cured by 1783 . He married, supported a family as a tutor in Russia and as a Gymnasium professor (Dewhurst 177-201). 
the theatre was like bedlam with rolling eyes, shaking fists and hoarse cries in the auditorium. Strangers embraced one another in tears, women staggered towards the exit on the point of swooning. There was a universal commotion like in Chaos, and from its mists was born a new Creation (Dewhurst 69-70).

Schiller's flamboyant success was an offense against good taste from the standpoint of his benefactor, the Duke, and he was warned to refrain from further public lapses of judgment. ${ }^{59}$ Schiller however was young, lionized and angry; he continued to call attention to himself and offend. Once more he disappeared to attend one of his plays, was discovered, rebuked, incarcerated for two weeks and commanded to refrain from writing and publishing. When the Duke rejected his plea to be allowed to do literary work, Schiller left. On September 22, 1782, he and his friend Andreas Streicher, as Doctors Ritter and Wolff, rode out to Mannheim. Dr. Ritter did not come back.

After his escape, Schiller scraped by financially, writing plays and essays, starting periodicals to be vehicles of his support - $\underline{\text { Rheinische Thalia }}$ (1784), $\underline{\text { Thalia }}$ (1787), Die Horen (1795) - a life-long gambit. Supported minimally by Dahlberg of Mannheim Theatre for a year (1783-84), he was saved by strangers, part of his public. Young people like himself, fans of the playwright creator of Karl Moor, offered him a home at Leipzig (he arrived in 1785), financial support and camaraderie - in short, a life-saving community. His mutually satisfying and intellectually reciprocal relationship with one of them, Christian Gottfried Körner, lasted the rest of his life. Their lively and intimate

${ }^{59}$ The Duke's displeasure had consequences; Karl Eugen had a history of punishing offending subjects with long imprisonments. The poet Schubart, who had called the Academy "a slave plantation" in print, thereby identifying its "strictly instrumental use of local abilities," was lured back to Württemburg in 1777, arrested and imprisoned for ten years (Reed Schiller 9, 10). 
correspondence yielded the Kalliasbriefe, Schiller's incomplete but provocative effort to provide a deduction of an objective principle of beauty.

Philosophically, Schiller's oppositions - sense and reason, authority and autonomy confronted each other in early works and his search for the middle, once posited in terms of Mittelkraft in his dissertation, was articulated in "The Stage as a Moral Institution" (1784). In that piece, he wrote: "[o]ur nature ... demands a middle-state [einen mittleren Zustand] which unites the two opposed extremes, moderates the harsh tension between them, and facilitates the transition from one state to another" (xxxiv).$^{60}$ The stage, and later all art, became for him a representation of an transformational aesthetic state, one that allows humans to "rejoic[e] in the full knowledge of what it means to be a human being - 'ein Mensch zu sein' - strengthened and healed to our fellow creatures" (Schiller qtd. in W\&W xxxiv). During the time in Mannheim, Schiller wrote two plays, Fiesco and Intrigue and Love [Kabale und Liebe, originally titled Luise Millerin]; he then worked on another, Don Carlos, for the next several years. This play became something of a monster; written over too long a time, it escaped the inspiration of its inception. Each infusion of content required protean form-switching, and the play lengthened each time Schiller wrestled to get it under control. In the meantime, he grew up, he later wrote; he simply outgrew the play's principals (Reed $\underline{\text { Schiller } 48-49 \text { ). }}$

At something of a loss because of difficulties with Don Carlos and always in need of work that would support him, he began to write history. He moved to the Duchy of

${ }^{60}$ In "Anthropology," Reill incorporated Schiller's early work into his argument for Enlightenment vitalism. That author traced vitalistic interest in the "middle" through Schiller's example of an elaborately represented "expanded" or "extended" middle full of paradox and "creative oxymorons" (like "material ideas" and an "organ of thought"). All the while Schiller, Reill noted, followed "a logic of the ambiguous, enthroning complementarity over unity" (256-261). 
Weimar in 1787, enjoyed historical research, published and gained a position as professor of History at Jena in 1789 (partly due to Goethe's intervention) ${ }^{61}$ By 1790 he was granted a small pension by Duke Karl August of Sachsen-Weimar and, therefore, was able to marry and support a household. He had prospects of happiness he had hardly dared to imagine in his wife, his children, his colleagues and later, his garden.

He, however, became seriously ill in 1791 , so ill that rumors of his death reached as far as Denmark. When he recovered, his supporters there were overjoyed at the news. Recognizing the precarious state of his health (and of his affairs if he were unable to work regularly), they decided to arrange financial support: a three year grant from the Duke of Augustenburg allowed Schiller the leisure to study Kant and provided him the occasion to write On the Aesthetic Education of Man In a Series of Letters.

In the summer of 1794 he finally met Goethe in a situation that led to private conversation and to immediate but formal intimacy. They were involved on an almost daily basis through letters and visits for the rest of Schiller's life. Shortly after their first meeting, Goethe wrote to him: "I have always had a high regard for the rare integrity and seriousness that are plain in everything you have written and done" (Reed Schiller1).

Integrity. Seriousness. For Schiller, the movement toward wholeness was an affirmation of his own humanity. The measures of the goal were autonomy (which included all relations and connections) and freedom (within the boundaries of sociability) to self-develop and to encourage others. Because he was "addicted to the figure of

${ }^{61}$ Schiller was already reading Kant. Reinhold wrote Kant that Schiller's "universal history ... is designed on the lines of your plan, which he grasped with a purity and ardour that made him double dear to me" (14.vi.1789). Reed wrote that Schiller set out to be "Kant's Newton" of history (which made Schiller quite busy trying to be Newton) (Reed Schiller 56). 
antithesis," because he negotiated a dynamic balance of opposites, of sense and thought, of art and science, of necessity and freedom, of autonomy and dependency, he was a person who had to strive self-consciously for that development. And because he was intimately aware of the tenuousness of existence, he reached for intensivity and extensivity in the process of daily living. To this end, "[t]he role of art, the integration of the psyche and the possibilities of exercising freedom," wrote Lesley Sharpe, were "matters that preoccupied Schiller for much of his creative life" (3).

Personal autonomy encompassed all the other tasks. The battle for freedom was a battle enjoined early on: the struggle against the strictures of Karlsschule and his Duke through respites in the infirmary, the subversively written and produced Robbers and his escape from medicine. On his own he faced life's basic needs - and struggled to be selfsupporting by writing in the arts and philosophy. His need to establish himself played out in battles with his own inner conflictedness, with the overpowering image of another, Goethe, and with his own illnesses, his battered physicality. The first he settled with the establishment of a career, then a household and circle in Jena and Weimar, and a reciprocal friendship. In the civic sphere, the Aesthetic Letters was his method to promote a sustainable freedom, an enlightenment for himself and others, the possibility of autonomy for the whole person with the help of society.

He opposed himself to Goethe, at first against the famous genius' reputation and then within their friendship. Before their meeting, he had circled Goethe like an injured dog, and, in effect, kept himself subjectively in the great poet's shadow. ${ }^{62}$ "This feeling of

${ }^{62}$ W\&W noted Schiller's lucidity about his ambivalence. He wrote to Körner of Goethe: "It is a curious mixture of hate and love he has aroused in me, a feeling not unlike that which Cassius and Brutus must have felt for Caesar. I could murder his spirit, and again 
being Nature's stepchild was not to be assuaged," according to Wilkinson and Willoughby, "until to such knowledge of Self was added knowledge of the Other" (xxxvii). It was through that relationship with Goethe, the sociability of that friendship, their shared values and co-authorship, that Schiller came to accept himself as an equally legitimate type. He was a modern, a sentimentalist made up of creative and selfreflective capacities.

More, even as a Zwitterart, he realized he had the same enjoined task as Goethe did. In the end both had to be free, each had the duty to fulfill his potential, each must seek beauty in his own way and live a graceful life. In this, he always struggled with himself: for example, in 1792, after a period relatively barren of creativity, he wrote to Körner that he was ready to write creatively again.

My pen has a veritable itch to start on Wallenstein. It is really only in art itself that I feel my full powers; in theorizing about it I always have to plague myself with principles. And I'm no more than an amateur there anyway. But for the sake of poetic practice I am very ready to philosophize about the theory of it. Criticism itself must now make good the damage it has done me. And it has indeed done me damage. For the boldness, the living fire, I felt before I was aware of any rules at all, has been absent for many a year. I now see myself creating and fashioning. I observe the play of inspiration, and my imagination behaves with less freedom since it feels itself no longer unobserved. Yet once I have got far enough for artistry to become as much nature to me as nurture is to the truly cultivated man, then my imagination will recover its former freedom and suffer no inhibitions except those it freely imposes upon itself. (W\&W xxxv).

love it with all my heart" (25.ii.1789). And, "I have to laugh when I think of all I have written to you about Goethe. You really will have seen me in all my weakness .... The long and the short of it is that this man, this Goethe, is in my way, and a constant reminder that fate has treated me harshly. How lightly was his genius born along by his fate, and how hard have I had to struggle ..." (9.iii.1789) (xxxvii). What a friendship Schiller had with Körner and what an opportunity for repair of self-inflicted injury was his friendship with Goethe. 
His progress in overcoming his inhibitions ran through "On Grace and Dignity" ["Über Anmut und Würde"] where he slighted Goethe (for whom he had both respect and envy), to the Aesthetic Letters, where he granted Goethe an appearance as the ideal natural scientist (XIII) and perhaps as the ideal artist (X), to the last "On Naïve and Sentimental Poetry" [Über naïve und sentimentalische Dichtung 1795-6]. There he presented two human types, the naïve and sentimental, the realist and idealist, of equal value. After he first articulated his imbalance to Körner, it took him four years to get back to Wallenstein with his powers whole.

Schiller was chronically ill for most of his adult life, and he opposed with his spirit the terrible necessity of the physical. He was a thin, tall, bird-like presence with a delicate constitution and a tendency toward melancholy (which he banished with frenetic energy and activity, writing all night when his health permitted and recovering in the mornings). From early in his life, he had some respiratory weakness which translated into a susceptibility to infection, either bronchitis or pneumonia. In 1791, he became desperately ill. His condition, possibly a tubercular empyema of one lung that ruptured though his diaphragm to his abdominal cavity, left him an invalid for the rest of his life. A limited breathing capacity, severe abdominal cramping (a symptom of partial obstruction of the intestines due to the adhesions of past infection) and a weakened respiratory and immune system, made terrifying bouts of illness a realistic possibility every winter thereafter. He wrote to Goethe in 1794, "I will do what I can and when the 
building collapses I will perhaps have rescued what is worth preserving from the fire (31.viii.1794)" (Reed Schiller 5). ${ }^{63}$

In 1776, when Schiller was just a student, Abel delivered his "Speech on Genius" at a Karlsschule assembly.

The genius, filled with a sense of his strength, filled with noble pride, casts aside degrading fetters, and, scorning the cramped dungeon where the common mortal pines, tears himself free with heroic audacity and flies like the kingly eagle far above the tiny, base earth, soaring in the sunlight. You curse him for not remaining on the old track, for leaving the confines of wisdom and virtue - insects, he flew to the sun (Abel qtd. in Dewhurst $305,365)^{64}$

Schiller heard his words eagerly - he intended then to be the eagle he became.

${ }^{63} \mathrm{My}$ reconstruction based on information provided by Dewhurst and Reeves 82-85. Schiller's comments to Körner over the course of their correspondence, and particularly after 1791, show that he anticipated serious illness and death each winter. In 1793, two years after his near-fatal illness, he wrote to his friend: "From this letter you can see that the asphyxiating angel has passed over me so far. Three weeks have passed since the date at which I became ill last year, and four have passed since the day I became ill two years ago ..." (Bernstein Trans. Bird-Pollan 147).

${ }^{64}$ Information in this section was distilled from the following sources, Dewhurst 31-86; Reed Schiller passim; Sharpe, Schiller passim and W\&W xxix-xlii. 


\section{CHAPTER VII}

\section{EPILOGUE: SCHILLER TODAY}

"[T]he direction is at once the Destination, and the Way is completed from the moment it is trodden" (IX.6)

Time to sit, with our backs to the garden shed, another lawn chair pulled up, hat put on its empty seat, a place to remind us of Schiller - who brought us this far. The dogs have chased and flopped, panting, in the shade. Let's look out on the garden.

Our Schiller, a synthesizer of reason, feeling and development, proposed a drive theory of human nature. This archetypal theory described playing as quintessentially human and humans as fully human only when they played.

What happened to this large claim?

Without its context of vitalistic science, it hid within the Aesthetic Letters like a little engine of argument. Only when a few parts of it were lifted out - to be quoted - then, what we heard had the ring of an aphorism, as difficult as a kōan. What did he say?

But there is a way to hear his theory as a claim about who we really are, a way to use it to play with our identity in earnest. Lately Robert Richards suggested that Naturphilosophie (the science that developed out of the vitalism of Schiller and Goethe's time) provided Darwin with a way of perceiving nature that led him to his theory of

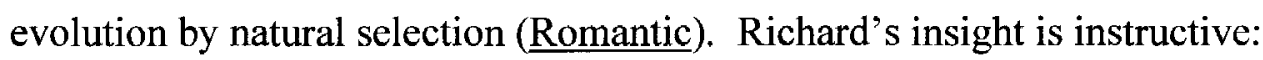

Naturphilosophie was not considered normal science; what it and its late Enlightenment vitalistic beginnings provided to Darwin was an aesthetic view of nature. Through it, 
Darwin experienced nature as a confused whole - he intuited nature as Baumgarten, Goethe, the Humboldts and Schiller did - as an organism, complete in all its connections and relations. Grounded in that experience of nature, supported by his own research and the work of many others, he developed the theory of evolution by natural selection.

Schiller developed, out of his vitalistic context, a theory about the human being as a whole, a theory of the mind's structure, one that includes all its relations and connections. His theory of human nature may have value for us as a template. It might serve as a model for a current general theory of human evolution: as a macroevolutionary innovation, play advanced behavioral flexibility and organismic autonomy. Much of what we value in ourselves (and consider to be species-specific) can be seen as elaborated derivatives of ancestral mammalian play. ${ }^{1}$

${ }^{1}$ Schiller's hypothesized mind structure as generative of play and evolved by the success of play would constitute a macroevolutionary innovation. According to Rosslenbroich, "[a]ttempts to explain the origin of macroevolutionary innovations have been only partially successful ... . [P] ]atterns of major evolutionary transitions have to be understood first, before it is possible to further analyse the forces behind the process. The hypothesis is that major evolutionary innovations are characterized by an increase in organismal autonomy, in the sense of emancipation from the environment [and] ... increasing autonomy is defined as the evolutionary shift in the individual system environment relationship, such that the direct influences of the environment are gradually reduced and a stabilization of self-referential, intrinsic functions within the system is generated. This is [a] relative autonomy because numerous interconnections with the environment and dependencies upon it are retained. Features of increasing autonomy are spatial separations, an increase in homeostatic functions and in body size, internalizations and an increase in physiological and behavioral flexibility" (623 my emphasis). Schiller detected "a glimmer of freedom even into the darkness of animal life" (XXVII.3); Rosslenbroich found autonomy to be an active (rather than passive) biological adaptation characterized by separation from the environment, homeostatic capabilities, internalization of function, increase in size and flexibility within the environment (626). These adaptations are to be observed behaviorally in conventional play (637). If such play is considered a marker for pleasurable enframed attention, it signals increased autonomous adaptation from the broader category of structural and functional changes: 
In order to bring Schiller's theory forward, to situate it in the life sciences of our time, the unknowns that late Enlightenment scientists struggled with must be named (in as far as it is possible). What they had attempted to manage with regulative judgment were the perceived design features of living organisms that appeared to program future development. The reproductive and developmental capacities of living forms have now been explained naturalistically through the theory of evolution by natural selection and its mechanism, genetics. Applied to Schiller's theory, the theory of evolution reframes the play-drive into an adaptation, a trait developing by natural selection over evolutionary time.

How can we, as an exercise in imaginative construction, put Schiller's theory on the tracks of evolution? How should Schiller's developmental history of man be retold? As he wrote, we were animals like other animals, first physically and then socially playful. Then, we developed as hominids expanding our functional behavioral flexibility through mental playfulness to aesthetic autonomy. Our play is potentially homologous with, directly biologically related to, that of other social mammals, our elaborate capacities but descendents of the play of our evolutionary ancestors. This is an interdisciplinary

separation from environment (creation of a safe space socially and internally), homeostasis (keeping internal mental and cultural spaces relatively stable), internalization (the social play space is increasingly internalized as mentation), increase in size (more and more mental functions remain internal as opposed to being acted out; culture creates a larger and larger protective boundary among the individual, his society and nature) and flexibility (an infinite number of autonomous internal and external behavioral variations possible). That autonomy is adaptive complements Schiller's experience of freedom as "enjoined" [aufgegeben]: it is part of our nature, our process, our responsibility to develop toward autonomy, and it is the purpose of culture, as macro-play, to make individual freedom and autonomy a possibility (XIII.2, XIV.2, W\&W xxxiv, Schaper "Towards" 159). Play just may be sublime. 
construct, essentially, a proposal for a shared project of study. To propose that playfulness, pleasurable framed and flexible attention, is an inherited adaptive capability, one that itself became fabulously elaborated in its history, is to ground ourselves in our fixed evolutionary history. It is also to use an intuition of the confused whole to further our understanding of our own nature and nature itself. Whether this Anschauung is an idea or an experience, playfulness should be taken more seriously by scholars in the sciences and the humanities.

It is important to remember two things about Schiller's theory of play: it is not really about behavior, though it has profound implications for all of human behavior, for animal and human play behavior. Schiller made a hypothesis about the structure and function of the human mind. To restate his theory in a more contemporary way (and in broad brush), he held that the older emotional part of the mind (the sense-drive) and the newer rational part of the brain (the later developing form-drive) interact, and interact in progressively more complex, asymmetrically reciprocal ways. For him they interacted in different hypothetical stages: the physical (senses and emotions) developing toward the aesthetic through the steps he called animal, rational animal, and human. Considering Schiller's perspective and what we are learning about animal minds, we might say that the rational and emotional interact in animals (and by implication in us) to allow for the experience of feelings and for judgments regarding the senses and internal well-being. ${ }^{2}$ When we were

\footnotetext{
${ }^{2}$ In the seventeenth and eighteenth centuries, there was both study and speculation about animal's cognitive abilities. Hume, an author with whom Schiller was familiar, wrote: "First, it seems evident, that animals as well as men learn many things from experience, and infer, that the same events will always follow from the same causes. By this principle they become acquainted with the more obvious properties of external objects, and gradually, from their birth, treasure up knowledge of the nature of fire, water, earth, 
like "rational animals," our drives interacted as they might in animals with their own species of reason. Then they promoted a developing sense of self, sense of the other (first as sympathy, then as empathy and a rudimentary theory of mind) and some capacity for representation. Our species-specific capacity to play (to combine the two parts of the mind for representation, mental and physical expression) was augmented by greatly elaborated and co-operatively functioning senses, the eye and the ear. Our pleasure in representation further developed our self-consciousness to self-awareness and our empathy to knowledge of other minds. Our particular love of Schein motivated us in the use of language, the sciences and arts. For us, for Schiller, species-specific, ideal play seems like the harmonious reciprocal interaction of those two parts of the nervous system, the emotional and the rational, in another relation with a sensate ideal, beauty. This complex interaction promotes contemplation (the aesthetic state) and freedom of choice. This is what we humans can do: we experience beauty and out of that experience, know ourselves as autonomous beings. This is ideal play, and like all of Schiller's ideals, it cannot be fully realized, but it is realizable as a process of developing . . . ourselves. Other interactions of the sense-drive and form-drive, the emotional and rational parts of

stones, heights, depths, \&c., and of the effects which result from their operation. The ignorance and inexperience of the young are here plainly distinguishable from the cunning and sagacity of the old, who have learned, by long observation, to avoid what hurt them, and to pursue what gave ease and pleasure" (An Enquiry 59). Exploring the cognitive capacities of animals engages many scientists today, and their efforts form the basis for both popular and scientific literature. For example, Griffin's Animal Minds (1992) and Heinrich's Mind of the Raven (1999); Bekoff, Allen and Burghardt's The Cognitive Animal (2002), Russon and Begun's The Evolution of Thought: Evolutionary Origins of Great Ape Intelligence (2004), or Geary's The Origin of Mind: Evolution of Brain, Cognition and General Intelligence (2005). 
the brain, are for us species of degenerative play, play not in balanced and dynamic tension or harmony. These are less than the best we can be - for ourselves and for others.

While Schiller's theory is about the structure of the mind, as it is experienced by a subject observing his own interiority, almost all modern theories of play rely on observable behavior to make claims about that behavior. Generally, modern theorists begin with the conventionally identifiable, but impossible to define, attributes of play. Pleasure, fun and purposeless activity (action that has no apparent connection to survival or reproduction) are the hallmarks of this play. It is animal play, children's playing - and adults' "mere play." Behavior defined in this way is only the smallest part of what Schiller theorized about: it is like the outward and visible mark of broad subjective and objective processes. Schiller brought us a bigger picture (a confused whole) - much more than the modern fragmented parts the separate disciplines can generate. He has arrived from the opposite pole. This should give us pause. And it does. Can soy-beans and durian fruit be compared? Of course not! Schiller would say. But experience proves that they will be. This is mental play: Schiller's theory and the theories current about the phenomenon of play together can provide a new direction of thought and research. Play research is being and will be continually restructured to reflect access to subjective states in animals and humans through new technology, and play will come to be defined by what happens in the brains of animals and humans correlated with their behavior. This combination of theory and the technology is what we have been waiting for.

Such play would be part of Schiller's concern and a pledge of what he believed we can be. For the humanities, the homology of animal and human play would suggest a bio-cultural ground, out of which might come a general theory of human nature, a 
connection with our long history and our living environment. The recognition of this ground, this connection with evolution, would perform a profoundly important realistic function: it would focus the humanities on meaning and value of our lives in our world. It would tether the humanities to a common, shared reality, evolutionary history. What happened has happened. We are our history, and the equipment that promoted our survival, through flexibility, would seem to invite our best thought ... and management. The recognition that we can and do attend to anything, whether it be bikes, dogs, eighteenth-century texts, nuclear weapons, football, clay, guppies, sports bras or grandkids (and can make of them a life) puts the work of the sciences and the arts in a new perspective. Such an intuition would encourage us to be true to what we valorize to recognize the arts and humanities as the tools of development, of transformation. ${ }^{3}$ It would mobilize us against the naturalistic fallacy: just because our flexibility (our capacity for pleasurable framed attention) is an amazingly successful adaptation, one that has enabled us to overwhelm the earth, does not make it fate, does not make it right, should not have it - out of our curiosity and daring-do - make our decisions for us. Because it is often easier to play at the lower registers of energy, emotion and cognition, doesn't mean we should do that either. As humanists, our concern is Schiller's: might

3 "How pitiable the man who wants and makes nothing higher with the noblest tools, science and art, than what a day-laborer does with the most common! Who in the realm of perfect freedom carries with him the soul of a slave! . . Soon enough his specialty will disgust him as piecework, desires will quicken within him which it cannot satisfy, and his talent will mutiny against his vocation. Now everything he does seems fragmentary to him; he sees no purpose to his activity and yet cannot endure purposelessness. He is crushed by the wearying details of his work . . . He feels himself cut off, torn away from the interdependence of things, because he has failed to relate his work to the world as a whole" (Schiller "Nature" 323). 
things be better? How do we ensure our autonomy and that of others, those others who now include non-human beings? How do we develop with our fellows? ${ }^{4}$

\section{Two Theories: Views from Biological and Social Science}

Science is neither a philosophy nor a belief system. It is a combination of mental operations that has become increasingly the habit of educated peoples, a culture of illuminations hit upon by a fortunate turn of history that yielded the most effective way of reading about the real world ever conceived (Wilson 49).

Just as Schiller's play theory of human nature required the context of vitalistic science for its full appreciation, it requires today, the context of today's science, the current study about life and human nature, for its meaningful application. And, as it always was, science is in flux. The data and theories of science - and the examples brought to bear on problems in the humanities from that sector - must be constantly updated, corrected, elaborated. . and reapplied. It is as if the time of science runs faster than human cultural time. When we decide to incorporate science into our considerations, we must be attentive about it, even vigilant. It is easy to be caught out, leaning on an old plinth. Nonetheless, theories and data from the disciplines of biology and the social and behavioral sciences are as essential for contextualizing the humanities as they are for situating Schiller's theory of human nature. And an understanding of the theory of evolution by natural selection is basic to the appreciation of any application of

\footnotetext{
4 "The Idealist, it seems, is as close to earth as the Realist; he merely does not accept the limiting Reality Principle, but holds to his own Possibility Principle - even when its demands seem to verge on the impossible." Schiller wrote in his last letter to Wilhelm von Humboldt: "'after all, we are both idealists, and we would be ashamed if people were to say that things shaped us and not we them' (2.iv.1805)" (Reed Schiller 104-105).
} 
the life sciences. ${ }^{5}$ With that theory as foundation, we can make a trial context for Schiller's theory by considering two recent theories of play, a theory from ethology and a summary of theories from the social sciences. In the first study about the ancestral play behavior in mammals, ethologists, through observation, experimentation and comparison, hypothesized a behavioral archetype. This theory-building operation is familiar to us from eighteenth-century morphology, from Goethe's intuition of the Urpflanze and Schiller's drive theory of play. In the next example, from the social and behavioral sciences, an interdisciplinary play researcher presented a general theory of human playing, one that represents that human behavior as ubiquitous - invading and informing all forms of culture. It reads like Schiller's list of late Enlightenment symptoms and fragmentations: the play that catches us up and becomes our life.

These studies provide general forms for the flood of contemporary material; they are theories that might excite us, exercise our imagination and reintroduce us to our world from a different perspective. They provide a context for reworking Schiller's theory of human nature. They are hypotheses, like Schiller's, based on data, and meant to stimulate further thought. They are meant to be amended and elaborated.

\section{Evolution, the Scientific Environment of Our Time}

Nature deals no better with Man than the rest of her works: she acts for him as long as he is incapable of acting for himself .... But what makes him Man is precisely this: that he does not stop short at what Nature

\footnotetext{
${ }^{5}$ Resources about evolution range from the simple graphic Introducing Evolution by Evans and Selina to Ridley's textbook Evolution. E. O Wilson edited and introduced Charles Darwin's major works in From so Simple a Beginning: The Four Great Books of Charles Darwin; Janet Browne wrote a wonderful two volume biography of Darwin; Jones' Darwin's Ghost and Reznick's The Origin Then and Now present the Origin of the Species with interpretations and annotations. Lyell's Principles of Geology and Paley's Natural Theology are representative of historical works that influenced Darwin.
} 
herself made of him, but has the power of retracing by means of Reason the steps she took on his behalf, of transforming the work of blind compulsion to the work of free choice ... (III.1).

What do we know now about the steps that nature took?

The first truth which issues from this serious examination of nature is a truth which perhaps humbles man. This truth is that he ought to classify himself with the animals, to whom he bears resemblance by everything he has that is material (Buffon in Lyon 150 my emphasis).

"Again and again, we shall turn to natural selection to understand animal behavior." (Dugatkin 6) $^{6}$

Since Schiller's time, two broad new understandings of living forms have developed that, once they were elaborated, have not only remained stable, but have promoted further knowledge and even generated new fields of investigation and discovery. They are evolution by natural selection and its support, genetics. Today's theory of evolution began with Darwin's hypothesis about natural selection: "Natural selection is ... the process whereby traits that confer the highest relative reproductive success (that is, the greatest relative fitness) on their bearers and that can be passed down across generations increase in frequency over many generations (evolutionary time)" (Dugatkin 6). Another one sentence explanatory variation of the theory provides us a species of depth perception: "Natural selection is a non-random difference in reproductive output among

\footnotetext{
${ }^{6}$ Behaviors depend on three factors for transmission: natural selection, cultural transmission and individual learning: in his time, Schiller considered development [Bildung] in humans to be a reciprocal interaction of social (cultural) transmission and individual education (factors - Dugatkin 6-18). His developmental history (XXIVXXVII) was suggestive of development toward humanity as a species but I am not aware of any evidence that Schiller entertained anything but a fixed species concept. He accepted variation within species - yes - but no transformational or transmutational thinking about the species itself. He did not supply a mechanism - only a history of development.
} 
replicating entities, often due indirectly to differences in survival in a particular environment, leading to an increase in the proportion of beneficial, heritable characteristics within a population from one generation to the next" (Gregory 156, 161). Evolution by natural selection requires variation in traits (as emphasized in the initial definition); there must be differences, different phenotypes controlled to some degree by genetic endowment, i.e. different alleles for genes, in order for natural selection to function. Nature must have choices. Nature as well provides differences: the second definition includes a stated acknowledgement of the pressure of "particular environments," thereby emphasizing that the right fit can be a local, idiosyncratic and even limiting phenomenon. Some fitness is better than others. In summary, according to Ridley, "[n]atural selection is easiest to understand, in the abstract, as a logical argument, leading from premises to conclusion." First, reproduction and heredity must be posited: "The excess fecundity and consequent competition to survive in every species provide the preconditions for the process Darwin called natural selection." Then, there must be variation in individual characters among the members of a population and also variation in the fitness of organisms. (74). ${ }^{7}$

\section{Ancestral Mammalian Play}

Not everything in human lives is culture. There is also biology. Human senses, emotions, and thought existed before language, and as a consequence of human evolution. Though deeply inflected by language, they are not the product of language. Language, on the contrary, is a

\footnotetext{
${ }^{7}$ The theory of evolution by natural selection's predictive and generative power has been huge: it has produced a tremendous amount of new information and insight, and has itself been enhanced by the addition of genetics and population theory (The New Synthesis, ca. 1920-40). It is undergoing further development through evolutionary-developmental theory (Evo-devo) and organism theory (ca. 1990-present) (Pigliucci passim).
} 
product of them: if creatures had not evolved to sense, feel, [play!], and think, none would ever have evolved to speak." (Boyd "Getting" 19 my inclusion of [play!], obviously a transgressive act).

What traits are common to all contemporary playing mammals, ones that may be the result of common descent? In a relatively recent article in the Quarterly Review of Biology (2001), ethologists Marek Špinka, Ruth Newberry and Mark Bekoff reviewed the research literature about play behavior in animals, collected data on the features of play in mammals from their own observations and experiments, and hypothesized the ancestral function of play. ${ }^{8}$ Based on their findings, they posited that the function of ancestral mammalian playfulness was "training for the unexpected." Špinka, Newberry and Bekoff theorized that a "major ancestral function of play [was] to rehearse behavioral sequences in which animals lose full control over their locomotion, position, or sensory/spatial input and need to regain these faculties quickly." Further, because recovery from awkward scrambling occurs in "biologically significant situations," accompanied by intense emotion, animals will be advantaged who "in play learn how to deal with the painful emotions of being surprised or temporarily disoriented or disabled." Play enhances the ability of animals to cope emotionally with unexpected situations: its "self-induced mishaps" and socially relaxed situation help the animal to avoid incapacitation by emotional overreaction to stress (142).

${ }^{8}$ Ethology: the naturalistic study of behavior from an evolutionary perspective (Burghardt 10). The aims of ethological research include 1) study of the factors that cause or control behaviours, 2) inquiry into the ontogeny, the development of the behavior and its mechanisms, 3) study of the adaptive value of performance (enhancing fitness) and 4) inquiry into the evolutionary origins and phyletic radiation of behavior and 5 ) attention to the "private experience" of the player (from Tinbergen's four aims plus Burghardt's added fifth in Burghardt 11-14). 
Play is nearly ubiquitous in mammals and, in spite of extremely diverse play styles, content, participation and perceived function, mammalian play has common features that suggest

either a common ancestry or a similar set of selection pressures that acted in all diverging mammalian orders in the Cenozoic. In our view, [the authors continued] it is more parsimonious to assume that there is a basic phylogenetic and functional unity underlying mammalian play than to assume that the "superficially similar" play patterns widely distributed in mammals evolved independently many times during mammalian phylogeny. Hence a search for a major function of play seems to be justified and important, as it is for other widely distributed mammalian characteristics such as sleep (142).

The common characteristics of mammalian play include the following: 1) the play of mammals includes an emotional component - players appear to be "having fun." The playing subject shows signs of excitement, pleasure, intrinsic motivation and relaxation; such behavior draws adjectives like "bouncy," "capricious . . exaggerated," "frisky," "boisterous," and "ebullient" from serious ethologists. This subjective component usually gives researchers trouble, but these audaciously

hypothesize that play is emotionally exciting (perhaps even thrilling, though not intensely frightening) and rewarding, maybe even pleasurable, while at the same time being relaxed. [They] suggest that this combination of affective attributes is unique to play, producing the complex emotional state that is referred to as "having fun" in human folk psychology (144).

"Having fun" shows, in their view, in the kinematic, structural, and motivational character of play. The animals' excitement "is revealed in the vigor and speed of play movements," their pleasure evidenced in the active seeking and "working out" of play situations, and their relaxation apparent in the willingness of the animal to self-handicap. 
2) Play involves self-handicapping, deliberate changes in social or physical routines that put the playing individual at some disadvantage. Further, play is demarcated by signals for beginning and ending that appear to be derived from postures of self-handicapping. These self-handicapping actions indicate not only self-evaluation and evaluation of playmates' state of mind and fitness but, because the focus of attention on play requires a decrease in vigilance, they imply a prior evaluation of the safety of the environment. And, 3) play implies rich cognitive content. "It is a cognitively demanding activity" and its benefits include locomotor, emotional and intellectual versatility, an enlarged behavioral repertoire and an enlarged capacity to handle unexpected events outside the play situation (145). ${ }^{9}$

Again, play in mammalian species is characterized by intrinsic motivation and enjoyment, capacity to focus on some stimuli and exclude others, thus creating an "as if" environment and sustaining focus within that zone. As intrinsically motivated, it has an internal teleology, but can be considered externally without purpose or goal (hence the common consideration that play is purposeless activity). Play occurs when resources and

${ }^{9}$ Other descriptions of animal play from the literature are as follows: animal play appears purposeless (in terms of providing immediate survival benefit) to many observers but includes structural components like motoric exaggeration, repetition, fragmentation or disordering of sequence is currently the common construct which may be practice. Some definitions sound downright Schillerian: "A free and creative form of individual or social behavior, often occurring without obvious external provocation" (Kortmulder quoted in Burghardt 55). And another: "Play is improvised performance, with variations, of skilled motor and communicative actions in a context separate from the environment" (Fagen in Burghardt 56). In the end, purposeful purposelessness, voluntary performance (motivational independence of ends other than pleasure) of modified patterns of repeated behavior in a predictable developmental period performed when the animal is healthy and free from stress identify play for ethologists (68-82). Miller: "play is activity, motor or imaginative, in which the center of interest is the process rather than the goal" ("Ends" 97). 
security are sufficient and it releases and increases energy in the system by means of transformations. Behaviorally, play is indicated by mimesis, by scrambled imitation, repetitions, adding and subtracting, distorting and elaborating parts of instinctive routines, by physical, social and mental innovation. The play itself is full of content and shows conceptualization through designated space (the safe area), the signals of beginning and continuing, the flexibility of social hierarchy and the new meanings of gestures within its bounds. It is a natural place to practice rule-keeping and rulebreaking. ${ }^{10}$ For example, the play-biting in animals shows self-handicapping, as well as play's conventionality and transgressiveness all in a gesture: a bite is not a bite, but it is not not a bite. Overall it is an exercise in flexibility and inventiveness.

Špinka, Newberry and Bekoff hypothesized that "training for the unexpected" promoted survival in direct and indirect ways. Play could increase social problemsolving, self-assessment skills, and ability to cope emotionally. And multi-leveled play interactions might develop community by increasing awareness of members (as the player exercises his theory of mind). In sum, they posited result of playing to be behavioral flexibility outside of play. In the Aesthetic Letters, Schiller proposed that the "test for the genuineness of [aesthetic experience] is that we emerge from it with no inclination to one kind of activity rather than another, but ready to meet any immediate challenge that life may present" (W\&W lxxxiv). It should return us, more flexible for the experience of play, to the flux of life.

\footnotetext{
${ }^{10}$ Play is intrinsically transgressive: one can be "bad" without being "bad" but also not "good."
} 
Based on the shared qualities seen in mammalian play and current work on the neurophysiology of play, playfulness (that is, the subjective state of the player) might then reasonably be described as a general capacity - rather than being a modular one (like habitat selection, mating, exploration). We might hypothesize like Schiller that it is a system of co-ordination and modulation, a fluid management of hierarchy, a generalized use of the mammalian nervous system. ${ }^{11}$

The distinction between reason of other species and our own reason is a very active line of research in ethology today. Just as Rousseau, Herder and Schiller put human beginnings back to the time of language and (eye-and ear dominated) complex representation development, Špinka, Newberry and Bekoff hypothesized that there was a ground of complex play in animals based in secure social and environmental situations, communication of intent, theory of mind and capacity for some representation. It is the beginning of a kind of flexibility that would allow judgments relative to survival to be extended, modified and expanded. ${ }^{12}$

\section{The Functional Ambiguity of Play}

Brian Sutton-Smith organized the theory of play literature from a broad variety of disciplines - ethology, anthropology, psychology and psychiatry, history and politics, sociology and the arts - into eight categories based on arguments about play function.

${ }^{11}$ An interesting indication of homology is the cross-species communication possible in play - we think we know when other animals are playing - and we appear to breed (artificially select for) companion animals with perceived playfulness.

${ }^{12}$ These authors referenced Schiller as the originator of "surplus energy hypothesis," a common mistake in the English literature, due to a summary of his ideas by Herbert Spencer (1898). A short review of play literature confirms that Schiller was typically understood and dismissed through this characterization. 
These perspectives, called rhetorics by the author, cover the entire natural and cultural domain of play. Each justifies play according to certain "ends" play serves (such as development or skill acquisition) or conversely by the values play was believed to support in the individual or his culture (such as striving for excellence or selfactualization). In this broad view of play, play mode or meta-play is independent of the relatively recent dichotomy between work and recreation.

Sutton-Smith also made his own argument for play as a model of adaptive variability. His theory of play, one that includes all the others, is the following. From the stand-point of evolutionary biology, play reinforces the plasticity of higher animal brains and is therefore a principal author of our survival and the survival of many higher animal species. Given that survival is the perfect potential end of adaptation, and plasticity the mechanism of survival, Sutton-Smith agreed with Schiller (without knowing it), agreed to the latter's suggestion that play promoted pluri-potentiality in the species - and in the individual, flexibility to achieve one's potential. His theory, though couched in the language of adaptation and selection, refers, I believe, to play as a vast generator of cultural variety rather than as a potentiator of organismic structural change in the playing animal over evolutionary time.

Basic to Sutton-Smith's understanding of play is its ambiguity: because play is liminal and paradoxical - it hovers between reality and subjectivity, between doing and not doing - a sort of not-not doing - it is hard to pin down. ${ }^{13}$ These ambiguities provide

\footnotetext{
${ }^{13}$ Sutton-Smith (S-S) adapted Empson's very literary argument to play (Empson, William. (1930) Seven Types of Ambiguity. New York: New Directions, 1966.) Empson wrote, "'Ambiguity' itself can mean an indecision as to what you mean, an intention to mean several things, a probability that one or other or both of two things has been meant, 
an environment, like an undulating island of water plants, where creativity develops.

And that environment, in turn, may provide enough uncertainty to promote development of connections and blends that in their own way stabilize through the survival value of more autonomous functioning.

Given that the play experience shimmers, moment to moment, it has proved to be a challenging phenomenon for those who study it. The field is so broad and the behavior so intrusive into all other human cultural categories like religion, politics and work for example, that many have approached play from the stand-point of function and dealt with those play modes that seemed productive of a particular end. In this, each group tended to adopt a stance of persuasion, a rhetoric, to support their distinctions, inclusions and value hierarchies. That defensive posture may be due to what Sutton-Smith was quick to point out: players do not experience their play as the rhetoreticians say they might. While the motivated experience only lately found an argument of its own (play as individuality), even the older rhetorics isolate aspects of play.

and the fact that a statement has several meanings" (5-6). He located ambiguity in a sort of metasphere, hovering over, between as well as in and out of writer and/or reader. Sutton-Smith enjoined this point-of-view for play. So that his reader entered the work with an appreciation of the complexity of the ambiguous, Sutton-Smith began by listing William Empson's seven types of ambiguity, contending that the multiple ambiguities both expand the possibilities of play and increase its tension (and risk). Play is play 1) by ambiguity of reference (What is happening, something real, such as choking or some sound indicating an angry cat?), 2) by ambiguity of referent (Is the thing itself, say, a bicycle or is it standing for something else like an airplane?), 3) by ambiguity of intent (Do you mean it or are you kidding, pretending?), 4) by ambiguity of sense (Is it to be taken seriously or as preposterousness?) 5) by ambiguity of transition (Are you still playing when you said that?), 6) by ambiguity of contradiction (A woman playing a dog as in the play Sylvia, or a man dressed as a woman), and 7) by ambiguity of meaning (Is it a play or a real punch?) (3). 
The old rhetoric of play as progress, often applied to children and animals, insists that these (and not adults) grow and develop by playing. This view emphasizes the imitative element of play as preparatory for adult life. Originally it was believed that ontogeny recapitulated phylogeny, that children played their way up the ladder of civilization and the developmental stages. From that perspective, play was seen as "having value not just for itself but because of other functions that it serves in individual development and group culture." Generally though, play is regarded as a "form of adaptation ... a preparation for the future, a form of learning or socialization [which] generates mastery and feelings of competence" (18). An ambiguity develops in the argument that play is progress because the participants of play rarely think of themselves as progressing. When asked, children themselves put "little or no emphasis on the kind of growth that adults have in mind with their progress rhetoric." They play for fun and "are highly motivated to play," so much so that play is often used by adults as part of a reward system. Children (and animals) play because they must: they play because they cannot do otherwise. ${ }^{14}$

\footnotetext{
${ }^{14}$ Children who do not play suffer from mental or physical illness. Sutton-Smith (whose interests lie in child folklore and child play unsanctioned and/or denied by adult culture) found that adult culture sought to deny large areas of children's play, to "domesticate" cruel play, wild, illicit or sexual play and irrational play. These obviously contradict the clean and neat category of progressive play. Play, wrote Sutton-Smith, can be seen as "motivated primarily by feelings and not just by images of reality" rather than a phenomenon demarcating cognitive development (157). Children's play is filled with aberrant images, the bizarre, the fantastic and gruesome, of paracosms (whole fantasy worlds), as well as mockery and extended parody (117). That a group of well-acquainted children most resemble a traveling troupe of medieval players summarizes SuttonSmith's sense of the rootless, theatrical, transgressive and tricksterish aspects of children's dark play (159).
} 
The next ancient rhetoric has play managing chance, the experience of fate. Here play gives the "illusion of mastery over life's circumstances" or the experience of risking in a limited way, losing and emerging from play relatively intact (the mastery of losing) (54). Alea, games of chance and gambling, are almost universal. Their appeal may stem from our basic need to experience the impersonality of the universe on a personal scale, thereby denying it. It may be a way, also, to fail voluntarily, to recover, rise and play again; here the player works through the experience of failure in a contained scenario. Further, the engagement with fate through luck rather than the engagement of opportunity by talent turns progress on its head and brings with it a particular egalitarian justice. This makes fate a trickster and maintains tension in a play sphere of unmatched opponents.

The rhetoric of play as power emphasizes such games as (but not limited to) sports contests with clear goals, rules and winners, and describes play as a representation of conflict (10). Whether societal, interpersonal or intrapsychic, the player involves himself because he feels himself to be a cause, a force. If he wins, he has triumphed without destruction; if he loses, it is a circumscribed loss. Further, the construction of the play space may allow a kind of winning that is compensatory, a wish-fulfillment. The contest provides clear goals in contrast to the indeterminate competitiveness in everyday life. On a cultural level however, this type of play services or sublimates conflict; it either habituates players to competition or provides a structured outlet, so it both sanctifies violence and trivializes it; whether alea moderate and direct the aggression drive and limit its expression, or whether contests honor and therefore encourage the behavior they seek to control is controversial. 
In the rhetoric Play as Identity, parades, religious and secular festivals, graduations, and community services like Christmas tree lighting or battleship launching allow participants to reaffirm their place in a group. They are "forms of bonding, including the exhibition and validation or parody of membership and traditions in a community" that function as a "means of confirming, maintaining, or advancing the power and identity of the community of players" $(10,91)$. The ambiguity of this play (which attempts to reduce ambiguity about membership) emerges from behind the scenes of such events: who is organizing the festival? What commercial or political hegemony, what cultural imperialism is in play?

The last rhetorics are of more recent origin: Sutton-Smith places them in the context of the last two hundred years and correlates them to the rise of individual consciousness. They are the rhetorics of self, of the Imaginary and of frivolity. The rhetoric of play in regard to the self focuses on the psychology of the individual player. ${ }^{15}$ Theories within this rhetoric begin in the subjective experience of the player and find play to be a state of mind, a way of being and seeing, and an attitude toward life. In the study of the individual's experience of play, heightened subjectivity is described as play's capacity to fully involve and provoke an ecstatic emotional response, a "peak or flow experience," through involvement (185). While, through this rhetoric, play lends itself to metaphors of

\footnotetext{
${ }^{15}$ For Sutton-Smith, the origins of this rhetoric were Freud's explanations (and subsequent psychological and psychoanalytic refinements) of particular playing in individual mental life, its effects or functions (173). While he mentioned Kant and Schiller, he did not describe their contributions in any depth nor did he acknowledge the implications of Schiller's presentation. Of Schiller's work he wrote: his "is indeed the broad view of the play function" and followed his remark with the usual quotation of XV.9. (131 Schiller's XV.9 is qtd. from trans. Snell).
} 
freedom, autonomy, individualism, authenticity and self-actualization, one of its troubling ambiguities is the degree to which, when in the flow, the individual experiences a loss of autonomy without being aware of his loss. There, his experience is (retrospectively described) as unselfconscious and completely absorbed into the process. Because there are these different ways of playing, the player becomes aware of his different subjectivities. Where is the self to be located then?

The rhetorics of play as the engagement in the Imaginary, the association of play with the not-real, the fanciful, the visionary and with creativity, derives historically from the Romantic period, according to Sutton-Smith, when the concept of imagination began to take the place of (or carve out an area from) the idea of soul. To make real the heterogeneous nature of this category, he listed all relevant subject fields, ones of music, art, literature and the cultural mythologies. He includes personal capacities like flexibility and the "art of making what is present absent or what is absent present." From his perspective, the justification for such broad inclusion comes from the work of Gregory Bateson. This anthropologist

point[ed] to the paradoxical and metacommunicative nature of play, showing that play is not just play but is also a message about itself (a metamessage), being both of the world and not of the world (paradox). The child playing mother is both a mother and yet not a mother. Thus one can enact something real in play while denying that one is saying anything about the world, and thus be both innocent or guilty at the same time; only the shared knowledge of secrets allows others to know which truth, if either, is most intended. The act of play is always by itself manqué, and is certainly opaque, but as such it can yield to the most mysterious of transformations (139 my emphasis). ${ }^{16}$

${ }^{16}$ Sutton-Smith referred to Bateson's Steps to An Ecology of Mind. 
This last reference to transformation is a critical contribution to the study of play. That play's transformative power, that ambiguity and fluidity experienced in the protected space of play can lead to qualitative change, is both play's risk and its reward. It is also the promise of other cultural forms, based on the model of play, like psychotherapy. Sutton-Smith also cites usages in which metaphor is "language play" and play is "behavioral metaphor" (127-150). There is now some consideration in cognitive science and linguistics circles, however, that metaphor is rather the structural and evolutionary ground of language (Fauconnier). It may also be that it is not play that is behavioral metaphor, but it is play that is the evolutionary ground of complex emotional/cognitive behaviors (Schiller AeL).

The last historical rhetoric, that of play as frivolity, is the home of Dionysus, the fool, the joker and the trickster, the place where nonsense and inversion, the idle, the vertiginous, the trivial and the useless reside. It requires the category of work to oppose it and the upright and hard-working to denigrate it. It lives in the back-spaces; it can be the aristocratic gaming for game's sake or conspicuous consumption (Veblen); it can be dirty play of children, the Mardi-Gras alter-identity of a correct businessman, the ride on the roller-coaster or the game on the Midway, or the middle-aged women's hobby of collecting Barbie Dolls.

This collection of theories from the various disciplines and cultural domains is an implicit acknowledgement of the fragmentation of modern life (and knowledge) that so concerned Schiller. By discovering play everywhere, however, Sutton-Smith also promoted play to the status of a generic category that contains potentially all species of human doing. As such, his work catalogues the manifestations of Schiller's play-drive - 
the balanced and unbalanced, the mere, the dangerous and the ideal - without a valorization of the aesthetic as paradigmatic. ${ }^{17}$ Are all our cultural extensions play? Some retaining, some having lost their motivational pleasure? ${ }^{18}$

\section{Applications: Play and its Pleasure, Structure and Attentions}

In struggling to understand and describe the effect of the aesthetic state on different personalities, Schiller wrote that " $[\mathrm{b}] \mathrm{y}$ means of beauty sensuous man is led to form and thought; by means of beauty spiritual man is brought back to matter and restored to the world of sense" (XVIII.1). In the "middle," there is a place of meeting, made accessible by contemplation of a sensate ideal. There, matter and form, passivity and activity, feeling and thought, play. Both analysis and experience seemed to oppose the possibility of such a transformation - and yet - Schiller saw that we, when we contemplate a beautiful object, are irresistibly moved and drawn in, yet kept at a distance. We are "at

${ }^{17}$ Sutton-Smith synthesized the work of the following (by category): 1) the work of ethologists like Fagen, Groos; affective neurologists like Panksepp; educators like Piaget, Erikson and Sutton-Smith; anthropologists like Schwartzmann; psychologists, psychiatrists like Winnicott, Erikson, 2) Callois on gambling, Sutton-Smith on cruel play. 3) Nietzsche, Huizinga, Spariosu; Goffman, and Geetz; 4) Anthropologists, folklorists, Freud and Geetz. 5) Kant, the Romantics, Idealists, Bakhtin, Derrida and Barthes. 6) Husserl, Heidegger, Gadamer, Spariosu, Csikszentmihalyi and Hans. 7) Pop Culture historians. Schiller was considered of a type with Kant, the Romantics and Idealists in the rhetoric of the self. The classic play texts are Huizinga (Homo Ludens) and Caillois.

${ }^{18}$ Wilkinson and Willoughby: "[i]t would certainly be worth re-examining [Schiller's] whole theory of play as a primary instinct which finds its highest human manifestation in aesthetic phenomena. For if some recent investigations of both human and animal play have revealed it as not just an excess of animal spirits, or a luxury product of the mind, but rather one of the primary message-systems, a means of communication, other investigations - such as research into the painting activity of apes - seem to show that some form of aesthetic satisfaction may be a primary need even in animals . . But [nothing can be undertaken] until the original form of his theory has been unearthed from under the rubble of misconceptions that has overlaid it" (clxxxvi my emphasis). 
one and the same time in a state of utter repose and supreme agitation, and there results that wondrous stirring of the heart for which mind has no concept nor speech any name" $(\mathrm{XV} .9)$.

Schiller was so imaginative and exuberant, his language and ideas so evocative, that his formulations, ones like the preceding, raise more problems than they provide solutions. It may have been his playful intent, a sort of self-handicapping way to keep us all involved. Nevertheless, many questions linger, and it seems important to highlight three interest areas and suggest them as subjects for further study, particularly in their function as components of play. They are the following: pleasure, the contents and structure of common reason (common sense, innate ideas) and attention. Each has a history in the eighteenth century, and some history of scholarship as well; each is currently an object of interest in one discipline or another, but may not, like play, receive the attention it deserves.

\section{Pleasure (and Its Special Senses)}

Nature has an equal interest in perpetuating all species and thus inspires us each with the same motive. That motive is pleasure, pleasure which in the human species sweeps everything before it. In spite of multiple obstacles in the way of a union of two hearts, and a thousand torments that must follow, Nature still leads the lovers to her desired end (Maupertuis 34 my emphasis).

Pleasure - is the means and the end of a drive, but for play it must be pleasure that can be both delayed and sustained, pleasure that can be disengaged from, that is, one that does not have the insistency, the immediacy and the necessity of the drives that pertain to survival and continuation of the species. Pleasure is vitally connected with well-being (pleasure vs. pain), with mental organicity like wholeness, completion or perfection 
(satisfaction vs. frustration), and it is the indication of emotional involvement, the mood of the subject and his assessment of the environment (feelings) through his sensations. This bolus of pleasure, for Schiller, is a product of the German aesthetic tradition: pleasure is a valuable, life-giving source of well-being and the motivator he needed for the free will accomplishment of duty. It was basic to the whole man and basic to his appreciation of beauty, his entry into the aesthetic state and the achievement of autonomy. It makes opening the gate to human potentiality possible.

Schiller's particular pleasure was the kind that developed out of representation, and it came from the two senses. Regarding the elaboration of sense in humans, Schiller remarked (as did Rousseau) the importance of that transformation to the course of our entire development:

It is nature herself which raises man from reality to semblance, by furnishing him with two senses which lead him to knowledge of the real world through semblance alone. In the case of the eye and the ear, she herself has driven importunate matter back from the organs of sense, and the object, with which in the case of our more animal senses we have direct contact, is set at a distance from us. What we actually see with the eye is something different from the sensation we receive; for the mind leaps out across light to objects. The object of touch is a force to which we are subjected; the object of eye and ear a form that we engender. As long as man is still a savage he enjoys by means of these tactile senses alone, and at this stage the senses of semblance are merely the servants of these. ... Once he does begin to enjoy through the eye, and seeing acquires for him a value of its own, he is already aesthetically free and the play-drive has started to develop (XXVI.6 my emphasis).

Humans have spectacular extension and augmentation of the eye and the ear: each sense organ has systems that are reciprocally coordinated and complexly connected to multiple 
areas of the brain. ${ }^{19}$ They are together active in language and symbol-production: much of language - structurally and strategically - is based on metaphors and visual metaphors predominate (Fauconnier). The late development of writing is evidence of further involvement of sight with language elaboration. The play of these senses, with the play of their systems, is basic to our own mental play. Such play is useful - saves energy, increases survival, creates bonds and of course art.

Just as people did in the early modern period, we also need familiarity with nature, in all her peculiarity, in all her particularity and multiplicity, in order to recognize what is possible - in order to be able to imagine how things work. Kenneth Catania would have us look at the star-nosed mole as an example of how natural selection functions to "develop" by differential survival (given evolutionary time) an energy-saving survival device, in this case, a sense organ. This little animal, known for a fantastic elaboration of sense, also has vestigial features; it is like the one about which Goethe complained to Schiller: "The mole" he wrote, "is perfect but ugly because its form permits only a few,

${ }^{19}$ Knowledge about nature helps us to understand - by increasing our imagination and thereby stimulating humans to see more reality. For this paradoxical purpose, Brian Boyd reflected on vision: "vision does not transfer all the space, shape, surface, and color that is out there into the mind in any immediate or transparent way, nor is human vision finer, as humans had often smugly assumed ... . It was supposed for a long time that we were unique in having color vision; in fact we cannot see ultraviolet light as bees do, infrared light as pit vipers do, colors at night as some moths do, polarized light as many birds, insects, and even plants can; we have trichromatic vision, which is better than the dichromatic of many species, but pigeons have tetrachromatic vision. But although human vision misses out on much potential visual information, it effortlessly does far more than we are aware of, unconsciously integrating some fifty different brain areas to make complex, real-time sense of visual input" ("Literature and Evolution" 4). 
limited actions, and the preponderance of certain parts renders him misshapen (Scientific $22)^{20}$

\section{The Star-nosed Mole}

This remarkable little animal, the star-nosed mole, has been extensively studied by Catania, and it has made an appearance in Nature and in the best-selling work of popular science, Richard Dawkins' The Ancestor's Tale (242-246). Not only has its behavior been documented ethologically, but the appendages of its star, the specialty organs on each appendage (Eimer's organs) and the apparatus' afferent sensory connections to three different mirror-image cortical areas in the brain have been researched microanatomically.

The star-nosed mole (Condylura cristata) has a snout surrounded by twenty-two fleshy and mobile appendages. This unusual structure is not an olfactory organ, as might be assumed from its location, nor is it used to manipulate objects as might be guessed from its appearance. Rather, the star is devoted to the sense of touch, and for this purpose the appendages are covered with thousands of small mechanoreceptive Eimer's organs [found in all Talpidae (moles), a few thousand in most, but the star mole has 25,000 - these, in configuration, may be capable of distinguishing objects in the 10-100 $\mu \mathrm{m}$ range, a new realm of perception for mammals]. Recent behavioral studies find that the star acts much like a tactile eye, having a small behavioral focus or "fovea" at the center - used for detailed explorations of objects of interest. The peripheral and central nervous systems of the mole reflect these behavioral specializations, such that the small behavioral focus on the nose is more densely innervated in the periphery, and has a greatly enlarged representation in [multiple mirrored areas of] the somatosensory cortex,$\ldots$ a representation highly correlated with patterns of behavior [rather than density of innervation]. The many surprising parallels between the somatosensory system of the mole, and the visual systems of other mammals [including primates, mentioned in

\footnotetext{
${ }^{20}$ This is an excerpt from the short paper, "The Extent to Which the Idea 'Beauty is Perfection in Combination with Freedom' May Be Applied to Living Organisms." Goethe wrote it for Schiller as an aid to thought while the latter was hard at work on the Aesthetic Letters.
} 
another context,] suggest a convergent and perhaps common organization for highly developed sensory systems (Catania, "A nose” 367-8, 371-2).

What of the evolution of man and his senses? The eye and the ear? What of his hand?

\section{Common Reason and Innate Ideas (Sensus communis, Sensorium commune)}

"Beauty is the promise of function."

Charles Darwin

If the basic behavioral endowment of animals is considered from an evolutionary point-of-view, every behavior represents historic, deeply historic, antecedents. Darwin wrote, considering the Phaedo, "that [Plato believed] our 'necessary ideas' arise from the pre-existence of the soul, are not derivable from experience - read monkeys for preexistence" (Notebook M, 1838). The Darwinian adjustment of our a priori ideas, our innate ideas, our Common Sense, from the eternal to the deep historical, grounded in the survival capacities of our animal ancestors, also suits our explorations of culture. One of our habits of mind and behavior is playfulness, and it is a linkage, a confused whole, of ancient capacities in many, many species.

Part of Schiller's theory of beauty is that, while beauty is relation, it is without doubt in the object as well as from the subject. That beauty was in the object by common judgment implied a reciprocal relation between objects and the way we as members of the same species represented them to ourselves. His understanding, I believe, of rudimentary reason, the reason that first develops from the history of successful surviving, is the ground of the judgment of taste. ${ }^{21}$ The reason that promotes basic survival is augmented

21 "The logical order of our ideas, according to Condillac, is not primary, but a derived fact; it is only a sort of reflection of the biological order. What on a given occasion seems to be essential, depends not so much on the nature of things as on the direction of 
by the reason of self-awareness, of empathy (and theory of mind) and the capacity with representations. The common reason of his century had various definitions but it included these basic judgments, and Schiller, by making formed content the process-andproduct of the play-drive, accepted a particular kind of structure basic to conscious and unconscious attention. A central aspect of his theory is the relationship of this structure with subject and object. These - it is now possible to consider - are held in tension by their relation through evolution by natural selection. We perceive in certain ways because even complex perception includes historical judgments that allowed our ancestors a measure of relatively more successful survival.

Did he answer the question, why do we attend to art? Here is a beginning: let us assume a deep interest in anything that ensures our lives, our happiness, safety, security and well-being. As a product of Schiller's play, art is a signal of a kind of prosperity, of a space where the basic concerns of life are met, and where is found a level of abundance, a richness beyond basic survival needs. It is just as surely as animal playing, a signal of environmental safety. And because we are social, it is an object of shared attention: we assume others will attend to art and they do. ${ }^{22}$ As such it is a signal of psychical and

our interest; and our interest is determined by that which is advantageous for us and necessary for our self-preservation" (Cassirer 104). Brian Boyd: "If we are evolved creatures, our brains are not guarantors of truth, citadels of reason, or shadows of the mind of God but simply organs of survival, built to cope with the immediate environment and perhaps to develop some capacity to recall and anticipate. Evolution has no foresight and no aims, least of all an aim like truth. It simply registers what suffices, what allows some organisms to last and reproduce better than others" ("Getting" 22).

22 " $[\mathrm{H}]$ umans are geared to learn from one another through joint attention, the expressiveness of the human facial musculature, the precision of human pointing (all of which develop before language, and make it possible), and language. Our capacity for 
social security. Let us assume a deep interest in our own kind, an alerting to the human evidence both as a sign of presence, of social safety, of vigilance directed away from anticipated threats to objects without utility in the realm of force or need. ${ }^{23}$ Art is the evidence of human action - no, not just doing, but being: each piece of art is a stamp of the human mind, a general and a unique artifact of person and culture. It is not just a representation of nature: it is our Schein, our take on experience and existence. It bespeaks agency, and agency is something we love so well that we make every effort to apply it even when it does not exist. Some experience is so deep within us that we sense by apperception instead of perception: we often take agency, which includes cause-andeffect and result, as given in experience rather than created within us below the level of self-awareness. ${ }^{24}$ These experiences in particular are mirrored and reinforced in art

social learning, for acquiring our own culture, also makes it possible to appreciate and enjoy the culture of others" (Boyd "Getting" 28).

${ }^{23}$ Enlightenment thinkers built on Pufendorf's (1672) theory of natural sociability [socialitas] (called "unsocial sociability" by Kant). Pufendorf suggested that man entered into a situation of interdependent relations when the development of "more complex and sophisticated wants required the continual assistance of others for their fulfillment." Ferguson (1767) remodeled socialitas, previously "a propensity, [into] a capacity" (Wokler 125, 128).

${ }^{24}$ This need of humans may speak to the difficulty that many have in grasping evolution by natural selection: though it is explained in language that implies the opposite, evolution is not an agent; it does not function by linear cause and effect, it does not have results, and it is not progressive. We typically need explanations with concepts imbedded in them like agency, cause and effect, result, or goal to help us put pieces together like a puzzle - a demand of common reason. Gregory examined common misconceptions about evolution by natural selection and he found that it was "notoriously difficult to grasp" and that misconceptions persist even in the face of education. The nature, the intuitively grasped nature, the reflection of everyday experience and the nature revealed by systematic scientific investigation are fundamentally at odds with one another (Gregory 166-7). Subjects of several studies included agency, intentionality, teleology and response to need in their understandings of natural selection. They saw it as an event 
objects. Rather than functioning like a reminder of particularity (as might the artist's signature tucked into the corner of his work), the art object acts as a relation of connectedness and identity, as if the semi-transparent wash beneath the images and brushwork called out to our common humanity. And this wash speaks to us of freedom, freedom to change things, things as we find them into things that express what is humanly experienced, thought and felt. As an example of freedom and agency, but unique and particular, art speaks the promise of our own potential. We feel this promise in the first encounter by taking in the new object of our experience, this work of art, by contemplation - when it reciprocally works in and with us to develop something new in each of us. ${ }^{25}$

\section{Attention}

In nature everything is connected to everything else .... But with its infinite multiplicity nature is a spectacle only for an infinite mind. In order that finite minds might have some share in the enjoyment of this

rather than a process, and they considered it an all or nothing, rather than a probabilistic process (e.g., unfit individuals all die; all fit individuals live) (164-172). Again, Boyd summarized our need for agency: "Evolution has equipped us with fast and frugal heuristics, rough ways of knowing that suffice for our mode of life .... We therefore have, for instance, a systematic bias toward overinterpreting objects as agents" (23 my emphasis). Schiller wrote regarding the advancement of knowledge (science): "If the manifold potentialities in man were ever to be developed, there was no other way but to pit them one against the other. This antagonism of faculties and functions is the great instrument of civilization... Only through individual powers in man becoming isolated, and arrogating to themselves exclusive authority, do they come into conflict with the truth of things and force the Common Sense, which is otherwise content to linger with indolent complacency on outward appearance, to penetrate phenomena in depth" (VI.12).

25 "In modern works of art freedom, the human capacity for autonomous sense-making, appears, that is, art works are unique objects, and as unique sources of normatively compelling claims, they are experienced as products of freedom, as creations; their uniqueness and irreducibility are understood as the material expression of an autonomous subjectivity" (Bernstein xi). 
spectacle, they must acquire the faculty [Vermögen] of setting limits to multiplicity, which it does not possess; the faculty of isolating and directing its attention [Aufmerksamkeit] at will. We exercise this faculty at every moment of our existence; without it there would be no existence for us; for all these diverse sensations [Empfindungen], we would sense nothing at all; we would constantly be prey to the present impression; we would dream without knowing what we are dreaming. (Lessing qtd. in Bell 36).

What is attention? What was once vigilance for survival, fixation on nutriment, scanning for foraging and hunting, the stare of assessment of movement and agented danger, became over evolutionary time, curiosity, exploration, assessment of self in the social order, interest, and play.

In the eighteenth century, attention began in sight - seeing, watching, observing, attending, contemplating ... these levels bespoke degrees of emotional and cognitive involvement. It was recognized in natural philosophy and history as a method, in medicine as a potential health hazard, and in religion as a powerful enhancer of dutiful feeling, thinking and action (Hagner). Schiller recognized attention early but he transformed it into archetypically human play, a method of development, a prescription and a cure for the ills of the individual and his society and the way of freedom to explore human potential in feeling, thinking and action. ${ }^{26}$

${ }^{26}$ It "must have been Abel who prompted Schiller to stress attention in [his earlier first dissertation] Philosophy of Physiology as the source of freedom in an otherwise mechanistically determined perceptual system." Crediting Abel with a psychological theory that Schiller built upon, Dewhurst and Reeves identified a combination of ideas from Ferguson and Garve relating to attention. Bonnet, according to them, pinpointed "attention [Aufmerksamkeit], the ability to concentrate on a particular set of ideas and impressions." They acknowledge "self-preservation and material needs stimulat[ing] our intellectual power through the goad of pain and the bite of pleasure" as the foundation of human attentiveness, one with which Schiller would have been acquainted. The provenance of attention theory included d'Alembert in the Preliminary Discourse and 
In positing a contemplative state based on a sensate ideal, one that frees humans to real choice, Schiller took a middle course between the uses of attention to approach contemplation. He steered between the attention that is observation [Beobachten], a virtuoso occupation of many natural historians of the time, and meditation, a religious activity [fromme Betrachtung] practiced (variously) by the different Protestant (Lutheran and pietist) and Catholic traditions in the German States.

Given the epistemological streams that mingled to form vitalistic knowledge, the level at which the external world could be recognized was extremely important in the eighteenth century. Humans glanced, saw, noticed, perceived, apperceived, attended, observed, watched ... contemplated. Then, sight was the sense that was most often associated with empirical verification, with observation, collection, and comparison. According to Lorraine Daston, who examined the natural historical tradition of empirical observation and description [Beobachten] in order to understand how nature accrued value during the Enlightenment, noted that many empirical projects were tied to natural theological considerations. She found that certain areas of nature became "worthy objects of study and personal dedication" by the naturalist's often heroic "disciplines of attention [by which they] beatified even the most inauspicious objects" (100). The object and the attention were reciprocally valorized as useful, a merging of the fit and the good, which within the rationalist aesthetic tradition, was the perfection of sense (beauty). The naturalists' delight in observing and their attribution of design became, in her view, "less an argument from evidence than an experience of self-evidence," a reciprocal of

Rousseau's hypothetical developmental history of man as well. How can it be that man chooses badly then, if these prods are so directive? (Dewhurst 129-130). 
justification and intensification of their activities. The researchers were self-conscious

because their one-sided intensities lent to parody and satire, but many could not help themselves. ${ }^{27}$ The particular object, each one's own chosen object was one that fostered delight, one that deserved rapt attention, provoked affection, concern and protection from criticism. This reciprocal intensification was not mere seeing but the "art of observation," practiced by the likes of Bonnet, Deluc, Réaumur, Saussure, Senebier, Swammerdam and many, many others. ${ }^{28}$ Their remarkable feats of attention can be imagined from these accounts:

Reaumur, for example, counted the number of bees leaving the hive in one day, arriving at a sum of over eight-four thousand departures in fourteen hours (approximately one hundred per minute) (114).

Genevan naturalist Charles Bonnet dedicated every waking hour from 5:30 A.M. to 11:00 P.M. for twenty-one days to observation of a single

${ }^{27}$ The portrait of the virtuoso in Addison, the jabs of Pope's Dunciad and the characters of the period's comedies included the type who devoted his time and treasure to the miniscule, the insignificant and the despised life forms. Shadwell's character, Sir Nicholas Gimcrack of The Virtuoso, "squandered two thousand pounds of his nieces" money to finance experiments ranging from the microscopic observation of mites in cheese, to blood transfusions from a sheep to a madman, to the reading of the Bible by the light of a luminescent leg of pork - all parodies of experiments actually performed by members of the Royal Society of London." Locke wrote that it is the "mark of a little genius to be wholly conversant among insects, reptiles, animalcules, and those trifling rarities that furnish out the apartment of a virtuoso ... [Such pursuits] make us serious upon trifles, by which means they expose philosophy to the ridicule of the witty and the contempt of the ignorant. In short, the studies of this nature should be the diversion, relaxations and amusements not the care, business, and concern of life" (102, 103-4).

${ }^{28}$ Schiller's observation that the intensification on one power led to progress in mankind but narrowness in the individual included all pursuits and occupations, not just natural history. He wrote the following about this kind of dedicated attention: "Only by concentrating the whole energy of our mind into a single focal point, contracting our whole being into a single power, do we, as it were, lend wings to this individual power and lead it, by artificial means, far beyond the limits which Nature seems to have assigned to it" (VI.13). 
aphid in order to determine whether the species could reproduce parthenogenetically.... [H] became evermore emotionally attached to [my little aphid, ma pucerone].... When he lost sight of his aphid one June morning, he was disconsolate (106).

While the point of departure of religious meditation may have been the experiences of daily life, such contemplation was a dedicated encounter, one with a lesson. The intent was to "transport contemplatives to a more abstract, spiritual realm beyond that of the senses. Post-Reformation works of meditation, both Protestant and Catholic, insisted on a purely interior realm of religious vision distinct from the carnal and the sensual" $(106) .^{29}$

Schiller tried to find his place in the culture of attention and a way to describe the experience of the aesthetic. He wrote to Körner, considering the types of attention given to and perceptions received from nature:

There are two ways of representing appearances. We are either intentionally directed towards their cognition; we observe [beobachten] them; or we allow things to invite us to represent them. We merely watch [betrachten] them.

When we watch appearances we are passive in that we receive impressions; active, in that we subject these impressions to our forms of reason ... (8.ii.93 "Kallais" in Bernstein 148).

Contemplation of beauty, for him, was doubly invitational; humans were both passive in receiving and active in creating in enframed attention. He chose beauty because of the pleasure of sensate attention, the consensual ground of judgment, and the autonomy it

${ }^{29}$ Daston's sources are late seventeenth and early eighteenth-century ones; it would be a valuable project to locate references and research about meditation in the mid- and late eighteenth century on the continent and in England. Several historical methods of meditation might be researched, including the word-based lectio divina (meditative reading) or Torah study, and the use of works of art, icons, stations of the cross, or stained glass images to direct and format contemplative experience. 
engendered. Unlike meditation on the good, the moral or religious, contemplation of beauty enjoined freedom, not duty. Play likewise, as a complex of reciprocal interactions, combined sense and form. It must begin, end or include pleasure or the anticipation of pleasure; it must be invitational, an entry into a different time and space. Schiller's claim that human play is pleasurable but flexible formatted attention with respect to a sensate ideal (a felt-thought thing, a representation, an appearance [Schein], beauty) is itself a Schein of his hope. It was his hope that the huge human capacity to attend to anything and format it, the capacity that has made us what we are - shockingly successful as a species but wasteful of the individual (VI.13) - could be managed on an individual basis through the pause (that is, contemplation and aesthetic education) that results in the freedom to choose and rechoose our course. Otherwise, unbalanced play betrays us to violence (French Revolution), card-playing (Schiller's particular vice), virtuoso interests (insect collections, eighteenth-century studies), systems of belief (principles over people) or works of a fragmented genius (Kant's Critiques). Uncoupled and unmodulated, it builds on appetites and proclivities; continued by habit or perseveration, it loses its own pleasure in addiction. Subverted to utility, it leads to a surfeit of materialism; suborned by beliefs, it ends in loss of freedom, inflexibility, and hypocrisy. By play, humans can lose contact with reality itself.

\section{The Last Frontier: the Sublime}

We call an object sublime if, whenever the object is presented or represented, our sensuous nature feels its limits, but our rational nature feels its superiority, its freedom from limits. Thus, we come up short against a sublime object physically but we elevate ourselves above it morally, namely, through ideas ( Schiller "On the Sublime" ("Von Erhabenen" 1793) Essays 23). 
Where is the sublime? ${ }^{30}$ So important and fertile a subject in the eighteenth century, it is not apparent today. Perhaps it masquerades, hidden in plain sight, on cable news, in gothic genres, in what computers can do, in what we can do with computers or the genome, but it is not the open and vital interest that it once was. Should it be recovered?

The sublime is a huge subject, without bounds. With respect to both art and life, German aesthetics struggled not only with understanding beauty, but with distinguishing it from the sublime, the beauty that trespasses its own boundaries: the "centrality of the overstepped limit suggests an efficient approach to the variety of eighteenth century versions of the Sublime in both theory and practice ..." (Leidner 3). In terms of Schiller's theory of play, the sublime is associated with both world and agent, as the unattainable end and the unformable content, as the over-reaching action, the overwhelming feeling and the unspeakable thought. It is of profound importance to man's creative potential and his motivation. ${ }^{31}$ The sublime is the well that provides the infinite and the eternal, the raw content and novel forms for man's play. Play is our

${ }^{30}$ Where did it all begin? For eighteenth-century aestheticians, theorizing about the sublime stemmed from considerations about rhetoric: "The first and most excellent of these [attributes of great writing] is a boldness and grandeur in the Thoughts .... The second is call'd the Pathetic, or the power of raising the passions to a violent and even enthusiastic degree; and these two being genuine constituents of the Sublime, are the gifts of nature, whereas the other sorts depend in some measure upon art" (Longinus trans. Clark (1770) qtd. in Monk 13).

${ }^{31}$ The consideration of the sublime interested Schiller greatly: he mentioned it often in his work on beauty, used it in plot and character in his drama and treated the subject separately on three different occasions: in "Of the Sublime" ["Vom Erhabenen"] (1793), "On the Sublime" ["Über das Erhabene"] (written around 1794-5, published 1801) and "On Tragic Pity" (1793) ["Über das Pathetische"] (along with a number of other essays on tragedy). Schiller's "Auch ein ander Heftchen über das Erhabene vom Erhabenen" was lost, eaten by Herder's dog. 
world, and beauty is our best way of representing it and making our own freedom possible: the sublime is the edge of reality just beyond our attempts to contain it and the leap to a human function beyond our current definition of humanity.

The sublime and beauty are related by play's paradoxical qualities - boundaries are intrinsic to it and yet it is freeing. It is freeing until - it is not, until particular playing defines, fragments and limits us. If no new form and content breaks the boundaries of the old attention, of the old organization, to build ever more broad, balanced and harmonious mental environments, play becomes insipid and regimented; we are bored. Luckily, humans are curious; we seek stimulation and change, or we are simply dragged from ourselves by the new. We actively seek or are sometimes forced to think or act beyond the boundaries of our experience as well. Passively, we position ourselves for experience with the unbounded or the ungoverned. Actively, we transgress. We break bounds ourselves, delight in others' exploits or thrill at nature beyond all bounds, experience beyond hope, fear and imagination. What is beyond play? What is it in beauty, or what in life, that provokes us to break the conventional form, to seek the next new content? to redraw the boundaries?

The sublime is problematic: it is relative. In conventional situations, times and places of safe play, knowns are managed and play is tame. The frame is obvious, itself an elaborate work of art. And inside it, the beauty is full and round, turning on itself, away from the corners before they are even approached. The bounds between the culture and the non-included rest (nature) are stark as cliffs. In a culture like that, deviance is transgression, and transgression leads to banishment, to living beyond the Pale. 
Internally, such an entrenchment turns to boredom and trivialization, acceptance sometimes, but occasionally, defiance and a dangerous, but sublime break-out.

In times or cultures of heterogeneity, when engagement is more diverse, where the play of self, community, country, and religion do not heavily reinforce each other, the boundaries are liminal: the ocean of the sublime can be tested from the beaches of play. The home of beauty, which is the representation of as-much-of-reality we can gracefully manage and the image of as-much-of-ourselves as we can freely actualize, can be left and the new, the intense and unknown brought back.

The sublime is relative to the experience of each individual. As a comet of the new, the strange, the terrifying, the surprising and the unbelievable, it drops into each one's own play; it calls out the fresh, the courageous, the unusual, the shocking and the novelty-seeking agent from his mental home. That is why education is individual for Schiller: each person must dare to perceive, to attend, to know - to incorporate new content into play. Each must audaciously own or create new forms. In this way, we exercise our capacities and develop human potential.

\section{Sublime of Agency and the Sublime Out of Our Context}

But since in the enjoyment of beauty, or aesthetic unity, an actual union and interchange between matter and form, passivity and activity, momentarily takes place, the compatibility of our two natures, the practicability of the infinite being realized in the finite, hence the possibility of sublimest humanity, is thereby actually proven (XXV.6)

For the humanist of the eighteenth century, the sublime expression of agency was genius. The genius was at once the person to whom the sublime came as the overpowering and unpredictable daemon - and the human who stepped up into his 
chariot to control the thundering team of his powers. ${ }^{32}$ That through genius, "the talent (natural gift) that gives the rule to art," man wrestled form and content into beauty, brought it within the bounds of play, is one of the paradoxes of the relationship between the beautiful and the sublime (Kant $\S 46) .{ }^{33}$

With regard to the environmental sublime: at present many in the humanities believe that the sciences are out of bounds - mostly we want their content for metaphors and for fun, but we fear their forms. ${ }^{34}$ For their part, the scientists - even in their play - sense

32 The genius was susceptible to the daemonic, which has the inhuman, unknowable quality of the sublime. Goethe described it as follows,"[e]verything that limits us seemed penetrable by it, and it appeared to do as it pleased with the elements necessary to our existence, to contract time and expand space. It seemed only to accept the impossible and scornfully to reject the possible. This essence, which appeared to infiltrate all the others, separating and combining them, I call 'daemonic' [dämonische] after the example of the ancients and others who had perceived something similar. I tried to save myself from this fearful thing by taking refuge, as usual, behind an image" (Goethe qtd. in Steigerwald "Goethe" 315).

${ }^{33}$ The ideas of genius reframe (transgress); they create a bickering about boundaries, rules and definitions and often a scramble to claim the new space. There is a founder's or possessor's advantage. The new frame, for those whose attention is attracted, becomes the territory to be controlled and administered, the place of display. In this way, the new is the bridge to the sublime that many can travel across. What was beyond human imagination at first, beyond our immediate grasp, is made accessible by someone who fashioned, discovered or promoted it, a "supra" human, a genius. It is he who parents new representations in our minds, engenders new mankind as well. Schiller's theory about play has something to say to us about this process, about Beauty and boundedness, about transgressivity and the Sublime, about genius. According to Abrams, genius "cannot indicate scientifically how it brings about its product, but rather gives the rule as nature. Hence, where an author owes a product to his genius, he does not himself know how the ideas for it have entered into his head, nor has he it in his power to invent the like at pleasure, or methodically, and communicate the same to others in such precepts as would put them in a position to produce similar products" (Abrams 207).

${ }^{34}$ We love their data for our metaphors: humans, writers and artists must constantly dip into reality. In the March 2008 PMLA (123:2,340-357), M. Allewaert's "Swamp Sublime: Ecologies of Resistance in the American Plantation Zone," a critique of Bartram's Travels (1791), explored intersecting cultural spaces in the eighteenth century. 
our sublimity: they want only so much of us as well. They probably think that, though

we inhabit the land of play, we really float above it like wind-surfers. It is, as you know, such a beautiful - pleasurable, exciting and relaxing - view, from above.

Sometimes then the sublime is, as Schiller intimated, a species of beauty, part of what play includes, an energetic beauty (XVI, XVII) ${ }^{35}$ And it is accurate to say that

She claimed Bartram had failed to colonize the sub-tropical swamps of North America through the Enlightenment practice of description, including collection and classification of everything, especially plants. In spite of the task and his relish of it, Bartram was nearly overwhelmed by overgrowth, inundation, disease and danger, i.e. the natural or environmental danger threatens the sublime (as what can be at some point gotten under control): it just barely survives as does he. In fact, perhaps only writing retrospectively did he rescue life-threatening conditions to the sublime. Here, the play of pleasurably attended content enclosed in a safely intelligible form; its Sublime is alternately defined by European sensibility as nature refusing to be tamed, by "savage" sensibility as the European Master and then by transformed European sensibility as the practice of slaveholding. What was for Bartram a sublimity that could easily devolve to terror---the dense foliage, the camouflaged predator, the sucking mud---provided escaped slaves, Maroons, opportunities for hiding, escaping and visualizing their enemies: a perspectivally reformatted content. As a result of his experience, consciously sublime but unconsciously fraught with fear, Bartram was transformed: he projected the power of the swamp on the Maroons and, through his paranoia, became acutely aware that the cultural form, slave-holding (which concentrated shame and rage in its subjects) made revolt inevitable. Ergo: Bartram wrote that slavery should be abolished. In his article from the same number, "From Idiot Beast to Idiot Sublime: Mental Disability in John Cleland's Fanny Hill," D. Christopher Gabbard traced the use of La Mettrie's L homme machine in Cleland's Memoirs of a Woman of Pleasure (1748-9). Gabbard charted Cleland's raucous excursion into the mid-century controversies in this way: Cleland managed the natural philosophical issue, the definition of the human species, from two perspectives Fanny is a voyeur of the prodigious sublime, i.e. what is beyond human nature as admirable potential, a potential that is in this case parodically lodged in the sensual (sensual appetite and its sign, an erection) and sees the boundary between the human and the animal, the natural Sublime (the instinctual drive for satisfaction) traversed by both Good-natured Dick and Louisa.

${ }^{35}$ There are two species of beauty actually in evidence, according to Schiller, with the ideal functioning as the generic. "Energizing beauty can no more preserve man from a certain residue of savagery and hardness than melting beauty can protect him from a certain degree of effeminacy and enervation. For since the effect of the former is to brace his nature, both physical and moral, and to increase its elasticity and power of prompt 
ideal beauty is sublime, that is, that it is the beauty that is beyond the bounds of possible expression or instantiation but nonetheless always to be sought. Sometimes, however, the sublime is just beyond bounds, the form before it is form and the content before it is content. Thrust at us unsuspecting, it confronts us with the demand that we bring it into play. Our sublime agency thrills at the chance to manage it with new form and full feeling, with the opportunity to create beauty, to represent life in art. Today, humanists can choose to play with our century's biological sublime: we can, for example, grab hold of its theories and its data to put Schiller's theory into play. After all, through him we have been training for the unexpected. ${ }^{36}$

reaction, it can happen all too easily that the increased resistance of temperament and character will bring about a decrease in receptivity to impression; that our gentler humanity, too, will suffer the kind of repression which ought only to be direct to our brute nature, and our brute nature profit from an increase of strength which should only be available to our free Person. That is why in periods of vigour and exuberance we find true grandeur of conception coupled with the gigantic and the extravagant, sublimity of thought with the most frightening explosions of passion; that is why in epochs of discipline and form we find nature as often suppressed as mastered, as often outraged as transcended" (XVI.3, 4). That Schiller dealt mainly with melting beauty in the Aesthetic Letters, led to the representation of the work as a torso with one arm missing.

${ }^{36}$ Schiller: "Because it is our calling to orient ourselves, in the face of all sensuous limitations ... the sublime must come to the assistance of the beautiful in order to make the aesthetic education a complete whole and expand the human heart's sensitivity to the entire scope of our calling, extending even beyond the world of the senses" ("Concerning the Sublime" ("Über das Erhabene" 1794-6) Essays 83-84.) 


\section{REFERENCES}

Abrams, M. H. The Mirror and the Lamp: Romantic Theory and the Critical Tradition. Oxford: Oxford University Press, 1971.

d' Alembert, Jean le Rond. Preliminary Discourse to the Encyclopedia of Diderot. Trans. and Intro. Richard N. Schwab. Chicago: University of Chicago Press, 1995.

--- and Denis Diderot. The Encyclopedia of d'Alembert and Diderot. Collaborative Translation Project. http://quod.lib.umich.edu/d/did/.

Allewaert, M. "Swamp Sublime: Ecologies of Resistance in the American Plantation Zone." Publications of the Modern Language Association 123.2(2008): 340-357.

Ameriks, Karl. The Cambridge Companion to German Idealism. Cambridge: Cambridge University Press, 2000.

Amrine, Frederick, Francis J. Zucker and Harvey Wheeler, eds. Goethe and the Sciences: A Reappraisal. Dordrecht: D. Reidel Publishing Company, 1987.

Aulie, Richard P. "Caspar Friedrich Wolff and his 'Theoria Generationis,' 1759." Journal of the History of Medicine and Allied Sciences XVI.2 (1961): 124-44.

Beiser, Frederick C. Schiller as Philosopher: A Re-Examination. Oxford, New York: Clarendon Press, 2005.

Bell, Matthew. The German Tradition of Psychology in Literature and Thought, 17001840. New York: Cambridge University Press, 2005.

Bernstein, J. M. Classic and Romantic German Aesthetics. Cambridge: Cambridge University Press, 2006.

Binder, Devin K., Karl Schaller and Hans Clusmann. "The Seminal Contributions of Johann-Christian Reil to Anatomy, Physiology, and Psychiatry." Neurosurgery 61.5 (November 2007): 1091-1095.

Blankaert, Claude. "Buffon and the natural history of man: writing history and the 'foundational myth' of anthropology." History of the Human Sciences 6.1 (1993): 13-50. 
Boulby, Mark. Karl Philipp Moritz: At the Fringe of Genius. Toronto: University of Toronto Press, 1979.

Boyd, Brian. "Getting It All Wrong." The American Scholar 75.4 (2006):18-30.

---. "Literature and Evolution: A Bio-Cultural Approach." Philosophy and Literature 29 (2005): 1-23.

Boyle, Nicholas. Goethe: The Poet and the Age. Volume II: Revolution and Renunciation (1790-1803). Oxford: Clarendon Press, 2000.

Brown, T.M. "From mechanism to vitalism in eighteenth century English physiology." Journal of the History of Biology VII (1974): 179-216.

Buffon, Georges Louis Leclerq. “The 'Initial Discourse' to Buffon's Histoire Naturelle: The First Complete English Translation.” Trans. John Lyon. Journal of the History of Biology 9.1 (Spring 1976): 133-181.

Buffon, Georges Louis LeClerq. Buffon's Natural History, General and Particular ( 8 volumes, 1781$)$. Trans. William Smellie. On line: http://faculty.njcu.edu/fmoran/buffonhome.htm; http://faculty.njcu.edu/fmoran/vol3ass.htm.

Burghardt, Gordon M. The Genesis of Animal Play: Testing the Limits. Cambridge: MIT Press, 2005.

Burke, Edmund. A Philosophical Enquiry into the Origin of our Ideas of the Sublime and Beautiful. Ed. Adam Phillips. Oxford: Oxford University Press, 1998.

Caillois, Roger. Man, Play and Games. Trans. Meyer Barash. Urbana: University of Illinois Press, 2001.

Caneva, K. L. "Teleology with Regrets." Annals of Science 47 (1990): 291-300.

Cantor, G.N. "The Eighteenth Century Problem." History of Science XX (1982): 44-63.

Caron, Joseph A. "'Biology' in the Life Sciences: A Historiographical Contribution." History of Science XXVI (1988): 223-268.

Cassirer, Ernst. The Philosophy of the Enlightenment. Trans. Fritz C.A. Koelln and James P. Pettegrove. Princeton: Princeton University Press, 1951.

Catania, K. C. "A nose that looks like a hand and acts like an eye: the unusual mechanosensory system of the star-nosed mole." Journal of Comparative 
Physiology A: Neuroethology, Sensory, Neural, and Behavioral Physiology. 185 (1999): 367-372.

---. "A Star Is Born." Natural History (June 2000) on line: http://www.naturalhistorymag.com/picks-from-the-past/201397/a-star-is-born

-.-. "Evolution of Sensory Specializations in Insectivores." The Anatomical Record Part A. 287A (2005):1038-1050.

Catania, K. C. and Fiona E. Remple. "Asymptotic prey profitability drives star-nosed moles to the foraging speed limit." A Letter to the Editor. Nature 433 (3 February 2005): 519-522.

Cawadias, A.P. "Théophile de Bordeu: An Eighteenth Century Pioneer in Endocrinology." Proceedings of the Royal Society of Medicine XLIII.93 (November 2, 1949): 1-6.

Chamberlain, Timothy J. Eighteenth Century German Criticism. New York: Continuum, 1992.

Clark, William, Jan Golinski, and Simon Schaffer, eds. The Sciences in Enlightened Europe. Chicago: University of Chicago Press, 1999.

Curran, Jane V. and Christophe Fricker. Schiller's "On Grace and Dignity" in Its Cultural Context: Essays and a New Translation. Rochester, NY: Camden House: 2005.

Daston, Lorraine and Fernando Vidal, eds. The Moral Authority of Nature. Chicago: University of Chicago Press, 2004.

Dawkins, Richard. The Ancestor's Tale: A Pilgrimage to the Dawn of Evolution. Boston: Houghton Mifflin Commpany, 2004.

Denby, David. "Herder: culture, anthropology and the Enlightenment," History of the Human Sciences 18.1 (2005): 55-76.

Dettelbach, Michael. “'Baconianism' in Revolutionary Germany: Humboldt's Great Instauration." The Skeptical Tradition around 1800: Skepticism in philosophy, science and society. Eds. Johan van der Zande and Richard Popkin. Boston: Kluwer, 1998. 175-186.

Dewhurst, Kenneth, Nigel Reeves, and Friedrich Schiller. Friedrich Schiller, Medicine, Psychology and Literature: With the First English Edition of His Complete Medical and Psychological Writings. Berkeley: University of California Press, 1978. 
Diderot, Denis. Rameau's Nephew and Other Works. Trans. Jacques Barzun and Ralph $\mathrm{H}$. Bowen. Introduction by Ralph H. Bowen. Indianapolis: Bobbs-Merrill Educational Publishing, 1964.

Duchesneau, Francois. "Vitalism in late eighteenth-century physiology: the cases of Barthez, Blumenbach and John Hunter." William Hunter and the EighteenthCentury Medical World. Eds. W. F. Bynum and Roy Porter. Cambridge: Cambridge University Press, 1985. 259-295.

Dugatkin, Lee Alan. Principles of Animal Behavior. New York: Norton, 2004.

Elias, Julius A. Friedrich Schiller: The Poet as Philosopher. Diss. Columbia University, 1963.

Engell, James. The Creative Imagination: Enlightenment to Romanticism. Cambridge: Harvard University Press, 1981.

Fauconnier, Gilles and Mark Turner. The Way We Think. New York: Basic Books, 2002.

Figlio, Karl. "Theories of Perception and the Physiology of the Mind in the Late Eighteenth Century." History of Science 13 (1975): 177-212.

Fink, Karl J. "Storm and Stress Anthropology." History of the Human Sciences 6.1 (1993): 51-71.

Fox, Christopher, ed. Psychology and Literature in the Eighteenth Century. New York: AMS Press, 1987.

Frängsmyr, Tore, J.L. Heilbron and Robin E. Rider, eds. The Quantifying Spirit in the Eighteenth Century. Berkeley: University of California Press, 1990.

Ginsborg, Hannah. "Kant on Understanding Organisms as Natural Purposes." Kant and the Sciences. Ed. Eric Watkins. Oxford: Oxford University Press, 2001. 231258.

Glass, Bentley, Owsei Temkin and William L. Straus, Jr., eds. Forerunners of Darwin 1745-1859. Baltimore: Johns Hopkins Press, 1968.

Goethe, Johann Wolfgang. Faust: der Tragödie erster und zweiter Teil Mit einem Nachwort von Thomas Mann. Zürich: Diogenes, 1974.

---. Faust: A Tragedy (Second Edition). Trans. Walter Arndt. Ed. Cyrus Hamlin. New York: W. W. Norton \& Company, 2001.

---. Faust/Part One. Trans. Philip Wayne. Baltimore: Penguin Books, 1963. 
---. Italian Journey [1786-1788]. Trans.W. H. Auden and Elizabeth Mayer. London: Penguin Books, 1970.

---. Scientific Studies (Goethe: The Collected Works, Volume 12) Trans. Douglas Miller. Princeton: Princeton University Press, 1988.

Gregory, T. Ryan. "Understanding Natural Selection: Essential Concepts and Common Misconceptions." Evolution: Eductation and Outreach 2 (2009): 156-175.

Grimm, Jakob and Wilhelm. Deutsches Wörterbuch von Jacob Grimm und Wilhelm Grimm. November 9, 2009. http://germazope.unitrier.de/Projects/WBB/woerterbuecher/dwb/wbgui.

Gross, Steffen W. "The Neglected Programme of Aesthetics." British Journal of Aesthetics 42.4 (2002): 403-414.

Hagner, Michael. "Toward a History of Attention in Culture and Science." MLN 118.3 (April 2003 German Issue): 670-687.

Haigh, Elizabeth L. "Vitalism, the Soul, and Sensibility: The Physiology of Théophile Bordeu." Journal of Medicine and Allied Sciences XXXI (1976): 30-41.

Haller, Albrecht von. "'A Dissertation on the Sensible and Irritable Parts of Animals" with an Intro. and Trans. by Owsei Temkin." Bulletin of the History of Medicine 4 (1936): 651-99.

Hankins, Thomas L. "Eighteenth-Century Attempts to Resolve the Vis Viva Controversy." Isis 56.3 (1965): 281-97.

---. Science and the Enlightenment. Cambridge: Cambridge University Press, 1985.

Hansen, LeeAnn. "From Enlightenment to Naturphilosophie: Marcus Herz, Johann Christian Reil, and the Problem of Border Crossings." Journal of the History of Biology 26:1 (Spring, 1993): 39-64.

---. Johann Christian Reil and "Naturphilosophie" in Physiology. Diss. University of California, Los Angeles, 1985.

---. "Metaphors of Mind and Society: The Origins of German Psychiatry in the Revolutionary Era." Isis 89:3 (1998): 387-409.

Harrison, Charles, Paul Wood, and Jason Gaiger, eds. Art in Theory 1648-1815: An Anthology of Changing Ideas. Malden, MA: Blackwell Publishing Ltd., 2000.

Hazard, Paul. The European Mind: 1680-1715. Cleveland: World Pub., 1963. 
Hein, Hilde. "The Endurance of the Mechanism: Vitalism Controversy." Journal of the History of Biology 5:1 (Spring, 1972): 159-188.

Herder, Johann Gottfried. Selected Writings on Aesthetics. Trans. and ed. Gregory Moore. Princeton: Princeton University Press, 2006.

---. Philosophical Writings. Ed. and Trans. by Michael N. Forster. Cambridge: Cambridge University Press, 2002.

Huizinga, Johan. Homo Ludens: A Study of the Play Element in Culture. Boston: Beacon Press, 1950.

Hulliung, Mark. The Autocritique of Enlightenment: Rousseau and the Philosophes. Cambridge: Harvard University Press, 1994.

Hume, David. An Enquiry Concerning Human Understanding. Stilwell, KS: Digireads.com Publishing, 2005.

---. A Treatise of Human Nature. Second Edition with revision and notes by P.H. Nidditch. Analytical Index by L.A. Selby-Bigge. Oxford: Clarendon Press, 1978.

Huneman, Philippe. Understanding Purpose: Kant and the Philosophy of Biology. Volume 8: North American Kant Society Studies in Philosophy. Introduction. Rochester: University of Rochester Press, 2007. 1-36.

Kant, Immanuel. The Critique of Pure Reason. Trans. J. M. D. Meiklejohn. http://philosophy.eserver.org/kant/critique-of-pure-reason.txt.

---. The Critique of the Power of Judgment. Trans. Paul Guyer and Eric Matthews. Ed. Paul Guyer. Cambridge: Cambridge University Press, 2000.

---. Observations on the Feeling of the Beautiful and Sublime. Trans. John T. Goldthwait. Berkeley: University of Califoronia Press, 1960.

Kuhn, Thomas S. The Structure of Scientific Revolutions, Second Edition, Enlarged. Chicago, University of Chicago Press, 1970.

---. "What are Scientific Revolutions?" The Probabilistic Revolution: Volumes 1 and 2. Eds. Lorenz Krüger, Lorraine J. Daston, Michael Heidelberger, gerd Gigerenzer and Mary S. Morgan. Boston: MIT Press, 1987. 7-22.

de La Mettrie, Julien Offray. Machine Man and Other Writings. Ed. and trans. Ann Thomson. Cambridge: Cambridge University Press, 1996. 
Larson, James L. Interpreting Nature: The Science of Living Form from Linnaeus to Kant. Baltimore: Johns Hopkins University Press, 1994.

---. "Vital Forces: Regulative Principles or Constitutive Agents? A Strategy in German Physiology, 1786-1802." Isis 70:2 (Jun., 1979): 235-249.

Laudan, Larry. Progress and Its Problems: Towards a Theory of Scientific Growth. Berkeley: University of California Press, 1978.

Lee, Michael G. The German 'Mittelweg': Garden Theory and Philosophy in the time of Kant. New York: Routledge, 2007.

Leidner, Alan Charles. Literary Versions of the Sublime from Winckelmann to Goethe. Diss. University of Virginia, 1981.

---. The Impatient Muse: Germany and the Sturm und Drang. Chapel Hill: University of North Carolina Press, 1994.

Lenhoff, Sylvia G., Howard M. Lenhoff, and Abraham Trembley. Hydra and the Birth of Experimental Biology, 1744: Abraham Trembley's Mémoires Concerning the Polyps. Pacific Grove, CA: Boxwood Press, 1986.

---. "Tissue Grafting in Animals: Its Discovery in 1742 by Abraham Trembley as He Experimented with Hydra." Biological Bulletin 166 (Feb. 1984): 1-10.

Lenoir, Timothy. "Kant, Blumenbach, and Vital Materialism in German Biology." Isis 71.1 (Mar. 1980): 77-108.

---. The Strategy of Life : Teleology and Mechanics in Nineteenth Century German Biology. Chicago: University of Chicago Press, 1982.

Locke, John. An Essay Concerning Human Understanding. Abridged and ed. Kenneth P. Winkler. Indianapolis: Hackett Publishing Company, Inc., 1996.

Look, Brandon. "Blumenbach and Kant on Mechanism and Teleology in Nature." The Problem of Animal Generation in Early Modern Philosophy. Ed. Justin E. H. Smith. Cambridge: Cambridge University Press, 2006. 355-372.

Lord, Beth. "'The House that Kant Built.' A review of Kant Trouble: The Obscurities of the Enlightened By Diane Morgan." PIi 10 (2000): 260-266.

Love, Sarah B. The Role of Connotation and Ideology in Economic Translation: A Case Study. Thesis. Université of Genève, 2009.

Lovejoy, Arthur O. Essays in the History of Ideas. London: Oxford University Press, 1960. 
Müller-Sievers, Helmut. Self-generation: Biology, Philosophy, and Literature around 1800. Stanford: Stanford University Press, 1997.

Neubauer, John. "The Freedom of the Machine: On Mechanism, Materialism, and the Young Schiller." Eighteenth-Century Studies 15.3 (Spring, 1982): 275-290.

---. "Reflections on the 'Convergence' Between Literature and Science." MLN 118.3 (2003): 740-54.

Newton, Isaac. Principia Mathematica (1687). Trans. Andrew Motte. On line: http://gravitee.tripod.com/genschol.htm.

Nisbet, H. B., ed. and trans. German aesthetic and literary criticism: Winckelmann, Lessing, Hamann, Herder, Schiller, Goethe. Cambridge: Cambridge University Press, 1985.

---. "Herder, Goethe and the natural "Type."” Publications of the English Goethe Society 37 (1967): 83-119.

---. Herder and the Philosophy and History of Science. Cambridge: The Modern Humanities Research Association, 1970.

Palti, Elias. "The 'Metaphor of Life': Herder's Philosophy of History and Uneven Developments in Late Eighteenth-Century Natural Sciences." History and Theory 38.3 (1999): 322-347.

Pigliucci, Massimo. "The New Evolutionary Synthesis: around the corner, or impossible chimaera?" The Quarterly Review of Biology 78.4 (Dec 2003): 449-453.

Play resources on line.

"The Play Ethic": http://www.theplayethic.com/pages/867066/index.htm. Qtd. Bartleby: http://www.bartleby.com/61/roots/lE112.html.

Kane, Pat. "The Play Ethic." Guardian (10/22/2000): http://observer.guardian.co.uk/life/story/0,6903,386013,00.html. "Players": http://www.theplayethic.com/pages/873322/index.htm. Study of games: http://ludology.org/index.php. Other references: http://www.bartleby.com/61/35/P0363500.html. "Gamble": http://www.bartleby.com/61/79/G0027900.html. "Game": http://www.bartleby.com/61/85/G0028500.html.

Pope, Alexander. The Major Works. Ed. Pat Rogers. Oxford: Oxford University Press, 2006.

Reed, T. J. The Classical Centre: Goethe and Weimar, 1775-1832. NewYork: Barnes \& Noble Books, 1980. 
---. "Kant and Schiller: The Delights and Dangers of Complexity." Publications of the English Goethe Society 75.2 (2006): 65-81.

---. "Paths through the Labyrinth: Finding your Way in the Eighteenth Century." Publications of the English Goethe Society 51 (1981): 81-113.

---. Schiller. Past Masters. Oxford: Oxford University Press, 1991.

Reich, Alisa Schulweis. Paul Joseph Barthez and the Impact of Vitalism on Medicine and Psychology. Diss. University of California, Los Angeles, 1995.

Reill, Peter Hanns. "Buffon and Historical Thought in Germany and Great Britain." Buffon 88: actes du Colloque international pour le bicentenaire de la mort de Buffon (1992). 667-679.

---. "Analogy, Comparison, and Active Living Forces: Late Enlightenment Responses to the Skeptical Critique of Causal Analysis." The Skeptical Tradition around 1800: Skepticism in Philosophy, Science, and Society. Eds. Johan van der Zande and Richard Henry Popkin. Dordrecht: Kluwer Academic, 1998. 203-211.

---. "Anthropology, Nature and History in the Late Enlightenment. The Case of Friedrich Schiller." Schiller als Historiker, Eds. Ernst Osterkamp, et al. Stuttgart: J.B. Metzler, 1995. 243-65.

---.. "Bildung, Urtyp and Polarity: Goethe and Eighteenth-Century Physiology." Goethe Yearbook: Volume 3. Columbia, SC.: Camden House (Publications of the Goethe Society of North America), 1986. 139-148.

---. The German Enlightenment and the Rise of Historicism. Berkeley: University of California Press, 1975.

--.. "Herder's Historical Practice and the Discourse of Late Enlightenment Science." Johann Gottfried Herder: Academic Disciplines and the Pursuit of Knowledge. Ed. Wulf Koepke. Columbia, SC: Camden House, 1996. 13-21.

---. "Science and the Science of History in the Spätaufklärung." Aufklärung und Geschichte. Eds. Hans Erich Bödeker, Georg G. Iggers, Jonathan B. Knudsen and Peter H. Reill. Gottingen: Vanenhoeck \& Ruprecht, 1986.

---. Vitalizing Nature in the Enlightenment. Berkeley: University of California Press, 2005.

Richards, Robert. "Kant and Blumenbach on the Bildungstrieb Historical Misunderstanding." Studies in the History and Philosophy of Biology and Biomedical Sciences 31.1 (2000): 11-32. 
---. "Rhapsodies on a Cat-Piano, or Johann Christian Reil and the Foundations of Romantic Psychiatry." Critical Inquiry 24 (1998): 700-736.

---. The Romantic Conception of Life: Science and Philosophy in the Age of Goethe. Chicago: University of Chicago Press, 2002.

Ridley, Mark. Evolution, Third Edition. Malden, MA: Blackwell Publishing, 2004.

Roe, Shirley A. Matter, Life, and Generation: 18th-Century Embryology and the HallerWolff Debate. Cambridge: Cambridge University Press, 1981.

--.. "Rationalism and Embryology: Caspar Friedrich Wolff's Theory of Epigenesis." Journal of the History of Biology 12.1 (Spring 1979): 1-43.

Roger, Jacques. Buffon: A Life in Natural History. Trans. Sarah Lucille Bonnefoi. Cornell University Press, 1997.

---. The Life Sciences in Eighteenth-Century French Thought. Ed. Keith R. Benson. Trans. Robert Ellrich. Stanford: Stanford University Press, 1997.

Rosenberg, Daniel. "Introduction." Journal of the History of Ideas 64.1 (Jan. 2003): 1-9.

Rossi, Paolo. The Dark Abyss of Time: The History of the Earth and the History of Nations from Hooke to Vico. Trans. Lydia G. Cochrane. Chicago: University of Chicago Press, 1984.

Rosslenbroich, Bernd. "The theory of increasing autonomy in evolution: a proposal for understanding macroevolutionary innovations." Biology and Philosophy 24.5 (November 2009): 623-644.

Rousseau, G. S., and Roy Porter, eds. The Ferment of Knowledge: Studies in the Historiography of Eighteenth-Century Science. Cambridge: Cambridge University Press, 1980.

Rousseau, Jean Jacques. The First and Second Discourses. Ed. Roger D. Masters. Trans. Roger D. and Judith R. Masters. Boston: Bedford/St. Martin's, 1964.

Rudwick, Martin J. S. The Meaning of Fossils: Episodes in the History of Palaeontology. Chicago: University of Chicago Press, 1976.

Savile, Anthony, and Aristotelian Society (Great Britain). Aesthetic Reconstructions: The Seminal Writings of Lessing, Kant, and Schiller. Oxford: B. Blackwell, 1987. 
Schaffer, Simon. "Natural Philosophy and the Public Spectacle." History of Science 21 (1983): 1-43.

Schaper, Eva. "Friedrich Schiller: Adventures of a Kantian." The British Journal of Aesthetics 4.4 (1964): 348-362.

---. "Towards the Aesthetic: A Journey with Friedrich Schiller." The British Journal of Aesthetics 25.2 (Spring 1985): 153-168.

Schiller, Friedrich. Aesthetical and Philosophical Essays (Introducing the Dissertation on the "Connection between the Animal and the Spiritual Man"). Honolulu: University Press of the Pacific, 2001.

---. Essays. Eds. Walter Hinderer and Daniel O. Dahlstrom. New York: Continuum, 2005.

---. Letters On The Aesthetical Education Of Man. August 14, 2009. http://www.gutenberg.org/files/6798/6798-h/6798-h.htm\#2H_4_0004.

---. "The Nature and Value of Universal History: An Inaugural Lecture [1789]." History and Theory 11.3 (1972): 321-334.

---. On the Aesthetic Education of Man In a Series of Letters (English and German Facing). Trans. and eds. Elizabeth M. Wilkinson and L. A. Willoughby. Introduction and Commentary. Oxford: Clarendon Press, 1982.

---. The Robbers and Wallenstein. Intro. and Trans. F.J. Lamport. London: Penguin Books, 1979.

---. Über die ästhetische Erziehung des Menschen, in einer Reihe von Briefen. August 14, 2009. On line: http://gutenberg.spiegel.de/?id=5\&xid=2397\&kapitel=1\#gb_found.

Schiller, Friedrich and Johann Wolfgang Goethe. Briefwechsel zwischen Schiller und Goethe: Erster Band On line: http://gutenberg.spiegel.de/?id=5\&xid=5123\&kapitel=2\&cHash=d9ecefc $33 \mathrm{e} 2 \# \mathrm{gb}$ found.

---. Correspondence between Schiller and Goethe. Volume I. (1794-1797). Volume II. (1798-1805). Trans. L. Dora Schmitz. London: George Bell and Sons, 1898.

Schiller, Friedrich and Christian Gottfried Körner. Correspondence of Schiller and Körner. Volume I. London: Richard Bentley, 1849. 
---. Correspondence of Schiller and Körner, Volume II. On line:

http://books.google.com/books?id=JzAQAAAAYAAJ\&printsec=frontcover\&sou $\mathrm{rce}=\mathrm{gbs} \_\mathrm{v} 2$ _summary_r$\& \mathrm{cad}=0 \# \mathrm{v}=$ onepage $\& \mathrm{q}=\& \mathrm{f}=$ false.

Schmidt, James, ed. What Is Enlightenment? Eighteenth-Century Answers and Twentieth-Century Questions. Berkeley: University of California Press, 1996.

Schuster, Gerhard and Caroline Gille, eds. Wiederholte Spiegelungen: Weimarer Klassik 1759-1832. Ständige Ausstellung des Goethe-Nationalmuseums, Munich: Hanser, 1999.

Sharpe, Lesley. The Cambridge Companion to Goethe. Cambridge: Cambridge University Press, 2002.

---. Friedrich Schiller: Drama, Thought, and Politics. Cambridge: Cambridge University Press, 1991.

Sloan, Phillip R. "Buffon, German biology and the historical interpretation of biological species." British Journal for the History of Science XII (1979): 109-53.

---. "The Buffon-Linnaeus Controversy." Isis 67.3 (Sept. 1976): 356-375.

---. "From logical universal to historical individuals: Buffon's Idea of Biological Species." Histoire du concept d'espece dans les sciences de la vie; colloque international, mai 1985. 101-40.

---. "Kant on the history of nature: The ambiguous heritage of the critical philosophy for natural history." Studies in History and Philosophy of Biological and Biomedical Sciences 37 (2006): 627-648.

---. "Natural History, 1760-1802." Companion to the History of Modern Science. Eds. R. C. Olby, G. N. Cantor, J. R. R. Christie and M. J. S. Hodge. London: Routledge, 1990. 295-313.

---. "Performing the Categories: Eighteenth-Century Generation Theory and the Biological Roots of Kant's A Priori." Journal Of The History Of Philosophy 40.2 (2002): 229-53.

Smith, Justin E. H. ed. The Problem of Animal Generation in Early Modern Philosophy. Cambridge: Cambridge University Press, 2006.

Steigerwald, Joan. "Goethe's Morphology: Urphänomene and Aestheic Appraisal." Journal of the History of Biology 35.2 (2002): 291-328.

---. "Introduction: Kantian Teleology and the Biological Sciences." Studies in History and Philosophy of Biological and Biomedical Sciences 37 (2006): 621-26. 
---. "Instruments of Judgment: Inscribing Organic Processes in Late Eighteenth-Century Germany." Studies in History and Philosophy of Biological and Biomedical Sciences 33 (2002): 79-131.

---. "Kant's Concept of Natural Purpose and the Reflecting Power of Judgment." Studies in History and Philosophy of Biological and Biomedical Sciences 37 (2006): 712-34.

Sturm, Thomas. "Kant on Empirical Psychology: How Not to Investigate the Human Mind." Kant and the Sciences. Ed. Eric Watkins. Oxford: Oxford University Press, 2001. 163-184.

Swift, Jonathan. Gulliver's Travels and Other Writings. Ed. Mariam Kosh Starkman. New York: Bantam Dell, 2005.

Still, Judith, "État présent: Enlightenment hospitality: the case of Chardin." French Studies LX.3: 364-368.

Sulzer, Johann Georg. Dialogues on the Beauty of Nature and Moral Reflections on Certain Topics of Natural History. Trans. Eric Miller. Lanham, MD: University Press of America, 2005.

Sutton-Smith, Brian. The Ambiguity of Play. Cambridge, Massachusetts: Harvard University Press, 1997.

Špinka, Marek, Ruth C. Newberry and Marc Bekoff. "Mammalian Play: Training for the Unexpected." The Quarterly Review of Biology 76.2 (June 2001): 141-168.

Terrall, Mary. The Man Who Flattened the Earth: Maupertuis and the Sciences in the Enlightenment. Chicago: The University of Chicago Press, 2002.

---. "Salon, Academy, and Boudoir: Generation and Desire in Maupertuis's $\underline{\text { Science of }}$ Life." Isis 87.2 (June 1996): 217-229.

Thomson, Ann. Bodies of Thought: Science, Religion and the Soul in the Early Enlightenment. Oxford: Oxford University Press, 2008.

Toellner, „Mechanismus-Vitalismus: ein Paradigmawechsel? Testfall Haller.” Die Struktur wissenschaftlicher Revolutionen und die Geschichte der Wissenschaft. Meisenheim am Galn: Hain, 1977. 61-72.

Vartanian, Aram. La Mettrie's L'Homme Machine: A Study in the Origins of an Idea. Princeton: Princeton University Press, 1960. 
---. Science and Humanism in the French Enlightenment. Charlottesville: Rookwood Press, 1999.

---. "Trembley's Polyp, La Mettrie, and the Eighteenth-Century French Materialism." Roots of Scientific Thought: A Cultural Perspective. Ed. Philip Paul Weiner. New York: Basic Books, 1957. 497-516.

Watkins, Eric, ed. Kant and the Sciences. Oxford: Oxford University Press, 2001.

Wernly, Julia. Prolegomena zu einem Lexikon der asthetisch-ethischen Terminologie Friedrich Schiller. Leipzig: H. Haessel Verlag, 1909.

Westfall, Richard S. The Construction of Modern Science: Mechanisms and Mechanics. Cambridge: Cambridge University Press, 1977.

Wilkinson, Elizabeth M. "Reflections after translating Schiller's Letters on the Aesthetic Education of Man." Schiller Bicentenary Lectures. Ed. F. Holland. London: University of London Institute of Germanic Studies: 1980. 46-82.

Wilkinson, Elizabeth M. \& L.A. Willoughby, trans. and eds. The Aesthetic Education of Man in a Series of Letters. (English and German Facing). By Friedrich Schiller. Introduction. Commentary. Appendices. Oxford: Clarendon Press, 1982.

---. Models of Wholeness: Some Attitudes to Language, Art and Life in the Age of Goethe. Eds. Jeremy Adler, Martin Swales and Ann Weaver. Oxford: Peter Lang, 2002.

Wilson, Edward O. Consilience: The Unity of Knowledge. New York: Vintage Books, 1999.

Winnicott, D.W. Playing and Reality. London: Routledge, 1971.

Wokler, Robert. "From l'homme physique to l'homme moral and back: towards a history of Enlightenment anthropology." History of the Human Sciences 6.1 (1993): 121-138.

Veblen, Thorstein. The Theory of the Leisure Class: An Economic Study of Institutions. Amherst, NY: Prometheus Books, 1998.

Vidal, Fernando. "Psychology in the Eighteenth Century: a view from the enycylopaedias." History of the Human Sciences 6:1 (1993), 89-119.

Young, Edward. "Conjectures on Original Composition. In a Letter to the Author of Sir Charles Grandison." London: Millar \& Dodsley, 1759. Online at http://onlinebooks.library.upenn.edu/webbin/book/lookupid?key=olbp32476. 
Young, Robert M. "The Mind-Body Problem." Companion to the History of Modern Science. Eds. R. C. Olby et al. London: Routledge, 1990.

Zammito, John. "Kant's Early Views on Epigenesis: The Role of Maupertuis." The Problem of Animal Generation in Early Modern Philosophy. Ed. Justin E. H. Smith. Cambridge: Cambridge University Press, 2006. 317-354.

---. The Genesis of Kant's Critique of Judgment. Chicago: University of Chicago Press, 1992.

---. Kant, Herder, and the Birth of Anthropology. Chicago: University of Chicago Press, 2002.

---. " "This Inscrutable Principle of an organization': Epigenesis and 'Looseness of Fit' in Kant's Philosophy of Science." Studies in the History and Philosophy of Science 34 (2003): 73-109.

Zuckert, Rachel. Kant on Beauty and Biology: An Interpretation of the Critique of Judgment. Cambridge: Cambridge University Press, 2007. 


\title{
CURRICULUM VITAE
}

$\begin{array}{ll}\text { NAME: } & \text { Susan M. Bentley } \\ \text { ADDRESS: } & 87 \text { Valley Road } \\ & \text { Louisville, KY } 40204\end{array}$

CURRENT

PROFESSIONAL POSITION:

EDUCATION, Psychiatrist in private practice. 1985-present. Specialty: insight-oriented psychotherapy including medication management.

TRAINING \& SERVICE:

\author{
B.A., Anthropology \\ University of Colorado \\ 1965-1969 \\ Peace Corps, Malaysia \\ Birth Control Counselor \\ 1969-1970
}

M. A. Creative Writing (Poetry)

University of Denver

1973-1975; 1997

M. D.

(University of Colorado 1976-1977)

University of Louisville

1977-1980

Internship \& Residency

Department of Psychiatry

University of Louisville

1981-1984

Chief Resident in Psychiatry

University of Louisville

1982-1983 
Ph.D., Humanities

University of Louisville

2003-2009

\section{PROFESSIONAL CERTIFICATIONS \& LICENSES:}

Kentucky Board of Medical Licensure, 1982-present.

American Board of Psychiatry and Neurology, 1994 (Life).

\section{PROFESSIONAL SOCIETIES:}

Greater Louisville Medical Society (Jefferson County Medical Society); Kentucky Medical Society 1985-present.

American Psychiatric Association; Kentucky Psychiatric Association 1985-present.

\section{PUBLICATIONS AND AWARDS:}

Finalist, Emily Dickinson Poetry Contest 2003. Publication of poem.

Staged reading. Becoming Ariadne. Brave New Works Festival, Emory and Synchronicity Theatres. Atlanta: March-April 2001.

Staged reading. "Saturday Night" (as one-act play). Bellarmine University Theatre, Louisville: April 2001.

Finalist, Actors Theatre of Louisville National Ten-Minute Play Contest. 1999, 2000, $2001 \& 2003$.

Poetry published in the American Voice $(1995,1997)$, Georgia Review (1996) and Denver Quarterly (2000).

Poetry anthologized in American Voice Anthology (1998) and Intro 7: All of Us and None of You (1984).

Kentucky Arts Council Al Smith Individual Artist Fellowship (Poetry), 1995. 


\section{NATIONAL MEETINGS AND PRESENTATIONS:}

"Metaphor in the Creativity and Ambiguity of Natural Selection." The Nineteenth Annual Conference of the Society for Literature, Science and the ArtsEmergent Systems, Cognitive Environments. Chicago: November 10-13, 2005.

"Play: the evolutionary structure of culture and the consilience of disciplines." 2007 Conference of the National Association for Humanities Education--The Golden Gateways of the Humanities: Transgressions/Transformation, Dissonance/Harmony. Panel Moderator. San Francisco: February 28-March 3, 2007.

"Huge Claims for Play: Schiller's Archetype of Humanity, the Evolutionary Structure of Culture and Consilience of Disciplines." Midwest Junto for the History of Science $-50^{\text {th }}$ Anniversary Meeting. Iowa State University: April 13-15, 2007.

"Friedrich Schiller's Theory of Play: a case study in the value of contemporary life sciences to the humanities." ("Incorporating Current Evolutionary Perspectives in the Humanities"). Humanities Education and Research Association (HERA) Conference - Nature \& Humanities: Interdisciplinary and Intercultural Perspectives. Chicago: April 9-11, 2009,

\section{UNIVERSITY OF LOUISVILLE PRESENTATIONS \& PROGRAMS:}

"Patient Evaluation/Satisfaction of Labor, Delivery and Postpartum Services at University Hospital, Louisville." Grand Rounds, Department of Obstetrics and Gynecology, University of Louisville: May1979.

"Psychotherapy as a Literary Art Form." Grand Rounds, Department of Psychiatry, University of Louisville: March 1983.

"The Metaphor: Psychotherapy as Play." First Annual Humanities Graduate Student Colloquium-Interpretive Communities Across Time. University of Louisville: February 20, 2004.

"A Place for Metaphors in Scientific Creativity." Humanities Conference-New Directions and Intersections in the Humanities: The Arts, Religion and Philosophy. University of Louisville: April 1, 2005.

Dissent! A Louisville City and University-wide Program. Planned, directed, participated in and produced events as part of a Coordinating Committee. Louisville Community Organizations \& University of Louisville: Fall 2005Spring 2006. 
"The Golem of Prague, a one-act play." Dissent! A Louisville City and Universitywide Program, Fall 2005 - Spring 2006. Performed by the Squallis Puppeteers in conjunction with the installation "Eyes Wide Open: The Human Cost of War," Christ Church Episcopal Cathedral: April 9, 2006.

"Schiller at Play: Are Natural Philosophy and Medicine in the Game?" Humanities Conference - Crossing Borders: Interdisciplinary Study in the Arts and Humanities. University of Louisville: March 28, 2008. 